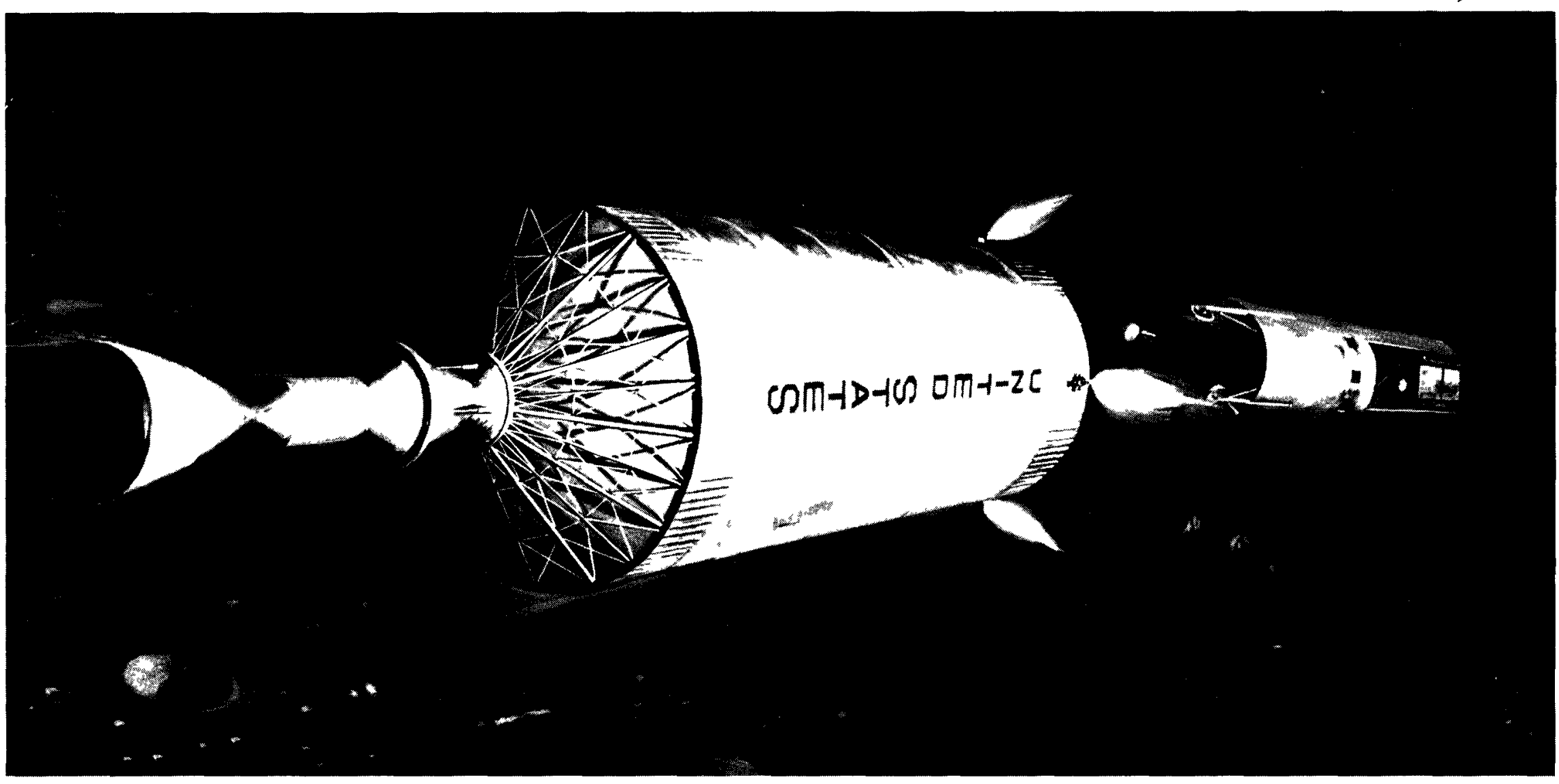

NUCLEAR SHUTTLE SYSTEM DEFINITION STUDY PHASE III FIRST INTERIM REVIEW

\section{SEPT 1970}

CONTRACT NAS8-14975 MASTER 


\section{DISCLAIMER}

This report was prepared as an account of work sponsored by an agency of the United States Government. Neither the United States Government nor any agency Thereof, nor any of their employees, makes any warranty, express or implied, or assumes any legal liability or responsibility for the accuracy, completeness, or usefulness of any information, apparatus, product, or process disclosed, or represents that its use would not infringe privately owned rights. Reference herein to any specific commercial product, process, or service by trade name, trademark, manufacturer, or otherwise does not necessarily constitute or imply its endorsement, recommendation, or favoring by the United States Government or any agency thereof. The views and opinions of authors expressed herein do not necessarily state or reflect those of the United States Government or any agency thereof. 


\section{DISCLAIMER}

Portions of this document may be illegible in electronic image products. Images are produced from the best available original document. 


\section{MASTER}

MSFC-DRL- 198

PDS $70-242$

DR L Line Item -2

NUCLEAR SHUTTIE SYSTEM DEFINITION STUDY

PHASE III FIRST INTERIM REVIEW

CONTRACT NAS8-24975

SEPTEMBER 2, 1970

Prepared for

George C. Marshall Space Flight Center

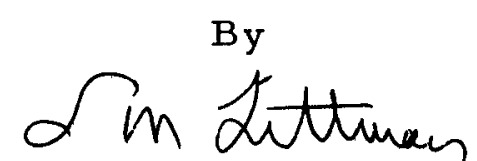

T. M. Littman

Program Manager
- NOTICE

This report was prepared as an account of work sponsored by the United States Government. Neither the United States nor the Uninistration, nor any of Research and Dever any of their contractors, their employees, neir employees, makes any subcontractors, or implied, or assumes any lega liability or responsibility for the accuracy, completeness or usefulness of any information, apparat us, product or process disclosed, or represents that its use would not process disclosed, or represents
infringe privately owned rights. 
This first briefing report, covering the work from 1 May to 28 August 1970 on the Phase III Reusable Nuclear Shuttle (RNS) Definition Study, is presented in accordance with the data requirements (MSFC DRL-198, DRL Line Item -2) of Contract NAS8-24975. 


\section{BRIEFING OUTLINE}

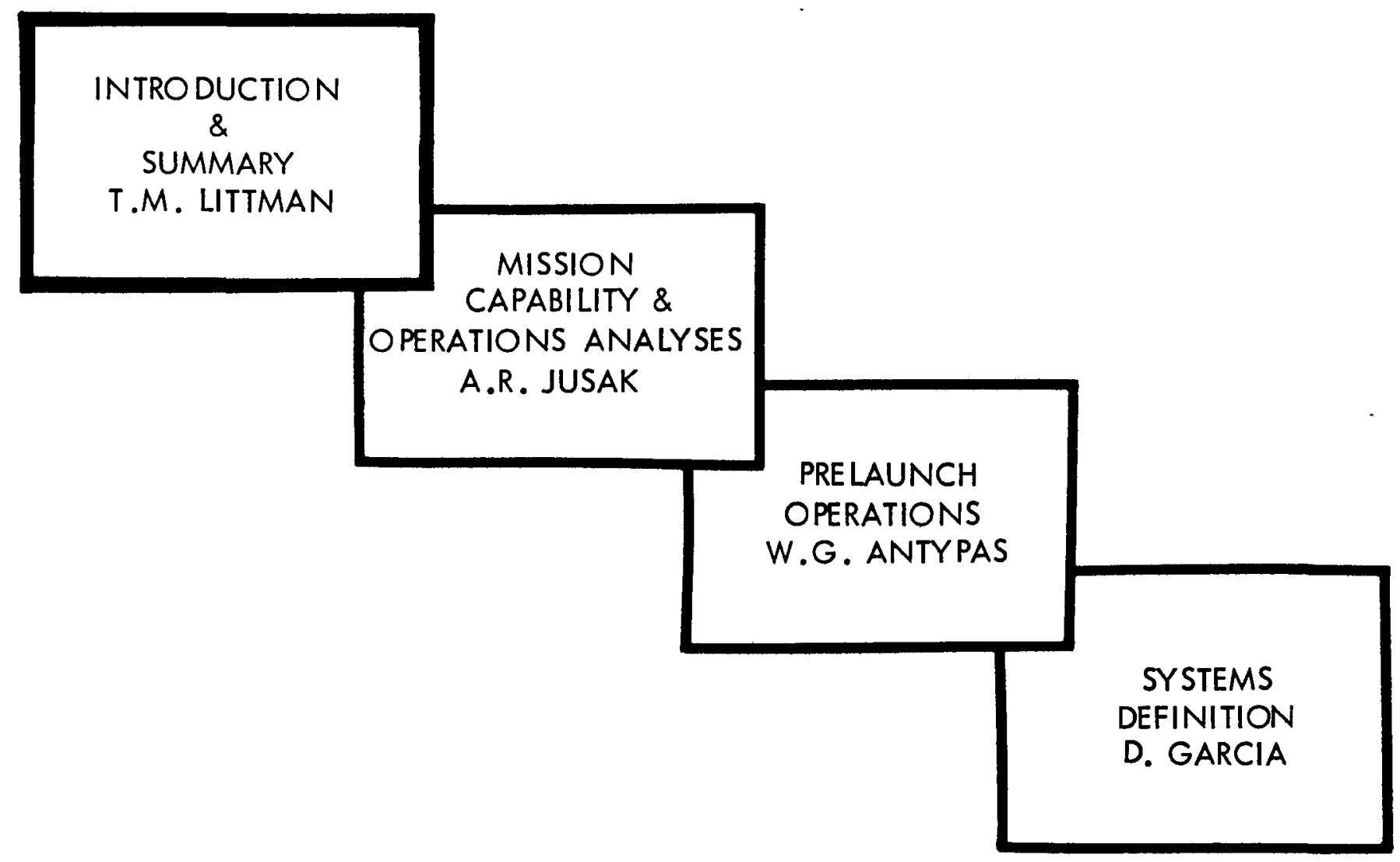


The basic goal of the Phase A studies is to define attractive RNS concepts to fulfill the anticipated requirements of manned/unmanned interorbital flights in the early 1980's. In addition, the design configurations must contain the inherent capability for growth to meet later manned planetary missions in a cost effective manner.

The third phase of the study has as its specific objectives completion of the RNS preliminary technical definition, support of related NERVA studies, identification of interfaces with other space system elements, and assessing cost reduction methods.

An important corollary to the technical definition objective is the search for improved design configurations as our knowledge of mission/operating requirements and technology improves. NASA identified several new concepts for evaluation; one additional NR concept also is under study. 


\section{PHASE III STUDY OBJECTIVES}

BASIC GOAL

- DEFINE ATTRACTIVE RNS CONCEPTS TO MEET ANTICIPATED MANNED/UNMANNED INTERORBITAL FLIGHTS IN EARLY 1980'S WITH EVOLUTIONARY GROWTH FOR MANNED PLANETARY EXPLORATION

SPECIFIC OBJECTIVES

- COMPLETION OF RNS PRELIMINARY TECHNICAL DEFINITION DESIGN

MISSION REQUIREMENTS / PERFORMANCE

INTEGRATED PROGRAM PLANNING

- SUPPORT RELATED NERVA STUDIES

- IDENTIFY INTERFACES WITH CURRENTLY PLANNED NASA SPACE SYSTEM ELEMENTS

- ASSESS COST REDUCTION METHODS 


\section{ASSUMPTIONS \& GUIDELINES}

The primary ground rules for the Phase III study are:

(1) RNS concepts employing 1974 technology will be limited to those characterized by a primary 33 -foot diameter propellant tank, but including configurations with attached "propulsion module" containing a small tank and the NERVA engine. All versions will be manrated.

(2) Launch to orbit of the primary RNS is by INT-21 with standard J-2 engines. The EOS will deliver the propulsion module, propellant, payload, and other supplies.

(3) Minimization of development and operational costs are of paramount importance as long as key mission objectives (based on the NASA mission model) and program milestones are not jeopardized. Emphasis will be given to the maximum practical use of existing facilities and equipment.

(4) Pertinent NERVA and other study documents are as specified in the RFQ.

First launch of the RNS is targeted for 1979 with IOC the following year. The MSFC traffic model is based on a substantial (lunar and synchronous) interorbital shuttle program but does include unmanned planetary flights as well as a dual manned Mars mission in the late 1980's. 


\section{ASSUMPTIONS \& GUIDELINES}

- 1974 TECHNOLOGY FOR INITIAL MAN-RATED RNS

- CURRENT NERVA FULL FLOW CYCLE ENGINE

- 33-FOOT DIAMETER MAIN PROPELLANT TANK

- RNS LAUNCH TO ORBIT BY INT-2I WITH STANDARD J-2 ENGINES

- SPACE SHUTTLE DELIVERS OTHER ITEMS

- MINIMIZE DEVELOPMENT \& OPERATIONAL COSTS WHILE MEETING:

KEY MISSION OBJECTIVES

MAJOR PROGRAM MILESTONES

- MAXIMUM PRACTICAL USE OF EXISTING FACILITIES \& EQUIPMENT

- MSFC TRAFFIC MODEL 
The final baseline of Phase II, updated by a weights analysis, and sized for 300,000 pounds of $\mathrm{LH}_{2}$, was selected as the initial standard of comparison for Phase III and the primary concept for investigating mission performance and operations. This configuration has a 33 -foot diameter integral tank with an inner (dual) cell for radiation attenuation and propellant management, elliptical bulkheads, and 5 percent ullage. The figure also identifies the major subsystems. An integrated double bumper meteoroid shield with GAC-9 insulation serves to protect the propellant and its container.

The dual cell concept was evolved in the search for a tank geometry with high propellant containing efficiency (minimum weight), low launch loads (minimum modification to the INT -21 booster), high radiation attenuation with minimum external shielding weight, and improved propellant management under zero gravity. Results of the Phase II study indicated that these goals could be met with the baseline concept. However, recent Monte Carlo radiation studies by ANSC, employing a dual-cell configuration with a 15 -degree conical tank bottom indicate that improved shielding protection to a payload may not be provided by the inner cell (as currently designed) due to multiple gamma scattering and neutron transport at low propellant levels. (The NR studies were conducted with improved Point Kernel programs which account for single scattering). Since NASA is currently funding another independent dual-cell radiation study, no additional NR analyses will be performed on this concept now. 


\section{RNS PHASE II BASELINE INBOARD PROFILE}

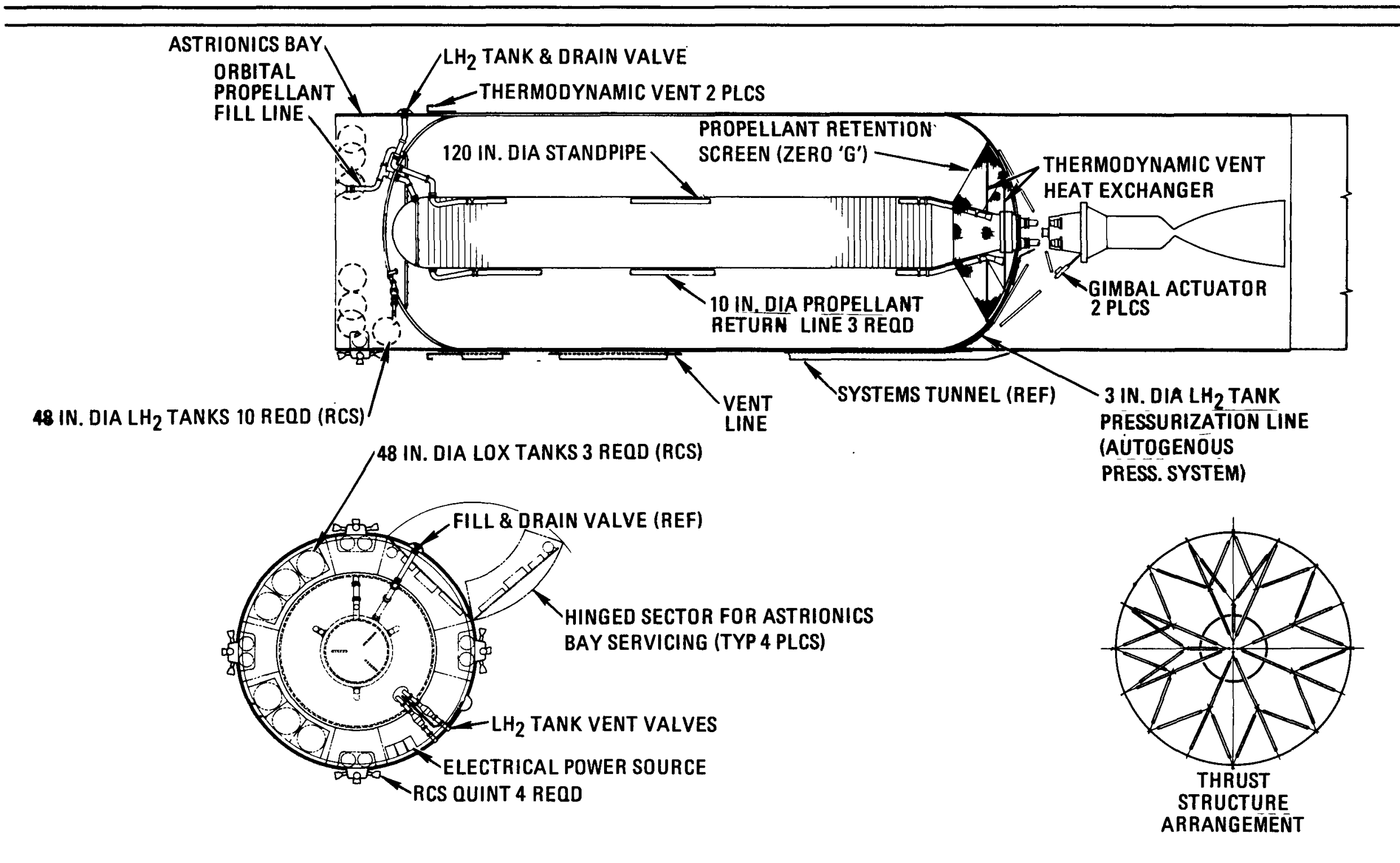


The configurations under consideration consist of the dual cell elliptical concept and variations of the conical aft bulkhead designs as shown in the accompanying figure. The forme $r$ is the resulting baseline from the previous contracted activities and will not be further investigated pending the outcome of current independent radiation analyses.

The single cell conical configuration is currently receiving the core of the design analyses. The parametric investigations include variations in half-cone angle from 5 to 15 degrees and cap radius from 25 to 125 inches. It is of importance to note that this configuration was investigated during the previous study contract and a baseline established at 15 degrees half-cone angle and 100 inches cap radius. The assessment of the lower range dimensional parameters is being emphasized to evaluate the reduction in radiation dose to the tank top; launch vehicle impact commensurate with alternate methods of launching the stage; and performance gains associated with reduction in external radiation shield. Resulting attractive arrangements of this basic concept will be further evaluated with the addition of an external small tank - hybrid design - as well as with a small inner tank - modified dual cell - to establish the performance and operational payoffs, if any, of the resulting systems. 


\section{PHASE III RNS CONFIGURATIONS}

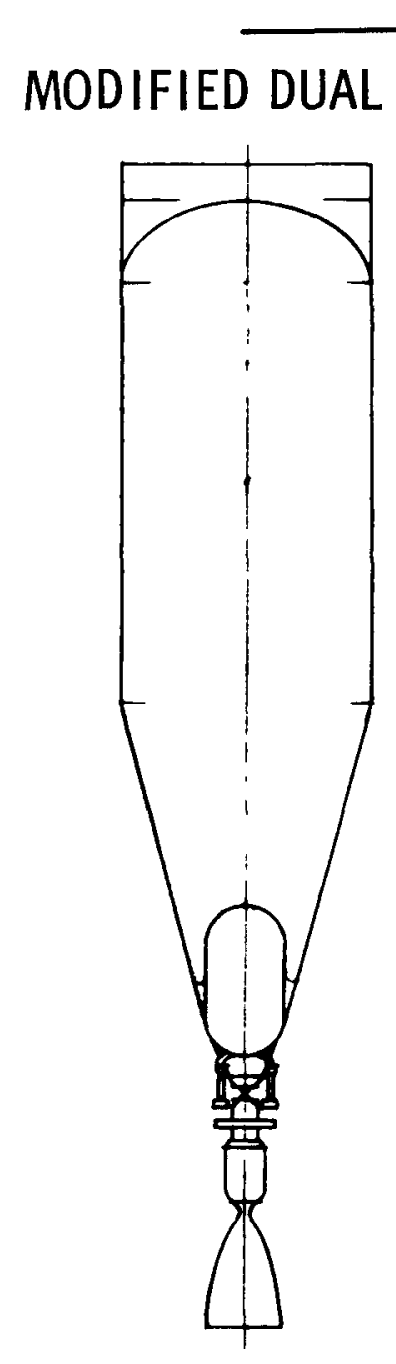

CONICAL AFT BULKHEAD
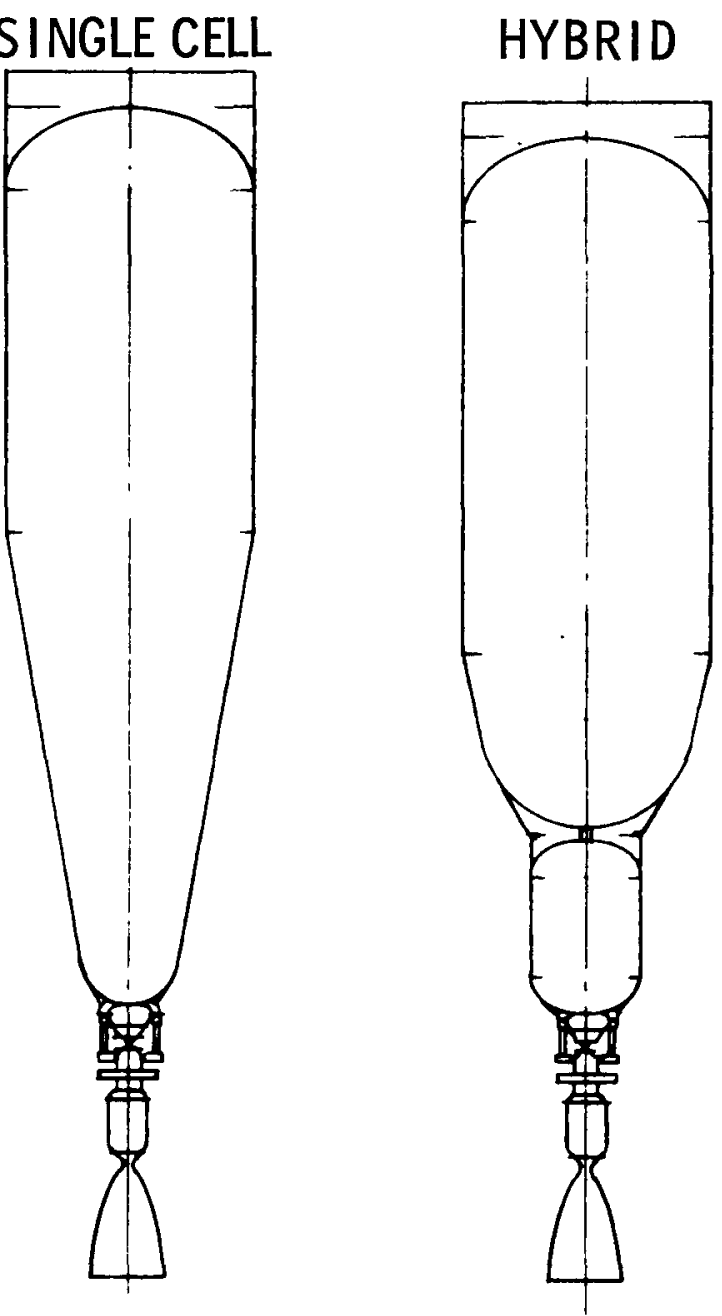

DUAL CELL- ELLIPTICAL

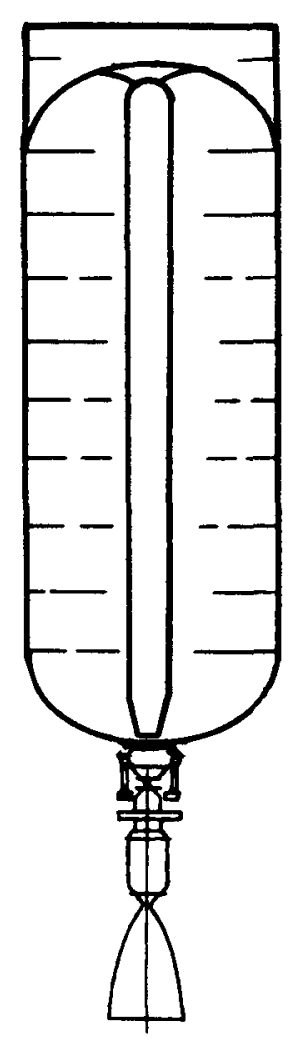


The Phase III study covers a twelve-month extension of the Nuclear Flight System Definition Program for the purpose of providing detailed analysis, conceptual design, and development requirements for a Reusable Nuclear Shuttle. This extension is intended to complete the original Phase A objectives and provide NASA with planning data for follow-on activities.

Phase III is being conducted basically in three steps with reduction in number of options and increase in analytical depth with each succeeding step. The first step, "Mission/System Options and Screening," represents the effort to date. Of paramount importance has been the investigation of mission operations and requirements including identification of alternatives and evaluation of their attractiveness in order to establish RNS design criteria and constraints. Orbital operations have received primary attention covering all steps required to support the RNS from rendezvous and docking to fueling and maintenance. Information management and flight operations are under investigation and will be completed prior to the next briefing.

The performance capability analysis considered Class I (lunar/geosynchronous orbit shuttle) and Class II (unmanned planetary) missions. Using improved analytical tools, the Phase II study results were updated and a realistic lunar mission model defined with launch opportunities, performance, and sensitivities.

In the area of pre-launch operations, effort was concentrated on evaluating the impact of new RNS configurations, particularly with respect to mating operations and transportation.

System definition studies were concerned with screening the new RNS configurations identified for Phase III by means of tradeoffs considering such factors as facility constraints, weight, thermal impact, performance, radiation environment, and boost loads. Through this process, the range of attractive design alternatives has been considerably reduced and a new baseline identified as a standard for comparing conical tank bottom concepts. The preliminary design data have been essential to support the operations studies and identify differences in design requirements and constraints.

An additional activity is to supply system engineering support at NASA-MSFC request during Phase III in all study areas.

This first part of the Phase III study concludes with the identification of a new baseline to be used as a reference standard for comparing the new conical tank bottom geometry configurations under study. 


\section{RNS PHASE III STUDY LOGIC}

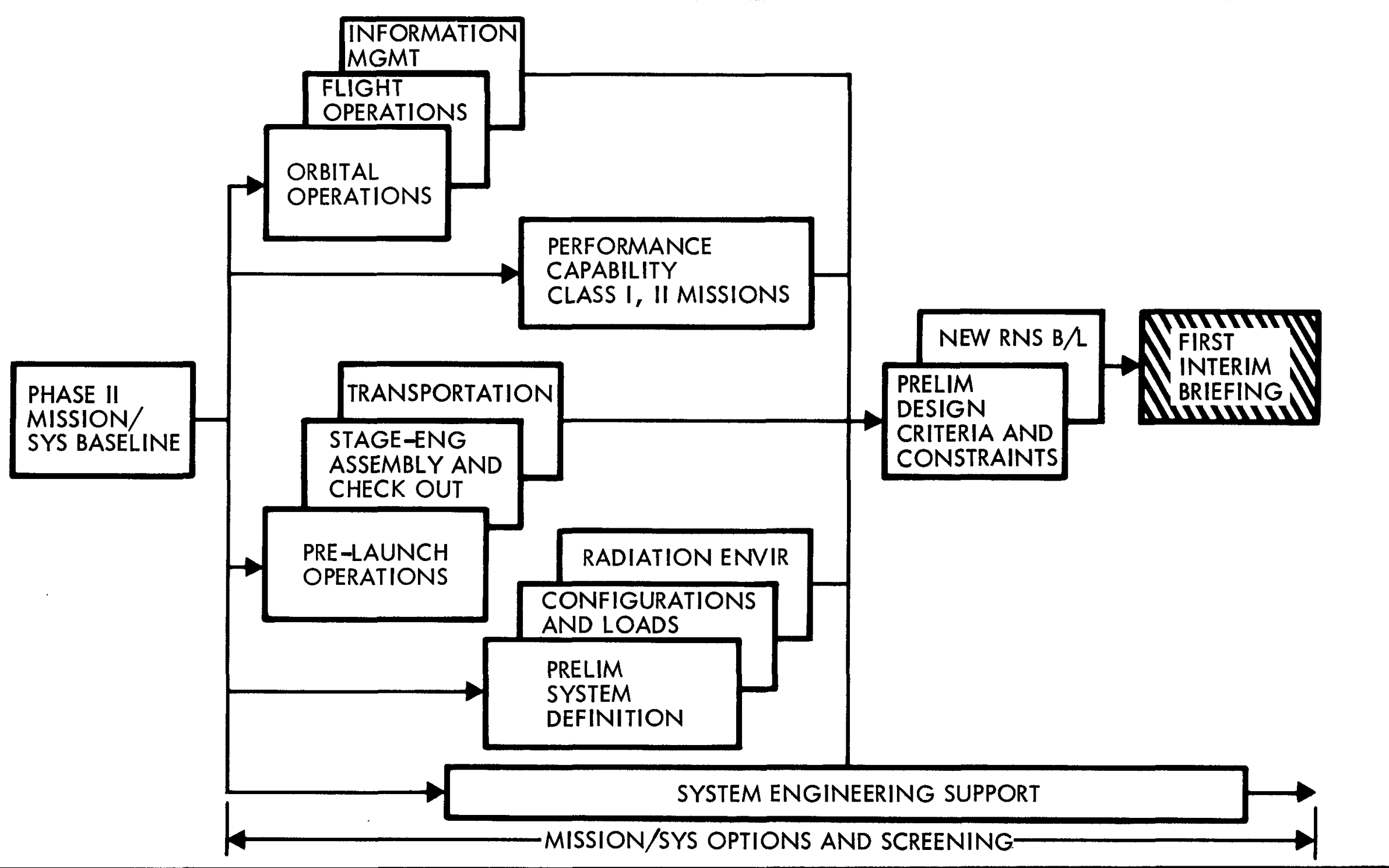




\section{R NS PHASE III STUDY LOGIC (CONTD)}

The second step in the Phase III study will be conducted to (1) complete the study of mission operations (including consideration of operational interfaces with other planned space program elements, safety, logistics, and earth launch); (2) investigate the growth capability of the RNS for Class III (manned planetary) missions using multistage arrangements; and (3) perform the major effort in definition of systems and the engine-stage interface. In addition, cost analysis trades will be initiated with particular emphasis on assessing cost reduction methods, and analyses begun on manufacturing, test, and facility requirements for the alternate configurations still under consideration.

The final step in the study will emphasize program planning for a select number of mission/system options along with final definition of the most attractive RNS design(s). 


\section{RNS PHASE III STUDY LOGIC (CONT)}

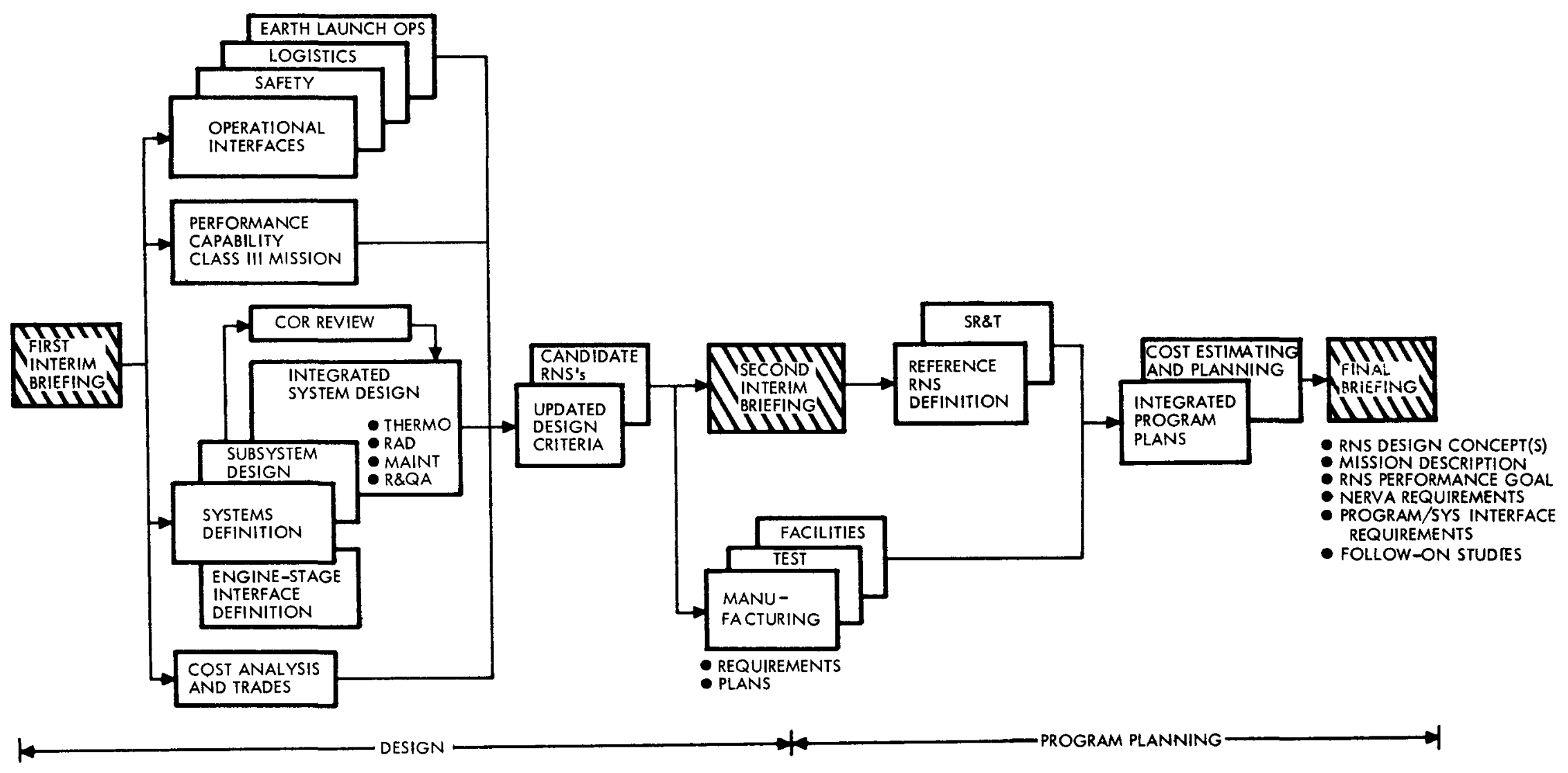


The Phase III studies to date have concentrated on four activities: (1) defining a realistic lunar shuttle mission cycle, (2) updating RNS performance capability for the lunar shuttle and unmanned interplanetary missions, (3) defining orbital operational alternatives and the requirements they impose on the nuclear shuttle; and (4) evaluating the characteristics of conical tank RNS configurations to identify an attractive geometry compatible with ground handling, facility, and orbital operating constraints; and offering the maximum performance considering such key design factors as radiation and thermal protection, boost loads, and system weight.

Launch opportunities to the moon were defined using two earth departure orbits $(258 \times 258 \mathrm{n} \mathrm{mi} \times 31.6$ degrees and $270 \times 270 \mathrm{n} \mathrm{mi} 55$ degrees) for a typical year (1985). The analysis was performed using a modified Apollo precision trajectory program. Payload performance was calculated over a range of launch window, flight times, and lunar orbit stay times using an updated version of the Phase III RNS baseline (dual cell, elliptical aft bulkhead, $300 \mathrm{~K} \mathrm{LH}_{2}$ ). In addition, RNS lunar shuttle mission performance was determined for alternate thrust profiles, cooldown utilization, and mission models (NR and NASA baseline). Data from the Phase II planetary injection performance analysis was updated and extended to include consideration of expendable $\mathrm{LH}_{2}$ tankage and multiburn thrusting. 


\section{RNS STUDY HIGHLIGHTS}

LUNAR SHUTTLE MISSION CHARACTERISTICS FOR ANNUAL CYCLE

RNS LUNAR PERFORMANCE FOR ALTERNATE MISSION/SYSTEM CONDITIONS

ORBITAL OPERATIONS - ALTERNATIVES AND REQUIREMENTS

- ON-BOARD CHECKOUT

- MAINTENANCE AND REPAIR

-PROPELLANT CONDITIONING AND TRANSFER

- RENDEZVOUS AND DOCKING

- AFTER SHUTDOWN RADIATION ENVIRONMENT

- ENGINE DISPOSAL

IMPACT OF ALTERNATE DESIGN CONCEPTS

- GROUND OPERATIONS AND FACILITIES

- RADIATION ENVIRONMENT

- THERMAL INPUT

- WEIGHTS

- booster loAdS

- ORBITAL OPERATIONS 
As previously mentioned, a key task of the initial Phase III study was to define a realistic lunar shuttle mission using a precision earth-moon trajectory program and determine if periodic launch opportunities exist yielding high performance capability. During Phase II, a simplified no-planechange model was employed utilizing a 55-degree inclined $270 \mathrm{n} \mathrm{mi} \mathrm{circular} \mathrm{earth} \mathrm{orbit.} \mathrm{In} \mathrm{con-}$ formance with the guidelines for the current study, the baseline earth orbit was taken as 31.5 degrees and $260 \mathrm{n} \mathrm{mi} \mathrm{circular.} \mathrm{The} \mathrm{precision} \mathrm{model} \mathrm{developed} \mathrm{for} \mathrm{this} \mathrm{baseline} \mathrm{is} \mathrm{discussed} \mathrm{elsewhere.}$ These results were extended to cover the 55-degree orbit and are presented here for comparison with the Phase II data. For the idealized no-plane-change mission considered in Phase II, launch opportunities were found to occur every 10.23 days with a mission recycle time of 40.9 days to permit performing logistics operations between flights. In Phase III precision ephemeris data were utilized for the year 1985. Here mission recycle time is almost 82 days (corresponding to three lunar sidereal periods) which is exactly twice the previously calculated value. However, there are two favorable mission opportunities during each cycle. These fall at intervals of approximately 50 and 30 days, for the assumed reference node of zero degrees, whereas the simplified analysis led to uniform 41 -day spacing. If a performance penalty can be tolerated, other launch opportunities are available at essentially the same recurrence period as previously noted. 


\section{LUNAR MISSION MODEL DEVELOPMENT}

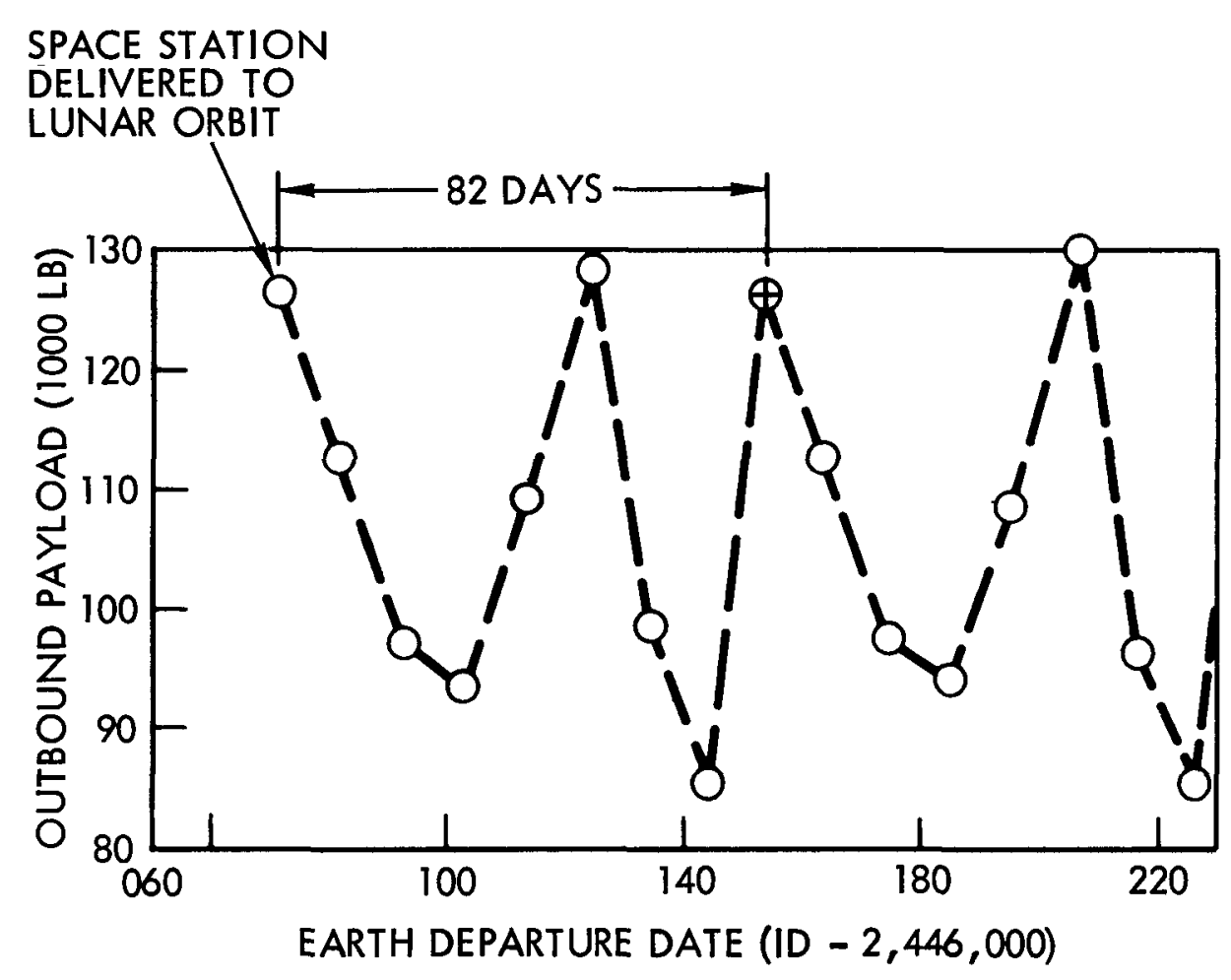

\begin{tabular}{|c|c|l|c|c|}
\hline STUDY & $\begin{array}{c}\mathrm{T}_{\mathrm{TL}} / \mathrm{T}_{\mathrm{TR}} \\
\text { (HR) }\end{array}$ & $\begin{array}{l}\text { LAUNCH } \\
\text { OPPORTUNITY }\end{array}$ & $\begin{array}{l}\text { MISSION } \\
\text { RECURRENCE } \\
\text { RECYCLE } \\
\text { (DAYS) }\end{array}$ & $\begin{array}{l}\text { LUNAR } \\
\text { STAY } \\
\text { (DAYS) }\end{array}$ \\
\hline PHASE II & $78 / 78$ & 10.23 & 40.9 & 18.7 \\
PHASE III & $92 / 76$ & 10.25 & 81.9 & 17.0 \\
\hline
\end{tabular}

PHASE II GUIDELINES

- GENERALIZE EARTH-MOON RELATIONSHIPS

- NO PLANE CHANGE AT LOI OR TEI

- EQUAL TTL AND TTE

PHASE III GUIDELINES

- PRECISION EARTH-MOON RELATIONSHIPS (1985)

- PLANE CHANGE AT LOI AND teI AS NECESSARY

- 92 HR TTL - VARIABLE TTE

ORBIT CHARACTERISTICS

- $270 \times 270 \mathrm{~N} \mathrm{Mi} 55^{\circ} \mathrm{INCL}$ EARTH ORBIT

$.60 \times 60$ N Mi POLAR LUNAR ORBIT 


\section{RNS LUNAR MISSION CAPABILITY}

Outbound/return payload curves are shown here for both NASA Phase III guideline and NR mission models under the assumption of maximum cooldown utilization and a two-burn translunar injection. These mission models assume an earth orbit of $260 \mathrm{n} \mathrm{mi} \mathrm{circula} \mathrm{r}$ inclined at 31.5 degrees and a lunar orbit of $60 \mathrm{n} \mathrm{mi} \mathrm{circular} \mathrm{with} \mathrm{an} \mathrm{inclination} \mathrm{of} 90$ degrees. A midcourse correction of 50 fps was used for each inter-orbit transfer leg (i.e., $T_{L} \& T_{E}$ ). Primarily because of lower plane change requirements, the NR mission allows 23,000 pounds more outbound payload for the same return capability. For comparison with Phase II performance calculations, the dashed curves indicate the effect of assuming an idealized constant 825 seconds $I_{S p}$ for the NERVA runs (exclusive of cooldown). The NR mission with averaged $I_{s p}$ represents our current "most realistic" estimate of the $300 \mathrm{~K} \mathrm{LH}_{2}$ capacity baseline dual-cell stage capability. Payload combinations (in 1000 pounds) are 147 outbound/0 return, $53 / 53$ and $0 / 84$.

Current NR study contracts have identified payloads for the RNS which would require increased propellant capacity. The lunar orbit payload delivery capability of the RNS was initially identified as 180,000 pounds in the LOSS study. The Space Tug study utilizes an RNS with payloads defined as 160,000 pounds delivered to lunar orbit and 20,000 pounds of payload returned to earth orbit. 


\section{RNS LUNAR MISSION CAPABILITY}

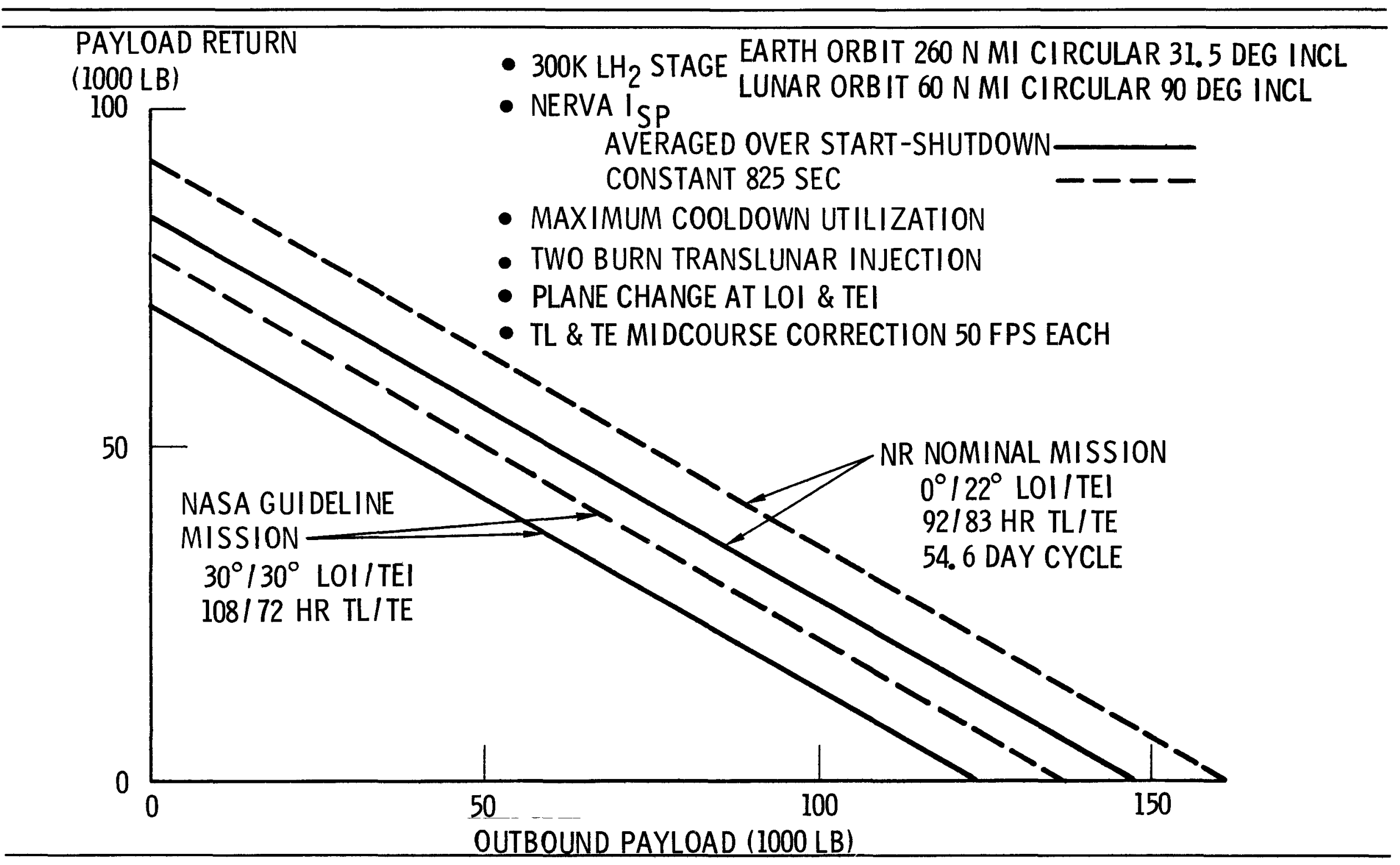




\section{RNS IAUNCH CONFIGURATION OPTIONS}

Several launch configurations of the RNS are under consideration in the Phase III study. The concepts consist of RNS vehicles in various degrees of assembly and launch attitude, boosted by the INT-21 and complemented as required by the Space Shuttle.

As shown in the adjacent chart, the first two configurations consist of completely assembled RNS's; however, while one is right side up, number two is inverted. The latter concept's attitude reduces the stage length above the S-II by approximately 20 feet. Since, as was shown in previous studies, the INT -21 structural capabilities are sensitive to payload envelopes, the resultant height reduction is beneficial. In the event that the NERVA cannot be boosted upside down (due to the acceleration load imposed by $5 \mathrm{~g}$ 's), a disassembled configuration (not shown) is possible wherein the NERVA would be separated from the propellant tank and held right side up in the nose cone. In this manner the height reduction (over configuration number 1) would still be achievable. However, orbital assembly will be required as for the next two configurations.

Further height reductions can be obtained by launching the propellant tank separately from the NERVA engine or from the propulsion module as in the case of the hybrid configuration. Depending on whether the propellant tank is right side up as in configuration 3 or inverted as in 4 , incremental height reductions of 14 feet and 20 feet, respectively, can be achieved. Therefore, total reductions in height of 54, 34, and 20 feet relative to configuration 1 can be obtained by employing concepts 4, 3, and 2, respectively. The propulsion module for the hybrid configuration and the NERVA modified for docking to a propellant tank are presented in the chart and would be delivered to orbit by the Space Shuttle. Configurations 3 and 4 do not impose additional constraints on the NERVA design since removal and replacement of the engine in orbit is already an engine design requirement. Whenever the configuration is inverted as in configurations 2 and 4, the astrionics unit would by necessity also be inverted. Since it is not known at this time if any potential problems can result from this attitude, a limited evaluation of the A. U. components will be conducted to uncover them. 


\section{RNS LAUNCH CONFIGURATION OPTIONS}
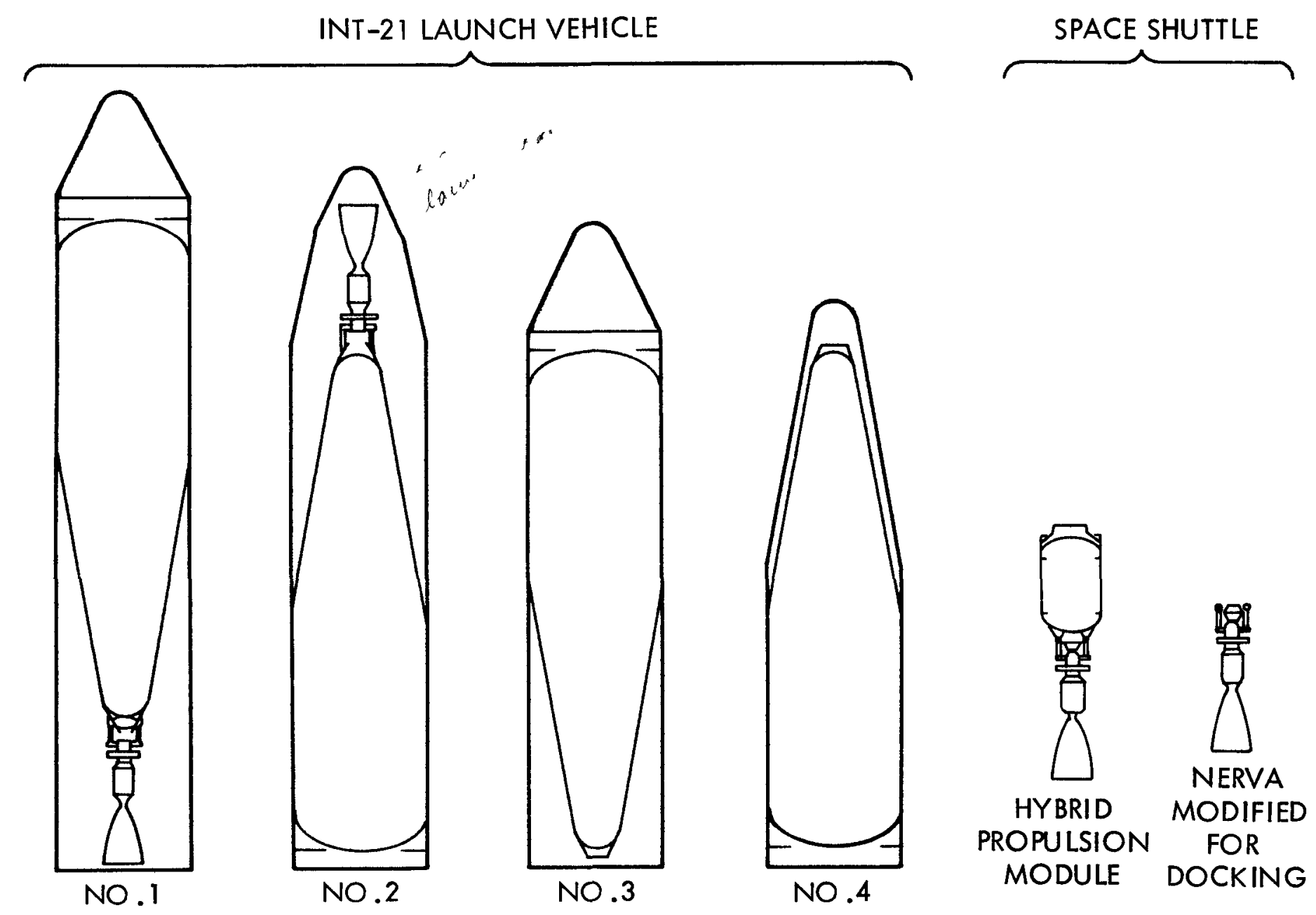
A parametric analysis of single tank conical aft bulkhead configurations with half cone angles less than 15 degrees and closeout cap radii varying from 100 inches to 25 inches was conducted encompassing structural, thermal, radiation, and performance effects. The chart illustrates on the left hand side the individual elements of the analysis. Uppermost is a description of the weight variation with the two leading parameters of half cone angle and radius. Next is depicted the penalty associated with increased boiloff, a result of propellant tank surface area increase with half cone angle decrease. Last, the lower left graph presents external shield weight requirements consistent with an integral dose at the top of the tank of $10 \mathrm{rem}$ in accordance with the study guidelines.

Total system weights were obtained by summing stage weight and shield weight. Using the 15-degree half cone angle with the 100 -inch radius as a reference point, weight differences for remaining configurations were determined and resultant incremental payload derived using performance partials for maximum payload out-bound, zero return for the lunar shuttle mission. Including the penalties associated with boiloff, the normalized incremental payloads were plotted and are presented in the right hand side of the chart in terms of half cone angle for 25, 50, 75, and 100 inch cap radii. As can be seen, the "optimum" configuration has a half cone angle of approximately 7 degrees and a cap radius of 25 inches. The payload advantage over the reference configuration, 15 degrees and 100 inch radius, is nearly 32,000 pounds, or approximately an increase over the payload basepoint of 25 percent.

To these results, facility and INT-21 strength capability constraints were imposed as shown. The uppermost line to the left represents a vehicle 190 feet long which corresponds to the maximum permissible height in the VAB and as can be seen encompasses all size tanks but the 25-inch radius with 5 degree half cone angle (predicated on using configurational arrangement 4 shown on the previous chart). However, based on earlier study data in conjunction with minimum load control on the INT-21, the maximum height permissible to obviate modification to the INT-2I (S-II tank wall) is 165 feet. This constraint is represented by the three cross lines identified as configurations 4 , 3 , and 2 compatible with the previous chart. Tank length differences between the three configurations are 20 feet between 4 and 3 and 14 feet between 3 and 2 . All configuration 1 sizes exceed the 165 foot INT - 21 strength limitation and consequently the representative cross line falls below the abscissa of the plot.

Therefore, the preliminary conclusion that can be drawn from this parametric analysis is that predicated on configuration 4, the "optimum" single tank configuration has a cone half angle equal to 8.5 degrees and a cap radius of 25 inches. 


\section{PRELIMINARY RNS DESIGN TRADE-OFF}
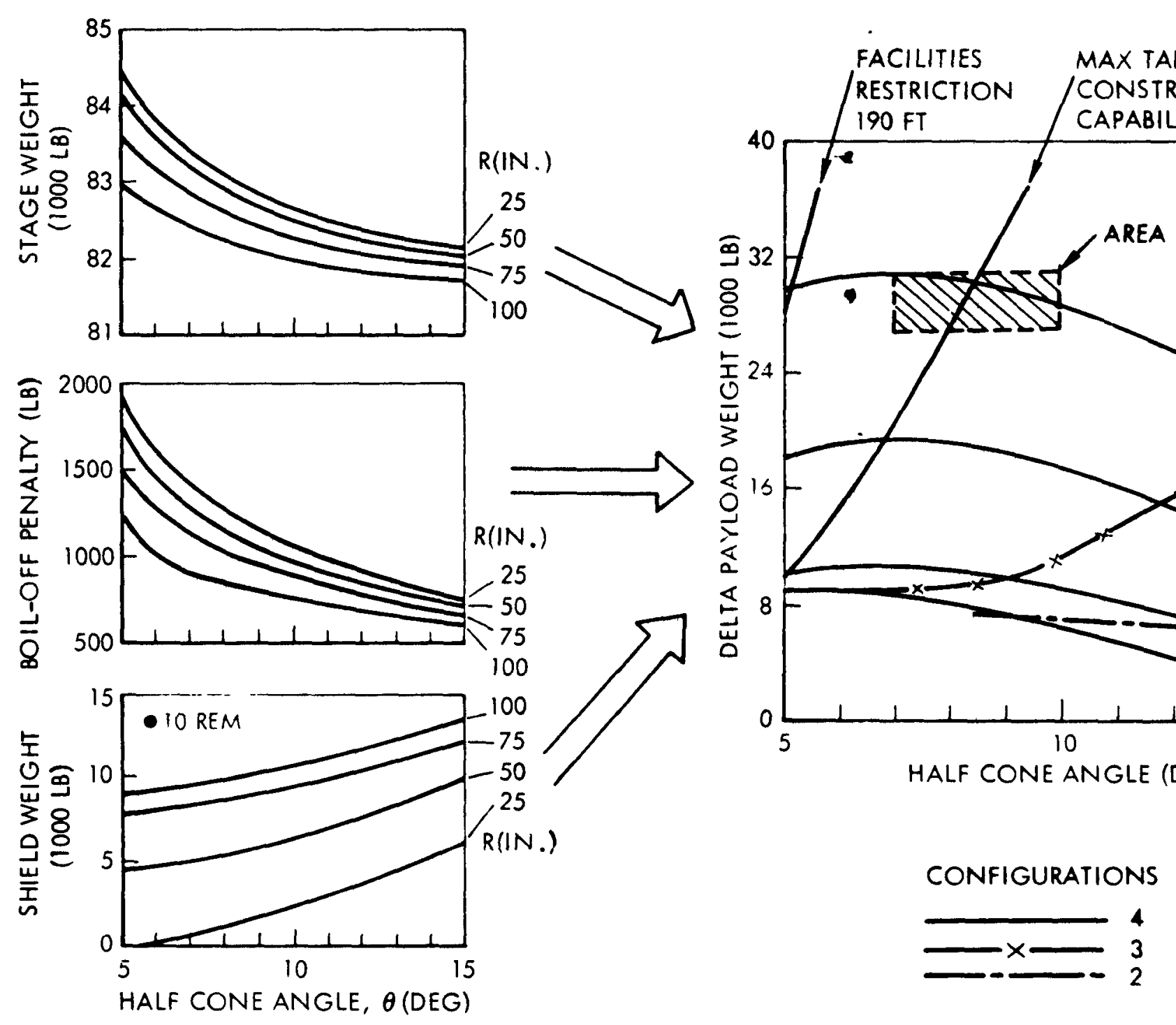
This chart summarizes the findings of preliminary Phase III studies in key areas of RNS orbital operations. The on-board checkout equipment will serve as prime test equipment in determing the status of the RNS subsystems during orbital pre-flight operations. The approach taken in establishing the checkout concept falls between the extremes of complete dependence on external support and an autonomous system. In the interest of reducing preprogramming and computer memory requirements, a qualitative (Go, No-Go) determination of RNS subsystem status will be made by the onboard checkout equipment (OBCO). Fault detection will not be limited to the time of checkout in the RNS operations orbit prior to departing on a mission, but will be active throughout the entire mission. Fault isolation only will be carried to the maintenance flight replaceable unit (FRU) level. The checkout function can be initiated by the maintenance "element" (permanent station or unit transportable when required), manned payload, or other space program element having a communications link with the RNS. Since the RNS will be checked and maintained in earth orbit, the same procedures and interfaces could be utilized on the ground to verify checkout system capability and programs prepared for orbital applications. Fault prediction through trend data analysis will require external support from the ground or space program element. Trend data analysis will facilitate the maintenance and logistic operations in that parameters approaching the predetermined limits will identify FRU's requiring servicing or replacement before actual failure or out-of-tolerance operation occurs. Performance of maintenance operations in orbit will require designs which facilitate removal and replacement by providing adequate access for space suited personnel or remote manipulators(depending on radiation levels and required capability) as well as providing engaging and locking mechanisms on the FRU's. No repair of FRU's in orbit is anticipated. A permanent or transportable maintenance element, depending on traffic rates, will be required to support the orbital maintenance operations.

A single transfer of propellant from a large tank to the RNS is the mode preferred since it is not constrained by the Space Shuttle launch rate. It requires a single rendezvous between $R$ NS and PD, and satisfies NERVA startup requirements. The centrifugal acceleration method of propellant location is very attractive from the standpoint of propellant losses incurred, requirements imposed on PD/RNS systems and providing hydrodynamic control in the receiver tank (i. e., RNS).

RNS rendezvous and docking should be autonomous and automatic to meet a broad spectrum of anticipated conditions. An obvious advantage of providing the RNS with a completely autonomous automatic capability are backup capability in the event of equipment failure on the active element docking with a passive RNS; also, the RNS can dock with a disabled vehicle during rescue operations. Manual override would be provided to satisfy the guideline requirement for manned payloads. In order to provide a compatible interface with other program elements maximum commonality for all interfacing systems is required. Radar and scanning laser radar are required to perform the acquisition functions of determing range and range rates.

Several factors, such as configuration, location from which operation is initiated, eventual disposition, and life of stage module and/or engine will determine final selection of disposal alternate. If the stage life exceeds that of the engine by a large margin, it probably will be advantageous to replace and dispose of the spent engine. Dis posal to a high altitude earth orbit with an auxiliary tank is attractive from the standpoint of propellant requirements. Injection into a heliocentric orbit requires more energy but might provide less interference with future space operations. Disposal of NERVA using a space tug which reached its "end of life" is another attractive mode. The problem of disposing of spent hardware needs study from a broader perspective than the RNS program alone if future space "environmental pollution" and overburdening tracking requirements are to be avoided. 


\section{ORBITAL OPERATIONS}

ON-BOARD CHECKOUT (OBCO) / M\&R

- QUALITATIVE STATUSING (INDEPENDENT OF GROUND FAC) FOR C/O AND FAULT DETECTION

- INTEGRATION OF FLIGHT AND GROUND C/ 0 REQUIREMENTS

- TREND DATA FOR FAILURE PREDICTION USING EXTERNAL SUPPORT

- DESIGN RNS USING FLIGHT REPLACEABLE UNITS (FRU) AND C/O TO THIS LEVEL

- MAINTENANCE "ELEMENT" REQUI RED - MAY BE PERMANENT OR TRANSPORTABLE BY TUG, DEPENDING ON TRAFFIC RATES

PROPELLANT TRANSFER

- USE PD WITH LARGE LH 2 TANK

- SINGLE TRANSFER BY CENTRIFUGAL ACCELERATION

RENDEZVOUS AND DOCKING

- AUTONOMOUS RNS CAPABILITY

- RADAR AND SCANNING LASER RADAR

- AUTOMATIC WITH MANUAL OVERRIDE

- MAXIMUM COMMONALITY FOR ALL INTERFACING SYSTEMS

DISPOSAL

- ENGINE ALONE CAPABILITY PROBABLY REQUIRED BASED ON LIFETIME

- PREFER DISPOSAL TO HELIOCENTRIC ORBIT WITH AUXILIARY TANK MODULE 
In a number of study areas the results are sufficiently definitive to permit drawing some pertinent conclusions. By using a precision earth-moon trajectory program which accounts for all significant tlight mode, geometry, and mechanics factors, it has been confirmed that repetitive mission cycles exist yielding high performance. For a rendezvous compatible circular earth departure orbit of $258 \mathrm{n} \mathrm{mi} \mathrm{at} 31.6 \mathrm{deg}$ rees inclination (almost identical to the guidelines orbit), launch opportunities occur every nine days with the optimum cycle repeating at 54.6 day intervals. Parametric performance analysis indicates that the 300,000 pound $\mathrm{LH}_{2}$ RNS size can deliver a maximum payload to lunar orbit of 147,000 pounds (with no return payload). However, some payloads under consideration in concurrent NR lunar studies indicate that an increase in RNS tank size of 15 percent might be required.

The ground operations investigation, which concentrated on KSC mating alternatives and transportation, indicates that a wide range of RNS configurations and sizes can be accommodated using existing facilities and equipment. A maximum RNS length of $190 \mathrm{feet}$ is possible if the VAB high bay area is used. This limitation results from the size of the INT $-21 /$ mobile launcher and available door clearance. Initial studies indicate that launch loads may be a more limiting factor in selecting tank size. One major unanswered question is the availability of KSC facilities to support the RNS program since it is uncertain to what extent earlier sytems (such as Space Shuttle) will demand these same facilities.

The initial Phase III study identified a conical tank bottom geometry which affords near-maximum performance while at the same time allowing use of the INT -21 booster(with a load minimum flight mode) and existing KSC facilities/equipment. This 165-foot-long tank can be launched inverted on the INT-21, but will require design of astrionic and other hardware to withstand accelerations to $5 \mathrm{~g}$ while upside down. Furthermore, the design, which will be employed as a standard (baseline) for comparing the new study configurations, requires NERVA launch by the Space Shuttle as well as orbital mating and checkout operations. These latter requirements appear achievable based on projected technology at this phase of analysis.

Design criteria for engine-stage reusability as well as final RNS configuration selection will be strongly influenced by induced and space environments over extended cyclical periods. Certain orbital operations -notably $M \& R$ and engine disposal - - can play a dominant role in RNS reusability economics. The current M\&R philosophy is based on use of flight replaceable units (FRU) which can be removed eithe $r$ by maintenance personnel or robots. However, major tank structural elements may require either difficult in-space repair or disposal of the entire system upon failure or damage. If economic considerations dictate disposal of engines prior to tank end-of-life, use of the hybrid RNS configuration propulsion module or a special disposal tank/astrionics unit may prove attractive alternates. The former limits disposal to a high altitude earth orbit. Both may require removal and handling operations in a highly radioactive environment. On the other hand, if engine and tank lifetimes are the same (permitting concurrent disposal), key orbital operations could be less demanding and allow greater freedom in selecting an RNS configuration based on performance/

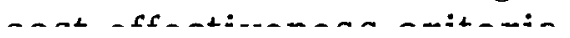




\section{PRELIMINARY PHASE III STUDY CONCLUSIONS}

- REPETITIVE LUNAR MISSION CYCLE CONFIRMED WITH HIGH PERFORMANCE

- SOME PAYLOAD MIXES UNDER CONSIDERATION EXCEED 300K SIZED RNS CAPABILITY

- GROUND OPERATIONS AT KSC CAN BE PERFORMED IN EXISTING FACILITIES FOR LARGE RANGE OF CONFIGURATIONS - 190 FT MAXIMUM RNS LENGTH

- MAXIMUM PERFORMANCE POSSIBLE IF NERVA LAUNCHED BY SPACE SHUTTLE \& RNS TANK BOOSTED INVERTED ON INT-21

- CONICAL AFT BULKHEAD RNS HAS ATTRACTIVE DESIGN AT

TANK LENGTH $\sim 165 \mathrm{FT}$

HALF CONE ANGLE 8.5 DEG

CAP RADIUS $\sim 25$ IN.

- OTHER FACTORS WILL INFLUENCE RNS FINAL DESIGN SELECTION

ORBITAL OPERATIONS IN A NERVA RADIATION FIELD

ENGINE LIFETIME \& DISPOSAL REQUI REMENTS 


\section{BRIEFING OUTLINE}

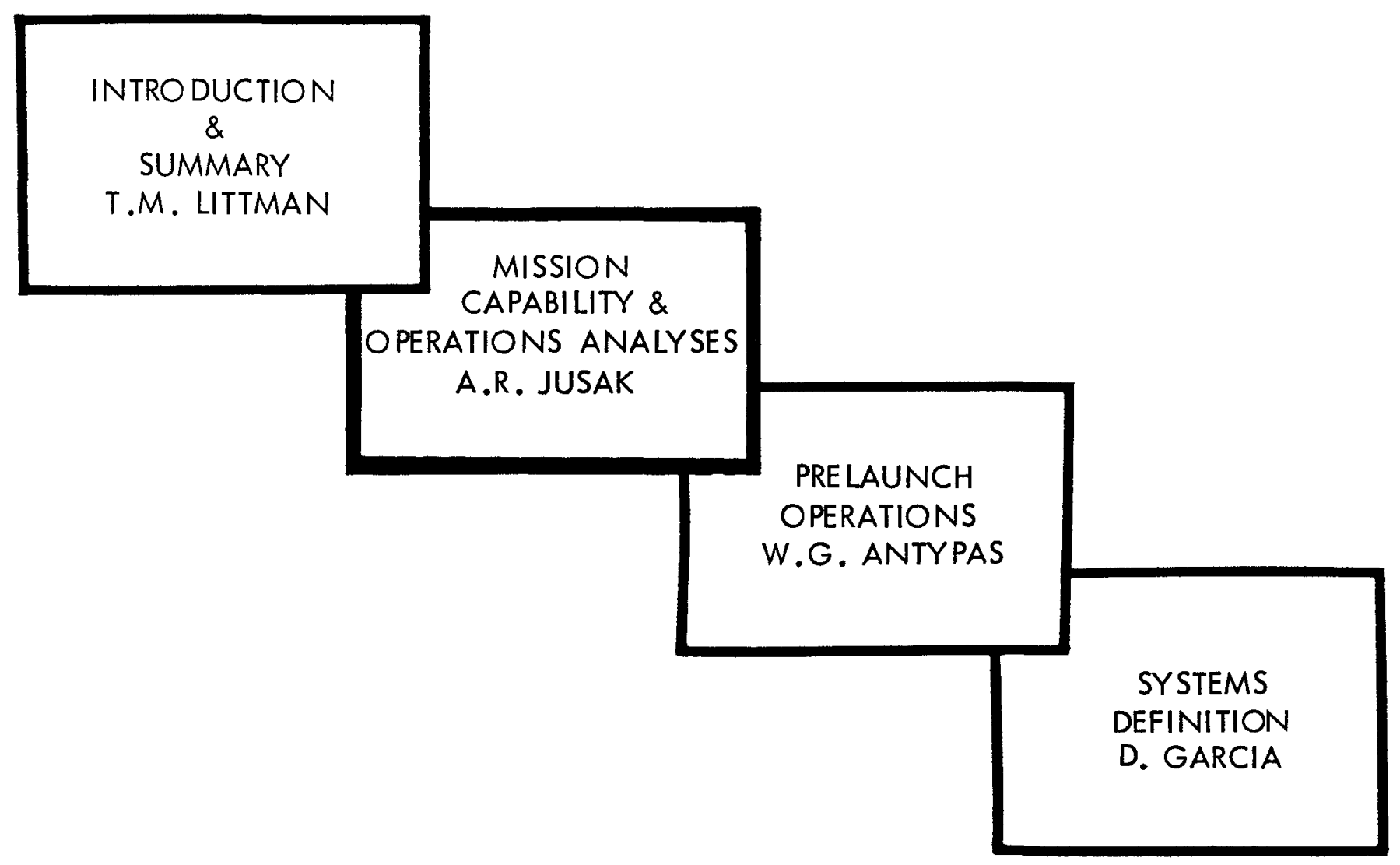




\section{MISSION REQUIREMENTS AND OPERATIONS ACTIVITIES}

During Phase II study activities the lunar shuttle mission design assumed a generalized Earth-Moon relationship to determine lunar injection launch opportunities and to determine lunar stay times. A no plane change mission departing a $270 \mathrm{n} \mathrm{mi} 55$ degree inclined Earth orbit to a $60 \mathrm{n} \mathrm{mi} 90 \mathrm{degree}$ lunar orbit served as the baseline.

In the beginning of the Phase III study, the year 1985 was selected for the performance/mission analysis because of the high RNS traffic density and because the high inclination of the Moon's plane tends to emphasize the effects due to the changing alignment of the Earth orbit. A $260 \mathrm{n}$ mi Earth orbit inclined at 31.5 degrees and plane changes at lunar orbit injection to a $60 \mathrm{nmi} 90$ degree inclined orbit defined the Phase III mission. Performance of the RNS was determined utilizing averaged $\mathrm{I}_{\mathrm{sp}}$ as well as constant 825 second $I_{\text {sp. }}$

Orbital operations analysis covered the areas of rendezvous and docking, maintenance, checkout, and propellant transfer. A number of spent stage disposal options were identified taking into consideration effects on mission operations, hazards and disposal configurations. Requirements were identified for various disposal modes and preferred disposal modes are proposed. 


\section{MISSION REQUIREMENTS AND OPERATIONS ACTIVITIES}

- MISSION CAPABILITY ANALYSIS
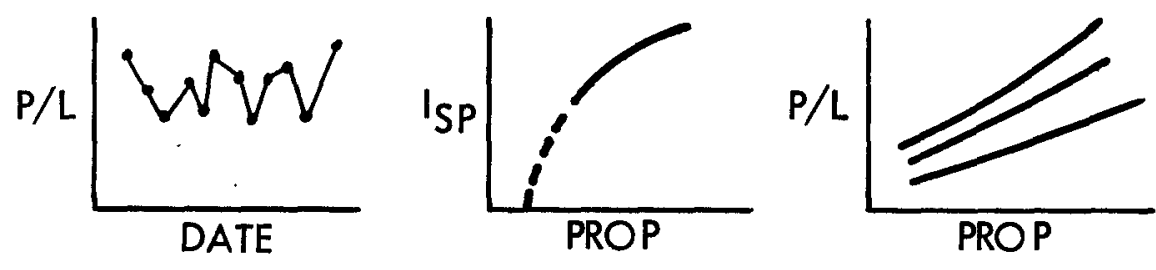

- ORBITAL OPERATIONS
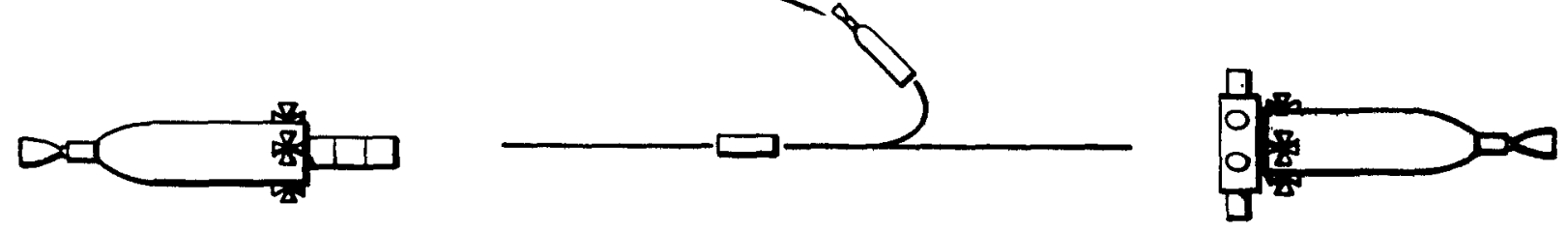

- SPENT STAGE DISPOSAL
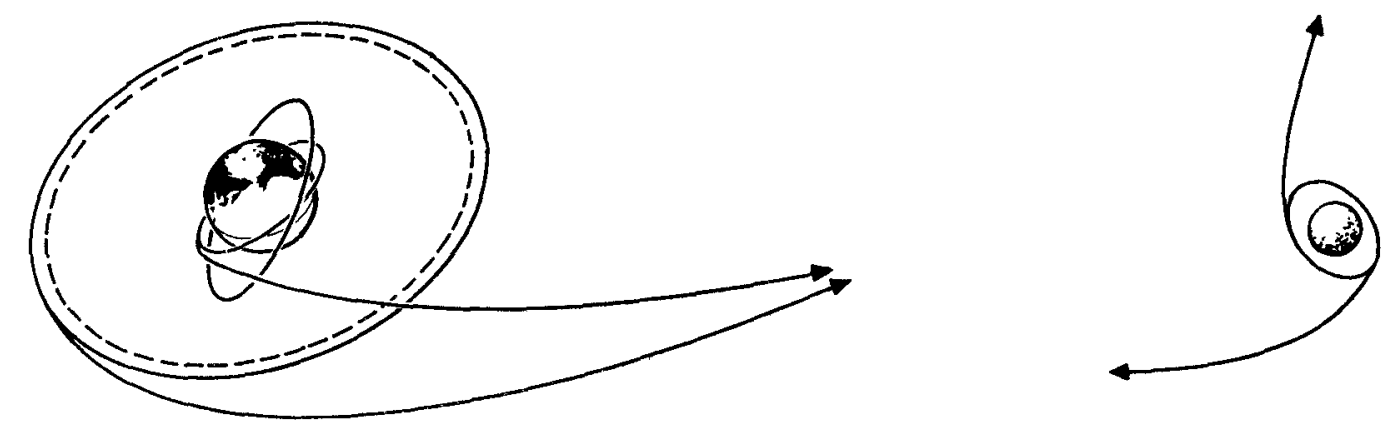


\section{GROUND RULES FOR LUNAR MISSION ANALYSIS}

Because the lunar shuttle mission is envisioned as the primary transportation task for the RNS, a detailed analysis of this mission's characteristics was undertaken. Objectives were to provide a better understanding of performance requirements; identify the range of variation of mission durations, delta-V's and other important parameters; and establish the pattern of flight opportunities throughout a typical year of RNS operations using a precise Earth-Moon model, semi-precise velocity requirements from $\bar{V} \propto$ tables and delta-V - loss curves, and an RNS performance model including cooldown and boiloff propellant expenditures. Optimization of mission parameters assumed a 10,000 pound return payload and sought to maximize out-bound payload.

The year 1985 was selected for the performance/mission analyses because of high RNS traffic density (per the guideline model) and because the high inclination of the Moon's plane (27 degrees) tends to emphasize the effects due to the changing alignment of the Earth orbit. A 31.6 degree, $258 \mathrm{n} \mathrm{mi}$ (above equator) Earth orbit assured rendezvous compatibility and near-repeating mission geometry on a 54.6 day cycle (two lunar sidereal periods). Reference Earth orbit orientation ( $\Omega$ ref) for the majority of calculations was a zero right ascension of the node at 1200 GMT, December $31,1984$. However, the effect of varying initial orientation also was established. The polar lunar orbit orientation was set by a maximum payload Lunar Orbit Space Station (LOSS) delivery flight assumed to take place upon the first opportunity after January 1 . The second transearth injection window provides lunar orbit stay times in the range of $10-18$ days and was, therefore, emphasized in the data development. 


\section{GROUND RULES FOR LUNAR MISSION ANALYSIS}

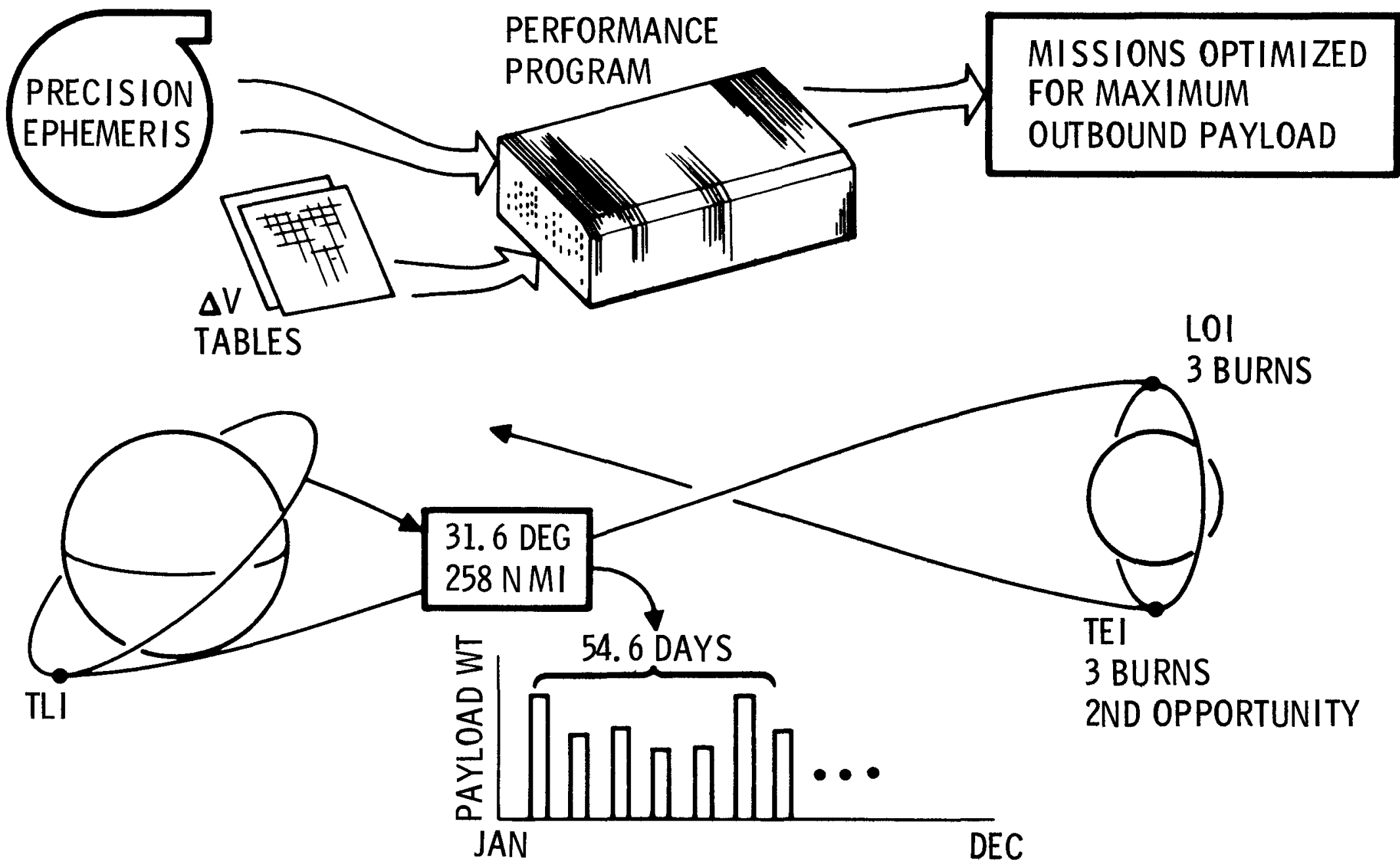


The analysis of LOSS delivery flights, where the lunar orbit is not initially constrained, revealed important mission design trends. In principle, there may be an advantage to accepting a plane change at TLI in order to improve other features of mission geometry and timing. This tradeoff did not pay in the cases considered, however, due primarily to the rapid rise in delta- $\mathrm{V}_{\mathrm{T}} \mathrm{LI}$ with plane change angles. The same effect is expected to hold for EOI but to a less pronounced degree because of the lower sensitivity of payload to delta $-\mathrm{V}_{\mathrm{EOI}}$. Only single burn maneuvers have been considered in arriving at these conclusions. Coplanar TLI and EOI are implicit in the other results presented. As with a TLI plane change, it may be expected that a plane change at LOI will pay off in other factors. Indeed a payload maximum resulted for LOI plane changes of about 0.5 degrees, but the improvement over coplanar LOI was negligible.

With coplanar TLI, LOI, and EOI decided upon, mission variables remaining for the LOSS delivery flight are initial Earth orbit alignment $(\Omega$ ref), Earth departure date, TEI opportunity (second was preferred), and transearth transit time. The payload optimization traded transearth energy and plane change, resulting in TEI plane changes as large as $60^{\circ}$. Variation of Earth departure date for fixed $\Omega$ ref indicated a TLI window of about 40 hours for a 5, 000 pound payload decrement from peak values. Variation in $\Omega$ ref over a full $360^{\circ}$ caused departure date to vary by 20 days, while payload and lunar stay time also varied significantly. Similar characteristics were found to apply to the first, second, and third TEI opportunities. 


\section{CHARACTERISTICS OF LOSS DELIVERY FLIGHTS}

- COPLANAR TLI \& EOI

- NEAR COPLANAR LOI ( $\approx 1 / 2$ DEGREE PLANE CHANGE)

- TLI WINDOW 40 HOURS FOR 5000 POUND PAYLOAD DECREMENT

- EFFECTS OF INITIAL EARTH ORBIT ALIGNMENT ( $\Omega_{\text {REF }}$ )

DEPARTURE DATA VARIES 20 DAYS

PAYLOAD VARIES 16,000 POUNDS

LUNAR STAY TIME VARIES 8 DAYS 


\section{LUNAR SHUTTLE MISSION - OUTBOUND PAYLOAD}

Following the nominal LOSS delivery flight, TLI opportunities will occur approximately every 9 days with a nearly identical, high payload recurring every sixth opportunity (54.6 days). This figure shows the pattern throughout 1985. The slow regression of the Moon's plane accounts for the slight drop in payload toward the end of the year. In practice such effects (e. g. , the neglected solar perturbations) would be easily accommodated by an occasional slight "tune up" of the Earth orbit orientation. 


\section{LUNAR SHUTTLE MISSION - OUTBOUND PAYLOAD}

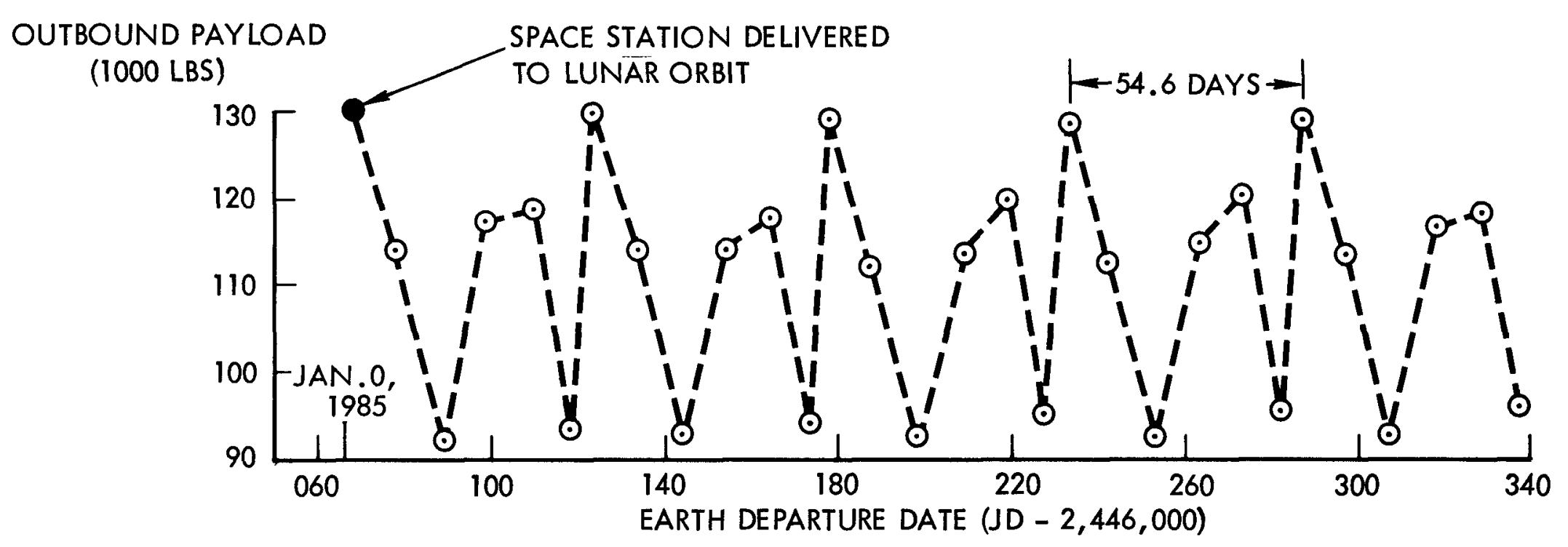

OUTBOUND PAYLOAD

(1000 LBS)

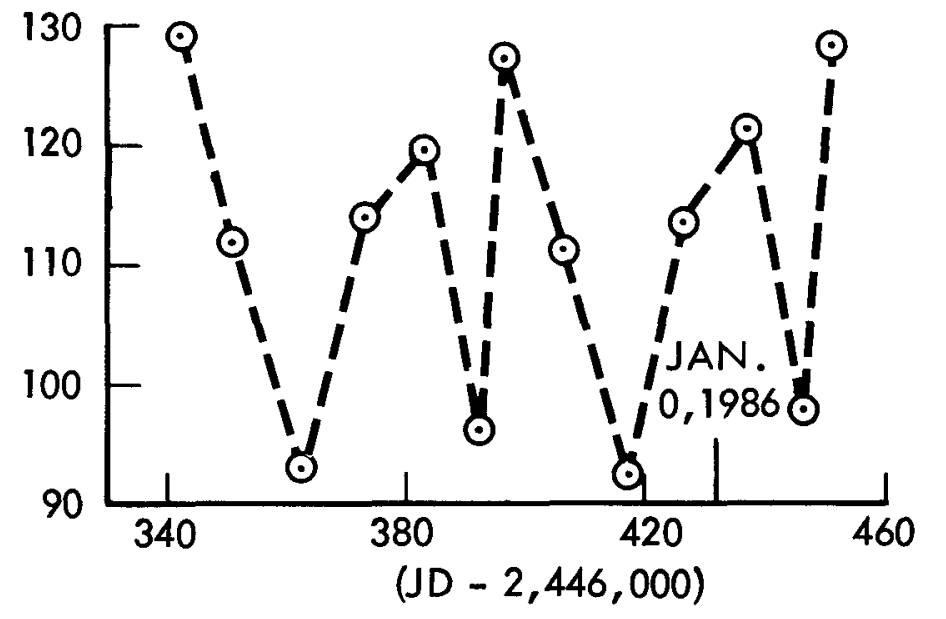

$$
\begin{aligned}
& \mathrm{h}_{\mathrm{C}}=258 \mathrm{~N} \mathrm{MI} \\
& \mathrm{i}_{\mathrm{c}}=31.6 \mathrm{DEG} \\
& \mathbf{\Omega}_{\mathrm{REF}}=0 \mathrm{DEG} \\
& \Delta \mathrm{T}_{\mathrm{TL}}=92 \mathrm{HOURS} \\
& \text { RETURN PAYLOAD }=10,000 \mathrm{LB}
\end{aligned}
$$




\section{CHARACTERISTICS OF REVISIT MISSIONS}

With the 54.6 day group of missions numbered 1 through 6 , the table summarizes the range of characteristics encountered over the entire year. For the intermediate flights, LOI and TEI plane changes are freely optimized and their sometimes large values dominate the performance picture. At a reduction of $10-15,000$ pounds of payload, it would be possible to utilize three of the intermediate flight opportunities, should the need arise to break the 54.6 day cycle for an emergency mission, or for the more favorable scheduling of other RNS activities. 


\section{CHARACTERISTICS OF REVISIT MISSIONS}

\begin{tabular}{|c|c|c|c|c|c|}
\hline $\begin{array}{c}\text { TLI } \\
\text { OPPORTUNITY } \\
\text { (IN SEQUENCE) }\end{array}$ & $\begin{array}{c}\text { PAYLOAD } \\
\text { (LB) }\end{array}$ & $\begin{array}{c}\text { TRANSEARTH } \\
\text { TIME } \\
\text { (HR) }\end{array}$ & $\begin{array}{c}\text { LUNAR } \\
\text { STAY TIME } \\
\text { (DAYS) }\end{array}$ & $\begin{array}{c}\text { MISSION } \\
\text { DURATION } \\
\text { (DAYS) }\end{array}$ & $\begin{array}{c}\text { PLANE CHANGE } \\
\text { LOI/TEI } \\
\text { (DEG) }\end{array}$ \\
\hline 1 & $\begin{array}{l}130,000 \\
\text { (NOMINAL) }\end{array}$ & 83 & 16 & 26 & $0 / 20$ \\
2 & $112-115,000$ & $106-118$ & 17 & 28 & $50 / 0$ \\
3 & $92-93,000$ & $125-128$ & 16 & 27 & $70 / 35$ \\
4 & $113-117,000$ & $78-88$ & 11 & 20 & $50 / 5$ \\
5 & $118-121,000$ & 128 & 9 & 20 & $15 / 50$ \\
6 & $93-94,000$ & $65-72$ & 11 & 20 & $50 / 60$ \\
\hline
\end{tabular}




\section{FLIGHT SCHEDULE FACTORS}

A LOSS delivery flight, representing delivery of a payload to a freely oriented polar lunar orbit, exhibits sizable changes in payload capability as the initial alignment of the Earth orbit is varied. In addition, other mission characteristics, in particular the leg times and total duration, undergo changes which define an envelope of requirements to be met by the RNS. Under the conditions of this analysis total durations varied from 20 to 26 days, due primarily to the change in stay time (second TEI opportunity) from 9 to 17 days.

When mission duration is related to the 54.6 day cycle of nominal missions, as shown here, ample time is available for scheduling of other RNS functions. Should the need arise, however, to insert or substitute an off-nominal flight as illustrated, insufficient time remains for the Earth orbital operations. A remedy is to switch to the first TEI opportunity, but stay time may be reduced almost to zero. 


\section{FLIGHT SCHEDULE FACTORS}

- NOMINAL MISSIONS: PL $=130 \mathrm{~K} / 10 \mathrm{~K}$

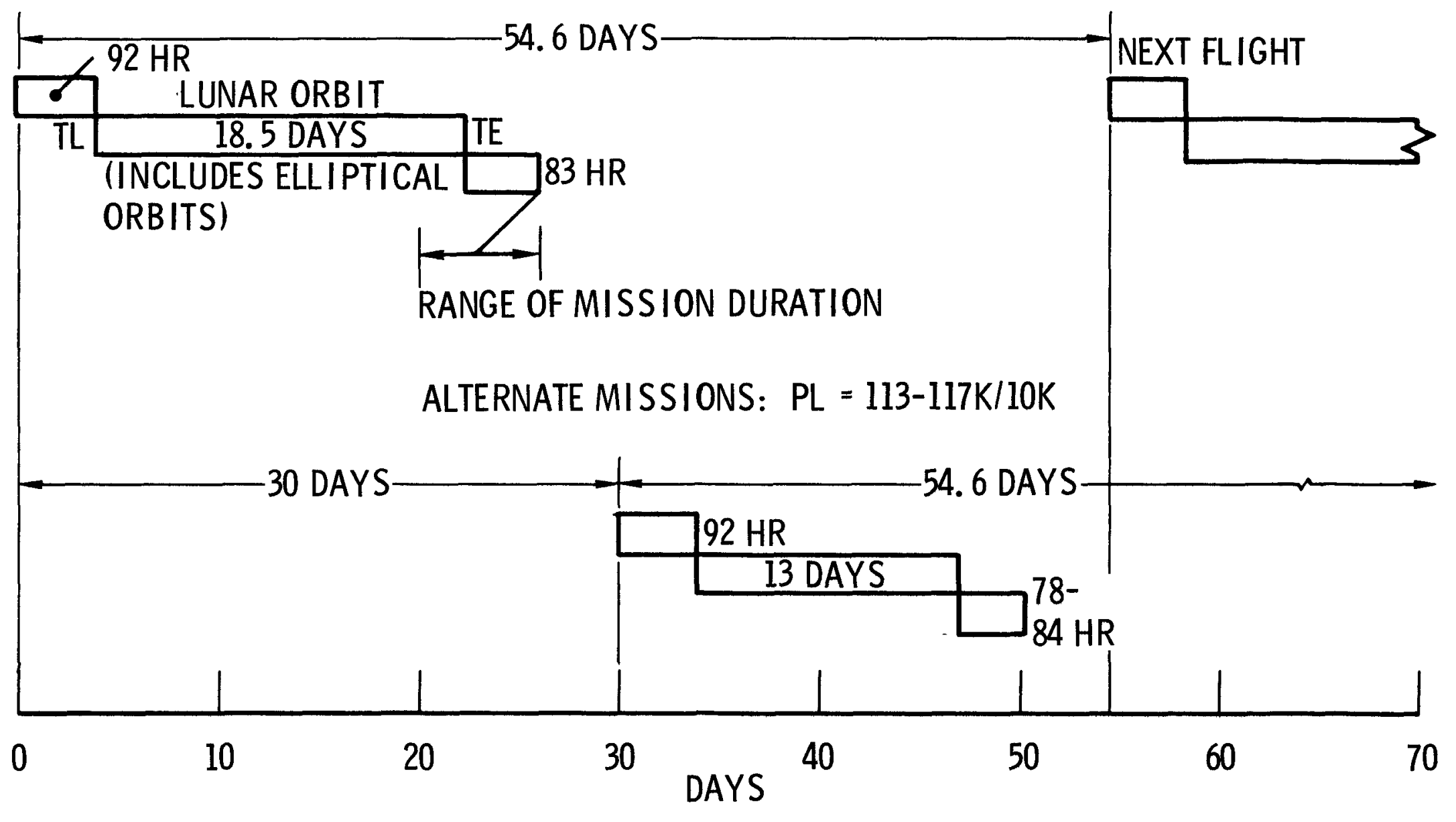


Assuming that the orbit inclinations are fixed at Earth and Moon (31.6 degrees and 90 degrees, respectively), it would appear that constraining the nodal orientations, as with pre-established space station orbits, would entail a performance penalty. For an individual mission, in a sense this is true. The LOSS delivery flights correspond to the case of a free lunar orbit. Here, under the nominal conditions of the analysis, payload delivered was 130,000 pounds. The payload capability on subsequent revisits, varying from 90,000 - 130,000 pounds, indicates that revisiting a constrained lunar orbit at the worst times can cost as much as 40,000 pounds of payload. Flights scheduled only at the 54.6 day intervals result in no payload penalty.

The change in LOSS delivery payload with initial Earth orbit alignment affords a comparison of free and constrained Earth orbits in the following way. Examination of a maximum payload flight (138, 000 pounds) shows that all delta-V's are near minimum; that is, the TEI plane change is near zero and the transit times are near minimum energy. For this mission no amount of fine tuning of mission parameters will increase the payload significantly and the re is no penalty in returning to the original Earth orbit. The lower payload flights computed (as low as 122, 000 pounds) departing on other dates with different $\Omega_{\text {ref }}$ use the same translunar transit time and coplanar TLI, LOI, and EOI. Therefore, the lower payload results entirely from a TEI plane change and nonoptimum transearth transit time occasioned by the requirement of returning to the original Earth orbit.

On any single shuttle flight then, the requirement to return to the original Earth orbit entails an apparent payload penalty of zero to 16,000 pounds. However, return to a free Earth orbit offers no guarantee of a desirable Earth orbit orientation for the next shuttle flight. The notion of repeating mission geometry at multiples of the lunar sidereal period must now be abandoned. Viewed in this way, constraining the Earth and lunar orbits appears as a performance and scheduling asset in that it assures high payload flights on a predictable basis. 


\section{IMPLICATIONS OF CONSTRAINED ORBITS}

PENALTY FOR SINGLE FLIGHT:

- LUNAR ORBIT

- LOI \& TEI PLANE CHANGES

- HIGH ENERGY FLIGHT TIMES

- COST UP TO 40,000 LB

- EARTH ORBIT

- NON-OPTIMUM $\Omega$ REF

- TEI PLANE CHANGE \& HIGH ENERGY

- COST UP TO 16,000 LB

ADVANTAGE FOR REPETITIVE FLIGHTS

- HIGH PAYLOAD ON PREDICTABLE BASIS THROUGH MISSION DESIGN

- SPACE STATION/PD COMPATIBILITY 


\section{LUNAR SHUTTLE MISSION OUTBOUND PAYLOAD \\ FROM 55 - DEGREE EARTH ORBIT}

In addition to the 31.6 degree orbit exhibiting 54.6 day periodicity, a 55 degree, $270 \mathrm{n} \mathrm{mi} \mathrm{Earth}$ orbit also was investigated for comparison with previous (Phase II) results. The mission geometry cycle in this case is 82 days, corresponding to three lunar sidereal periods. As previously anticipated there are two favorable missions during each cycle, shown here. They fall at intervals of approximately 30 and 50 days, for the assumed reference node of 0 degrees, whereas the simplified analysis led to uniform 41 day spacing. 
LUNAR SHUTTLE MISSION

OUTBOUND PAYLOAD FROM 55-DEG EARTH ORBIT

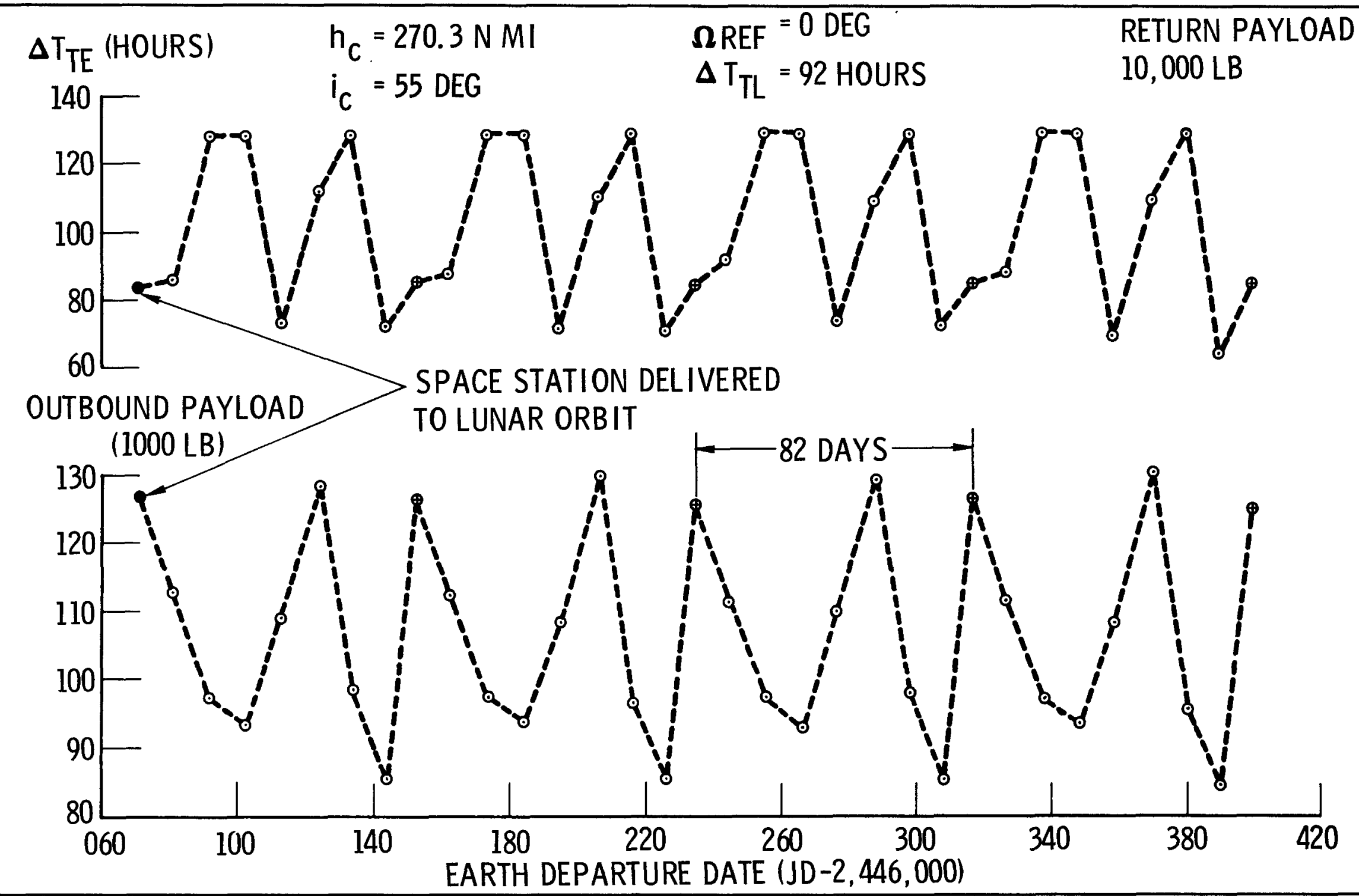




\section{NERVA CHARACTERISTICS FOR RNS}

\section{PERFORMANCE CALCULATIONS}

The NERVA full flow engine characteristics have been examined for impact on mission performance. In establishing average $I_{s p}$ as a function of main propellant flow, a steady stage $I_{s p}$ of 825 seconds was assumed in accordance with NASA study guidelines, while the ANSC values were used for other engine run phases. The most significant changes from previous engine data are an improvement in average $I_{s p}$ during the start-up and pump tail-off phases and a large increase (factor of three) in cooldown time. The latter effect will degrade the use of cooldown impulse for energy gain on escape trajectories such as TLI and TEI.

This figure summarizes the data to be used in RNS performance calculations. The solid curves reflect ANSC data where specific impulse, flow rate, and thrust are averaged over the engine operating phases of startup, steady state, and shutdown. The dashed curves are analytic best fits and extrapolations made to facilitate computer coding and to bridge the region between full power and available data on part power operation. For impulse propellant of less than 1,000 pounds, part power operation is assumed at a specific impulse of 500 seconds and a thrust of 1,000 pounds. Note that for LOI or TEI plane changes the effective $I_{s p}$ will be generally between 500 and 750 seconds. 
NERVA CHARACTERISTICS FOR RNS PERFORMANCE CALCULATIONS

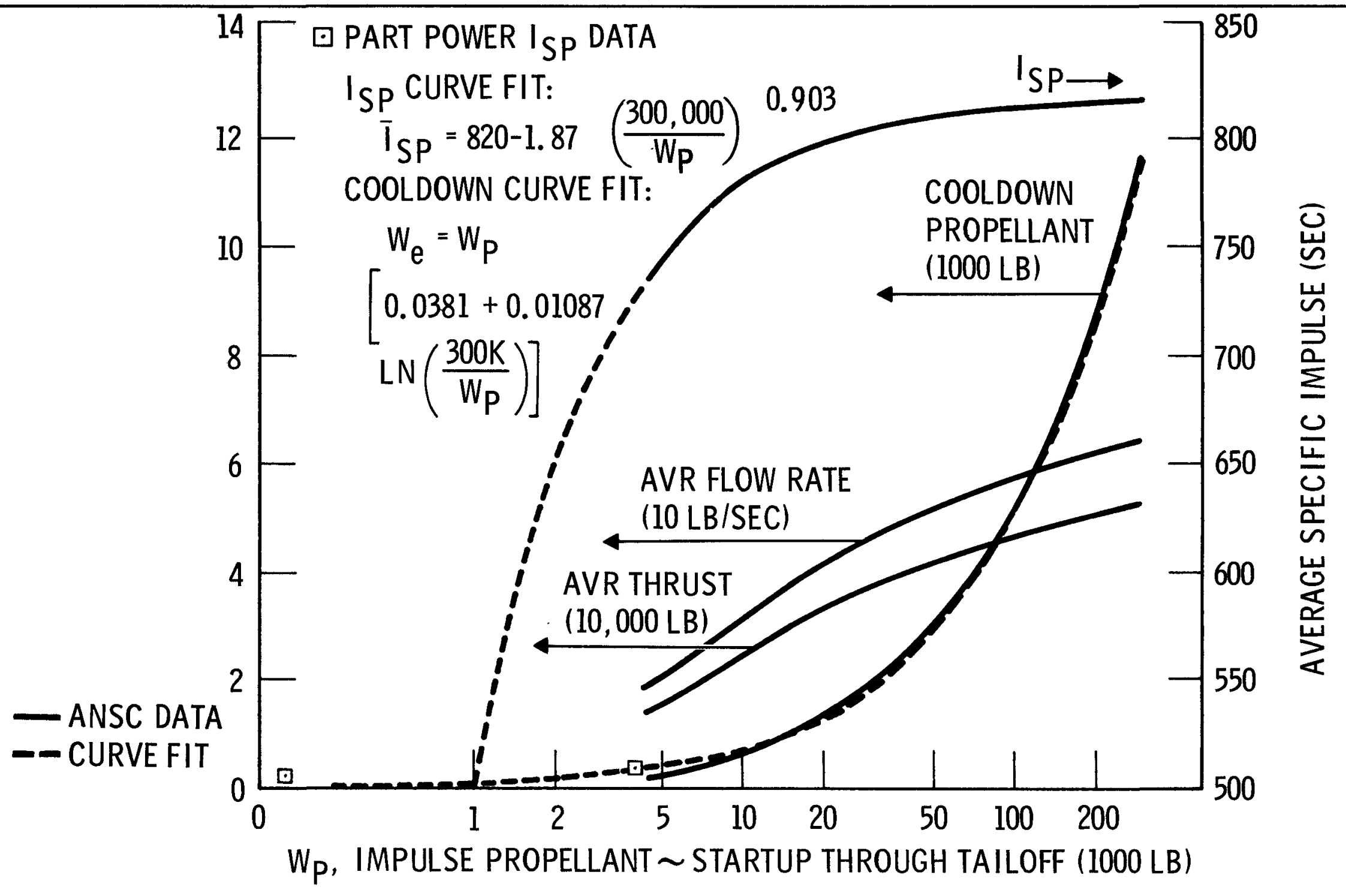




\section{COMPARISON OF ONE AND THREE BURN \\ LUNAR ORBIT MANEUVERS}

The diminishing NERVA specific impulse for small propellant consumptions suggested that an evaluation of multiburn maneuvers was needed before a lunar mission maneuver profile could be recommended. In the case of lunar orbit arrival or departure (LOI and TEI) where sizable plane changes are required, a three burn profile offers a large saving in delta $-\mathrm{V}$ compared to a single burn, but the three small delta-V's must be performed at a lower average specific impulse and will demand proportionately larger cooldown flows. The tradeoff of these factors is shown here for typical lunar shuttle weights. The angle $\delta$ denotes the angle between an arrival (or departure) V $\infty$ asymptote and the desired lunar orbit plane while the transit times indicate determine V $\propto$ magnitude. The propellant requirements compared include impulse propellant and cooldown but no energy gain is credited to the cooldown impulse. Evidently the three burn profile always pays off for out-of-plane angles greater than about five degrees, and even for zero plane change the arbitrary splitting of total delta-V into three parts increases total propellant requirements by only 800 pounds at LOI and 500 pounds at TEI. 


\section{COMPARISON OF ONE AND THREE BURN LUNAR ORBIT MANEUVERS}

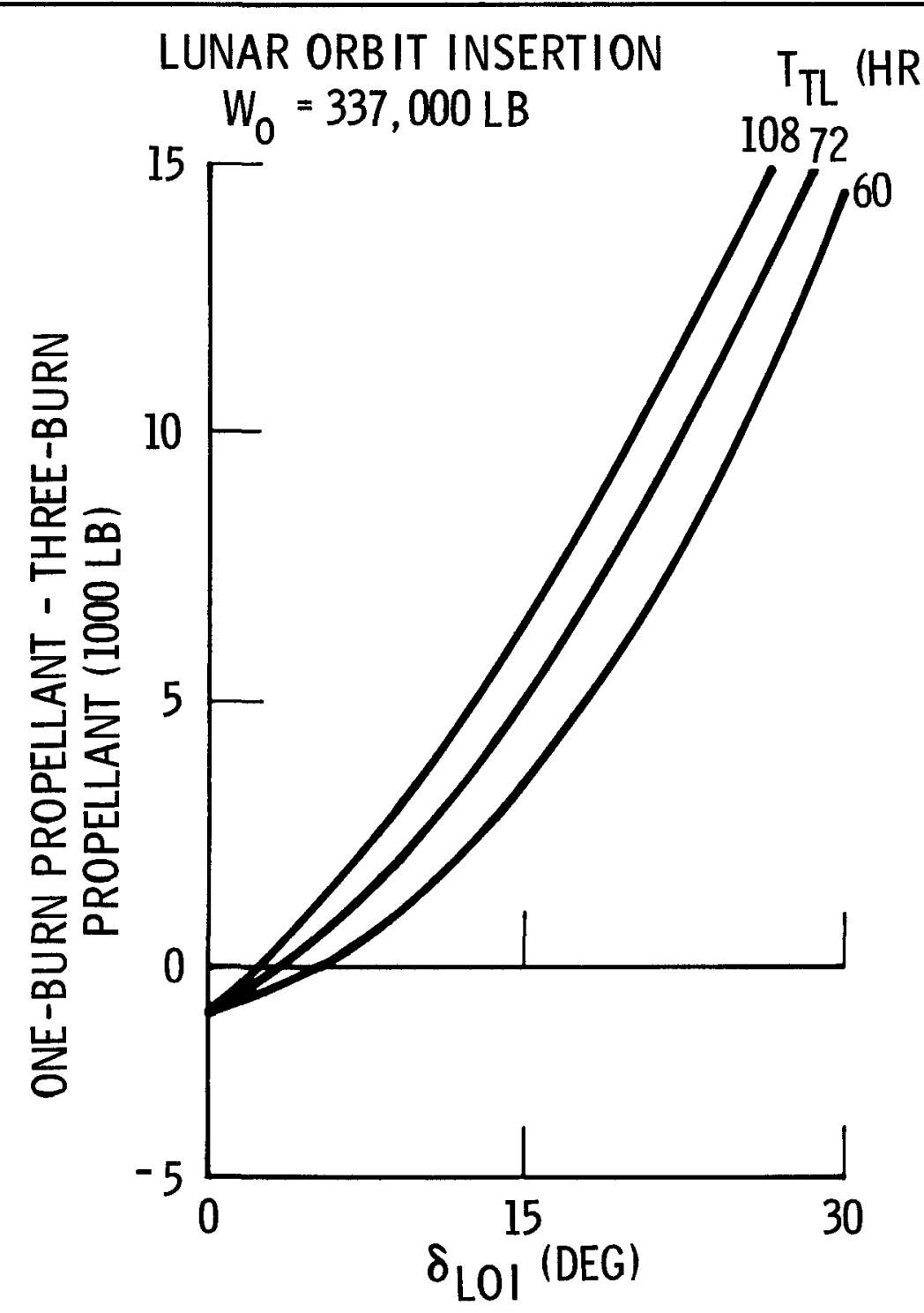

TRANSEARTH INJECTION

$W_{0}=196,000 \mathrm{LB}$

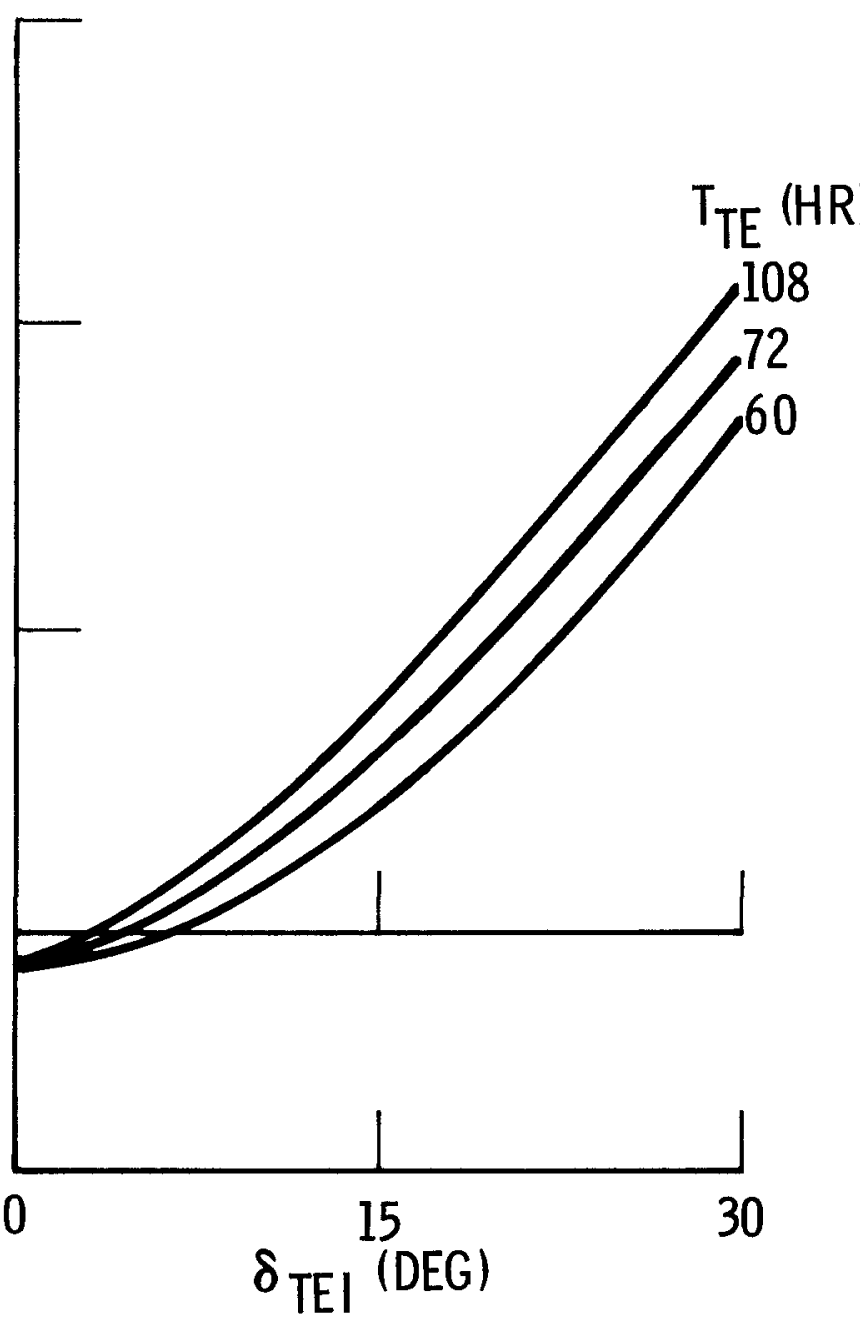


Multiburn departure from Earth orbit has been considered for the RNS as a means to reduce the large velocity loss which attends a single burn. As with the lunar orbit maneuvers, the reduction in required characteristic velocity is to be traded against the lower NERVA specific impulse and large cooldown flows. The curves on the left in this figure show the change in characteristic velocity obtained from propellant consumptions of $50 \mathrm{~K}, 100 \mathrm{~K}$, and $200 \mathrm{~K}$ pounds as number of burns is increased. The total propellant must accommodate cooldown (no energy gain assumed) as well as impulse propellant; hence as number of burns increases, more propellant must be allocated to cooldown and the remainder acts at a lower average specific impulse, resulting in decreased characteristic velocity as noted.

In spite of these effects, splitting a TLI burn (approximately 170,000 pounds propellant) into two or three parts pays well in reduced TLI propellant requirements, due to the lower velocity loss. The further reduction in velocity loss in going to four burns does not compensate for the lower NERVA performance. Based on this result, a two burn TLI is recommended as a desirable flight mode for the RNS. 


\section{EVALUATION OF MULTI-BURNS FOR EARTH ORBIT DEPARTURE}

NERVA PERFORMANCE PENALTY WITH SPLIT BURNS

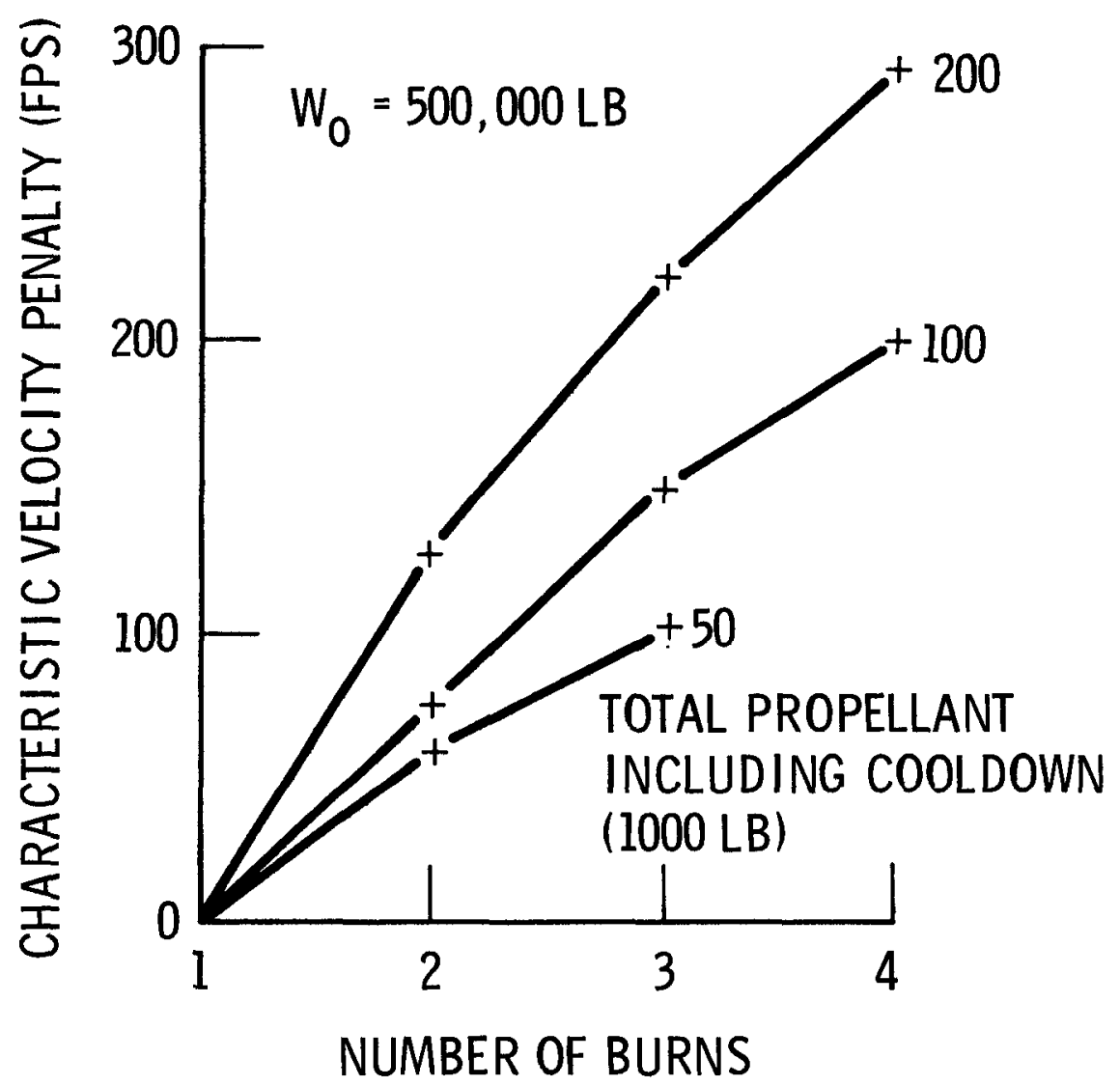

PROPELLANT SAVED ON TYPICAL TRANSLUNAR INJECTION

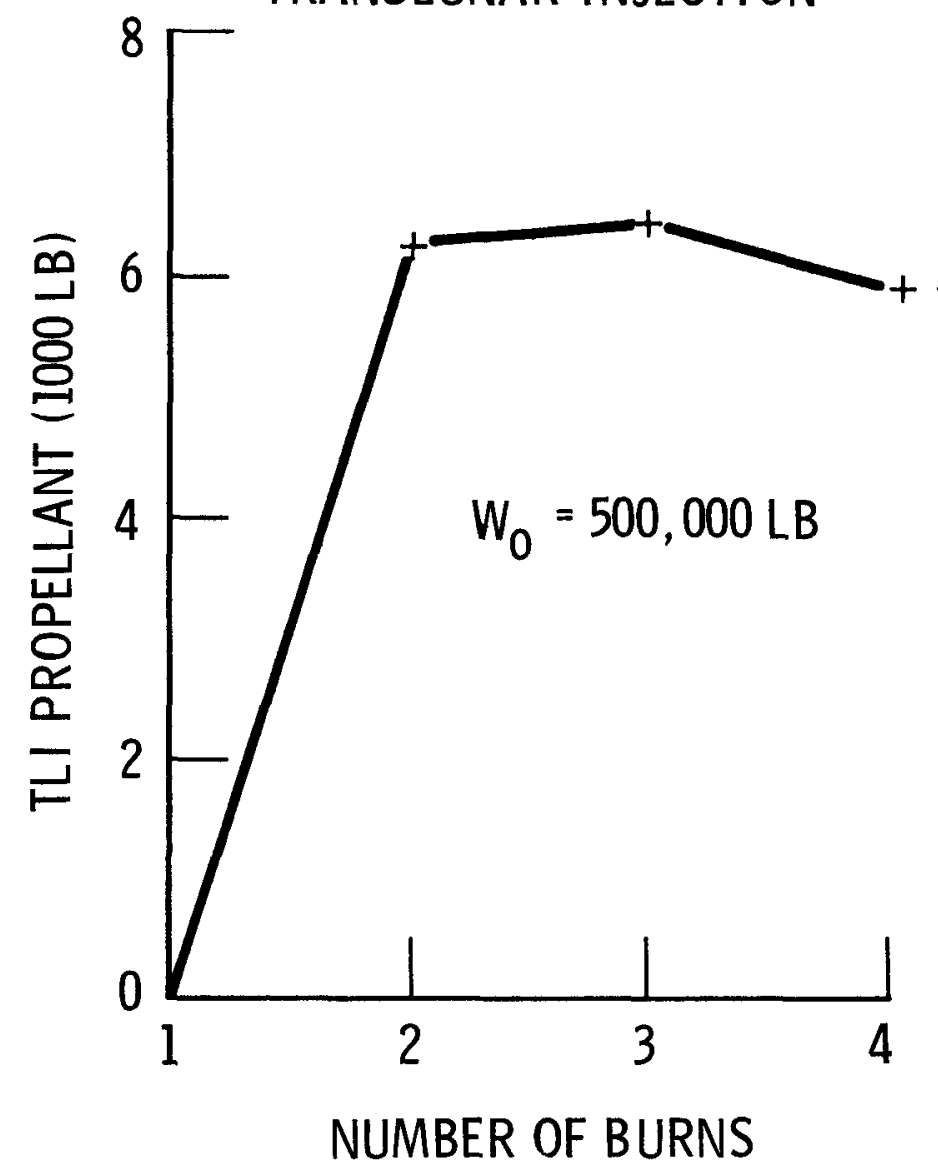


Current data for RNS performance calculations are summarized here. Stage weights are those of the early integral tankage dual cell elliptical configuration. Since fuel cell reactants and RCS propellant are separately accounted for they do not appear in "effective stage weight. " Usable propellant is based on $300 \mathrm{~K}$ total capacity.

In regard to NERVA cooldown it is assumed that propellant for $100 \%$ cooldown will be deducted after each engine run. The extent of inclusion of cooldown-created impulse in the performance calculation, however, will be a subject for study. 


\section{RNS PERFORMANCE MODEL}

NERVA CHARACTERISTICS

- SPECIFIC IMPULSE AVERAGED OVER STARTUP THROUGH SHUTDOWN

- PART POWER THRUST = $1000 \mathrm{LB} / \mathrm{ISP}=500 \mathrm{SEC}$

- $100 \%$ COOLDOWN PROPELLANT DEDUCTED AFTER EACH BURN

STAGE DATA (300 K STAGE)

- EMPTY WEIGHT (LB)

86,415

- RESIDUALS

5,850

- LESS FUEL CELL REACTANTS

$-1,200$

EFFECTIVE STAGE WEIGHT

USABLE PROPELLANT

91,065

294,150

- SCALING LAW 0. 14 LB STAGE WEIGHT PER LB USABLE PROPELLANT

- EXPENDABLES (LB/HR)

BOILOFF

4.4

FUEL CELL

2.0

RCS ATTITUDE \& BOILOFF

3.0

- TRANSLATIONAL RCS THRUST $=2000 \mathrm{LB} / \mathrm{ISP}=425 \mathrm{SEC}$

- 3/4\% FPR ADDED TO EACH NERVA $\triangle \mathrm{V}$ 


\section{LUNAR MISSION MODELS}

For performance reporting and tradeoffs, two missions have been considered: the NASA guideline mission per current study ground rules and an "NR nominal" mission patterned from the results of the lunar shuttle mission analysis. Delta-V's are given here for both one and two impulse TLI's, and for the NR missions, the coplanar LOI is indicated as a single burn. Velocity losses for the single burn TLI are computed as a function of $\mathrm{T} / \mathrm{W}$ and delta-V; other losses (constant) are $75 \mathrm{fps}$ at $\mathrm{TLI}_{1}, 110 \mathrm{fps}$ at $\mathrm{TLI}_{2}$, and $100 \mathrm{fps}$ at EOI. In addition to the major maneuvers, RCS translational maneuvers associated with orbital operations are included in the calculation of payload and total RCS propellant requirements. 


\section{LUNAR MISSION MODELS}

TRANSLUNAR TIME (HR) TRANSEARTH TIME (HR) LOI PLANE CHANGE (DEG) TEI PLANE CHANGE (DEG) LUNAR ORBIT STAY (DAYS)

DELTA-V'S (FPS)

TLI

LOI

TEI

EOI

\begin{tabular}{c|c} 
NASA GUIDELINE & NR NOMINAL \\
\hline 108 & 92 \\
72 & 83 \\
30 & 0 \\
30 & 22 \\
- & 17.5 \\
& \\
10030 & 10040 \\
$5000 / 5030$ & $5000 / 5040$ \\
$940 / 450 / 1850$ & $2730 / 0 / 0$ \\
$1850 / 450 / 1170$ & $1850 / 330 / 1010$ \\
10100 & 10050 \\
&
\end{tabular}

$\begin{array}{ll}\text { EARTH ORBIT } & 260 \mathrm{~N} \mathrm{MI} / 31.5 \mathrm{DEG} \\ \text { LUNAR ORBIT } & 60 \mathrm{~N} \mathrm{MI} / 90 \mathrm{DEG} \\ \text { TL \& TE MCC } & 50 \mathrm{FPS}\end{array}$




\section{RNS LUNAR MISSION CAPABILITY}

Outbound/return payload curves are shown here for both mission models under the assumption of maximum cooldown utilization and a two burn translunar injection. Primarily because of lower plane change requirements the NR mission allows 23,000 pounds more outbound payload for the same return. For comparison with earlier performance calculations the dashed curves indicate the effect of assuming a constant 825 seconds $I_{s p}$ for the NERVA runs (exclusive of cooldown). The NR mission with average $I_{s p}$ represents our current "most realistic" estimate of the $300 \mathrm{~K}$ stage capability. Payload combinations $(1,000$ pounds) are 147 outbound/0 return, 53/53 and 0/84. 


\section{RNS LUNAR MISSION CAPABILITY}

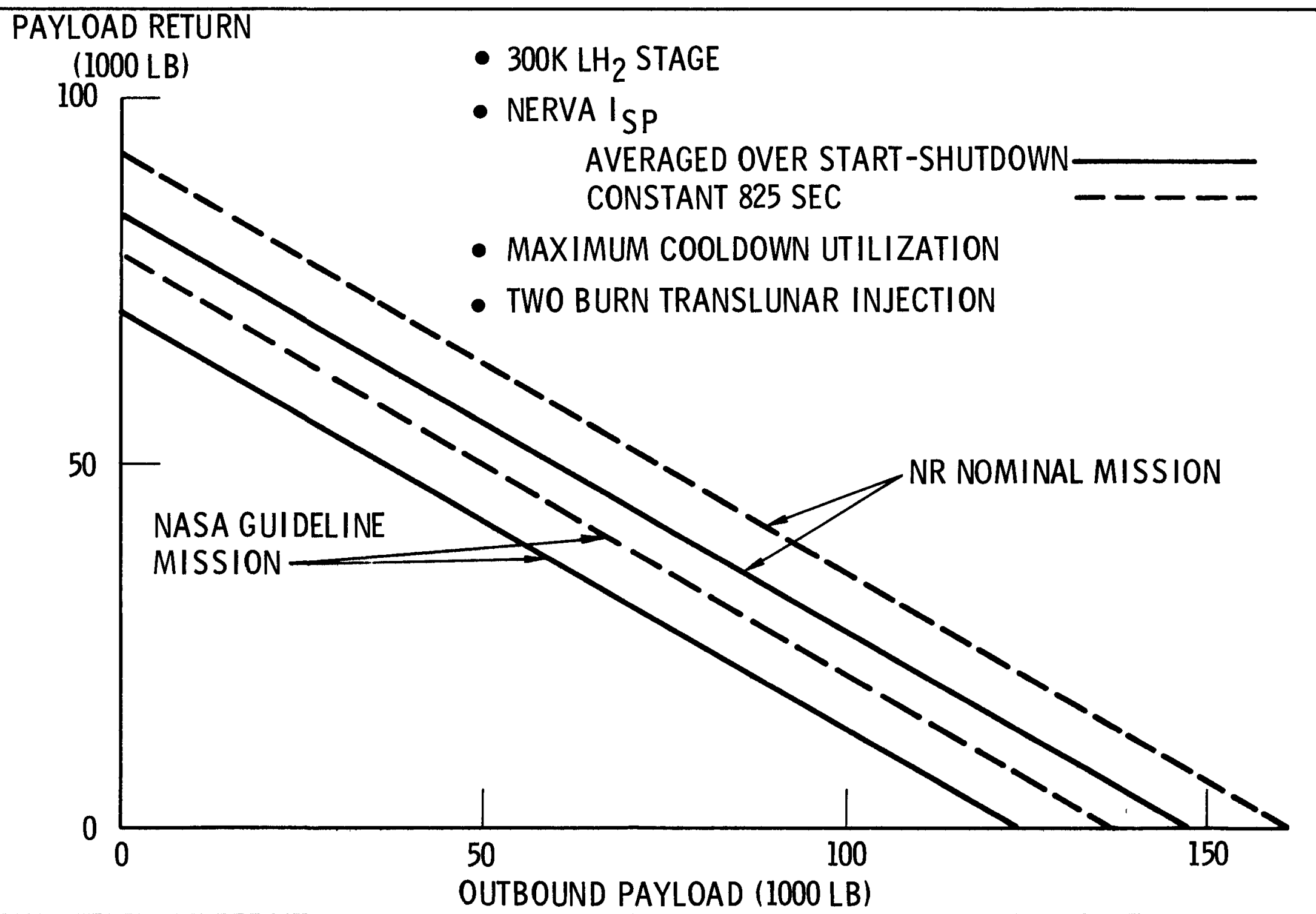




\section{MISSION AND PERFORMANCE TRADEOFFS}

In addition to the NERVA $I_{s p}$ and the mission models, other alternatives have been studied for their effects on lunar mission performance. For midcourse corrections it was found that there is little to choose between use of NERVA at 500 seconds or RCS at 425 seconds specific impulse. Use of cooldown impulse to contribute part of the required delta-V's raises outbound payload by 7,000 pounds. This result assumes delta-V contributions of $80 \mathrm{fps}$ for a single TLI burn, $30 \mathrm{fps}$ after TLI in the two burn case, $50 \mathrm{fps}$ after a single LOI burn, $35 \mathrm{fps}$ after $\mathrm{LOI}_{3}, 25 \mathrm{fps}$ after $\mathrm{TEI}_{3}, 200 \mathrm{fps}$ after EOI, and nothing after the other burns. These values are based upon work performed in Phase II, adjusted for the current cooldown profiles. Next to the mission model, the use of a two burn TLI has the largest effect on payload. The recommended alternatives are noted. 


\section{MISSION \& PERFORMANCE TRADEOFFS}

\begin{tabular}{|c|c|c|}
\hline VARIABLE & ALTERNATIVES & $\begin{array}{c}\text { CHANGE IN MAX } \\
\text { OUTBOUND PAYLOAD (LB) }\end{array}$ \\
\hline NERVA ISP & AVERAGED* VS CONSTANT 825 SEC & $-13,000$ \\
\hline $\begin{array}{l}\text { MIDCOURSE } \\
\text { CORRECTION } \\
\text { SYSTEM }\end{array}$ & $\begin{array}{l}\text { RCS ( } 425 \text { SEC) VS NERVA } \\
\text { PART POWER ( } 500 \text { SEC)** }\end{array}$ & NOT SIGNIFICANT \\
\hline $\begin{array}{l}\text { COOLDOWN } \\
\text { UTILIZATION }\end{array}$ & MAXIMUM* VS ZERO & $+7,000$ \\
\hline TLI PROFILE & TWO BURNS * VS ONE BURN & $+16,000$ \\
\hline MISSION MODEL & NR* VS NASA GUIDELINE & $+23,000$ \\
\hline
\end{tabular}


Using the NR mission model, payload growth for larger RNS propellant capacity has been investigated because of the high payload requirements stipulated in other space program areas. Stage scaling assumes 0.14 pounds effective stage weight per pound of additional tank capacity. The use of a tug crew module on the RNS is represented by the $15 \mathrm{~K}$ return payload line. As a round trip payload element, the crew module weight must be subtracted twice from the indicated outbound plus return value to get net outbound payload. Requirements identified in the LOSS study call for an RNS capacity of $330 \mathrm{~K}$ to $345 \mathrm{~K}$. 


\section{RNS SIZING FOR LUNAR MISSION PAYLOADS}

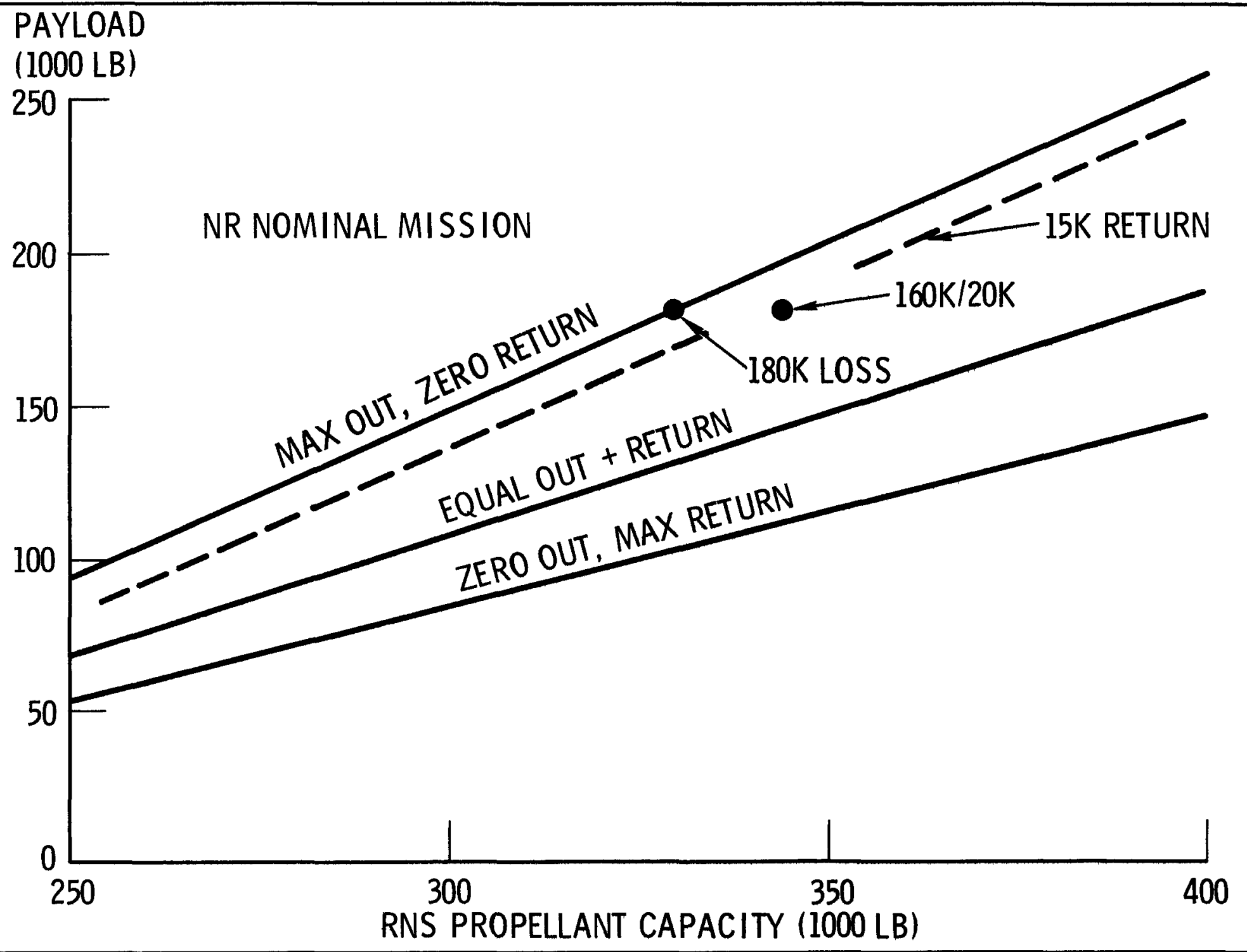




\section{COMPARISON OF RNS INJECTION MISSION MODES}

Expending the RNS, with a full tank of propellant, on an injection mission results in large payload weights for low to medium energy missions and substantial weights for the higher energy outer planet and comet missions. Application of multiorbit injection to further enhance payload for high-energy missions showed little effect in this case because of the unavoidable large velocity loss occurring above parabolic energy.

Assumptions for all the injection mission calculations included an effective stage weight of 94,000 pounds (representing partial load of RCS propellant and fuel cell reactants), usable propellant of

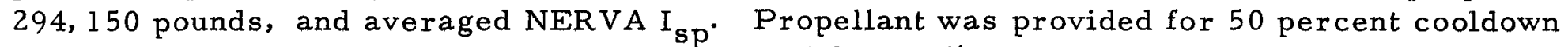
following the last expendable injection burn, and for $100 \%$ cooldown in other cases. Cooldown impulse contributed to mission energy requirements only in the expendable injection case. All maneuvers were coplanar.

Retrieval to a $260 \mathrm{n} \mathrm{mi} \mathrm{circular} \mathrm{orbit} \mathrm{following} \mathrm{payload} \mathrm{injection} \mathrm{seriously} \mathrm{reduces} \mathrm{the} \mathrm{mission}$ velocity level which the RNS can reach. The curve shown assumes a three burn injection profile, retro immediately after payload separation, five day return time, and no return plane change. It was previously shown that the addition of a chemical (expendable) upper stage can push the reusable mode payloads up to the level of the expendable curve. As an alternative means of obtaining higher velocity, use of an additional $300 \mathrm{~K}$ tank was investigated. The $300 \mathrm{~K}$ capacity may be provided by one or multiple tanks which are jettisoned between injection burns. Results for this case indicate an increase of $5,000 \mathrm{fps}$ in mission delta- $\mathrm{V}$ at the high velocity end, but this is still not sufficient for contemplated outer planet missions. 


\section{COMPARISON OF RNS INJECTION MISSION MODES}

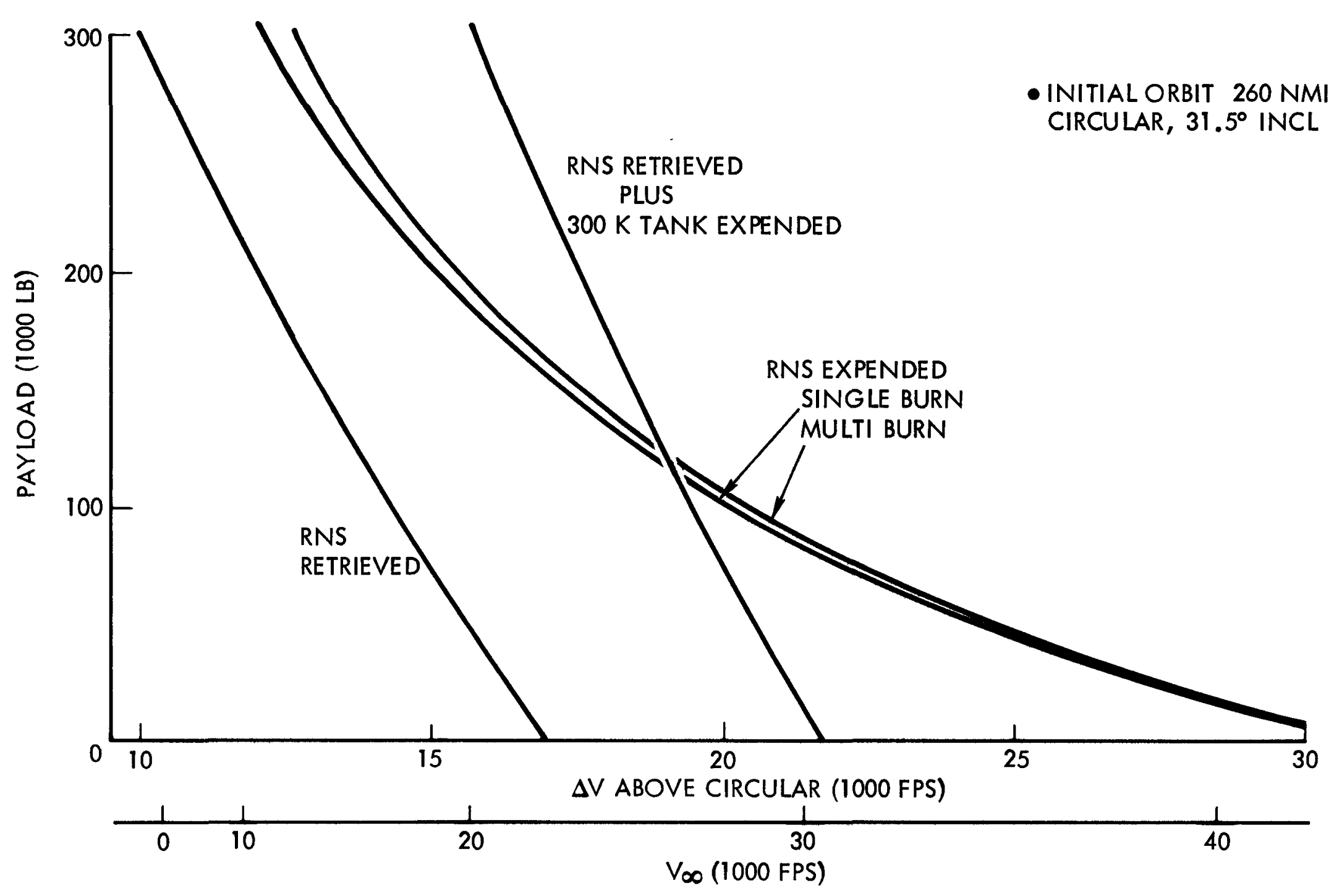


The orbital operations analysis activities covered the topics of rendezvous and docking, maintenance, on-board checkout, propellant transfer, cooldown propellant location and payload handling. Due to study schedule timing factors, the payload handling operations are not included in the briefing. Launch operations and candidate launch vehicle candidates were taken into consideration since they have a marked influence on vertually all orbital operations.

Requirements were established for the rendezvous and docking operations identifying approach patterns, detection ranges, closing rates, and stage orientation.

Maintenance analysis took into consideration the total mission operations and radiation environment which influenced maintenance philosophy, turnaround time, and subsystem operating time.

A concept was postulated and preliminary requirements identified for the on-board checkout to support orbital maintenance and mission flight operations.

Various propellant transfer schemes were evaluated and preferred propellant transfer mode identified.

Requirements for propellant location or settling during NERVA engine cooldown are identified. Pressure decay and its implications to the cooldown function is covered.

Each of the aforementioned subjects will be treated independently in the following discussion. 


\section{ORBITAL OPERATIONS}

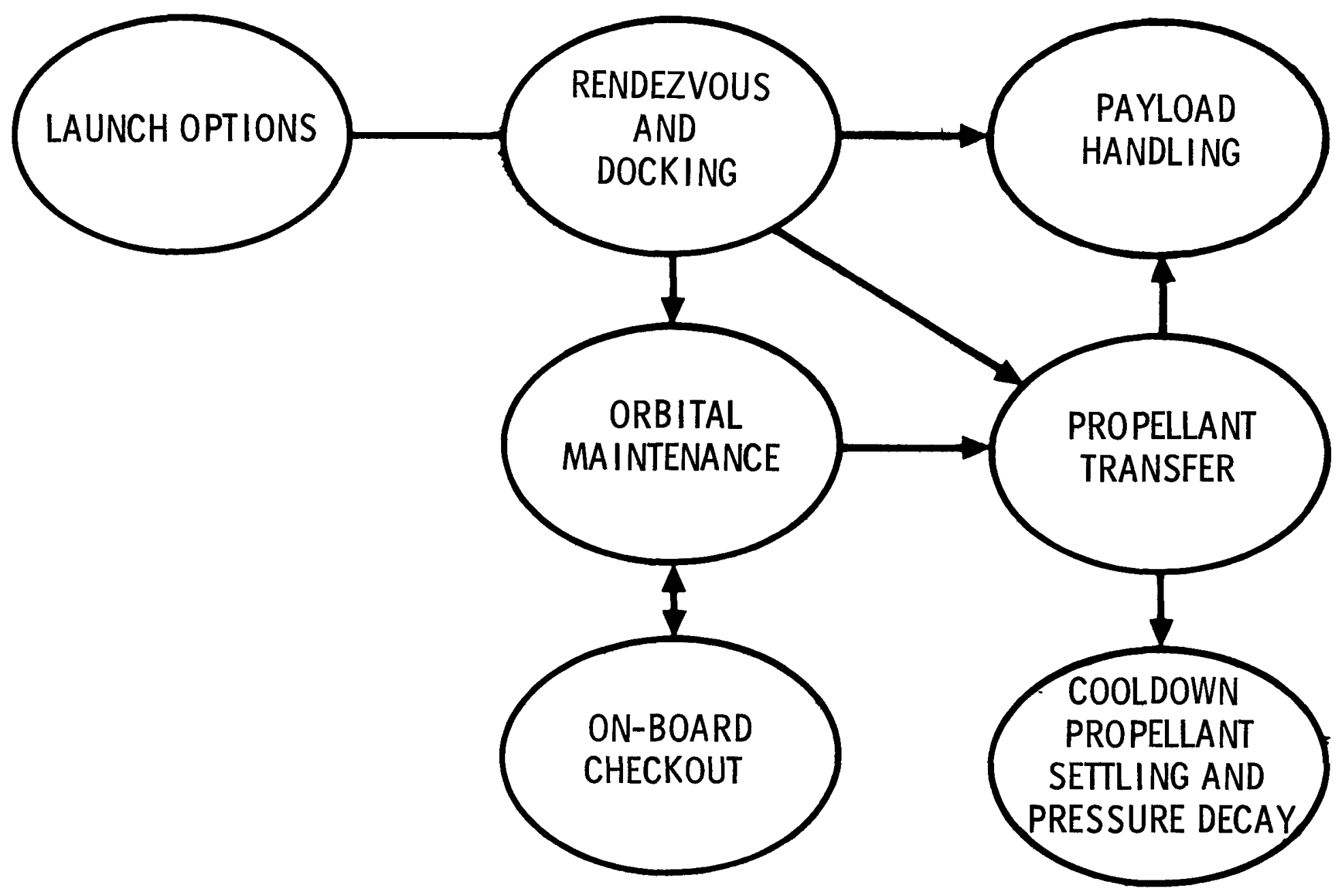




\section{ORBITAL ASSEMBLY AND LOGISTICS OPTIONS}

Three basic launch vehicles are identified which could support the launch of the RNS and other space program elements to the RNS operations orbit. Final selection of the RNS configuration will help establish the best launch vehicle combinations to be used for the orbital assembly and support operations.

The stage launched integrally with the NERVA engine could be accomplished by the Saturn V INT-21 vehicle or S-IIB and modified space shuttle booster. The stage would be boosted to the RNS operations orbit where post boost operations such as poison wire removal or anticriticality devices removal, post boost RNS stage checkout, propellant loading, and payload mating would take place.

Should the engine and stage be launched separately, the Saturn V INT-21 would launch the RNS stage tank and the space shuttle comprised of the orbiter and booster would launch the NERVA engine and/or propulsion module comprised of NERVA engine/auxiliary tank. The weight of the NERVA engine/fueled auxiliary tank may limit delivery to a $100 \mathrm{n} \mathrm{mi}$ orbit where a tug could perform the transfer from the $100 \mathrm{n} \mathrm{mi}$ orbit to the RNS operations orbit. During the stage engine assembly operations the RNS must provide an attitude orientation and hold function so that the engine can be assembled to it. A check of the engine stage interface functions will be made following the assembly to verify the assembly operation has been successfully completed and stage is now in an operational configuration for propellant trarsfer and payload mating.

Subsequent logistic support for resupply would be provided by the space shuttle either directly or through a propellant and/or maintenance element. 


\section{ORBITAL ASSEMBLY AND LOGISTICS OPERATIONS OPTIONS}

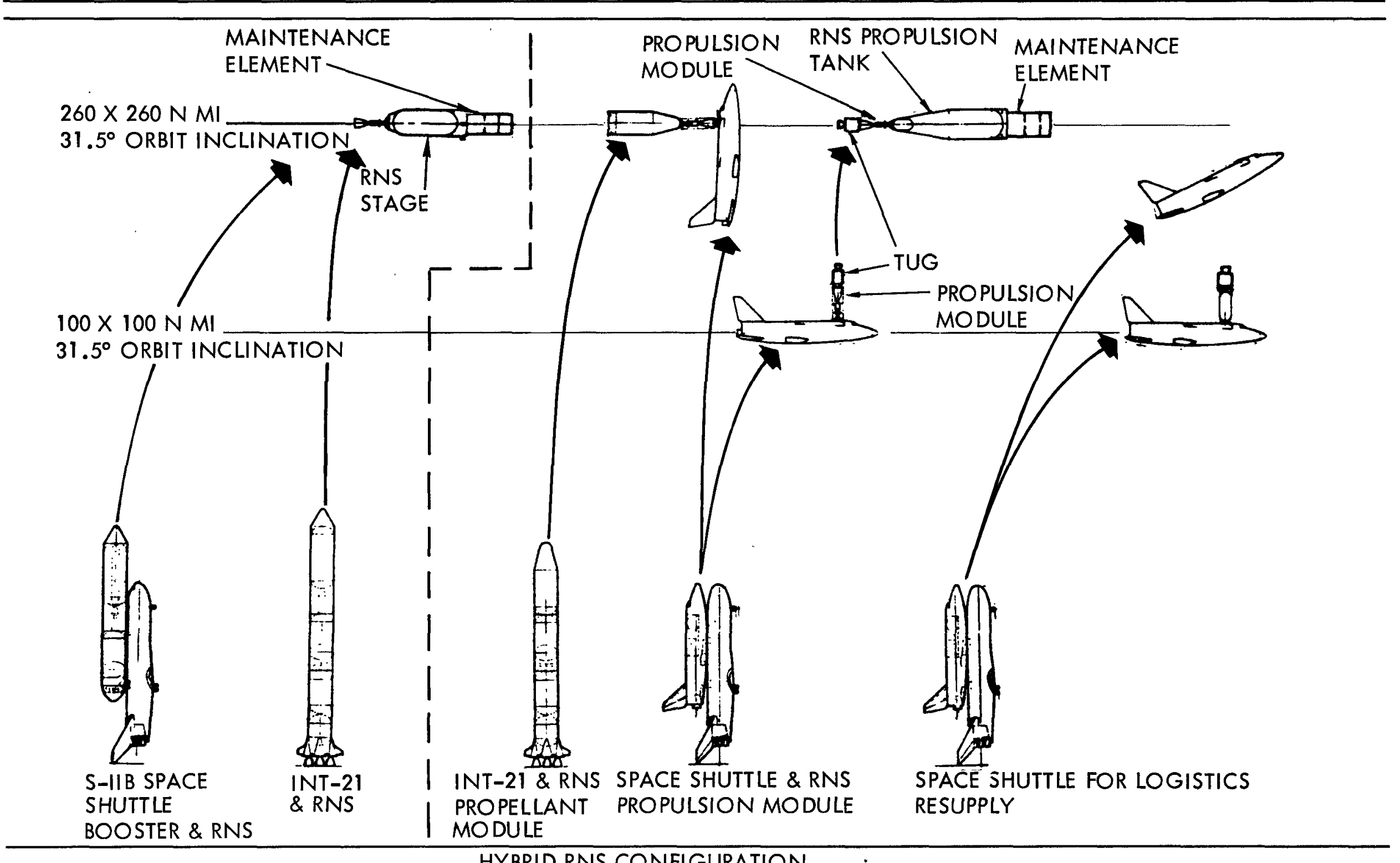

HYBRID RNS CONFIGURATION 
As shown on the opposite page, RNS rendezvous and docking can be autonomous and automatic. There are some obvious advantages to providing the RNS with a completely autonomous automatic capability. Redundant tracking equipment is provided for back-up if the other vehicle has equipment failure. The RNS can dock with a disabled vehicle with its scanning laser radar (SLR) operative. If the other vehicle is completely inoperative visual cues could still be used for docking with a man in the loop.

Alternatively, it can use a man in the loop to accomplish docking. Furthermore, vector range rate could be provided by the other vehicle obviating the requirement for tracking equipment onboard the RNS, other than a SLR receiver.

There are some obvious disadvantages to requiring a man in the loop. Visual cues must be provided either by having a man onboard one of the vehicles or by having TV. If the man is on the Earth or EOSS, for example, time lags introduced by data relay satellite systems could present a problem. The 10 minutes or so in which two vehicles pass overhead in low Earth orbit should allow an operator on Earth to dock them, but this is a rather inflexible situation.

It is recommended that the RNS have an autonomous, automatic capability for rendezvous and docking. 


\section{ALTERNATIVES FOR RENDEZVOUS \& DOCKING}

\begin{tabular}{|c|c|c|}
\hline ALTERNATIVES & ADVANTAGES & DISADVANTAGES \\
\hline $\begin{array}{l}\text { AUTOMATIC RENDEZVOUS AND } \\
\text { DOCK WITH MANUAL OVERRIDE } \\
\text { (RADAR AND SCANNING LASER } \\
\text { RADAR) }\end{array}$ & $\begin{array}{l}\text { - PROVIDES RNS WITH AUTOMATIC } \\
\text { AUTONOMOUS RENDEZVOUS AND } \\
\text { DOCKING CAPABILITY } \\
\text { - PROVIDES BACKUP VECTOR, } \\
\text { RANGE, AND RANGE RATE FOR TUG, } \\
\text { SHUTTLE, ETC. } \\
\text { - PROVIDES EMERGENCY CAPABILITY } \\
\text { FOR RNS TO DOCK WITH DISABLED } \\
\text { VEHICLE }\end{array}$ & $\begin{array}{l}\text { - POWER, WEIGHT, AND VOLUME } \\
\text { PENALTY IF PD, SHUTTLE, TUG, } \\
\text { ETC. COULD PROVIDE RENDEZ- } \\
\text { AND DOCKING DATA } \\
\text { - SCANNING LASER RADAR } \\
\text { REQUIRES COOPERATIVE } \\
\text { TARGET } \\
\end{array}$ \\
\hline $\begin{array}{l}\text { MAN-IN-THE-LOOP DOCKING } \\
\text { (USE RADAR/LASER DATA FROM } \\
\text { PD, SHUTTLE, TUG, ETC }\end{array}$ & $\begin{array}{l}\text { - POWER, WEIGHT, AND VOLUME } \\
\text { REQUIREMENTS FOR TRACKING } \\
\text { EQUIPMENT REDUCED }\end{array}$ & $\begin{array}{l}\text { - RNS NOT AUTONOMOUS } \\
\text { - NO BACKUP CAPABILITY }\end{array}$ \\
\hline
\end{tabular}

RECOMMENDATION: PROVIDE RNS WITH AUTONOMOUS CAPABILITY 


\section{COMPARISON OF ALTERNATE RENDEZVOUS PROFILES}

An RNS-active rendezvous at the end of a lunar shuttle mission uses RCS propellant which must be carried through the entire mission. (As an alternative, a tug could propel the RNS back to the PD.) Thus, the low delta-V associated with a Hohmann transfer is particularly attractive for this mission phase. The extensive analysis, simulation, and experience compiled with the Apollo-type rendezvous, however, suggested that it be examined as a possible basis for RNS rendezvous requirements. This table compares basic characteristics with a Hohmann transfer.

The essential features of the Apollo rendezvous profile are:

(1) Active vehicle and target in "coelliptic" orbits (that is, at a nearly constant $\Delta$ ) to compensate for any target orbit eccentricity

(2) $\triangle \mathrm{h}$ chosen large enough to mask altitude errors, but otherwise small to keep delta-V's low

(3) Terminal phase initiation (TPI) by means of a $\Delta V_{1}$ directed along the line-of-sight (LOS) to target

(4) Coast angle to nominal intercept chosen for low LOS direction change and low LOS angular rate during approach

These features aim to provide standardized rendezvous conditions and easy visual cues for pilot participation in the rendezvous procedures. Satisfactory values are $\Delta \mathrm{h} \approx 10 \mathrm{n}$ mi and transfer angle $\approx 130$ degrees, whether rendezvous is from below or above.

Estimated total $\Delta V$ in the table includes a factor of 2.5 applied to $\Delta V_{2}$ to account for actual RCS usage during the terminal phase, as predicted from simulations. On this basis the Apollo transfer requires 50 percent more delta-V. LOS direction does indeed remain more nearly constant during the Apollotype final approach but in regard to error sensitivity there is little difference.

Considering the desire for autonomous-automatic RNS operation, NR gives little weight to the pilotrelated rendezvous characteristics. For this reason and because of the low delta-V the Hohmann transfer rendezvous is recommended for the appropriate RNS mission phases. 


\section{COMPARISON OF ALTERNATE RENDEZVOUS PROFILES}

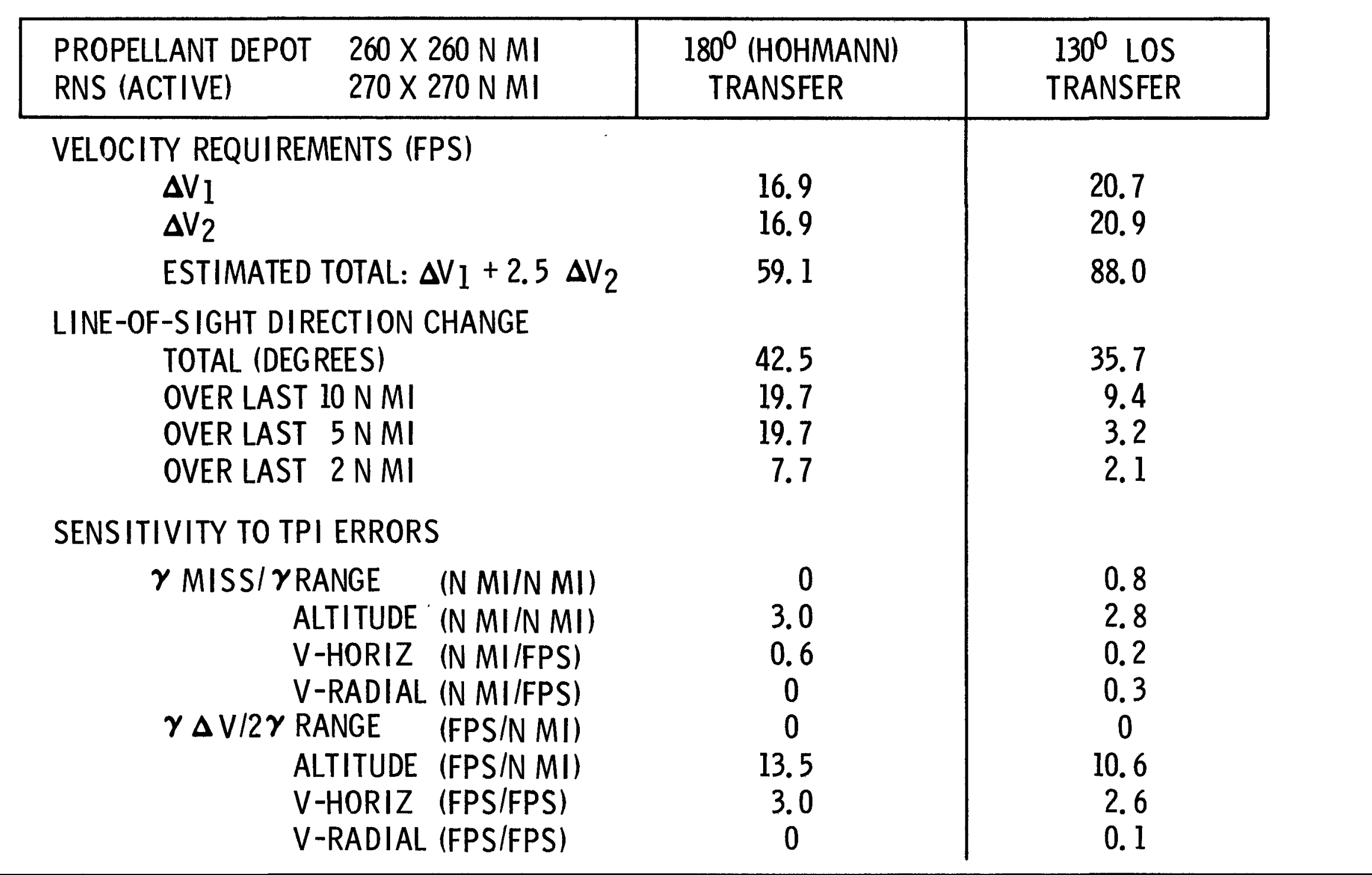




\section{MOTION OF RNS RELATIVE TO PD DURING TRANSFER}

A simplified rendezvous and docking example is illustrated for the recommended Hohmann transfer. Circular orbits of the propellant depot (PD) and RNS differ in altitude by $10 \mathrm{n} \mathrm{mi}$. At a range of 25.6 $\mathrm{n}$ mi a $17 \mathrm{fps}$ impulse opposite to the direction of orbital mition initiates the transfer. Another $17 \mathrm{fps}$ impulse, also opposite to the direction of orbital motion, completes the transfer. In the maneuver shown, the RNS is assumed to hold an inertially fixed attitude during coast, the apparent pitch motion being caused by the $180^{\circ}$ rotation of the coordinate system during the transfer. With use of $+X$ and $-X$ translations as shown, the nose of the RNS can point continuously in the general direction of the PD.

Trajectories determined by similar maneuvers, such as the 130 degree transfer with line-of-sight thrusting, give similar values for range at time oforbital transfer initiation. Therefore, variations of the Hohmann orbital transfer were used to determine parameter values such as detection range and transfer delta-V.

Angular closing rate in orbits near $260 \mathrm{n} \mathrm{mi} \mathrm{separated} \mathrm{in} \mathrm{altitude} \mathrm{by} 10 \mathrm{n} \mathrm{mi}$ is $0.91 \mathrm{deg} / \mathrm{hr}$, or approximately 60 knots. This velocity and the transfer range shown on the opposite page scale to within second order effects with altitude. For example, if the R.NS and PD orbital altitudes differ by $20 \mathrm{n} \mathrm{mi}$, the closing rate is approximately 120 knots and the Hohmann orbital transfer is initiated at $51.2 \mathrm{n} \mathrm{mi}$. 


\section{MOTION OF RNS RELATIVE TO PD DURING TRANSFER}

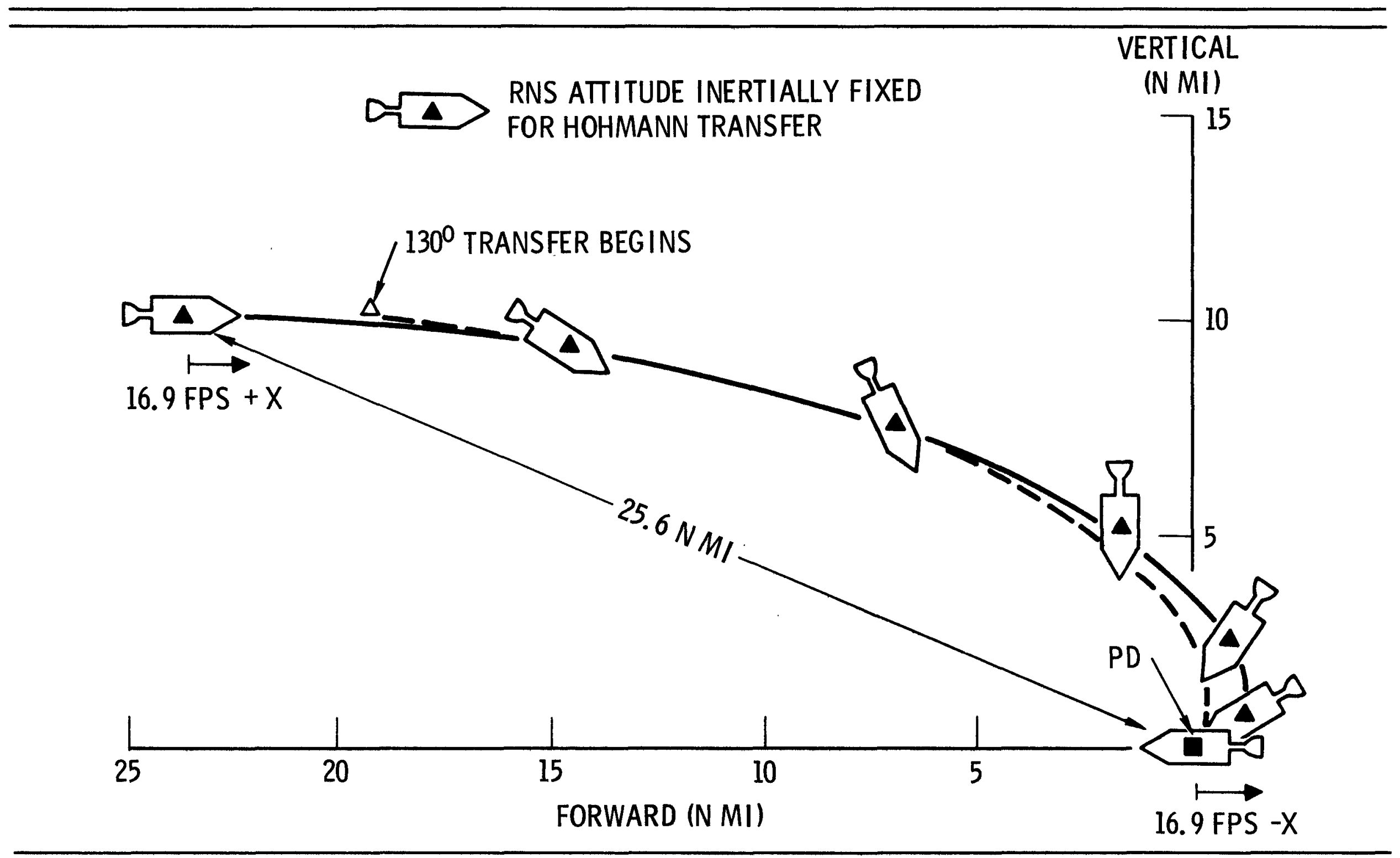




\section{RNS ACQUISITION AND TRACKING REQUIREMENTS}

The detection range requirement of $100 \mathrm{n} \mathrm{mi} \mathrm{results} \mathrm{from} \mathrm{the} \mathrm{assumption} \mathrm{that} \mathrm{the} \mathrm{RNS} \mathrm{went} \mathrm{into} \mathrm{a}$ circular orbit which differed in altitude by $20 \mathrm{n} \mathrm{mi}$ from the PD circular orbit due to a $10 \mathrm{n}$ mi insertion error. As indicated in the preceding text transfer between circular orbits differing in altitude by $20 \mathrm{n}$ mi begins at a range of $50 \mathrm{n} \mathrm{mi}$. Twenty minutes of tracking adds $40 \mathrm{n}$ mi and a $10 \mathrm{n} \mathrm{mi}$ bias was added to allow parking in the PD orbit at a distance of $10 \mathrm{nmi}$ from the PD.

A 30 foot position error at the end of the Hohmann transfer was reflected back to a range error at orbital transfer initiation ( $25 \mathrm{n} \mathrm{mi)}$ to give a $0.02 \%$ range accuracy requirement. The $3.94 \mathrm{inch}$ range accuracy requirement is to provide for docking and is the $3 \sigma$ value presently stated for the International Telephone and Telegraph (ITT) scanning laser radar (SLR). Radar range rate error of $6 \mathrm{fps}$ is equivalent to a $2 \mathrm{n} \mathrm{mi} \mathrm{error} \mathrm{in} \mathrm{altitude} \mathrm{in} \mathrm{a} 260 \mathrm{n} \mathrm{mi}$ orbit. During docking the SLR determines rate to $\pm 1 \%$ or $\pm 0.2 \mathrm{in} / \mathrm{sec}$, whichever is greater.

Radar angular accuracy was determined so that target vehicle position components of $1 \mathrm{n}$ mi out of the RNS orbit plane could be determined at $100 \mathrm{n} \mathrm{mi}$. During the 20 minutes of tracking the out of plane range component would change $1.0 \mathrm{n} \mathrm{mi} \mathrm{or} \mathrm{more} \mathrm{for} \mathrm{orbits} \mathrm{inclined} \mathrm{by} 1$ milliradian (mr) SLR angular accuracy provides for automatic docking.

The search volume requirement resulted from knowing RNS altitude to within $2 \mathrm{n}$ mi assuming $P D$ altitude was known to within $2 \mathrm{n} \mathrm{mi}$, and the orbit inclination was $1 \mathrm{mr}$ or less. The resulting maximum $4 \mathrm{n} \mathrm{mi} 4 \mathrm{n} \mathrm{mi}$ PD position uncertainty then encompasses a sector approximately $10^{\circ} \mathrm{x}$ $10^{\circ}$ at the RNS at a range of $50 \mathrm{n} \mathrm{mi}$. 


\section{RNS ACQUISITION \& TRACKING REQUIREMENTS}

FOR $\Delta H=20 \mathrm{~N}$ MI ACQUISITION RANGE INCLUDES: ORBITAL TRANSFER RANGE

$50 \mathrm{~N} \mathrm{MI}$

20 MIN TRACKING DATA =

AT 120 KNOTS

$10 \mathrm{~N}$ MI RANGE BIAS

DETECTION RANGE $(3 \boldsymbol{\sigma})$

RANGE ACCURACY $(3 \sigma)$

$40 \mathrm{~N} \mathrm{MI}$

$10 \mathrm{~N} \mathrm{MI}$

$100 \mathrm{~N} \mathrm{MI}$

$\pm 0.02 \%$ OR $\pm 3.94 \mathrm{IN}$.

(WHICHEVER IS GREATER)

RADAR RANGE RATE ACCURACY $(3 \boldsymbol{\sigma})$

\pm 6 FPS

SCANNING LASER RADAR (SLR)

RANGE RATE ACCURACY $(3 \sigma)$

$\pm 1 \%$ OR \pm 0.167 IN./SEC

(WHICHEVER IS GREATER)

RADAR ANGULAR ACCURACY

$0.6^{0}$

SLR ANGULAR ACCURACY

$\pm 0.02^{0}$

SEARCH VOLUME

$10^{0} \times 10^{0}$

TARGET VEHICLE ASSUMED COOPERATIVE 
The Maintenance/Refurbishment Checkout Cycle in the facing figure combines a logic-functional flow approach to present the RNS maintenance and repair (M\&R) and checkout philosophy. The intent of the chart is to display the "hands off" concept to be used during vehicle turnaround M\&R operations. The "hands off" concept is one which will entail the performance of corrective-type (unscheduled) $M \& R$ functions complemented with minimum preventative-type (scheduled) $M \& R$ activities. If all vehicle primary systems operated properly and no scheduled maintenance is required, then the $M \& R$ subsystem checkout cycle would only verify the secondary or back-up systems.

Vehicle status data, namely the onboard checkout (OBCO) system outputs (e.g., data printouts), visual inspection reports, and planned $M \& R$ requirements, are the basis for establishing system readiness. With the system deemed ready, scheduled maintenance, as required, is performed in place or by a spare replacement, with the necessary testing performed to ascertain system readiness. When the system is not functioning properly, unscheduled maintenance is enacted by fault detection/troubleshooting methods to determine the problem. As the problem is defined, the action cycle (same as with scheduled maintenance) is activated with the necessary testing performed to ensure system readiness.

RNS components and equipment, removed for reasons of malfunction, failure or time-replacement, will be placed in storage for future disposition. Those deemed reparable by the in-space M\&R elements will be housed at that element. Those that require reparable support or scrapped by Earth support facilities will be returned by an available space shuttle. The removed components and equipment that contain excessive radiation dosage will have to be maintained in a separate area/facility away from the $M \& R$ element. Three options may include:

(1) Storage in an available, empty S-II stage made ready for holding these items until a cooldown period elapses which allows the equipment to be repaired or dispositioned under safe operational conditions.

(2) Telescoping arm, extending from the $M \& R$ facility, allowing the equipment to cooldown for later dispositioning under a safe environment.

(3) Inoperative but radio active engines would require assistance of a tug for disposal to safe geocentric or heliocentric orbits. 


\section{MAINTENANCE/REFURBISHMENT/CHECKOUT CYCLE}

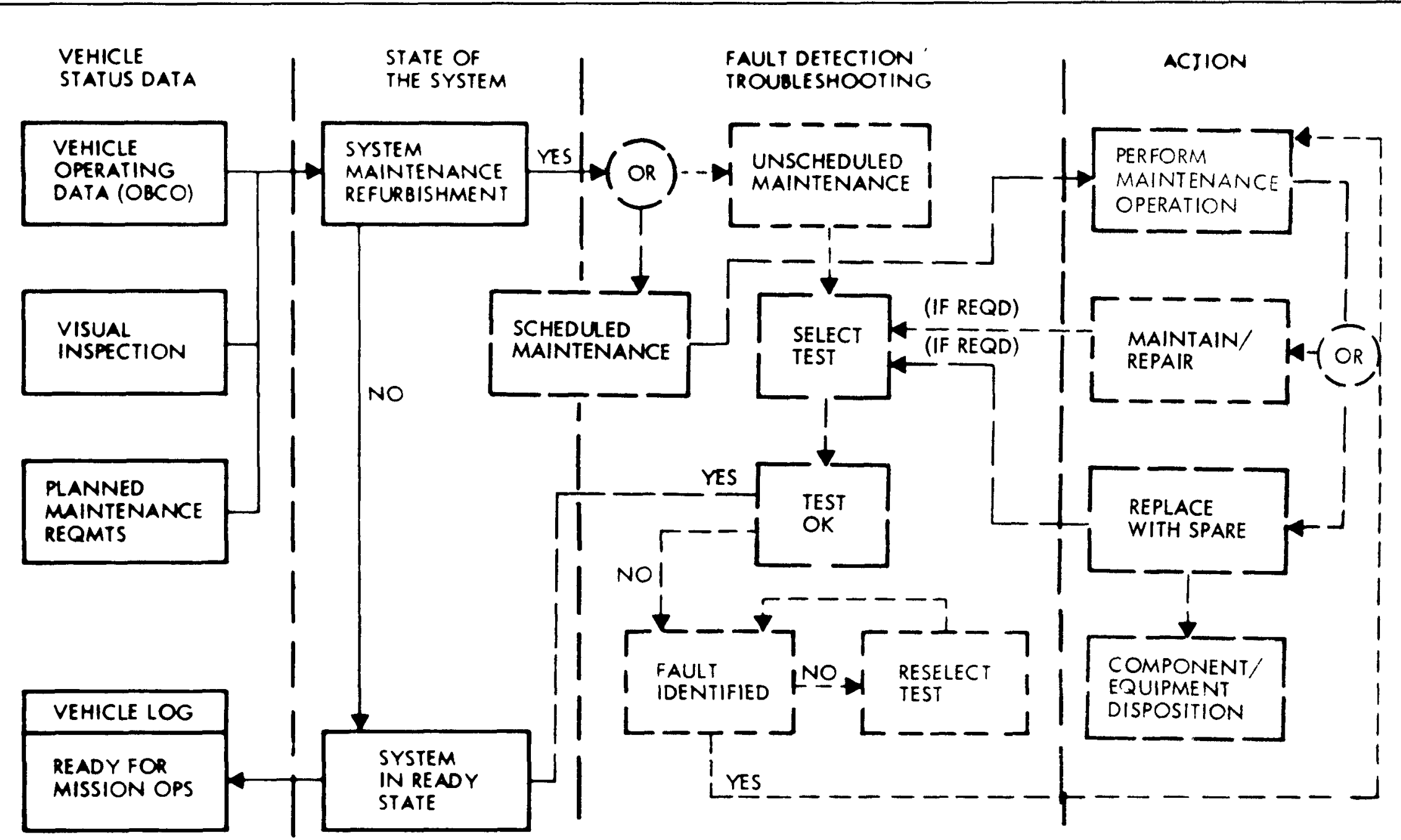




\section{RADIATION DECAY TIME TO $0.5 \mathrm{R} / \mathrm{HR}$ LEVEL FOR \\ DIRECT MAN-STAGE OPERATIONS}

Scheduled and unscheduled maintenance and repair (M\&R) support operation will be constrained by the radiation decay time to permit man-stage operations. Only minor stage maintenance operations limited to the 0-15 degree quadrant forward of the engine core midplane appear to be feasible without rather extensive additional shielding provisions up to 24 hours after the last engine shutdown cycle. This observation is predicated on the basic criterion of a $25 \mathrm{rem} / \mathrm{yr}$ allowable dose to maintenance personnel from the RNS.

Radiation levels of $25 \mathrm{rad} / \mathrm{hr}$ can be expected in the aft skirt area of the stage 24 hours after engine shutdown. A period of approximately 10 days would be required for the radiation level to drop to a point acceptable for direct access by maintenance personnel. In the engine area where radiation levels of 500 to $5,000 \mathrm{R} / \mathrm{hr}$ are expected 24 hours after shutdown, a waiting period in excess of a month would be required before maintenance personnel could approach subsystems in the vicinity of the engine.

Traffic models established for RNS operations may not permit the required waiting periods for radiation to decay to the level for direct access by man. In this event, it will be necessary to utilize remote manipulative devices or a space tug with manipulators to perform the $M \& R$ function. Any operations involving rendezvous maneuvers with a space tug for engine removal and/or maintenance will require additional shielding provisions for protection of the crew of the space tug, as well as remote handling equipment and manipulative devices. 


\section{RADIATION DECAY TIME TO 0.5 R/HR LEVEL FOR DIRECT MAN-STAGE OPERATIONS}

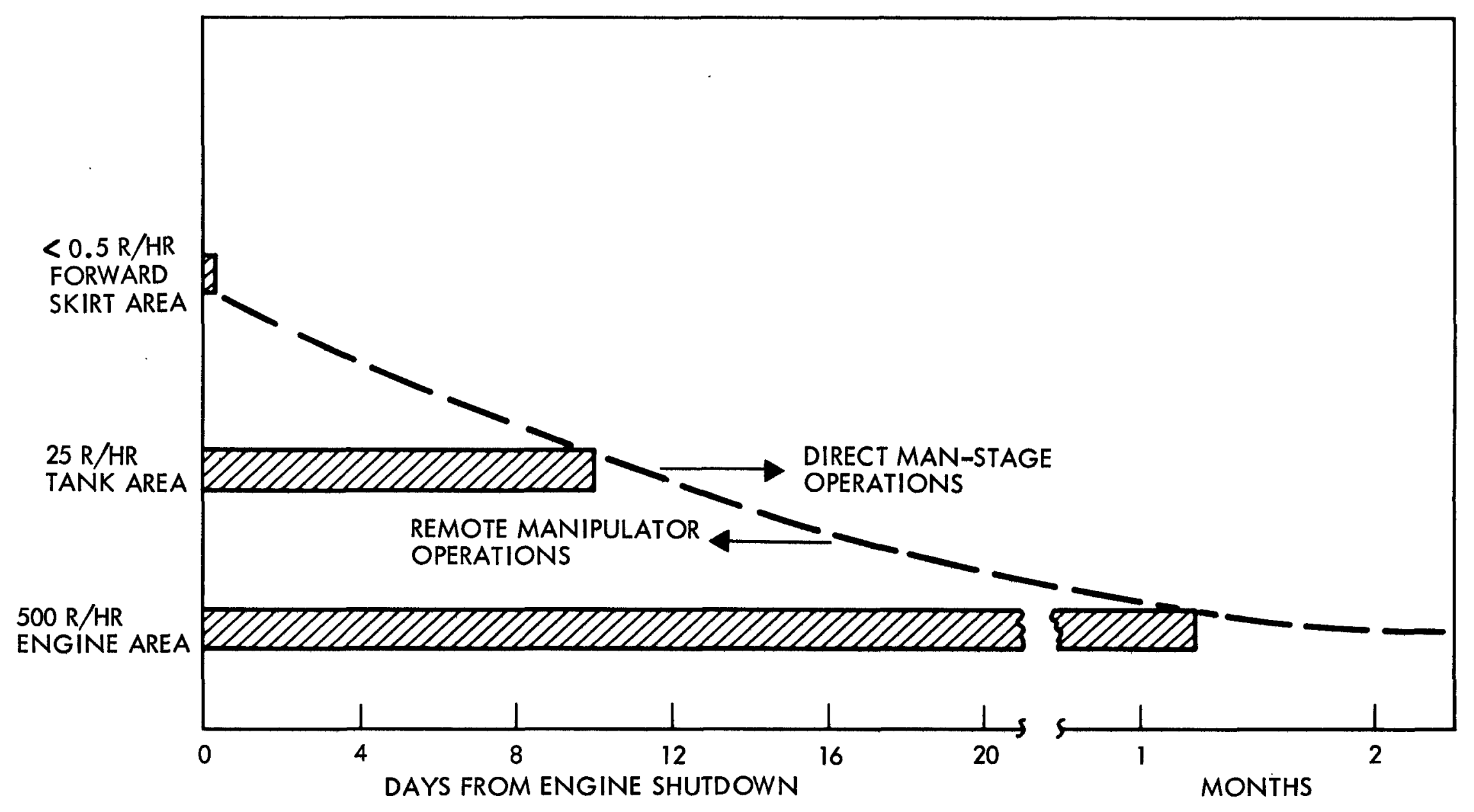


The RNS mission operation's maintenance and repair functions will follow a prescribed time schedule, as presented in the facing figure. Two sets of elapsed times are presented to reflect the estimated minimum and maximum $\mathrm{T} / \mathrm{A}$ times, as currently defined, based on review of preliminary RNS mission and $\mathrm{T} / \mathrm{A}$ operations and subsystem design data. Turnaround functions are presently considered to be accomplished by remote and/or direct manned operations. Unmanned, remote M\& $\mathrm{R}$ support operations were considered only as minor options. The minimum $T / A$ time is predicated on the basis that (1) the RNS return from its mission or the station tending phase without requiring unscheduled maintenance, (2) the visual inspection and functional checkout do not detect the requirement for unscheduled $M \& R$ activity, and (3) there are no scheduled $M \& R$ activities to be performed (refer to Maintenance/Refurbishment Checkout Cycle). The maximum $T / A$ time includes a time span for accomplishing the necessary scheduled and unscheduled maintenance and the final subsystem checkout following the maintenance activities. The shaded time, shown for the scheduled maintenance activity, is an estimate based on a review of preliminary subsystem data with conservative time allowances included for space M\&R operations (e.g., ingress/egress of work area, R\& R and servicing activities, EVA, etc.) and environment (e.g., zero-g, lighting, radiation-exposure limitations). The unscheduled maintenance activities would be performed in parallel with those of the scheduled maintenance and completed prior to the final checkout.

After the payload and RNS are demated, following any one of the three types of RNS missions, the RNS will be in a radiation cooldown phase prior to docking with the $M \& R$ element. The cooldown phase is not considered as part of the $T$ / A but rather a station tending activity. After the cooldown phase renders the RNS to a safe working level, the RNS is docked to the M\&R facility and a visual inspection is performed of the exterior structure. A functional checkout, utilizing the RNS OBCS, will be made and, if required, scheduled $M \& R$ operations, involving visual and nondestructive inspection techniques, subsystem servicing, and component $R \& R$, are performed by work area to minimize radiation hazards. During the same time span, the unscheduled $M \& R$ functions are performed on those subsystems or components as detected through visual and OBCO inspection methods. Following all M\& $\mathrm{R}$ operations, the final checkout of all systems is completed before propellant is loaded into RNS. The RNS and payload vehicles are mated and a final checkout is made of the integrated RNS-P/L vehicle prior to mission injection operations. 


\section{TURıJAROU,JD OPERMTIO,IS TI,rELIIJE}

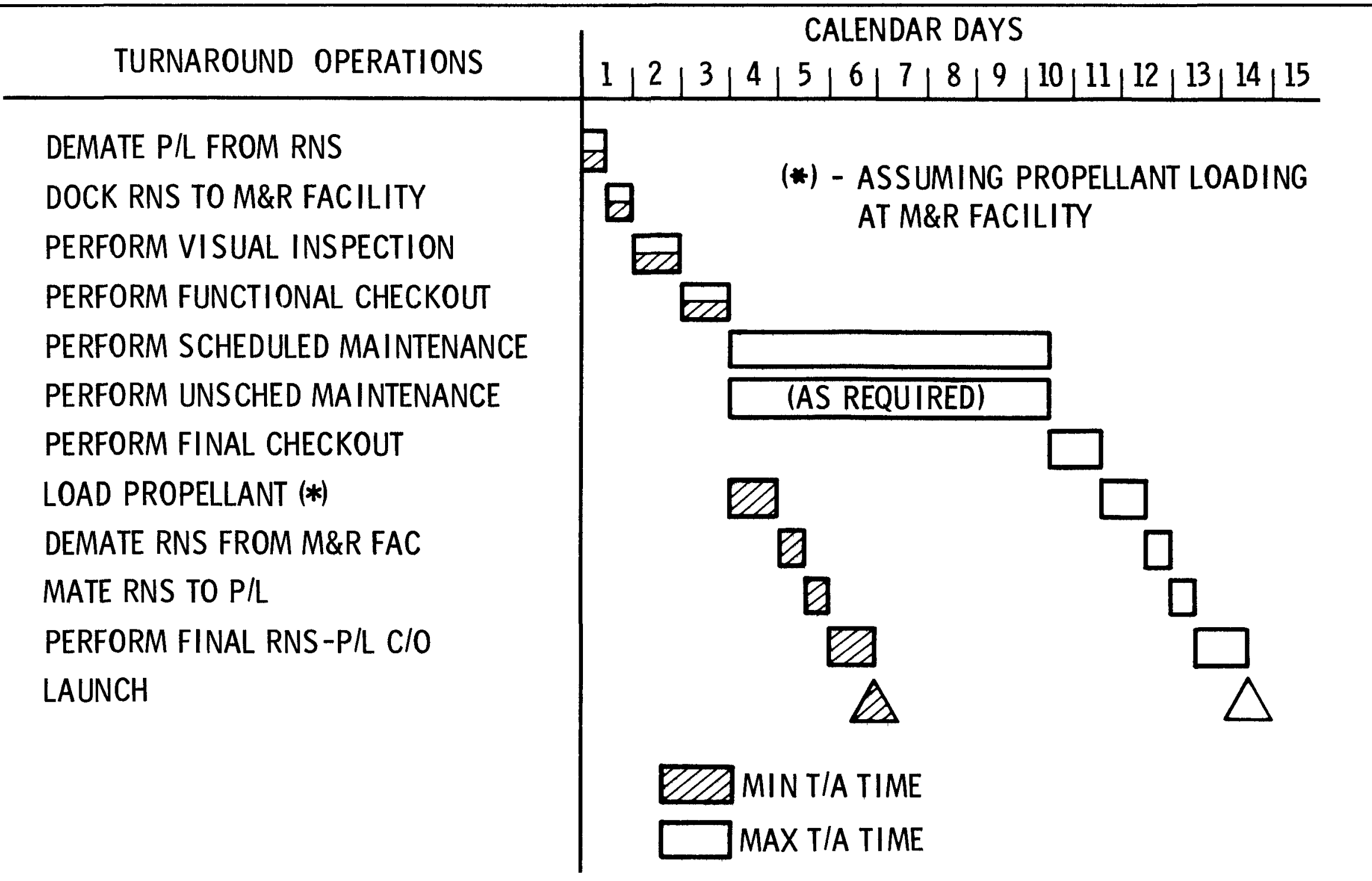


Methods of RNS stage orbital checkout could range from complete dependence on ground control through the telemetry radio command link to complete atonomy of the RNS stage. Complete dependence on the station would lead to operational complexity because of the high level space activities projected for the time period the RNS is to be operational. Complete atonomy on the other hand, would lead to extreme design complexity and preprogramming requirements. The approach taken for the on-board checkout will fall between these two extremes. The computer of the Information Management System (IMS) will serve as the focal point for on-board checkout. Although checkout will be initiated by and displays readout by space program elements other than the RNS, the IMS computer will contain the RNS subsystems checkout routines and fault isolation routines. Subsystems components and/or Flight Replaceable Unit (FRU) designs will be affected by on-board checkout since consideration must be given to subsystem/ FRU control signals initiated by the computer and the transmission of subsystem response to the computer for evaluation. The postulated data link between the IMS and subsystem elements is a data bus with digitized control and response signals. The subsystem/FRU designs must reflect a decoder/ encoder interface with the IMS to provide a compatible interface. A schematic block diagram of this IMS/subsystem interface is shown in facing figure along with the interface postulated for ground or maintenance element and the payload interface with the RNS. The data link between RNS stage and maintenance element indicates a requirement for both direct and RF links. The direct link would be utilized for checkout while the RNS is docked to the maintenance element whereas the RF link would be used to initiate automatic checkout of the mated RNS stage and payload prior to embarking on a shuttle or injection mission. A dashed line is shown between the RNS stage and the manned payload to indicate the point of interface for the control and display functions of the manned payload.

A direct connected interface is shown between the RNS stage subsystems and the maintenance element. This interface represents a linkage which would provide a maintenance element source medium such as gases, electrical power, propellant, etc. during orbital checkout while docked to the maintenance element. A similar or identical interface may be used for ground checkout to verify checkout procedures, displays, and data recording requirements which will ultimately be used in orbital checkout. 
ON-BOARD CHECKOUT CONCEPT

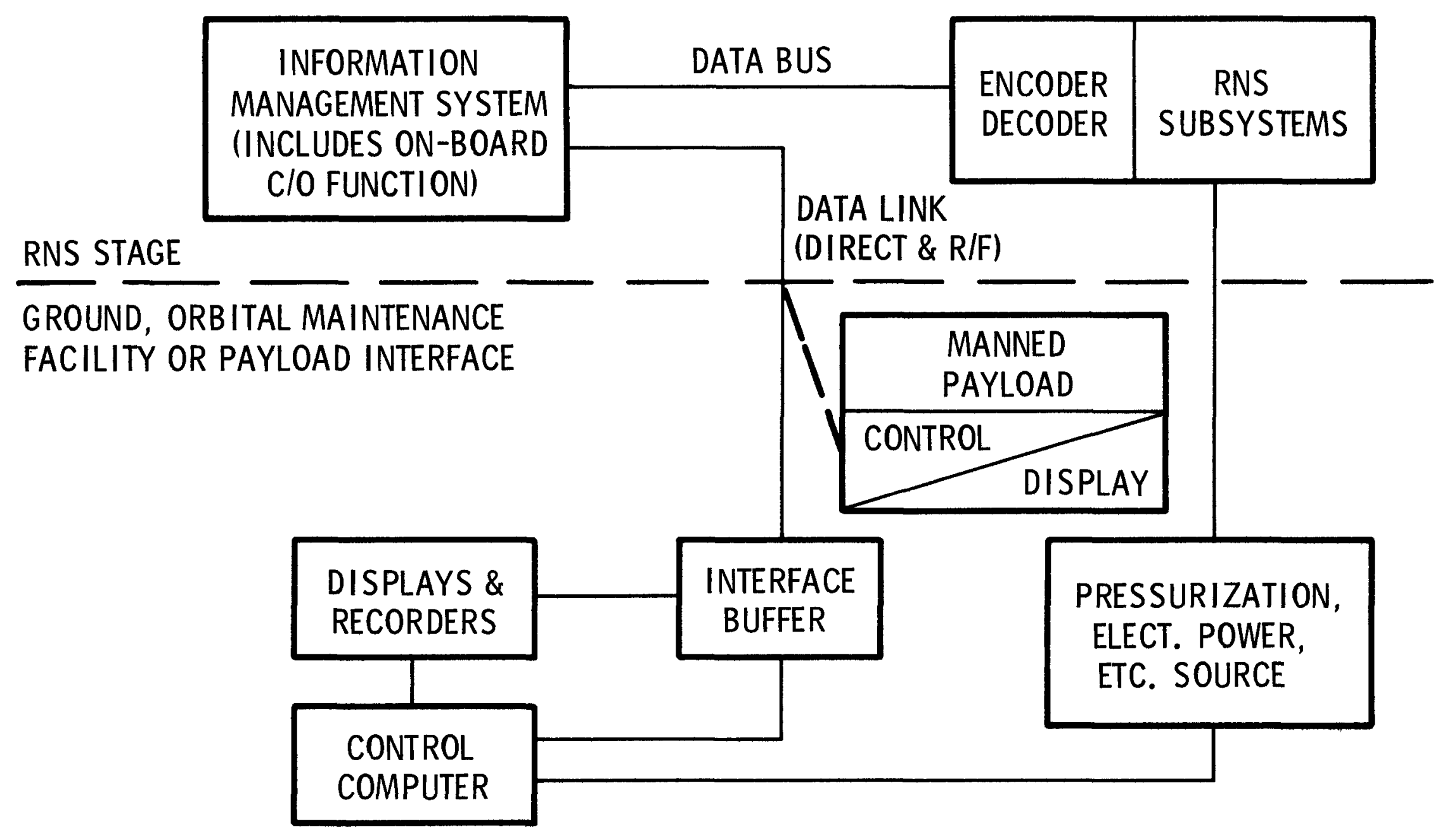




\section{PRELIMINARY OBCO REQUIREMENTS AND CRITERIA}

The time and location specified for RNS stage checkout has been identified as RNS Earth operations orbit prior to each mission. Since the Class I missions will involve payload transfer operations and may require extensive stay times at the lunar or synchronous orbit space station, additional vehicle checkouts are recommended to verify RNS systems are operational prior to departing these stations.

In order to keep the programming of checkout routines as simple as possible, qualitative checkout (i. e., GO, NO-GO) will be performed by the on-board checkout equipment.

Since the on-board checkout (OBCO) equipment will serve as a measuring device for determining status of stage subsystems it must first be self-checked against built-in standards to insure it is operating properly prior to evaluating stage system status. OBCO will utilize operational signals wherever possible and all redundant paths will be checked.

If because of operational constraints or safety considerations a FRU cannot be operated, the FRU will be checked as far down stream as possible without actuating the devices end output.

The on-board checkout equipment must detect malfunctions and isolate any fault to the FRU. Malfunction detection is not restricted only to the checkout in RNS operations orbit but will be required throughout the mission. Recording of malfunction for subsequent playback during maintenance operations will identify problem areas without having to perform a system check to detect malfunctions. Checkout of the RNS stage while docked to the maintenance element will be initiated by the maintenance element crew which must have the capability to accept and display checkout system data. When the payload is mated to the RNS stage, the interface checkout sequence may be initiated either directly by the crew of a manned payload or remotely by the crew of the maintenance element. Status of RNS stage systems will be transmitted for readout to the crew initiating the checkout and/or to the manned payload crew.

Failure prediction is postulated at this time to be achieved through support from ground facilities to limit the size of the on-board digital computer memory units and reduce the amount of computer programming. During engine operation and selected phases of flight, critical parameters will be recorded for evaluation either through payback to ground facilities or through use of the IMS computer. Data will be analyzed for parameter drift tendencies. Although parameters may be within specified tolerance bands, the drift rates and proximity to specified limits will provide an indication of impending malfunction. 


\section{PRELIMINARY OBCO REQUIREMENTS \& CRITERIA}

- CHECKOUT PRIOR TO DEPARTING - RNS OPERATIONS ORBIT, LUNAR ORBIT, SYNCHRONOUS ORBIT

- QUALITATIVE CHECKOUT BY OBCO EQUIPMENT

- OBCO EQUIPMENT TO HAVE SELF-CHECK CAPABILITY

- OBCO WILL UTILIZE OPERATIONAL SIGNALS WHEREVER POSSIBLE

- WHEN FRU * CANNOT BE OPERATED (SAFETY OPERATIONS - ETC) CHECKOUT FRU AS FAR DOWN STREAM AS POSSIBLE WITHOUT ACTUATING OUTPUT

- CHECKOUT ALL REDUNDANT PATHS

- RECORD MALFUNCTION DETECTION DATA FOR SUBSEQUENT PLAYBACK

- MALFUNCTION ISOLATION TO FRU LEVEL

- OBCO TO PROVIDE CHECKOUT CAPABILITY INDEPENDENT OF GROUND PARTICIPATION

- PROVIDE OBCO RF \& DIRECT LINK FOR INITIATING CHECKOUT \& TRANSMITTING CHECKOUT DATA TO INITIATING SPACE PROGRAM ELEMENT

- TREND DATA ANALYSIS FOR FAILURE PREDICTION REQUIRES EXTERNAL SUPPDRT

*FRU = FLIGHT REPLACEABLE UNIT 


\section{LOGISTIC OPTIONS}

Three logistic options are shown: these are direct transfer from the space shuttle and transfer utilizing two types of propellant depots as intermediaries. As the RNS requires $300 \mathrm{~K}$ lb of propellant and the shuttle payload for a $260 \mathrm{n} \mathrm{mi,} 31.5$ degree inclination orbit is $33 \mathrm{~K} \mathrm{lb}$, at least nine transfer operations are required - and this leaves no allowance for propellant losses and unusable payload. Furthermore, unless multiple space shuttles are available to service the RNS, the transfer time may become appreciable, thereby constraining RNS operation. On the other hand, use of a depot introduces an additional transfer operation and an additional space program element. One of the depots shown utilizes INT-21 launched tankage and requires fluid transfer both to and from the depot with a storage requirement dependent on the traffic plan. The other depots employ space shuttle payload propellant tankage placed in orbit by a modular exchange method. The tankage could be manifolded together to facilitate fluid transfer to the RNS. The merits of the various logistic options and storage configurations will be discussed in a subsequent chart. 


\section{LOGISTIC OPTIONS}

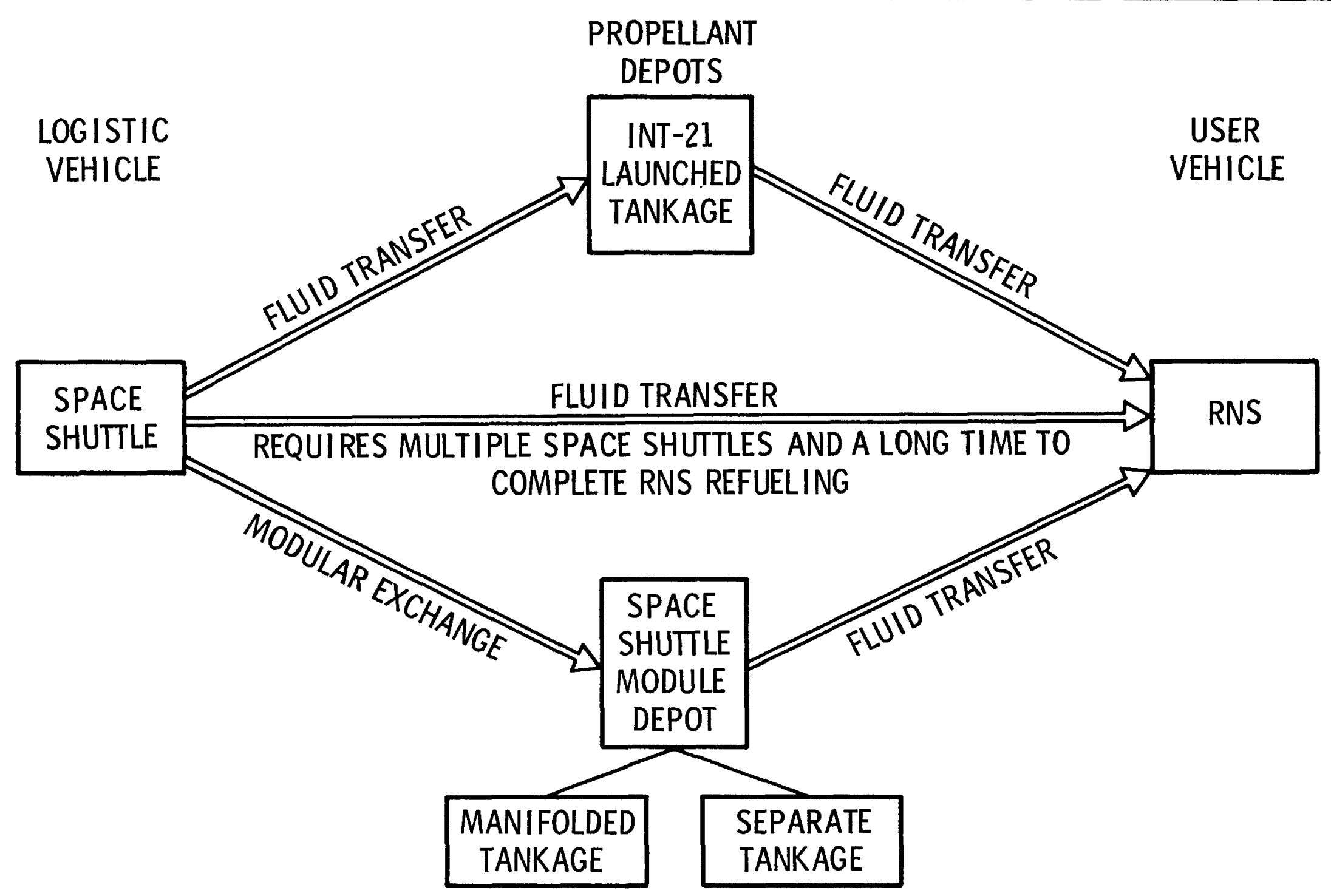




\section{LIQUID LOCATION CONTROL METHODS}

Liquid acquisition and position location control during transfer is of pivotal importance, as it impacts both vehicle and depot design as well as operation. Various location control alternatives are discussed below, with emphasis on the source tank (tanker).

To date, positive displacement techniques have been used mainly for small tanks containing storable propellant. Metallic bellows are preferred over polymeric bladders for cryogenic applications. The largest metallic bellows being studied is six foot in diameter (Arde Corp.), it is highly questionable if a suitable positive expulsion devices will be available for large tankers even in the late 70 .

Capillary devices can be used for total propellant control (e.g., multiple screens in series), for partial control, or as a means of propellant acquisition and collection via capillary pumping (channels and ducts). While capillary devices offer the simplicity of a passive transfer technique, technology problems such as bubble entrapment and possible boiling within the capillary device remain to be solved.

Artificial gravity fields may be grouped into techniques as linear acceleration, centrifugal acceleration due to spin or pitch axis rotation, and dielectroploresis. Each requires either supplement propulsion or power.

(a) Linear acceleration - the propulsion system used for thrusting may be either the existing RNS reaction control system (RCS), propulsive venting of hydrogen, or an additional RCS designed especially for the propellant transfer operation.

In general, linear acceleration is the most reliable transfer approach and is best understood as regards required technology. Compared to the other techniques, propellant losses are moderateto-high. Orbit changes present an additional complexity.

(b) Centrifugal acceleration - emphasis has been placed on rotation about the pitch axis rather than on spinning. The former method can provide relatively high g fields. Thus, good liquid location control in both tanks is possible, provided that deleterious interaction between propellant slosh and vehicle rotation can be prevented.

(d) Dielectrophoresis - cryogenic propellants are dielectrics and can be polarized by an imposed electric field. If the field is not uniform,liquid in preference to gas is drawn into the region of greatest intensity. This technique imposes power, electronic and hardware requirements. This method's principal advantages are that vehicle maneuvers are not required; weight penalty is generally low; and and the problem of trapped bubbles is avoided for suitable electrode designs. 


\section{LIQUID LOCATION CONTROL METHODS}

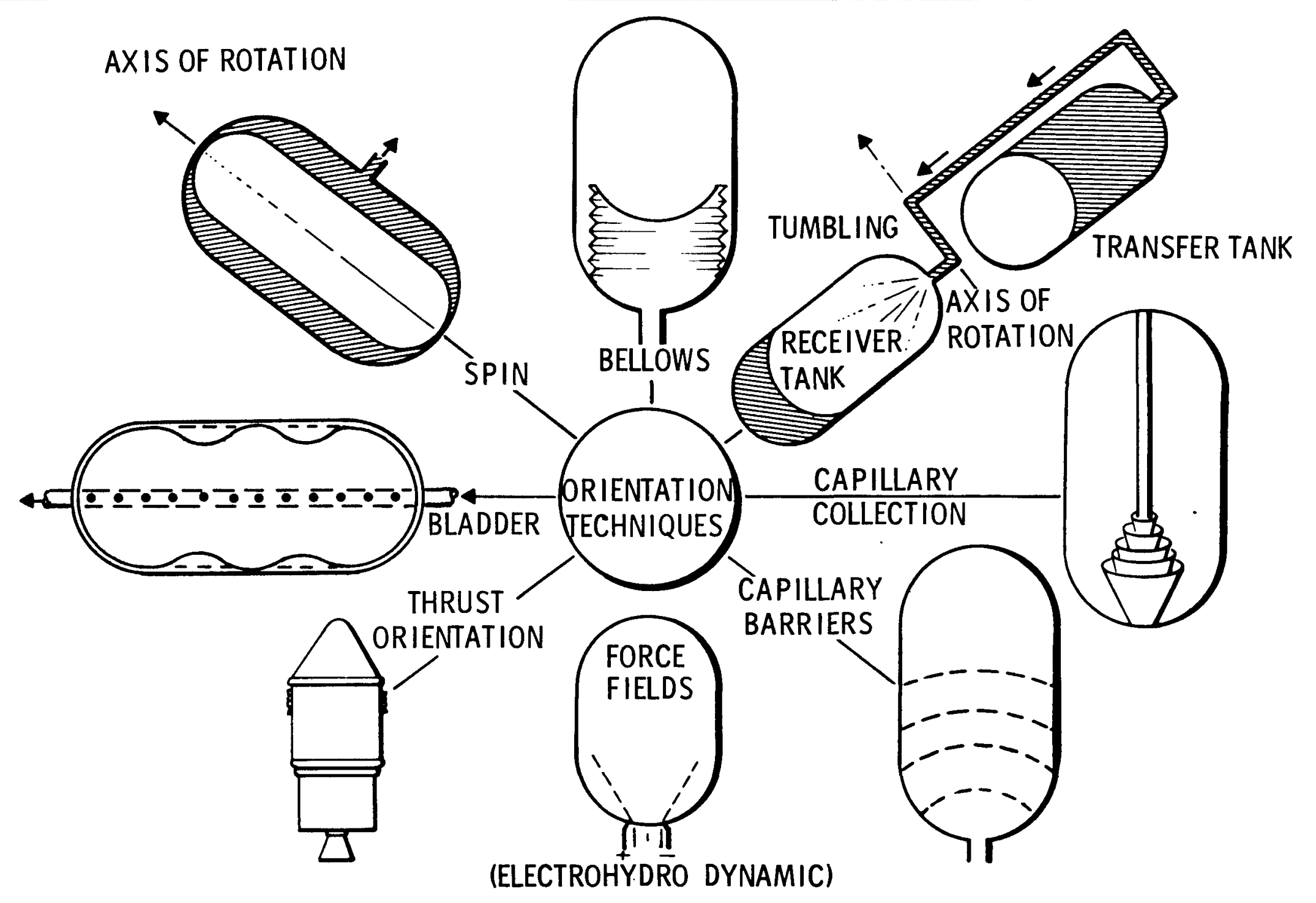




\section{RECEIVER TANK THERMODYNAMICS DURING FILLING}

A general discussion of receiver tank thermodynamics during in-orbit filling is presented here. Specific requirements and operations for filling of the RNS tank are given on a subsequent chart. In general, it is necessary to prevent excessive pressure build-up during filling if no vent filling is employed and to vent at the highest possible temperature if vent filling is employed.

Prechilldown - In this method initial flow to the tank is bypassed through a heat exchanger for cooling tank wall and tank contents. Use of a mixing device in the tank to facilitate cooldown is an option that should be considered. After tank and contents are cooled sufficiently, as indicated by strategically located temperature sensors, the tank is filled in the no-vent mode. Advantages of this method are: venting of the high quality initial flow from the source tank; efficient high-temperature venting during cooldown; and simplified filling. Disadvantages are the need for a well designed heat exchanger; a bypass valve and line; fairly elaborate controls and instrumentation.

No-Vent Filling - This method of filling is perhaps the most straightforward. However, problems due to pressure surges and thermal degradation of propellant must be considered and resolved. A variation of this method, giving moderate pressure build-up and controlled stratification, is recommended in a subsequent chart for filling the RNS.

Thermodynamic Venting - A thermodynamic venting system could be used for thermodynamic control during filling, with the proviso that any quality fluid may be presented at the inlet port upstream of the Joule-Thompson expansion valve. Vented fluid is saturated or superheated vapor. The thermal conditioning (T.C.U.) comprises the major portions of the thermodynamic venting system and consists of expansion valve, heat exchanger, mixer (optional), and temperature and pressure controls. Advantages of this technique are liquid location control is not critical and an existing system (with some modifications) is used. Operation of a thermodynamic venting system is not yet state-of-the-art for steady-stage (coast) operation or during the rapid transients of the fill process.

Direct Venting - This system requires a means of positive liquid location control during fill. Use of a varying angular momentum fill pattern is illustrated. Other methods such as artificial g could be employed. The main disadvantage of this method is that slosh disturbances during filling may lead to direct venting of liquid. Even elaborate screen and/or baffle arrangements to maintain the vent region liquid fill are not $100 \%$ reliable. 


\section{RECEIVER TANK THERMODYNAMICS DURING FILLING}

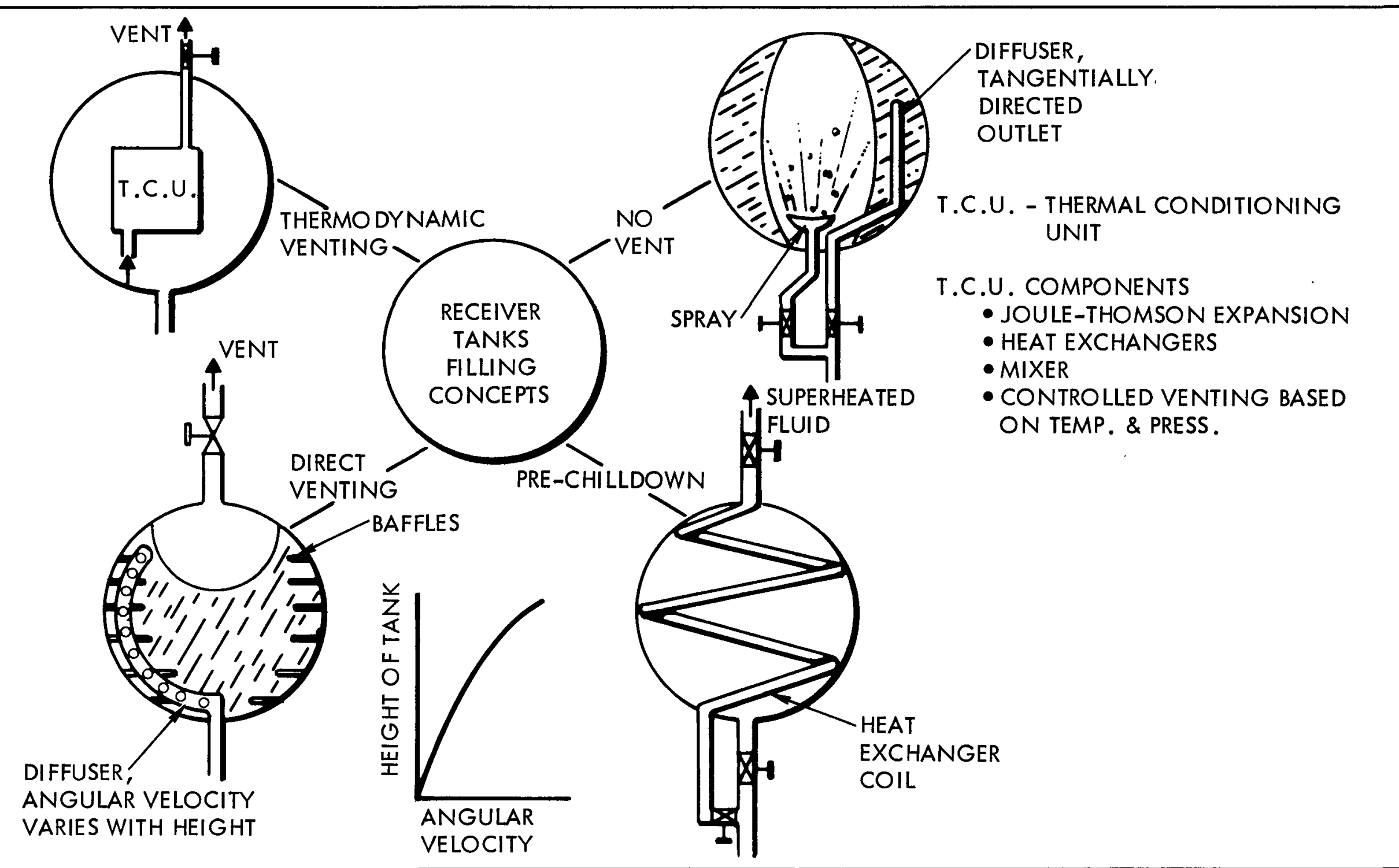




\section{PROPELLANT POSITION CONTROL DURING TRANSFER}

Based on the analyses conducted, the methods of propellant position control during transfer can be compared on a semi-quantitative basis. For the various methods a figure of merit from 1 to 4 (with 1 indicating best performance and 4 worst) has been determined for six key criteria.

Propellant losses are least for centrifugal acceleration as a high $\mathrm{g}$ field can be generated by relatively small amounts of reaction control system (RCS) propellant. The high g field results in small losses due to pull through. Continuous burn of the existing RNS RCS engines in the linear acceleration mode results in prohibitive RCS propellant losses.

Surface tension devices, as they function in a passive mode, are deemed to afford the least operational complexity; centrifugal acceleration because of possible attitude control, slosh, and "flashlight" nuclear radiation problems are deemed the worst method from an operations standpoint.

Linear acceleration has been used on several spacecraft for feedout operations and is considered well understood. Surface tension devices have achieved nearly the same status for storable propellant (e.g., nitrogen tetroxide), but considerable technology problems exist for cryogenic propellants.

Surface tension devices impose appreciable design problems, while propulsive venting impose design, control and system integration problems.

The linear acceleration methods make the greatest demands on subsystems because of RCS or propulsive venting requirements.

Analyses have shown that hydrodynamic and thermodynamic control of the receiver tank (i. e., avoidance of slosh, circulatory motion, and splashing; controlled thermodynamic stratification) is best achieved by the use of an acceleration field.

Assuming equal weight for the six criteria, the two best methods for propellant transfer are: (a) linear acceleration using source tank RCS sized specifically for propellant transfer, (b) centrifugal acceleration using rotation about the pitch axis. 


\section{PROPELLANT POSITION CONTROL DURING TRANSFER}

\begin{tabular}{|l|c|c|c|c|c|c|}
\hline \multicolumn{1}{|c|}{ METHOD } & $\begin{array}{c}\text { PROPELLANT } \\
\text { LOSSES }\end{array}$ & $\begin{array}{c}\text { OPERATIONAL } \\
\text { COMPLEXITY }\end{array}$ & $\begin{array}{c}\text { STATE-OF-THE-ART } \\
\text { TECHNOLOGY }\end{array}$ & $\begin{array}{c}\text { SYSTEM \& } \\
\text { DESIGN } \\
\text { COMPLEXITY }\end{array}$ & $\begin{array}{c}\text { SUBSYS- } \\
\text { TEM } \\
\text { REQMTS }\end{array}$ & $\begin{array}{c}\text { HYDRODYNAMIC } \\
\text { CONTROL } \\
\text { IN RECEIVER }\end{array}$ \\
\hline $\begin{array}{l}\text { LINEAR ACCELERA- } \\
\text { TION USING } \\
\text { EXISTING RNS } \\
\text { RCS ENGINES }\end{array}$ & 4 & 2 & 1 & 2 & 4 & 2 \\
\hline $\begin{array}{l}\text { LINEAR ACCELERA- } \\
\text { TION USING } \\
\text { CONTROLLED } \\
\text { PROPULSIVE } \\
\text { VENTING }\end{array}$ & 2 & 3 & 2 & 3 & 2 & 3 \\
\hline $\begin{array}{l}\text { LINEAR ACCELERA- } \\
\text { TION USING } \\
\text { SOURCE TANK RCS }\end{array}$ & 2 & 2 & 1 & 2 & 3 & 1 \\
\hline $\begin{array}{l}\text { CENTRIFUGAL } \\
\text { ACCELERATION } \\
\text { USING ROTATION } \\
\text { ABOUT PITCH AXIS }\end{array}$ & 1 & 4 & 2 & 4 & 1 & 1 \\
\hline $\begin{array}{l}\text { SURFACE TENSION } \\
\text { DEVICES }\end{array}$ & 3 & 1 & 3 & & & 4 \\
\hline
\end{tabular}

RELATIVE RATING: $1=$ BEST, $4=$ WORST 


\section{PROPELLANT TRANSFER AND CONDITIONING REQUIREMENTS}

The required state of propellant in the RNS after tanking is largely determined by turbopump and engine requirements for the autogenously pressurized first engine burn. Requirements ${ }^{*}$ are based on an engine restart requirement of 24 to 30 psia pressure, and $0 \%$ vapor at the tank outlet (upstream of the main propellant shutoff valve). During engine operation, the requirement at the tank outlet is for 30 psia pressure and $0 \%$ vapor. Propellant is to be no hotter than saturated at these pressures.

The propellant condition after tanking must be such that it will satisfy the above requirements at first engine burn. A study has been conducted to establish the propellant condition. Factors such as chilldown, acceleration field, initial tank condition, RNS tank and source tank hydrodynamics and thermodynamics, and heat leak were considered. To satisfy the restart requirement, the pressure at the end of tanking should be at least 29 psia. Temperature need not be uniform, but should lie between 38.2 and $39.3^{\circ} \mathrm{R}$. The upper temperature limit allows $1^{\circ} \mathrm{R}$ subcooling (relative to the 24 psia vapor pressure level) to assure that vapor will not form in the outlet region. The lower temperature limit assures that the ullage pressure collapse rate will be sufficiently low that the pressure at the tank outlet will not drop below the 24 psia level for first engine burn.

The propellant is, therefore, stratified and except at the interface, not in equilibrium with the vapor. This situation will greatly assist the autogenous pressurization subsystem and furthermore is more realistic than specifying that thermodynamic equilibrium exist everywhere. The propellant condition specified can be obtained by a combination of ground loading and topping at the appropriate temperature and pressure; thermodynamic control of the source tank prior to transfer; and thermodynamic and hydrodynamic control of the RNS tank during transfer. The first two operations will assure that the source tank propellant prior to transfer to the RNS tank is heated to the appropriate temperature above ambient saturation conditions. The last operation requires filling of the RNS in the no-vent mode until 29 psia pressure is obtained; thereafter, thermodynamic venting (Joule-Thompson expansion valve, heat exchanger, etc.) is utilized as required. Filling must be accomplished in a controlled manner to avoid slosh and splashing, thereby enhancing stratification.

The propellant conditioning requirements given above can be relaxed appreciable if NERVA turbopump and engine requirements are relaxed.

* Based on SNPO-NPRD-1, NERVA Program Requirements Documents, Space Nuclear Propulsion Office, Cleveland, Ohio, 21 November 1969 


\section{PROPELLANT TRANSFER \& CONDITIONING REQUIREMENTS}

- SLOSH AND PROPELLANT LOCATION CONTROL REQUIRED DURING FILLING

- TOTAL THERMODYNAMIC EQUILIBRIUM UNDESIRABLE

- CONTROLLED STRATIFICATION REQUIRED

- PRESSURE AFTER REFILLING = 29 PSIA

- PROPELLANT TEMPERATURE RANGE AFTER REFUELING $=38.2 \mathrm{TO} 39.3^{\circ} \mathrm{R}$ 
Many factors must be considered in comparing propellant transfer to the RNS through the use of an intermediary propellant depot (single transfer) versus direct transfer from the space shuttle (multiple transfer). The more important factors are outlined in the table.

Multiple transfer avoids the need for a propellant depot and affords the simplicity of a single step transfer operation. However, it is believed that these advantages are not sufficient to outweigh the advantages of an intermediary propellant depot. Through the use of the depot, RNS turnaround is not constrained by space shuttle delivery, as approximately ten space shuttles or space shuttle flights are required to refuel the RNS. The RNS need only rendezvous and dock once for refueling reducing operational complexity and radiation hazard. The depot can be specifically designed for efficient transfer and storage of propellant.

Finally the size of the space shuttle renders prohibitive the technique of positioning of propellant by acceleration. However, acceleration transfer is preferred overall (please see preceding charts), and in particular acceleration transfer in the single transfer mode appears to be the only way to satisfy RNS propellant condition requirements and meet the first restart autogenous pressurization requirements.

Thus, single transfer through the use of a depot is the recommended method from the RNS standpoint. 


\section{PROPELLANT TRANSFER TO THE RNS}

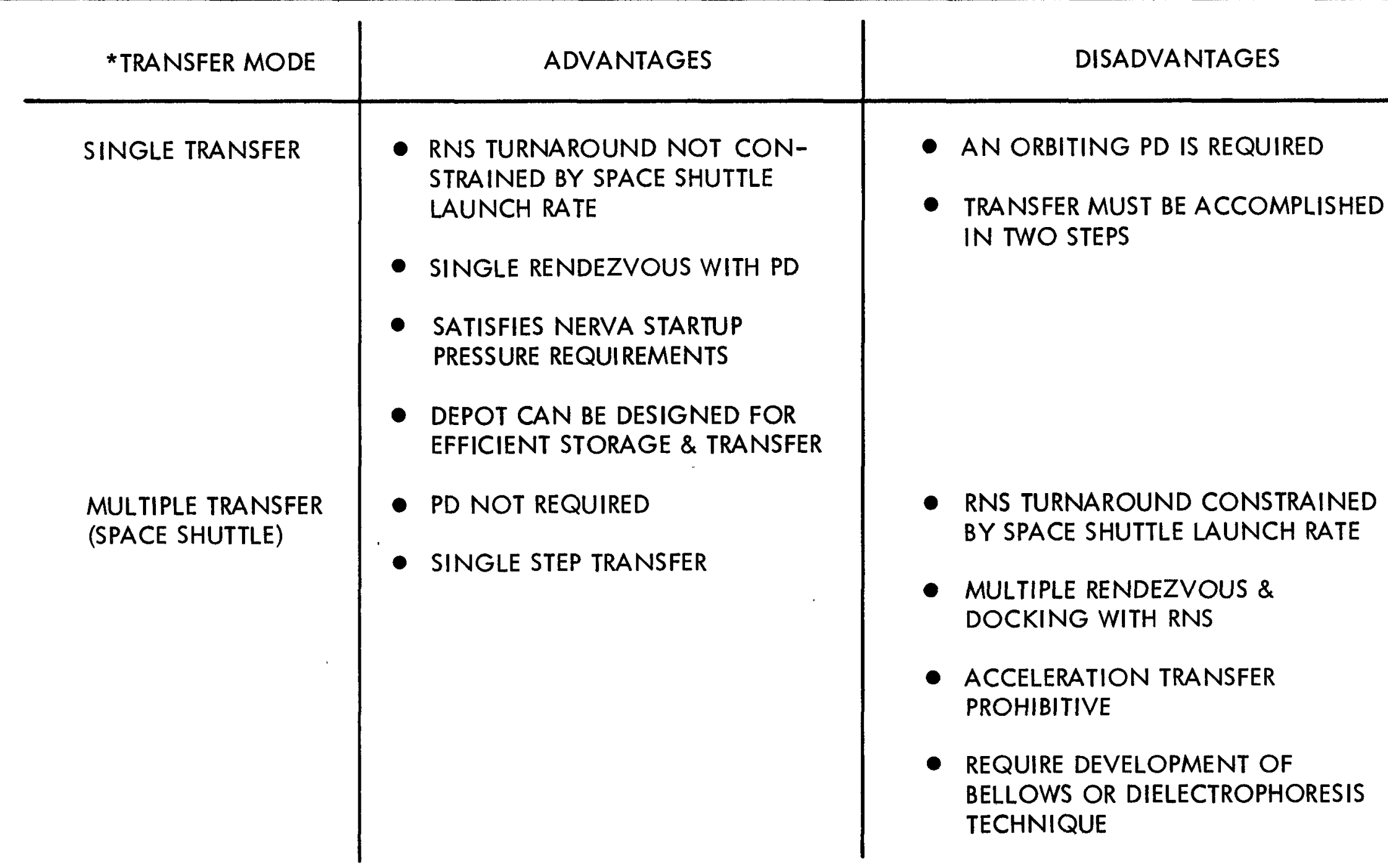

*SINGLE TRANSFER MODE RECOMMENDED AT THIS PHASE OF STUDY FROM RNS STANDPOINT 


\section{PROPELLANT FEEDOUT DURING COOLDOWN}

The approach taken to provide propellant feedout during engine cooldown, when the gravity field is very low, is to utilize capillary channels in conjunction with rewetting screens. Settling using Reaction Control System (RCS) engines requires appreciable RCS propellant and compounds the station keeping problem.

The feedout problem is most stringent during the final cooldown, although a problem exists to varying degrees for all of the cooldowns. For cooldowns prior to the final one, the probability of vapor rather than liquid being fed to the engine is miniscule. This is due to the use of capillary screens (at least three required) to create at least two compartments between the bulk of the tank and the outlet region compartment. These compartments (not all shown in figure) are numbered 1, 2, 3, etc. beginning with the outlet compartment. Thus, during cooldown prior to the last, vapor may pass into, say, the third compartment from the bulk fluid due to the bulk fluid being disoriented but the presence of vapor in the outlet region compartment can be avoided.

During the last cooldown, for worst case conditions, the tank is drained completely of propellant, except for programmed residuals. Thus, the third, second, and first compartment will be successively emptied. Our concern is with (1) propellant trapped within these compartments (and thus unavailable for cooldown), and (2) the problem of premature ingestion of vapor into the cooldown line outlet. To solve the former problem capillary pumps (open-sided channels) provide a preferred path for propellant, located anywhere within the compartment, to reach the screen below. The screen, a closely woven rewetting mesh (e.g., dutch twill stainless steel), preferentially passes liquid rather than vapor due to the action of the bubble pressure. Some propellant will be trapped in the compartments, as flow losses will eventually exceed the bubble pressure permitting vapor passage before depletion.

The latter problem ( 2 above) arises in the final phases of the last cooldown. Premature gas entry due to vortex formation or pull through are prevented by a vane type vortex baffle and a low porosity pull through baffle. High expulsion efficiency is provided by tapered open-sided capillary channels which can supply liquid to the outlet even under a low $\left(10^{-5} \mathrm{~g}\right)$ level negative $\mathrm{g}$. The capillary channels provide the additional benefit of inhibiting slosh and concomitant premature vapor feedout. 


\section{PROPELLANT FEEDOUT DURING COOLDOWN}

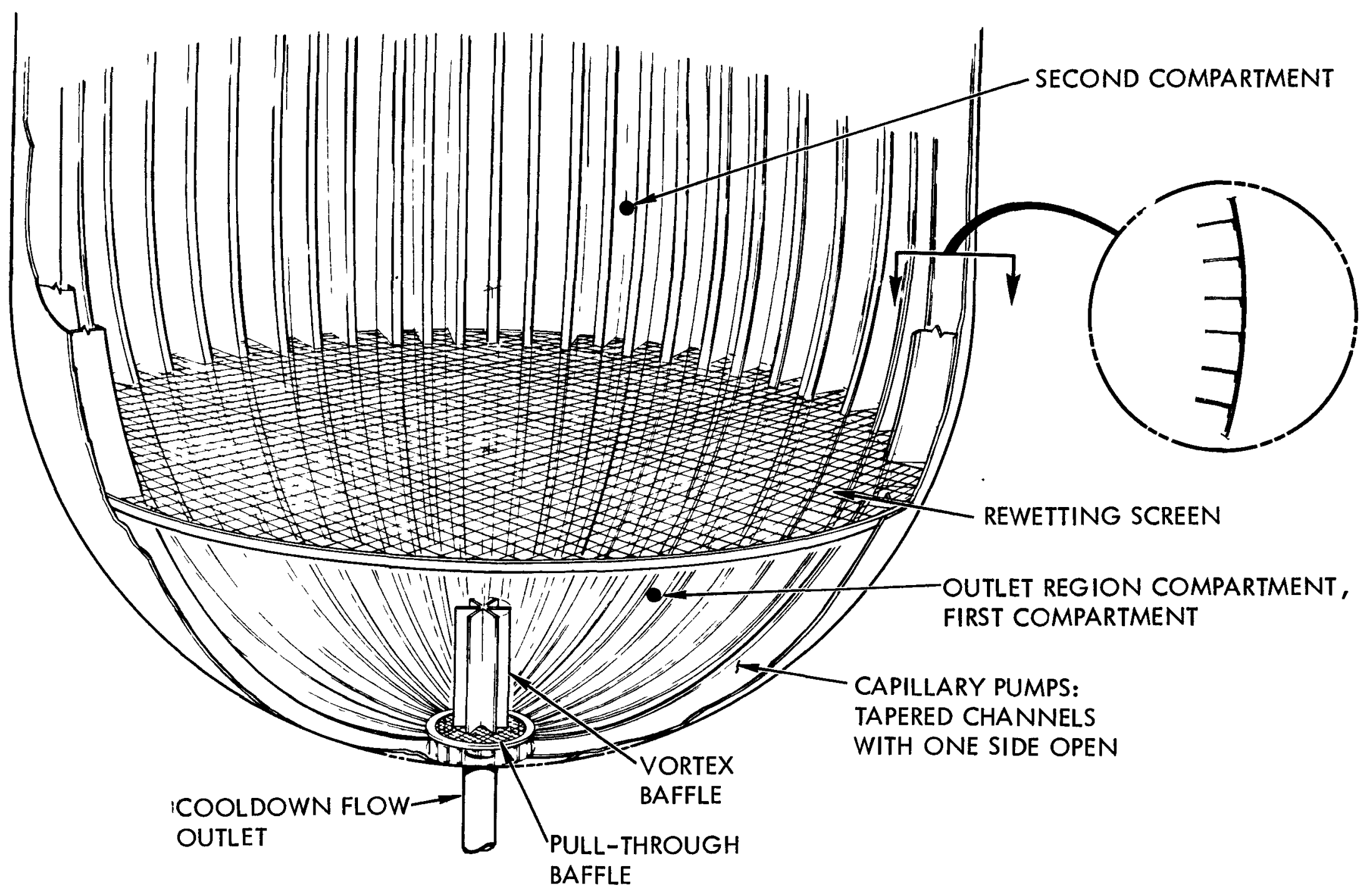


Three analytic approaches to tank pressure decay are presented to show the impact of propellant hydrodynamics on ullage gas thermodynamics. Cooldown following translunar injection is presented as it represents an extreme case (longest burn and longest cooldown time). The cases analyzed are as follows: (1) propellant was assumed to be quiescent, (2) propellant was assumed to mix energetically with the ullage gas beginning with the engine tail off phase, (3) an ANSC analysis assumed quiescent propellant behavior until the on-off phase of pulsed cooldown began; thereupon, the ullage collapsed instantaneously to $18 \mathrm{psia}$, (the vapor pressure of the bulk propellant). If the propellant slosh is minor at engine shutdown and subsequent maneuvers are at low rates and for short duration, then the assumption that propellant is quiescent is tenable. This can even be so during the on-off pulse phase where the propellant experiences intermittent "weightlessness, " provided vehicle maneuvers or disturbance are absent. Vehicle disturbance during weightlessness if severe enough can lead to behavior approaching that shown by the ANSC analysis curve. Finally, appreciable propellant slosh at engine shutdown can lead to intimate propellant-ullage gas mixing with rapid pressure decay as shown by the dashed maximum slosh curve.

Pressure collapse is controlled by the withdrawal rate of liquid, gas-liquid heat and mass transfer and heat leak from outside (this proved negligible). These effects were considered in developing the quiescent propellant curve with conduction heat transfer assumed between liquid and gas, and natural convection heat transfer between gas and wall. Maximum slosh analysis curve is an anticipated result based on analysis still in progress; it assumes propellant circulation, entrainment of vapor bubbles, and turburlent flow heat transfer coefficients.

ANSC is currently reassessing tank pressure requirements during cooldown. Should 18 psia (vapor pressure) and 5\% vapor prove acceptable then engine cooldown can be accomplished irregardless of the pressure decay curve followed. If this is not the case, then alternatives (given below) must be provided. Furthermore, tank pressure at engine restart is determined by the pressure-time curve during cooldown and coast. As the tank pressure required at restart is currently specified as 24 to 30 psia, the pressure decay of curves maximum slosh and ANSC analysis are not acceptable.

Alternatives to satisfy the pressure requirements during cooldown and restart are: (a) total propellant control during cooldown and coast, (b) auxiliary pressurization, (c) higher heat leak rates (preferable directed into the ullage region) during cooldown and coast, (d) relaxation of the engine requirement to 18 psia and $5 \%$ vapor. 


\section{TANK PRESSURE DECAY DURING COOLDOWN FOLLOWING TLI}

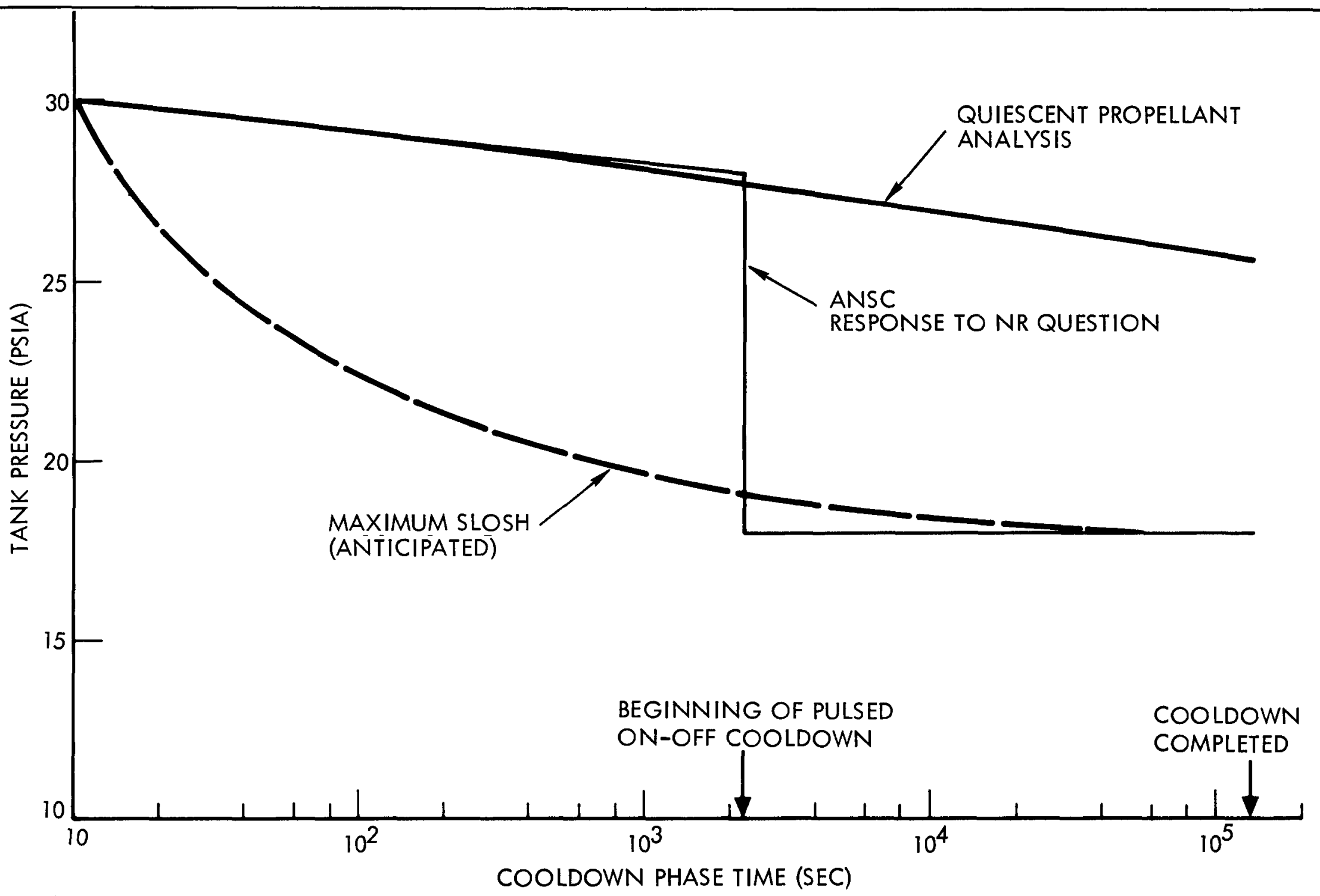


Disposal of the RNS stage (or NERVA engine) are influenced by three major factors which are identified as: (1) disposal configuration alternate for disposal, (2) the place or location from which the spent stage is disposed of, and (3) the place or loaction to which the disposal is made. These three factors with their options are shown in the facing figure.

The spent nuclear stage or engine may be disposed of in a number of ways after it has reached its end-of-life operating time and the implications of the various discard modes will be touched upon in the following discussion. An option identified deep ocean disposal, however, this mode of disposal is not considered desirable as a normal disposal mode because of the potential hazard to the Earth's population. This mode of operation would be considered only in emergency conditions where eventual Earth impact would occur as a result of a failure and a controlled disposal to specific Earth location would be least hazardous to the general populous.

Placing the spent stage in a long life Earth orbit from the RNS operations orbit or synchronous orbit is a desirable location for spent stages, however, the disadvantage to this location is that it requires surveillance to insure noninterference with future missions. Lunar orbit or lunar surface impact is not desirable from the standpoint of creating lunar mission hazards or contaminating the lunar surface with radioactive material and thus jeopardize future surface exploration. Depositing the spent stage or engine in one of the Earth-Moon libration points is attractive from the standpoint of knowing its location at all times, however, it would preclude the use of the Earth-Moon libration point for future scientific experimentation or operation.

Heliocentric orbit disposal is considered desirable from the standpoint of energy $(\approx 11,000 \mathrm{ft} / \mathrm{sec}$ from low Earth orbit and $\approx 3,500 \mathrm{ft} / \mathrm{sec}$ from lunar orbit) requirement and from the standpoint of safety. This approach, however, could pose a potential hazard of Earth impact if injection is unsuccessful.

Solar system escape would be a desirable method to discard the spent stage from the standpoint of safety, however, considerable impractical from the standpoint of energy requirements and for this reason is not considered as an acceptable disposal mode. 


\section{RNS DISPOSAL MODES}

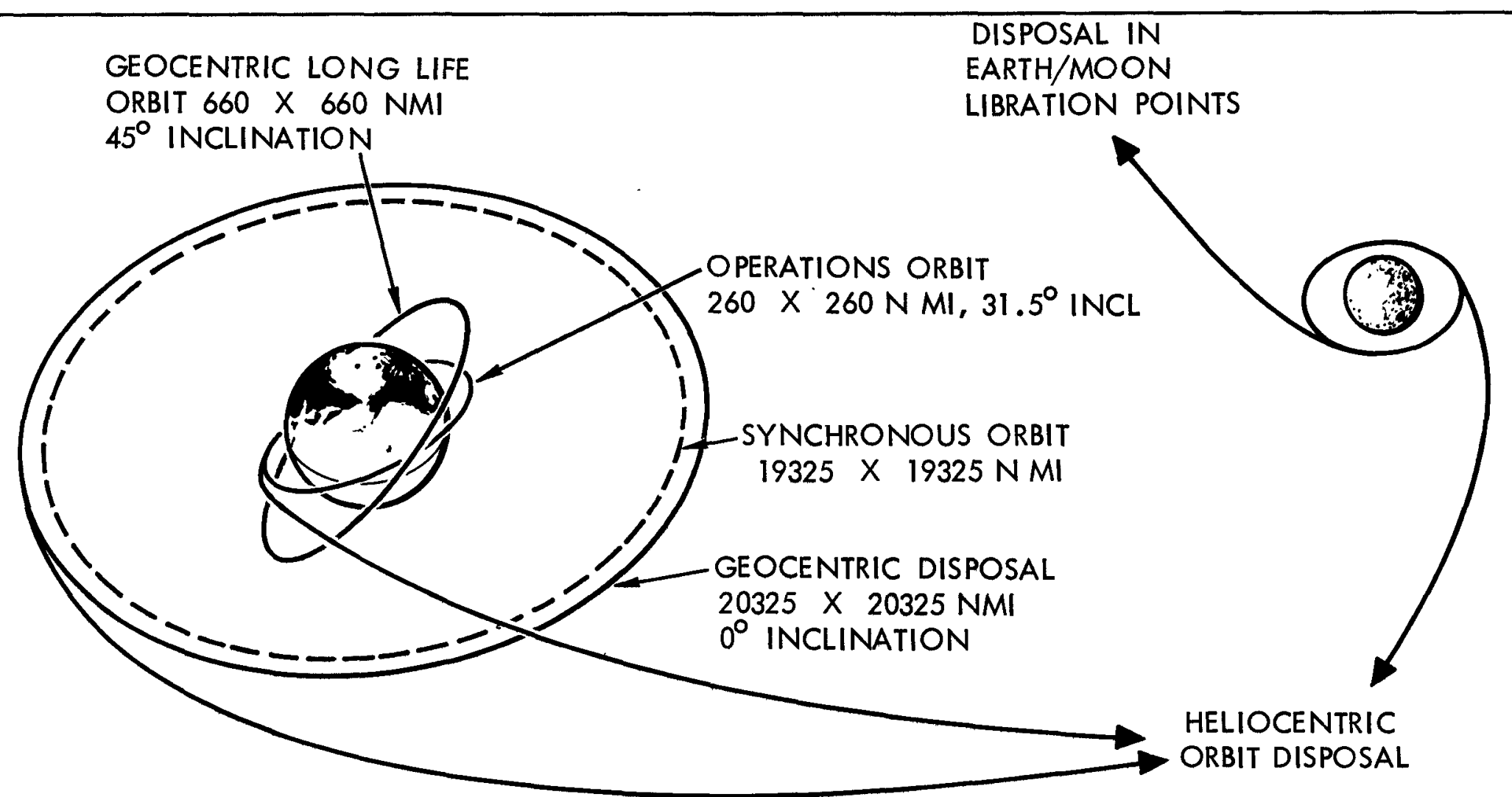

DISPOSAL CONFIGURATION

1. COMPLETE STAGE

2. PROPULSION MODULE (ENGINE + AUXILIARY TANK)

3. ENGINE ALONE VIA SPACE TUG 


\section{R NS STAGE DISPOSAL ALTERNATIVES}

The facing table illustrated the requirement for disposing of the vehicle as an integral unit. A number of geocentric disposal modes are available of which only a portion are identified. Depositing the RNS in an orbit $1,000 \mathrm{n} \mathrm{mi}$ above synchronous orbit from the geosynchronous orbit would require a relatively low delta-V $(\approx 200 \mathrm{ft} / \mathrm{sec})$ and small amount of propellant $\left(\approx 1,300 \mathrm{lb} \mathrm{LH}_{2}\right)$. This mode of disposal from geosynchronous is attractive from the standpoint of energy requirement and orbit life. However, transfer from low Earth orbit or lunar orbit would require much more energy. An orbit of $660 \times 660 \mathrm{n} \mathrm{mi}$ inclined at $45^{\circ}$ or greater has been identified as a potential orbit for disposal from the low Earth operations orbit of $260 \times 260 \mathrm{n} \mathrm{mi}$ inclined at $31.5^{\circ}$. This orbit was selected as a candidate because of its long life $(\approx 1,000$ years) and at an inclination which was different from the RNS operations or space station orbit inclination. A moderate amount of energy $(\approx 6,500 \mathrm{ft} / \mathrm{sec}) \mathrm{will}$ be required to transfer a RNS/engine into this orbit.

Velocity and propellant requirements for injecting a spent stage into a heliocentric orbit from either synchronous orbit or lunar orbit is very modest. Moderate velocity (11,000 fps) and propellant quantity is required to inject the stage into heliocentric orbit from the RNS operations orbit.

No additional subsystem requirements are imposed on the stage to execute the disposal alternatives. 


\section{RNS STAGE DISPOSAL ALTERNATIVES}

\begin{tabular}{|c|c|c|c|c|c|}
\hline DISPOSAL FROM & DISPOSAL TO & $\begin{array}{c}\approx \Delta V \text { REQMTS } \\
\text { (FT/SEC) }\end{array}$ & $\begin{array}{c}\approx \text { PROPELLANT } \\
\text { REQMTS (LB) }\end{array}$ & $\begin{array}{l}\text { RNS SUBSYSTEM } \\
\text { REQUIREMENTS }\end{array}$ & REMARKS \\
\hline $\begin{array}{l}\text { RNS LOW EARTH } \\
\text { OPERATIONS ORBIT } \\
260 \times 260 \mathrm{~N} \mathrm{MI} \\
31.5^{\circ} \text { INCLINATION }\end{array}$ & $\begin{array}{l}\text { GEOCENTRIC } \\
\text { CIRCULAR } \\
660 \times 660 \mathrm{~N} \mathrm{MI} \\
\geq 45^{\circ} \text { INCLINATION }\end{array}$ & 6,500 & 28,300 & $\begin{array}{l}\text { NO ADDED } \\
\text { REQMTS }\end{array}$ & $\begin{array}{l}\text { UTILIZE RNS } \\
\text { SUBSYSTEM } \\
\text { CAPABILITY }\end{array}$ \\
\hline $\begin{array}{l}\text { GEOSYNCHRONOUS } \\
\text { ORBIT }\end{array}$ & $\begin{array}{l}\text { GEOCENTRIC } \\
\text { CIRCULAR } \\
20325 \text { X } 20325 \text { N MI } \\
\text { OO INCLINATION }\end{array}$ & 220 & ${ }^{*} 1,300$ & $\begin{array}{l}\text { NO ADDED } \\
\text { REQMTS }\end{array}$ & $\begin{array}{l}\text { UTILIZE RNS } \\
\text { CAPABILITY } \\
\text { *PARTIAL POWER } \\
\text { THRUSTING } \\
\text { ISP }_{\text {SP }}=505 \text { SEC }\end{array}$ \\
\hline LUNAR ORBIT & GEOCENTRIC & $\begin{array}{l}\approx 3,000+\Delta V \\
\text { TO CIRCULARIZE }\end{array}$ & & & $\begin{array}{l}\text { NOT RECOMMENDED } \\
\text { USE ENERGY FOR } \\
\text { HELIOCENTRIC } \\
\text { DISPOSAL }\end{array}$ \\
\hline $\begin{array}{l}\text { UNMANNED } \\
\text { INJECTION MISSION }\end{array}$ & GEOCENTRIC & & & & $\begin{array}{l}\text { NOT PRACTICAL. } \\
\text { DISPOSE IN HELIO- } \\
\text { CENTRIC }\end{array}$ \\
\hline $\begin{array}{l}\text { RNS LOW EARTH } \\
\text { ORBIT }\end{array}$ & HELIOCENTRIC & 11,000 & 52,000 & $\begin{array}{l}\text { NO ADDITION- } \\
\text { AL REQMTS }\end{array}$ & $\begin{array}{l}\text { UTILIZE RNS SYSTEM } \\
\text { CAPABILITY }\end{array}$ \\
\hline $\begin{array}{l}\text { GEOSYNCHRONOUS } \\
\text { ORBIT }\end{array}$ & HELIOCENTRIC & 4,500 & 18,910 & $\begin{array}{l}\text { NO ADDED } \\
\text { REQMTS }\end{array}$ & $\begin{array}{l}\text { UTILIZE RNS SYSTEM } \\
\text { CAPABILITY }\end{array}$ \\
\hline $\begin{array}{l}\text { LUNAR ORBIT } \\
\text { (DIRECT OR } \\
\text { SWING-BY) }\end{array}$ & HELIOCENTRIC & 3,500 & 14,400 & $\begin{array}{l}\text { NO ADDED } \\
\text { REQMTS }\end{array}$ & $\begin{array}{l}\text { UTILIZE RNS SYSTEM } \\
\text { CAPABILITY }\end{array}$ \\
\hline PLANETARY & HELIOCENTRIC & 25 & 200 & $\begin{array}{l}\text { NO ADDED } \\
\text { REQMTS }\end{array}$ & UTILIZE RNS RCS \\
\hline
\end{tabular}




\section{PROPULSIVE MODULE DISPOSAL ALTERNATES}

Disposal of the propulsive module (engine plus auxiliary tank) or engine alone will be initiated from the RNS operations orbit. Velocity requirements for injection into long life Earth orbit $(660 \times 660 \mathrm{n} \mathrm{mi}$, $45^{\circ}$ inclination) or into heliocentric orbit are the same as for the stage as discussed on previous chart. Propellant quantity requirements, however, are considerably less for the proposal module comprised of auxiliary tank with pressurization control, attitude control, guidance, and electrical power.

A space tug will be required to dispose of the engine alone. This method, however, will require much more propellant as indicated on the facing table. Use of the tug in this instance assumed ample time for radiation decay such that the radiation level was not detrimental to the equipment of a remote controlled unmanned space tug. 


\section{PROPULSIVE MODULE DISPOSAL ALTERNATES}

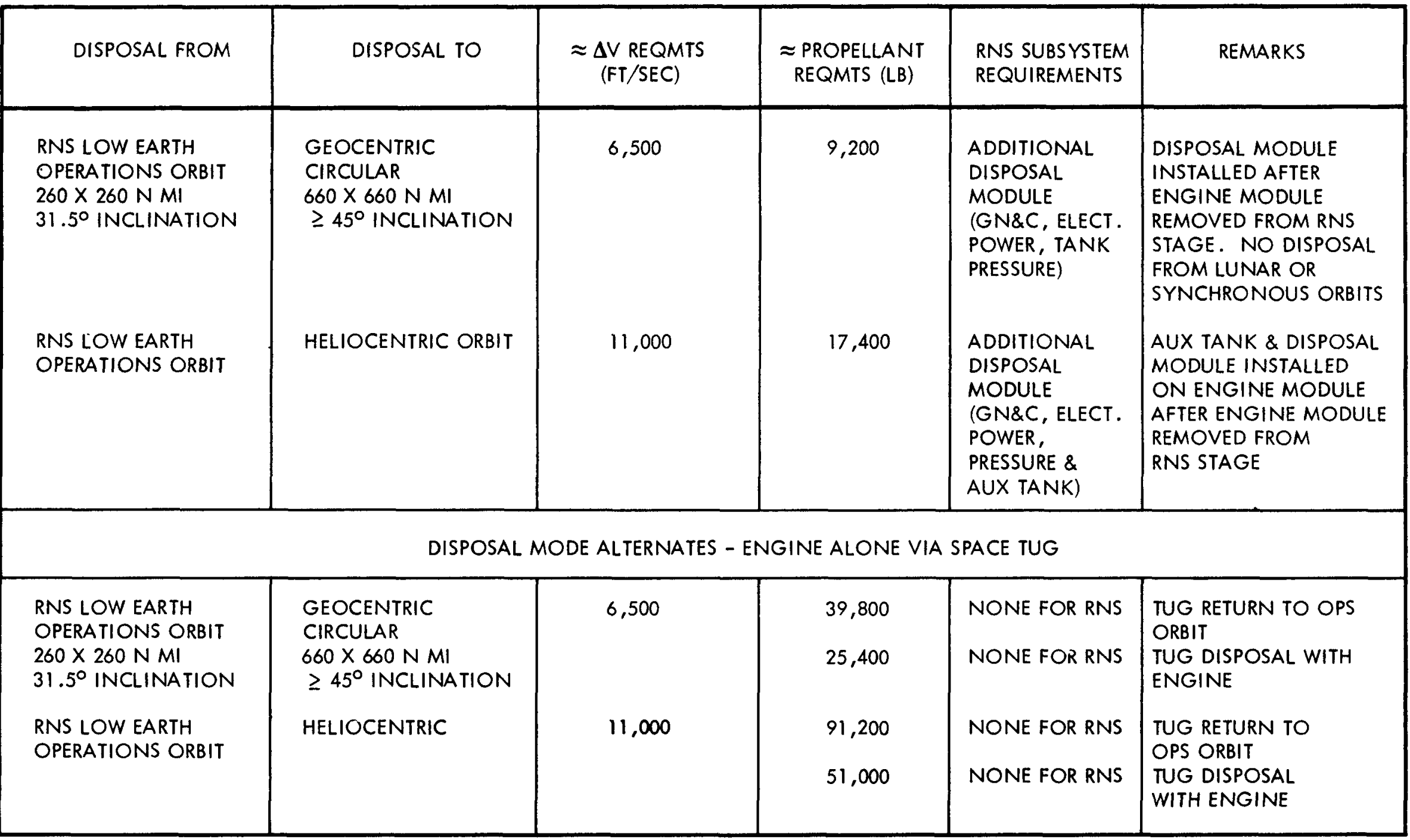




\section{CONCLUSIONS AND RECOMMENDATIONS}

Following the nominal LOSS delivery flight, TLI opportunities will occur approximately every 9 days with a nearly identical, high payload recurring every sixth opportunity (54.6 days). This basic pattern will hold year by year with slowly varying flight characteristics caused by the changing inclination of the lunar orbit plane. Ample mission planning flexibility appears to exist within the constraints imposed by pre-established Earth and lunar orbit orientations.

In the case of lunar orbit arrival or departure (LOI and TEI) where sizable plane changes are required, a three burn profile offers a large savings in delta-V compared to a single burn. Evidently the three burn profile always pays off for plane changes of greater than about five degrees. Multiburn departure from Earth orbit (TLI) also pays well in reduced propellant requirements due to lower gravity loss which attends a single burn.

Contract studies for MSFC and MSC identify payload delivery requirements of 180,000 pounds delivery/ zero return in LOSS study and 160,000 pounds/20,000 pounds return in space tug study. These payloads exceed the 300,000 pound $\mathrm{LH}_{2}$ sized RNS based on NR recommended mission model.

A maintenance element is required in the RNS operations orbit to satisfy the maintenance philosophy of remove and replace for malfunctioning units.

In order to preclude extensive preprogramming of the computer performing on-board checkout and keep computer memory requirements down, qualitative (GO, NO-GO) statusing will be performed by the onboard checkout equipment.

Because of the constraint of space shuttle launches on RNS turnaround time and the multiple rendezvous and docking requirements of the space shuttle to the RNS, the single uninterupted transfer of propellant to the RNS is the preferred mode.

If the entire stage is to be disposed of at the end-of-life, the energy and propellant requirements are minimal for injection to heliocentric orbit from lunar or synchronous orbit. Use of an auxiliary tank for disposal of the stage to heliocentric orbit is preferred over the use of the space tug unless the space tug is being disposed of as well.

Results of the 1985 lunar mission analysis indicate the NASA guideline mission appears to be unduely severe and it is recommended the NR lunar mission model be used as a baseline for reporting RNS performance. 


\section{CONCLUSIONS AND RECOMMENDATIONS}

- DESIGN OF LUNAR SHUTTLE MISSIONS FOR REPEATING FLIGHT CHARACTERISTICS IS PRACTICAL

- MULTIBURN TLI, LOI, AND TEI ARE HIGHLY ADVANTAGEOUS

- SOME CONTEMPLATED PAYLOADS EXCEED $300 \mathrm{~K}$ SIZED RNS CAPABILITY

- MAINTENANCE ELEMENT REQUIRED IN RNS OPERATIONS ORBIT

- QUALITATIVE STATUSING PERFORMED BY ON-BOARD CHECKOUT EQUIPMENT

- SINGLE UNINTERRUPTED TRANSFER OF PROPELLANT TO RNS PREFERRED

- HELIOCENTRIC ORBIT DISPOSAL OF STAGE FROM LUNAR OR SYNCHRONOUS ORBIT PREFERRED

- DISPOSAL OF ENGINE ALONE TO HELIOCENTRIC ORBIT PREFERRED USING AUXILIARY TANK MODULE

- RECOMMEND USE OF NR MISSION MODEL AS PERFORMANCE BASELINE

- RECOMMEND AUTONOMOUS RENDEZVOUS AND DOCKING WITH MANUAL OVERRIDE 


\section{REMAINING ACTIVITIES}

Reference trajectories will be developed for the first and second burns of the equatorial synchronous orbit shuttle mission with an optimized thrust attitude history. Emphasis will be given to identifying distinctive attitude requirements imposed by the included plane change.

In-house study of manned Mars mission configurations parallel the Phase II contract effort. In the remaining Phase III study, the departure stage and sizing analysis will be extended for a representative reference mission. The critical sensitivity of Earth departure weight will be established for the departure configuration. Conditions permitting use of common tank capacities for enroute and departure modules will be developed.

The Information Management System (IMS) concept for the RNS vehicle will be developed and expanded to encompass data and information management as sociated with on-board control, information management, ground network and/or satellite communications, remote commands, and identification of total information management and data flow.

A mission operations analysis will be conducted to identify and define physical and functional interface requirements which the RNS will impose on other system elements currently included in NASA planning.

Functional flow diagrams and requirement allocation sheets (RAS) will be prepared for the reference missions. Primary emphasis will be placed on the Class I and Class II missions with Class III missions analysis limited to the level necessary to identify requirements over and above those of the primary missions, leading to the evolutionary development of an RNS for manned planetary missions.

The safety analyses will be expanded from Phase II to include potential nuclear and non-nuclear hazards associated with the entire operational sequence. Additional emphasis will be placed on the definition of specific safety requirements associated with orbital assembly, normal mission operations, maintenance and repair, stage disposal and mission abort operations for the selected design configuration.

Logistic requirements necessary to support the low Earth orbital operations at the propellant depot will be identified. These requirements will include expendables replenishment and maintenance support personnel.

Emergency operations will be postulated and procedures requiring development listed for unmanned and manned payloads such that hazards to flight personnel or Earth populace will be avoided or minimized. 


\section{REMAINING ACTIVITIES}

- SYNCHRONOUS ORBIT REFERENCE TRAJECTORIES

- MANNED MARS MISSIDN STAGE PERFORMANCE

- INFORMATION MANAGEMENT SYSTEM CONCEPT

- INTERFACES WITH OTHER SPACE SYSTEM ELEMENTS

- FINAL FUNCTIONAL FLOW DIAGRAMS \& RAS

- LOGISTICS REQUIREMENTS

- SYSTEM SAFETY REQUIREMENTS

- EMERGENCY OPERATIONS 


\section{BRIEFING OUTLINE}

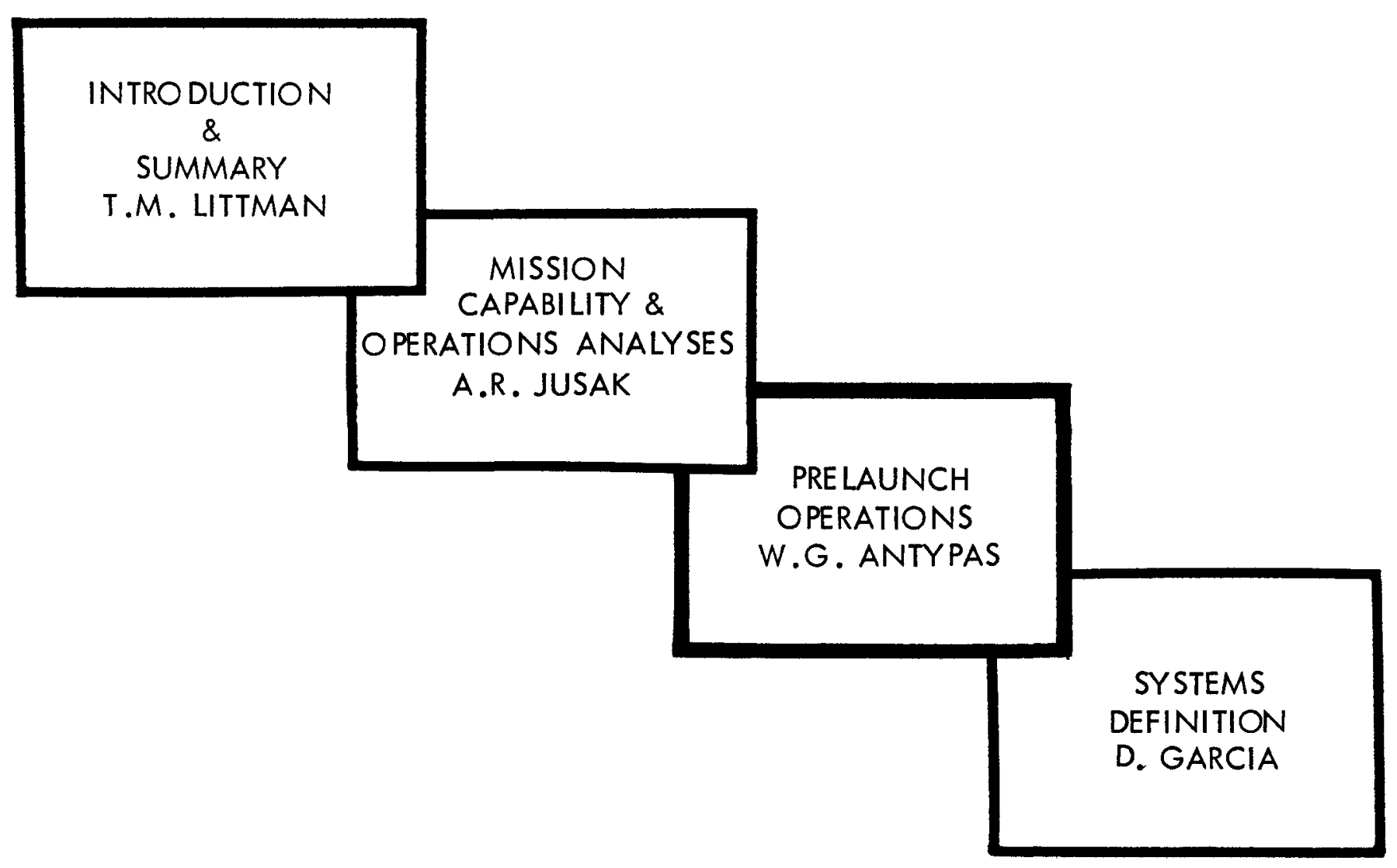


Phase III activities include two major areas: (1) re-evaluate, update, and expand results of Phase II, and (2) develop engine-stage-interstage mating alternates for new conical tank bottom configurations which include: (a) engine-stage mating site alternates, (b) engine-stage mating concepts, and (c) KSC facility limitations.

At the conclusion-of the Phase II study, a recommendation was made that cold flow and prelaunch flight readiness tests be conducted at KSC launch complex 34 or 37 . The recommendation was based on the availability of facility and GSE, minimum modifications, availability of manpower, and centralized operation. This recommendation is not applicable now mainly because LC 34 and 37 are being phased out. As a result of new site evaluation, NRDS seems to be most attractive and cost effective site to conduct cold flow development tests. Facilities, GSE, personnel and site support should be available when the first cold flow test article is available. Furthermore, the same GSE and checkout equipment can be used for CF/HT programs, resulting in more accurate evaluation of test results.

Assuming E/STS-2 activation in early 1977, and the availability of a cold flow test article early in 1977, it should be feasible to conduct the cold flow test program at NRDS. This can be accomplished by conducting an integrated CF/HT program using the same test article for cold flow and hot tests, therefore resulting in a better test mix of schedule compatibility. This integrated program mix could result in a longer hot test program which was established at 1.5 years during the Phase II study. In this schedule, the target Earth launch date for the first RNS test flight occurs before the end of 1979. This milestone is required to satisfy the NASA traffic model authorized by letter PD-SA-P-70-9, dated January 1970. Other constraints that established the hot test at 1.5 years are the IOC date, start of Phase B study date, manufacturing requirements, and test development requirements. Therefore, the integrated $\mathrm{CF} / \mathrm{HT}$ program will permit 3 years of combined testing.

The duration of the cold flow test program depends on the results of the initial tests and/or $\mathrm{CF} / \mathrm{HT}$ mix desired. It is to be noted that the use of NRDS for cold flow tests in conjunction with the hot test program is preliminary and will be reassessed when test analysis is performed.

As a result of the different RNS configurations under consideration and the VAB facility limitations, emphasis is directed towards engine-stage-interstage mating concepts, problems involved and constraints imposed on the stage and the engine, and the overall KSC mating operations. Also, consideration was given the stage transportation to establish transportation requirements imposed by the different stage configurations. 


\section{PRELAUNCH OPERATIONS ACTIVITIES}

- COLD FLOW DEVELOPMENT TEST SITE

- ENGINE-TANK MATING CONCEPTS \& FACILITIES

- STAGE TRANSPORTATION

- OPERATIONS TIMELINES 


\section{KSC PRELAUNCH OPERATIONS}

The KSC prelaunch operations functional flow diagram was updated to conform to the MSFC top level numerical coding format. Updating the functional flow sequence is based on the following information supplied by ANSC as a result of a meeting with their representative:

- Criticality test of reactor at WANL or assembled engine at NRDS

- No further criticality test required

- NRDS current baseline for reactor/engine assembly

- Engine to be shipped separately

- Nozzle extension, destruct system, and external shield (if required) to be shipped directly to KSC

o Peripheral poison wires to be removed prior to mating nozzle extension

Based on this information, the figure on the opposite page is a typical first level functional flow diagram representing the functions that will be conducted at KSC. The flow sequence does not take into consideration the operational modes or location of the functions, since the functional flow sequence is the same no matter where the operation is accomplished. Based on this functional flow, the different engine-stage mating concepts were developed and are discussed in the following charts. 


\section{KSC PRELAUNCH OPERATIONS}
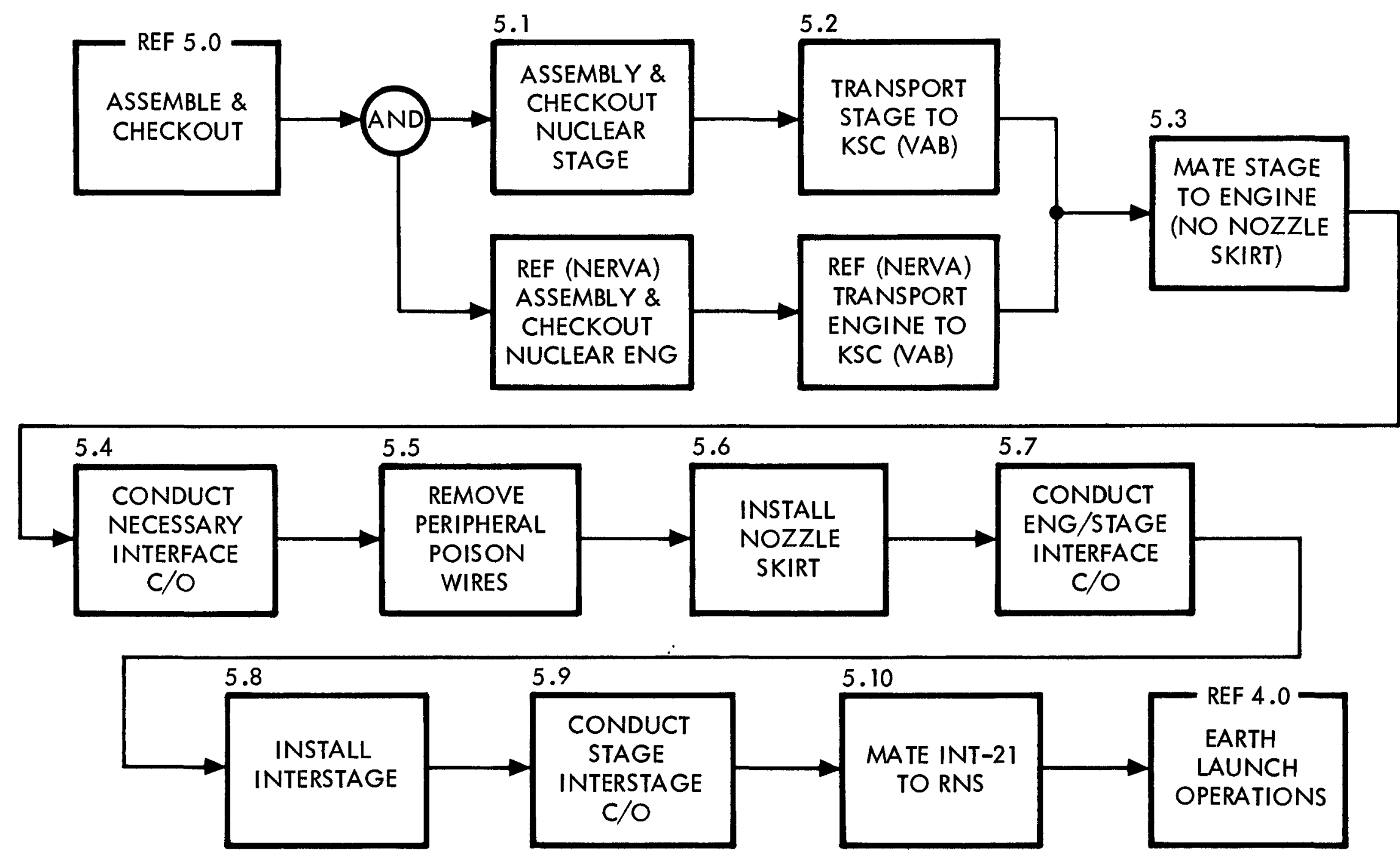


\section{ENGINE-TANK MATING CONCEPTS}

The current parametric design analysis of conical and hybrid tank configurations has necessitated the evaluation of alternate engine-tank mating concepts. The major concern is to develop engine-tank mating operations making maximum use of existing facility, GSE and transportation equipment, as well as minimizing the imposition of constraints and design requirements on the tank, the engine, and new handling equipment.

The limitations of the VAB facility and the inherent relative length of the aft bulkhead to the main tank makes it imperative that a number of techniques be considered to assemble and mate (in the VAB) the longest RNS stage possible. Based on these requirements, two alternates were considered, horizontal and vertical mating. In turn,each alternate is further divided into two operational concepts as shown on the opposite chart. The ground rule established by ANSC, that the peripheral poison wires should be removed before installing the nozzle extension, restricts the mating operation. Furthermore, the length of the interstage (length of aft bulkhead plus NERVA engine) in any instance exceeds the length of the main tank, therefore, imposing constraints design and handling/assembly problems. The different operational concepts that are considered are discussed and pictorially shown on the following pages. 


\section{ENGINE- TANK MATING CONCEPTS}

HORIZONTAL ASSEMBLY SEQUENCE

- TANK $\Rightarrow$ ENGINE $\Rightarrow$ NOZZLE EXTENSION $\vec{r}$ INTERSTAGE

- TANK $\Rightarrow$ INTERSTAGE $\Rightarrow$ ENGINE $d$ NOZZLE EXTENSION

VERTICAL ASSEMBLY SEQUENCE

- ONE PIECE INTERSTAGE

- SEMI-CIRCULAR (SEGMENTED) INTERSTAGE 
The tank with preinstalled thrust structure and forward and aft skirts is positioned in a horizontal attitude on a modified S-II transporter and moved into the low bay area of the vehicle assembly building. A work platform is installed adjacent to the aft bulkhead and positioned to accept the NERVA engine for installation. The engine is delivered on a mobile dolly with the counter balance inserted in the engine nozzle. Both units are lifted by the overhead bridge cranes, aligned, and attached to the thrust structure. The engine nozzle extension is lifted into position for installation with the engine utilizing the overhead bridge crane and handling slings. The interstage is placed on a handling and alignment dolly and moved in for installation with the aft skirt. A two level work platform will be used for this mating operation. After mating has been completed, a portable personnel access platform is moved into position for systems installation using the access door provided in the forward section of the interstage.

The RNS is now ready for mating with the booster stack. The RNS will be lifted by the overhead bridge cranes using special lifting devices attached to the forward and aft skirts.

(1) Transporter - for horizontal positioning and transporting stage.

(2) Engine counter balance - for stabilizing engine weights during single hoist pick-up.

(3) Engine nozzle structure - capable of handling inserted counter balance weight.

(4) Interstage alignment dolly - for moving and aligning the interstage in proper attitude with the stage aft skirt during mating.

(5) Interstage access door - for personnel and equipment access during system installation operations. 


\section{HORIZONTAL MATING}

(ENGINE/NOZZLE EXTENSION / INTERSTAGE)

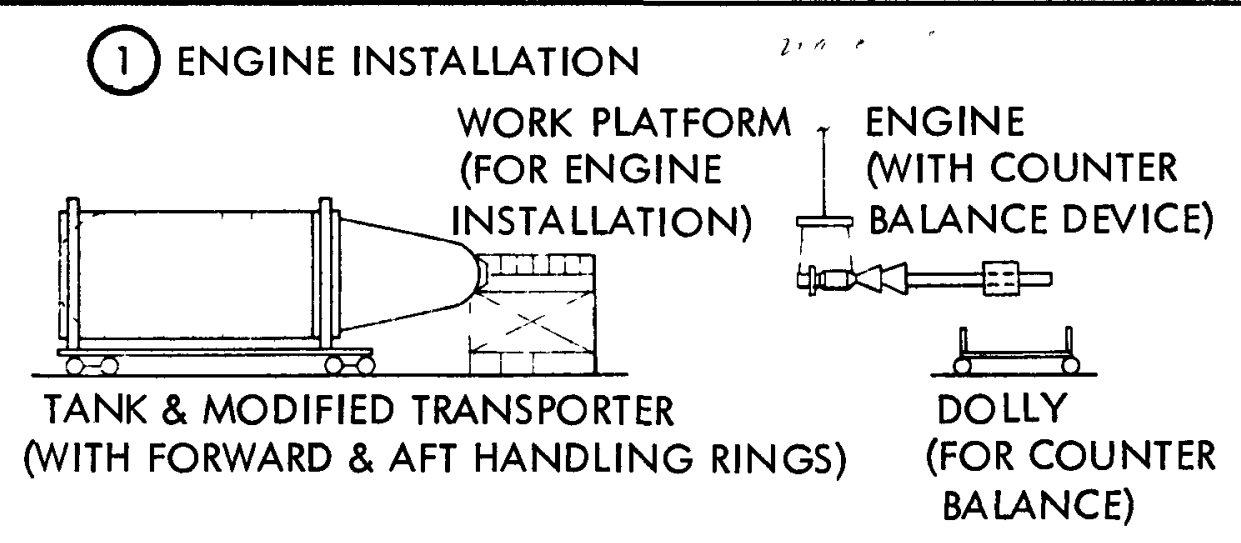

(3) INterstage installation

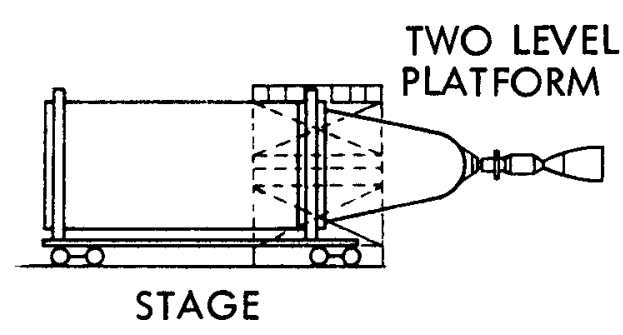

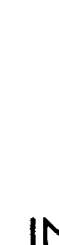

INTERSTAGE

(WITH HANDLING \& ALIGNMENT DOLLY)
(2) ENGINE NOZZLE INSTALLATiON

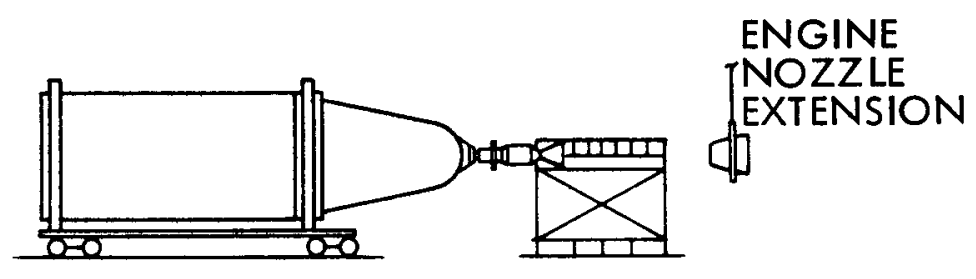

STAGE \& ENGINE

(4) SYSTEM INSTALLATION

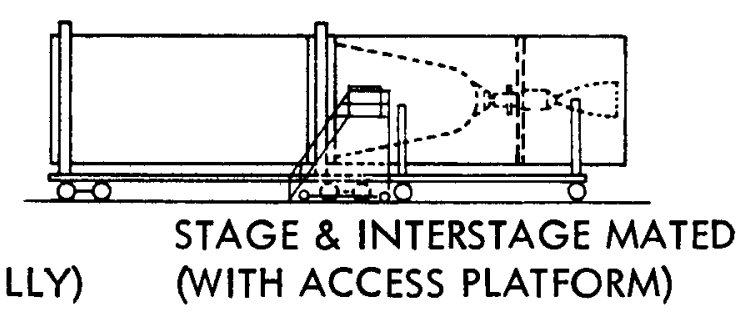

CONSTRAINTS \& DESIGN REQUIREMENTS

1. THRUST STRUCTURE TO CARRY LOAD OF ENGINE

2. ENGINE NOZZLE TO SUPPORT WEIGHT OF COUNTERBALANCE

3. FORWARD \& AFT SKIRT TO ACCEPT LIFTING \& ROTATING LOADS

4. INTERSTAGE ACCESS DOOR

5. OPERATION LIMITED TO LC 34 OR 37 \& TRANSFER AISLE 


\section{HORIZONTAL MATING (INTERSTAGE/ENGINE/NOZZLE EXTENSION)}

The tank with preinstalled thrust structure, forward and aft skirts is positioned in a horizontal attitude on a modified S-II transporter and moved into the low bay area of the vertical assembly building. A two level work platform is installed adjacent to the aft section of the tank and positioned to accept the interstage on a mobile alignment dolly for mating with the tank aft skirt. A portable personnel access platform is moved into position for preliminary systems installation using the access door provided in the forward section of the interstage. The engine is delivered on a mobile dolly with the counter balance inserted in the engine nozzle and both items are lifted into position by the overhead bridge crane, aligned, and the engine attached to the thrust structure. The portable personnel access platform will be used for personnel and equipment access during engine installation through the center access door in the interstage. The engine nozzle extension is lifted into position for installation with the engine utilizing the overhead bridge crane, handling slings and an aft work platform with an alignment positioning device. The personnel access platform is positioned with the forward access door and final systems installation is completed.

The RNS is now ready for mating with the booster stack. The RNS will be lifted by the overhead bridge crane using special lifting devices attached to the forward and aft skirts.

The following major components are required to support the stated operational sequence:

(1) Transporter - for horizontal positioning and transporting stage.

(2) Engine counter balance - for stabilizing engine weights during single hoist pick-up.

(3) Engine nozzle structure - capable of handling inserted counter balance weight.

(4) Interstage alignment dolly - for moving and aligning the interstage in proper attitude with the stage aft skirt during mating.

(5) Interstage access doors - for personnel and equipment access during systems and engine installation operations.

NOTE: An alternate method for engine installation can be incorporated by use of a catwalk and platform through the aft end of the interstage, rather than using a center access door in the interstage. 


\section{HORIZONTAL MATING}

(INTERSTAGE / ENG INE / NOZZLE EXTENSION)

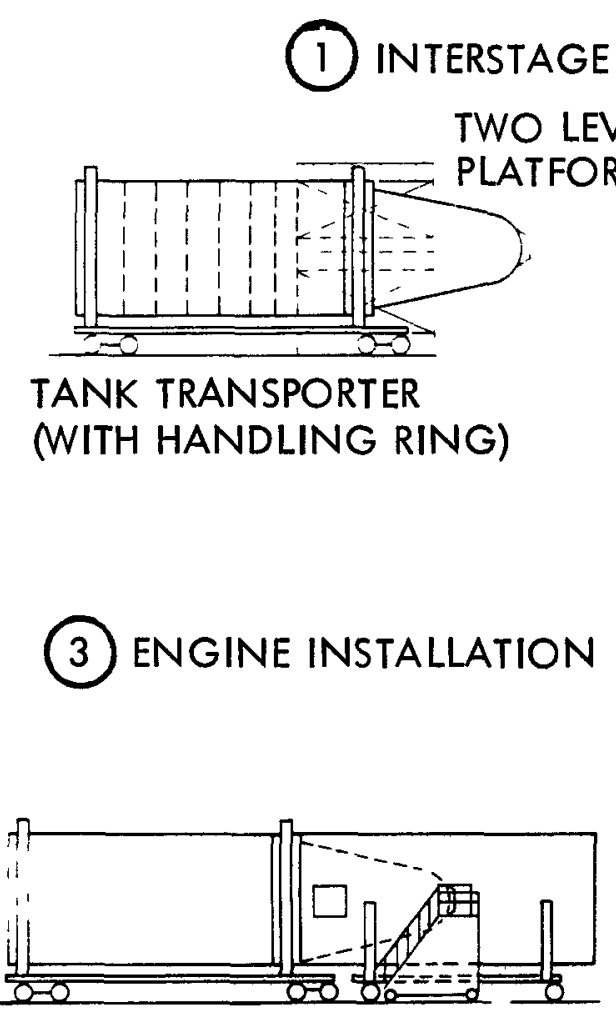

TANK \& INTERSTAGE

(WITH ACCESS PLATFORM)

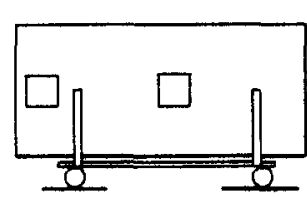

INTERSTAGE (WITH HANDLING \& ALIGNMENT DOLLY)
(2) INTERSTAGE SYSTEM INSTALLATION

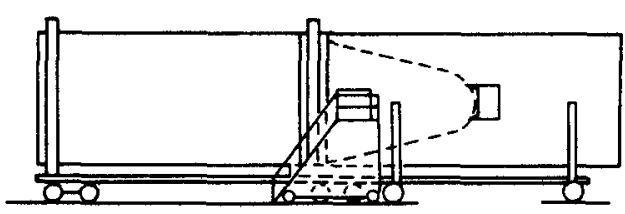

TANK \& INTERSTAGE MATED (WITH ACCESS PLATFORM)

\section{CONSTRAINTS \& DESIGN}

1. ENGINE/NOZZLE TO SUPPORT WEIGHT OF COUNTERBALANCE

2. INTERSTAGE ACCESS DOOR (ONE OR TWO)

3. FORWARD \& AFT SKIRT TO ACCEPT LIFTING \& ROTATING LOADS

4. OPERATION LIMITED TO LC 34 OR 37 \& TRANSFER AISLE 


\section{VERTICAL MATING (ENGINE/NOZZLE EXTENSION/INTERSTAGE)}

The tank with preinstalled thrust structure and forward and aft skirts is lifted from the transporter and positioned in the vertical tool in the vehicle assembly building high bay area. A work platform is installed inside the tool adjacent to the aft bulkhead for acceptance of the nuclear engine for installation. The engine is delivered on a portable dolly with a hydraulic lift platform for positioning and lifting the engine in place for attachment to the thrust structure. The engine nozzle extension is lifted into position for installation with the engine utilizing the portable hydraulic lift dolly. The interstage is placed vertically on a mobile dolly and work platform and moved into the tool with the stage raised by the overhead bridge crane to provide clearance between the interstage and the engine. The stage is lowered, aligned and mated with the interstage. After completion of mating and aft skirt and interstage, systems installation can be performed.

The RNS is now ready for mating with the booster stack. The RNS will be lifted by the overhead bridge crane using a special forward handling cone. The only major component required to support the stated operational sequence is a vertical tool for holding the stage in a vertical position during as sembly and mating operations. 


\section{VERTICAL MATING}

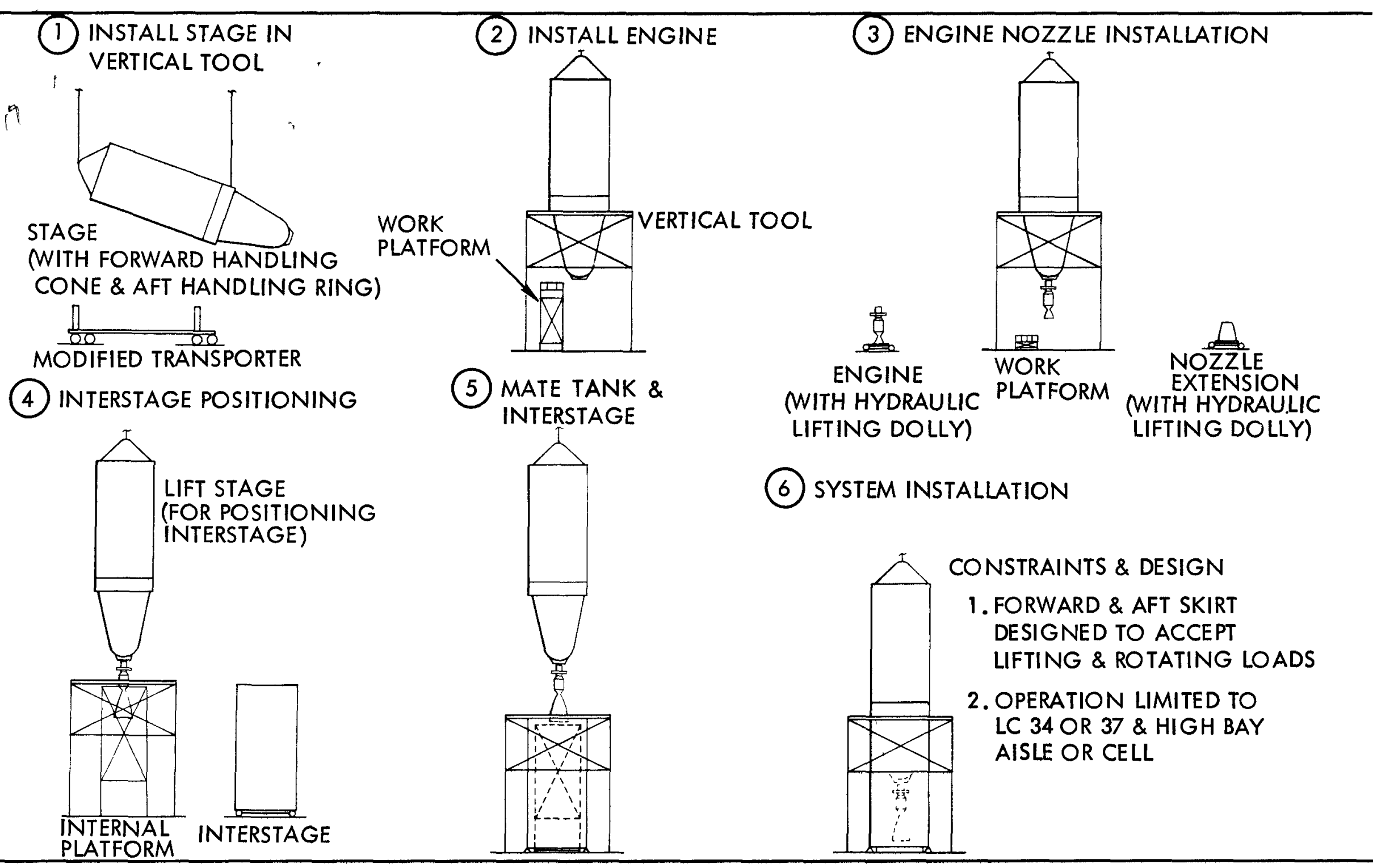


The tank with preinstalled thrust structure, forward and aft skirts is lifted from the transporter and positioned in the vertical tool in the vertical assembly building high bay area. A work platform is installed inside the tool adjacent to the aft bulkhead to accept the nuclear engine for installation. The engine is delivered on a portable dolly with a hydraulic lift platform for positioning and lifting the engine in place for attachment to the thrust structure. The engine nozzle extension is lifted into position for installation with the engine utilizing the portable hydraulic lift dolly. The interstage forward section is placed vertically on a mobile dolly and moved into the tool with the stage raised by the overhead bridge crane, the stage is lowered and mated with the forward interstage section. The interstage aft section is placed vertically on a mobile dolly and work platform and moved into the tool with the stage raised by the overhead bridge crane, the stage is lowered and the two interstage sections mated. The systems installation operation is then accomplished.

The RNS is now ready for mating with the booster stack. The RNS will be lifted by the overhead bridge crane using a special forward handling cone. The only major component required to support the stated operational sequence is a vertical tool for holding the tank in a vertical position during assembly and mating operations.

There is not too much difference between segmented and one piece interstage assembly requirements. However, a segmented interstage is considered to determine whether it is easier to mate with the tank than a one piece interstage aperation. Furthermore, the transportation of a one piece interstage might prove to be more critical and could impose a transportation problem.

The segmented interstage could be either cylindrical or semi-cylindrical. The main difference between the two is that the latter can be assembled without lifting the stage the height of the interstage for insertion inside the one piece interstage. Rather, the semi-cylindrical interstage can be used as a clam shell around the aft bulkhead and the engine for mating. The drawing does not reflect the semi-cylindrical assembly sequence. This will be assessed in the future. 


\section{VERTICAL MATING}

(ENGINE/NOZZLE EXTENSION/SEGMENTED INTERSTAGE)

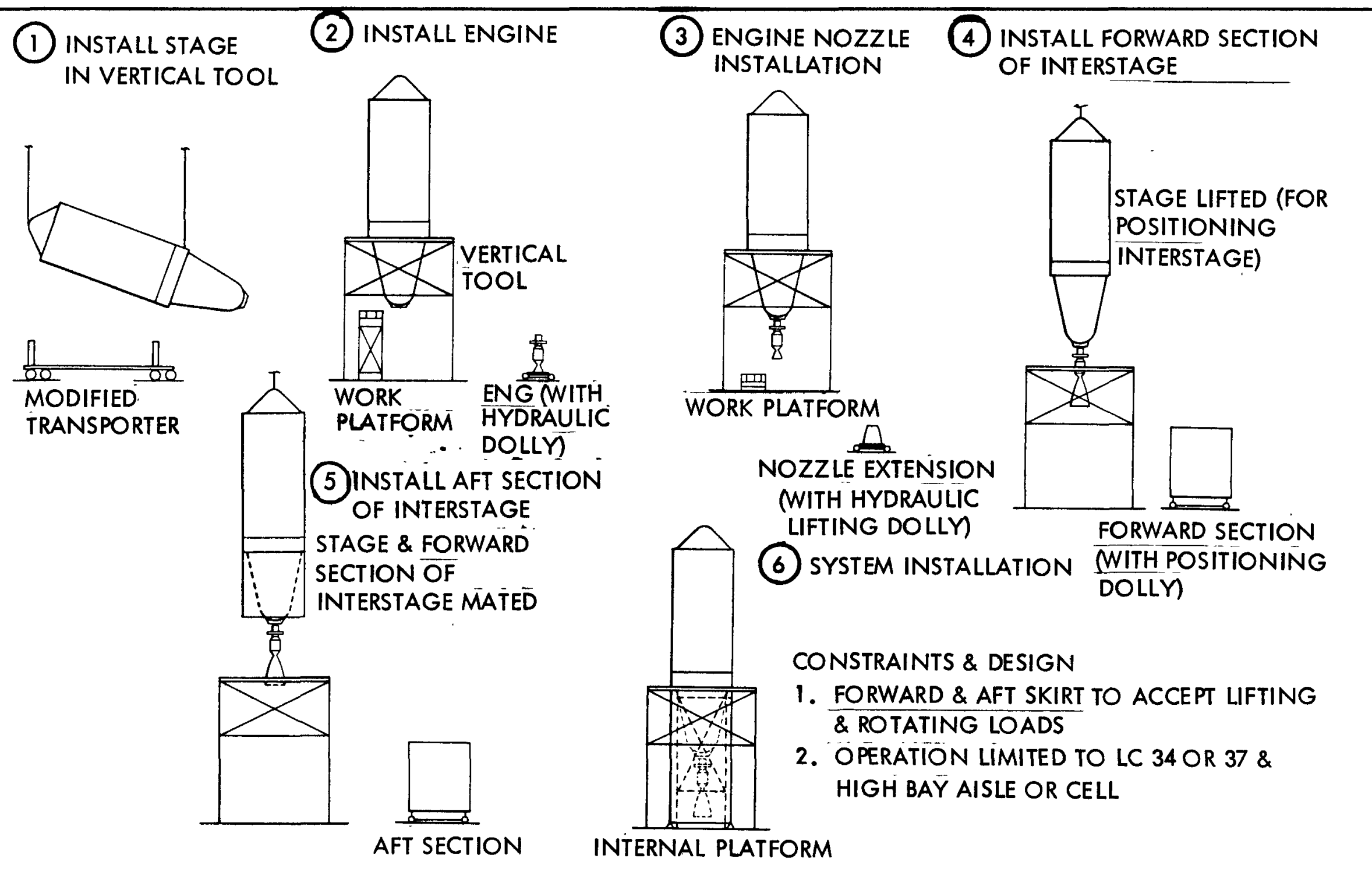




\section{VEHICLE ASSEMBLY B UILDING}

The isometric picture of the VAB is presented to clarify the operational flow sequence of the different engine-tank mating concepts. For example, in order to assemble and stack an INT-21/RNS on the mobile launcher (ML), the hammerhead crane should be rotating so that it will not interfere with the vehicle height. The stacked vehicle shown on the ML represents the maximum size RNS vehicle that can be accommodated in the VAB or an equivalent configuration length of approximately 190 feet. The vehicle shown in the high bay aisle is a completed RNS ready to be stacked on top of INT-21. This RNS is assembled and mated at one of the following locations: (1) at LC 34 or 37, (2) horizontally mated in the low bay transfer aisle, (3) horizontally or vertically mated in the high bay aisle, and (4) vertically mated in the unequipped high bay.

Based on the Phase B space shuttle study, preliminary analysis shows that for 25 launches per year the three existing high bays and two additional areas adjacent to high bays 3 and 4 are required. The study assumed increasing the rate to 75 launches per year, then three existing high bays and six additional cells adjacent to high bays 3 and 4 will be required. In either case, one high bay and high bay aisle may be available for the RNS program. It is to be noted that this is a preliminary analysis. Presently, several groups are evaluating a number of potential sites for the space shuttle program. The alternate operational concepts discussed assumes the VAB is available for the RNS program. 


\section{VEHICLE. ASSEMBLY BUILDING}

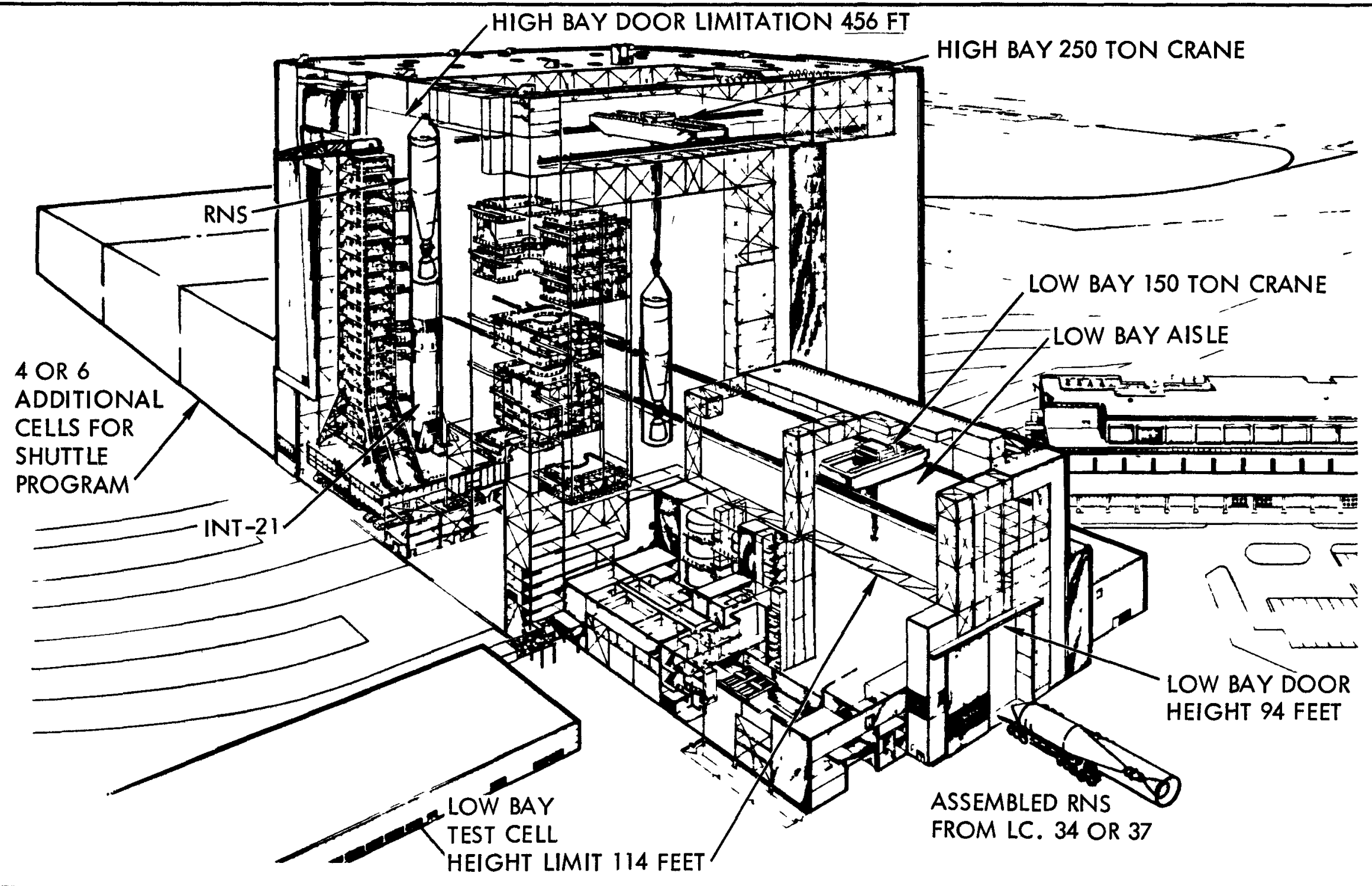




\section{ALTERNATE MATING SITES}

The following represents the four alternate prelaunch engine-tank-interstage mating sites that were evaluated: (1) mating in low bay aisle and checkout in test cell, (2) mating and checkout in low bay aisle, (3) mating and checkout at LC 34 or 37, and (4) mating and checkout in high bay (presently unequipped).

Vertical or horizontal mating in low bay aisle and checkout in S-II test cell will limit the RNS size that can be accommodated to approximately 100 feet (including stage support stand) without modification to the test cell roof.

Conducting the mating and checkout in the low bay aisle will limit the configuration to approximately 160 feet (including the stage support dolly or stand) depending on the mating concept used.

Vertical mating at LC 34 or 37 can be accomplished without interference with other programs or schedule impact. However, the length of the stage that can be accommodated is limited by the transportation mode and the VAB operation. If the mated stage is transported to the VAB in $a$ vertical attitude, the following requirements are essential.

(1) Transportation equipment similar to that of Saturn V (crawler transporter), but of a somewhat smaller size

(2) Modify roads, bridges, if any, to accommodate the transporter system

(3) Remove and relocate utility lines to clear the way for approximately 200 foot high stage

(4) Possibly new tie-down system, which is not required if transported horizontally

(5) New umbilical tower to support the stage as well as the umbilicals

High bay (presently unequipped) engine - tank -interstage operation is limited to vertical mating. The maximum RNS configuration that can be mated in the high bay and then transferred to be stacked on top of INT-21 is limited to 190 feet regardless of the type of interstage configuration. The length of the RNS is limited by the height of the mobile launcher, the S-IC stage, S-II stage, and high bay door clearance height of 456 feet.

On completion of engine-stage-interstage mating and checkout, the RNS vehicle will be lifted over the 170 foot transfer aisle/high bay partition and stacked on top of INT -21 . 
This table presents existing VAB facility and GSE limitations that will influence the RNS configuration that can be accommodated at each of the possible operational locations. The high bay door clearance of $456 \mathrm{feet}$ is the main limitation to the length of an RNS that can be assembled in the VAB. The length of the RNS is limited by the height of the mobile launcher (47 feet), the S-IC stage (138 feet), and S-II stage ( 81.5 feet) for a total height of 265.5 feet less 9.5 feet S-IC engines which extend below the ML platform, or a total stack height of $\sim 256$ feet. Based on the assumption that ten feet of clearance is necessary to roll out the ML with the INT-21/RNS, establishes a total RNS length of 190 feet (including the nose cone of $\sim 25 \mathrm{feet}$ ). Assuming it is possible to mate the nose cone outside the VAB (by incorporating a crane over the high bay door), the RNS length that can be handled will increase to 215 feet outside the VAB or 190 feet (without nose cone) within the VAB.

In all cases of operational concepts discussed previously, whether the engine-tank -interstage are mated horizontally or vertically, with one piece or segmented interstage, the maximum RNS vehicle that can be accommodated in the VAB is limited to 190 feet.

The above limitations apply only to stage configurations requiring main propellant tank/engine/interstage mating on the ground. For those configurations employing orbital assembly of the operational system, the two dimensional limits are 160 and 190 feet if assembly and checkout operations are conducted in the low bay aisle and high bay, respectively. This is approximately 35 feet longer than launching an assembled engine-stage-interstage. It is to be noted that in order to get maximum benefit of a stage length when stage is launched upside down, the nose cone has to be mated to the stage before stacking the stage on top of INT-21 booster. 


\section{VAB FACILITY LIMITATIONS}

\begin{tabular}{l|c|c|c}
\multicolumn{1}{c|}{ MAJOR ITEMS } & $\begin{array}{c}\text { LOW BAY } \\
\text { AISLE }\end{array}$ & $\begin{array}{r}\text { LOW BAY } \\
\text { TEST CELL }\end{array}$ & $\begin{array}{c}\text { HIGH } \\
\text { BAY }\end{array}$ \\
\hline TRANSFER AISLE (FT) & & & 525 \\
HEIGHT & 210 & & 92 \\
WIDTH & 92 & & 715 \\
LENGTH & 715 & & 250 \\
BRIDGE CRANE (TONS) & 175 & 5 & 462 \\
CRANE HOOK HEIGHT (FT) & 166 & 114 & 456 \\
MAXIMUM DOOR CLEARANCE (FT) & 94 & 116 & 47 \\
CRAWLER TRANSPORTER HEIGHT (FT) & & & 409 \\
MAXIMUM INT-2I/RNS STACKED (FT) & & & 209 \\
S-IC/S-II STACKED ON MOBILE LAUNCHER & & & \\
(FT) & & & \\
MAXIMUM RNS CONFIGURATION LENGTH (FT) & 160 & 100 & \\
\hline
\end{tabular}




\section{MATING SITES COMPARISON}

The table presents the evaluation of the four operational sites and mating concepts considered. The check mark ( ) represents most attractive option and the " $\mathrm{X}$ " the least attractive one. There is no designation for options which are of intermediate attractiveness.

It is to be noted that engine-tank mating complexity, projected availability of facility, existing facility and GSE limitations, and new handling and assembly tools were considered most pertinent in ranking the sites. To accommodate a maximum RNS vehicle configuration length with minimum operational complexity and facility modification, the high bay site seems to be most attractive. Second best is a combination of low bay/high bay transfer aisle operations. In this case the tank engine-interstage is mated in a horizontal attitude and then erected vertically in the high bay aisle where it is lifted by the 250 ton crane and stacked on the INT-21. The horizontal mating will impose major new handling tool requirements and in some cases impose design requirements on the enginestage thrust structure. Furthermore, the overall horizontal mating operation is more complex than that of the vertical. 


\section{MATING SITES COMPARISON}

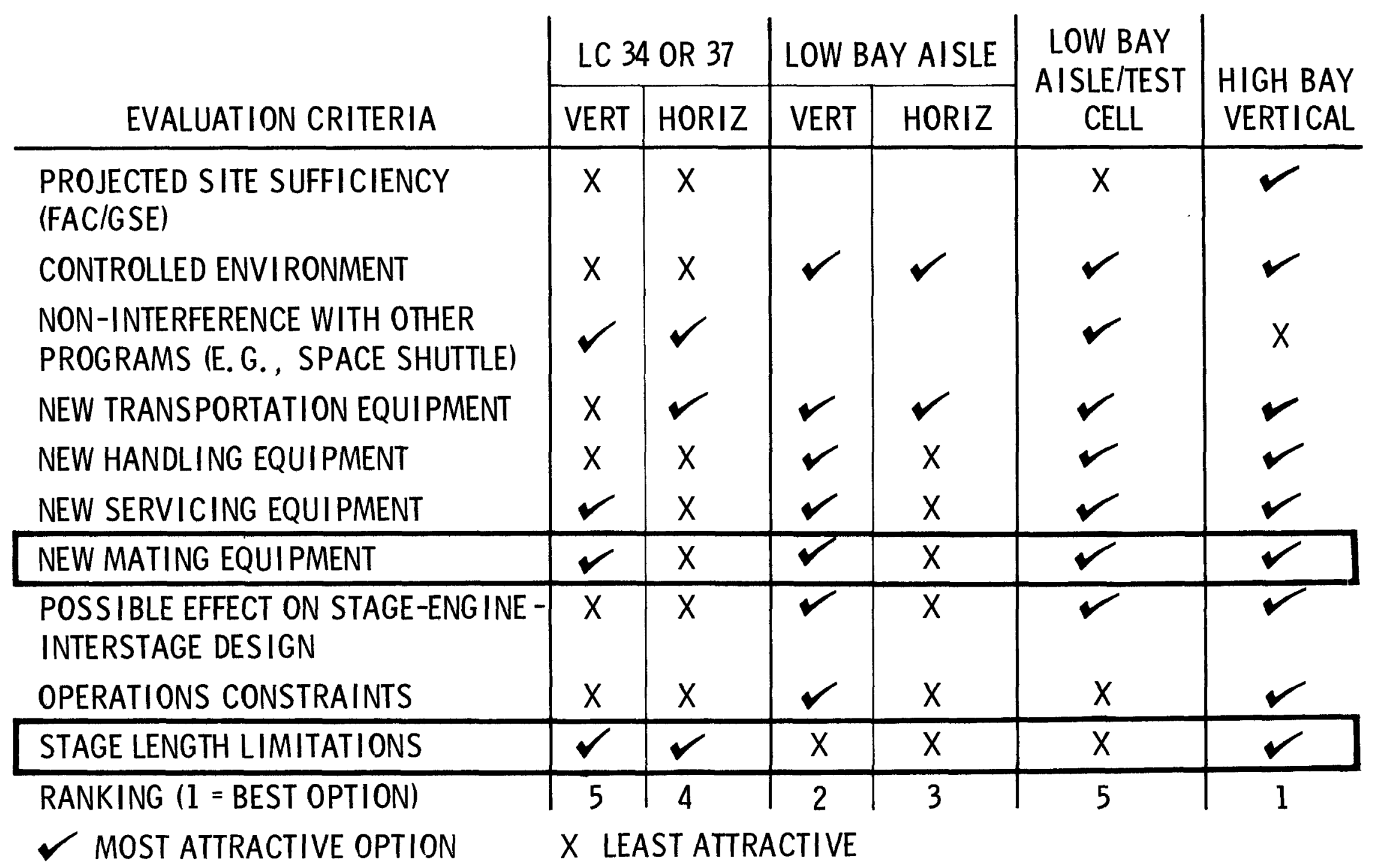


Evaluation of RNS stage transportation requirements shows that most of the configurations under consideration can be transported with the existing transporter with no modification to the structure. The S-II pallet is approximately 70 feet long (forward to aft support). The pallet can be extended approximately 20 feet without structural redesign. However, if it is necessary that the pallet extend beyond the 90 foot length, a new pallet would be required. The pallet fabrication is a low-cost item with respect to the overall transporter cost.

Preliminary assessment of HPI installation conducted by manufacturing and transportation groups shows that it is feasible to install the HPI at the manufacturing site. This would preclude a requirement for a total HPI application operation at KSC. However, some equipment will be required for repairs in case of damage during shipment and subsequent handling operations at KSC. This is analogous to current operational procedures.

Transporting the tank with HPI installed will follow the same procedure used in transporting an S-II stage from the manufacturing site to KSC. The transportation analysis performed showed that the tank will have approximately eight feet of aft skirt. All but 2 - 3 feet of the aft skirt will be covered with HPI. Based on this requirement, the tank support aft ring will be attached to the aft section (2 - 3 feet) of the aft skirt. This will permit the use of the existing transporter as is or modify the pallet as required by the tank configuration.

Based on KSC facility limitations, the longest conical tank bottom configuration that can be mated in the VAB is 190 feet. The stage weight of a typical $12^{\circ}$ half cone angle and 50 -inch cap radius without engine and interstage is approximately 52, 400 pounds. The stage weight plus the required transportation equipment will total about 70,000 pounds. This is within the existing transporter design limits.

The figure on the opposite page is a typical conical tank configuration loaded on the existing transporter. The main tank plus the aft skirt is about 65 feet long. The aft skirt will be used to attach the aft support ring. The cantilevered aft bulkhead is approximately 65 feet. In this case the loading on the forward axle is approximately 34,675 pounds and that of the aft axles approximately 35,340 pounds. Both loads are below the axles design loading capability. 


\section{OFF-SITE TANK TRANSPORTER UTILIZATION}

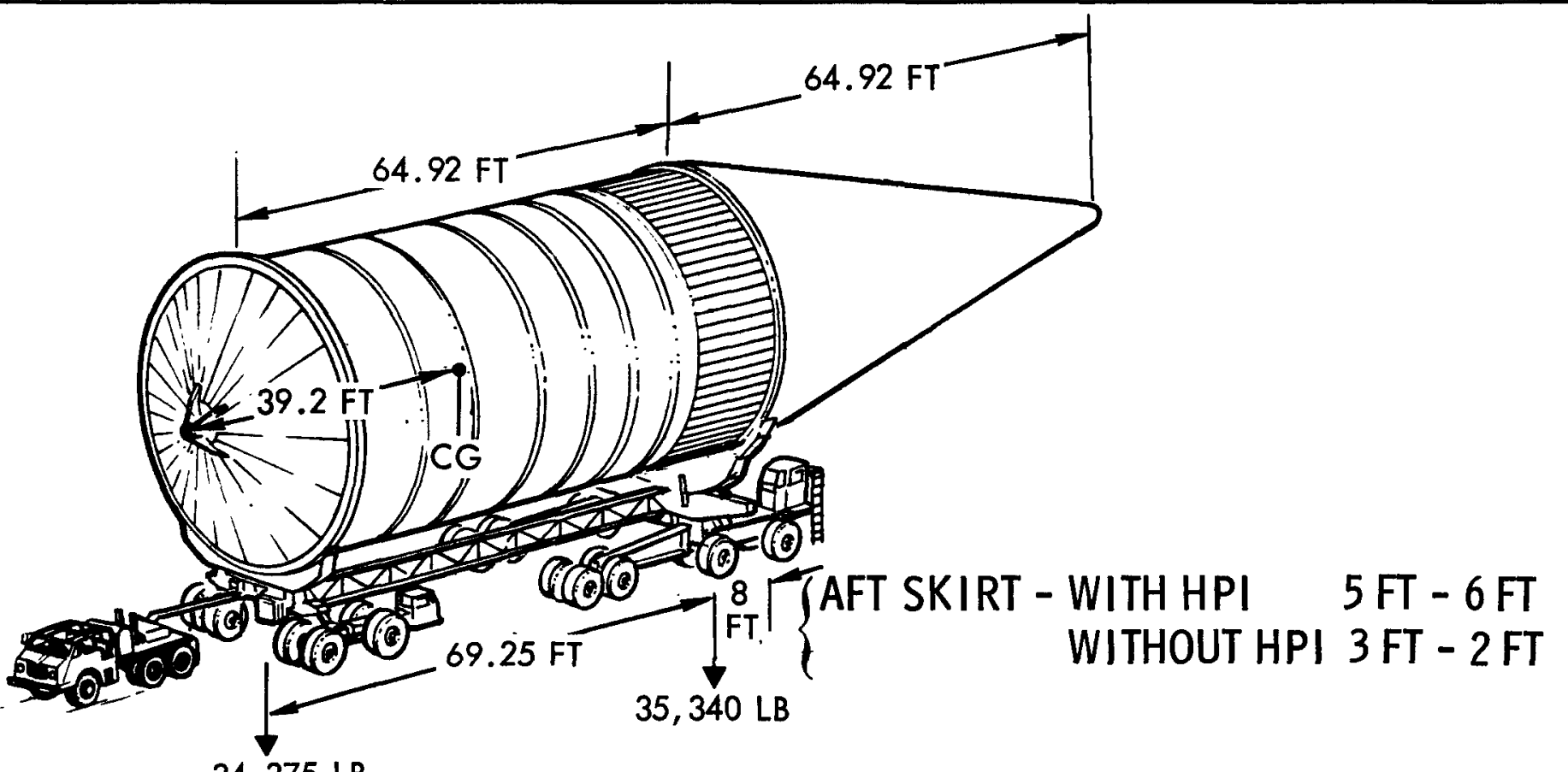

EXISTING TRANSPORTER DATA 34,375 LB

- AXLE LOADING (LB)

FRONT (ONE AXLE) REAR (TWO AXLES) EACH

- WHEEL BASE (FT)

'RNS STAGE CONFIGURATION

- HALF CONE ANGLE (DEGREES) 12

-CAP RADIUS (INCHES)

\section{CONCLUSION}

64,900

60,500

69.25

50
- NO TRANSPORTATION CONSTRAINTS AS A RESULT OF HPI INSTALLATION AT MANUFACTURING SITE

- NO REASONABLE CONSTRAINT ON STAGE LENGTH WITHOUT ENGINE MATED

- PREVIOUS ROAD TRANSPORTATION STUDY STILL VALID 
This figure represents the transport of an RNS (mated engine-tank) at KSC. For consistency purposes, the same typical configuration (12 degrees half angle and 50 inches cap radius) was evaluated. The weight of the tank, engine, interstage and the required equipment total about 135, 300 pounds. Based on c.g. Location approximately $(71$ feet from $A U)$ of the total system and the allocated weights, the existing transporter pallet needs to be spliced and extended about 20 feet, that is extending the total pallet length from 70 to 90 feet.

By extending the pallet length, a new aft support ring will be designed and installed on the interstage approximately 20 feet from the aft skirt and interstage interface location. In this manner, the c. g. will be located between the two axles for adequate load distribution. Based on preliminary analysis, the loading on the forward axle is approximately 37,435 pounds, and on the rear axles approximately 97, 875 pounds. Both loads are within the transporter design limits.

Preliminary calculations show that the RNS stage weight distribution will not exceed the transporter axle design loading. Also, the analysis showed that the cantilevered aft bulkhead will not impose any constraint on the transporter or stage design. However, if final analysis of the recommended stage shows that the aft bulkhead might impose transportation constraints or stage design requirements, a design will be established to extend the pallet length so that the aft bulkhead will be properly supported. 


\section{ON-SITE STAGE TRANSPORTER UTILIZATION}

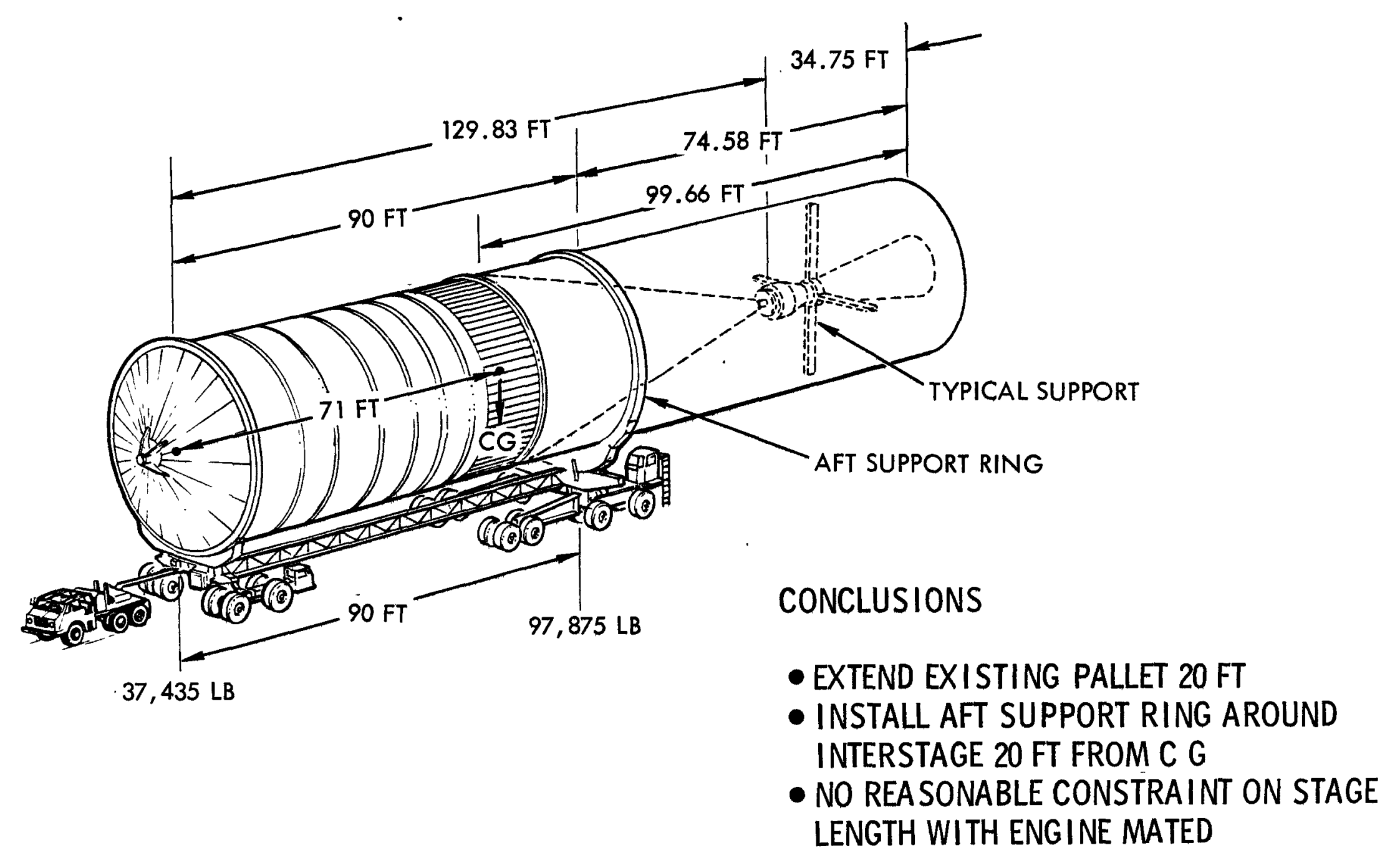




\section{VAB OPERATION TIMELINES}

Timelines developed during Phase II study have been re-evaluated and where necessary updated. Transportation timelines from the manufacturing site to KSC have remained unchanged. Land transportation of an RNS stage from Seal Beach to NRDS will require 7 - 10 days depending upon the route alternate. The previous road transportation study was re-evaluated with respect to the new stage configurations and found to be still valid.

Based on the updated functional flow diagram presented previously, VAB operation timelines have been updated. These timelines represent the operations conducted on all the stages from arrival at VAB to completion of assembly, mating, and checkout of the launch vehicle. The timelines do not differentiate between horizontal or vertical mating of the engine and tank. This will be accomplished when the operational concept is finalized. The updated timelines are based on Saturn V program, S-II stage operations, and in-house studies related to RNS stage. Where necessary, timelines were estimated.

The operations at the VAB are based on a one shift - five-day work week. The total VAB operations timeline of 35 - 40 days is not a cumulative total, since some S-IC, S-II, and RNS operations are simultaneously performed. 


\section{VAB OPERATION TIMELINES}

KSC (VAB) OPERATION

$S-11$

RNS

S-IC

S-II

RNS

INT-21/RNS

LOW BAY/TEST CELL

LOW BAY/TEST

HIGH BAY

HIGH BAY*

HIGH BAY*

HIGH BAY

TOTAL VAB CALENDAR TIME

* STACKING \& CIO OPERATION

WORKING DAYS

11

15

25

21

19

28

$35-40$ 
Based on the VAB facility limitations and the preliminary operational analyses, the following conclusions can be derived:

- Maximum RNS length that can be mated at LC 34 or 37, transported horizontally, and erected to a vertical attitude in the high bay aisle is limited by the VAB operation to 190 feet.

- The maximum RNS length that can be accommodated in the low bay using a segmented interstage is 160 feet including stage support dolly.

- None of the RNS conical tank bottom configurations under consideration at the present time can be mated vertically in the low bay aisle (using a one piece interstage).

o Engine -tank - interstage mating in the high bay aisle or high bay cell will accommodate a 190 foot RNS configuration.

o Engine -tank - interstage mating in a vertical or horizontal attitude will not affect the maximum RNS length.

- The length of the RNS is limited by the high bay door clearance of 456 feet.

- RNS height might be increased by approximately 25 feet if it is possible to mate the nose cone outside the high bay door.

o Horizontal mating will require special handling and mating equipment and will complicate the operation.

- In certain mating concepts, the operation will impose design constraints on the thrust structure, engine nozzle and possibly the interstage.

- Minor modification to existing transporter if pallet extension is limited to approximately 20 feet.

- No transportation constraints as a result of HPI installation at manufacturing site.

- RNS tank can be transported with no reasonable constraint on stage length without engine.

- RNS stage can be transported (on site) horizontally with no reasonable constraint on stage length with engine.

o Previous road transportation study results (Seal Beach to NRDS) still valid. 


\section{SUMMARY \& CONCLUSIONS}

VAB FACILITY LIMITATIONS (FT)

- LOW BAY AISLE

- HIGH BAY OR HIGH BAY AISLE

ENG INE-STAGE MATING

HORIZONTAL CONCEPT

- REQUIRES SPECIAL HANDLING AND POSITIONING EQUIPMENT

- IMPOSES DESIGN CONSTRAINT ON THRUST STRUCTURE

- COMPLEX MATING OPERATION

- IMPOSES NOZZLE DESIGN CONSTRAINT

VERTICAL CONCEPT

- IMPOSES LEAST FACILITY AND GSE REQUIREMENTS

- RELATIVELY SIMPLER MATING OPERATION

MAXIMUM RNS LENGTH (FT)

TRANSPORTATION

- NO MAJOR STAGE TRANSPORTATION CONSTRAINTS

- NO REASONABLE CONSTRAINT ON STAGE LENGTH WITH OR WITHOUT ENGINE MATED

- PREVIOUS ROAD TRANSPORTATION STUDY STILL VALID

- MINIMUM MODIFICATION TO EXISTING TRANSPORTER 


\section{R E M A INING ACTIVITIES}

Based on the final KSC operational concept, functional flow diagrams, listing of requirements and procedures will be updated. Manpower requirements will be reviewed and where necessary revised according to the development test and operational program. Facility and GSE modification requirements will be deferred until RNS stage configuration is better defined and ground operational concept selected.

Test requirements investigation will be directed towards identifying and establishing incremental development test alternatives, and conducting tradeoff analysis to determine the most feasible and cost effective alternate that will satisfy the operational program.

Manufacturing requirements will include the assessments of manufacturing techniques required for the fabrication of an RNS tank. These techniques will be evaluated in light of existing facility and tooling items at the recommended site. 


\section{REMAINING ACTIVITIES}

EARTH LAUNCH OPERATIONS

- FINALIZE FLOW DIAGRAMS

- IDENTIFY OPERATIONS REQUIREMENTS

- PREPARE LIST OF MAJOR PROCEDURES

- IDENTIFY MAJOR FACILITY \& GSE REQUIREMENTS \& MODIFICATIONS

- EVALUATE MANPOWER REQUIREMENTS

TEST REQUIREMENTS

- IDENTIFY \& ESTABLISH INCREMENTAL DEVELOPMENT TEST ALTERNATIVES

- CONDUCT TRADE-OFF ANALYSIS TO DETERMINE MOST FEASIBLE \& COST EFFECTIVE ALTERNATE THAT WILL SATISFY OPERATIONAL PROGRAM

- DEFINE PRELAUNCH CHECKOUT PHILOSOPHY \& ITS INFLUENCE ON KSC OPERATION

MANUFACTURING REQUIREMENTS

- ASSESS MANUFACTURING TECHNIQUES FOR PHASE III CONFIGURATIONS 


\section{BRIEFING OUTLINE}

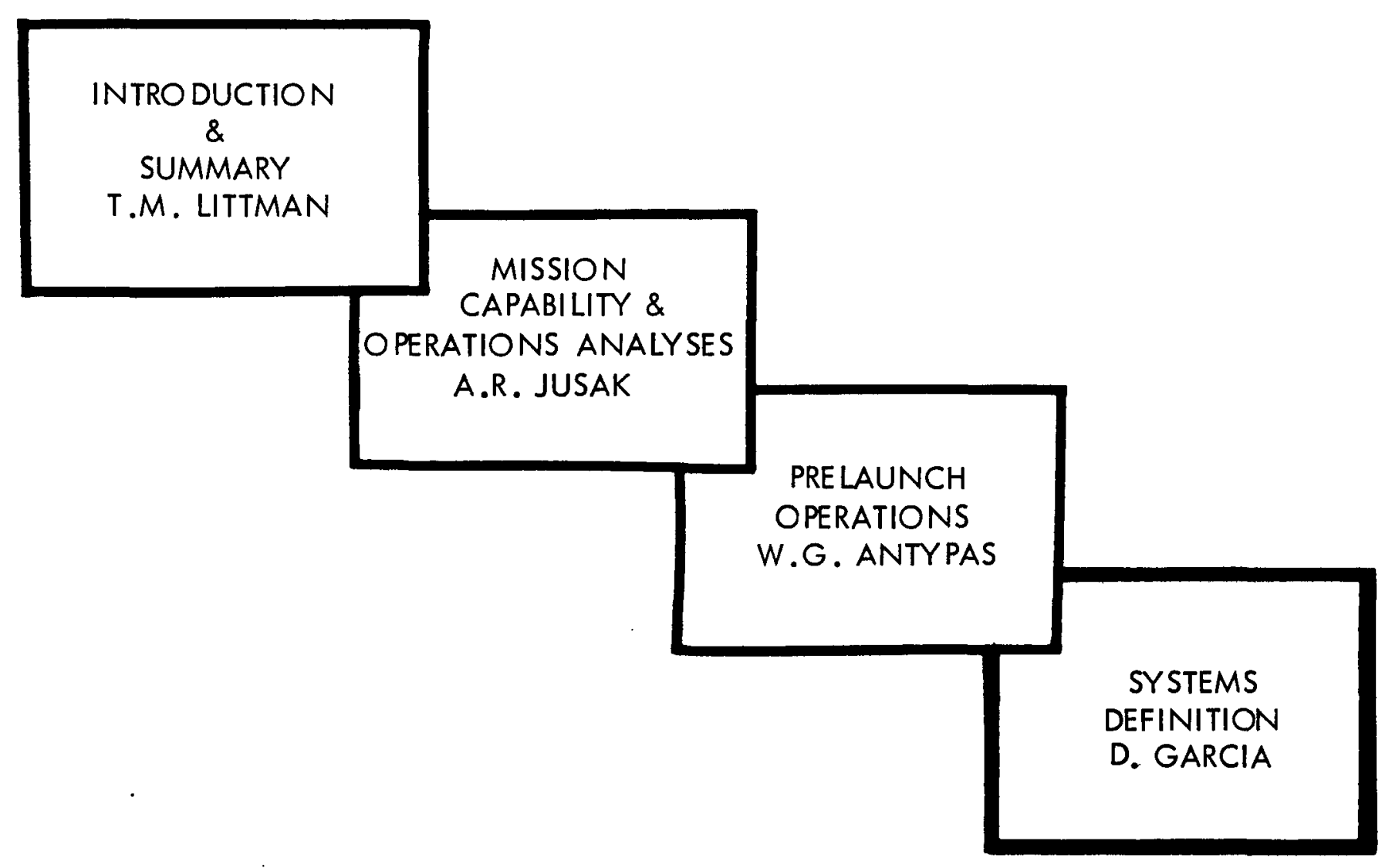




\section{SYSTEM DEFINITION ACTIVITIES}

The present system definition effort encompasses a wide range of activities. These include parametric analyses where the dimensional characteristics of stage design concepts are varied to assess the influence in structure, radiation dose to the tank top, and external shield weight. Loading impact on the launch vehicle also has been assessed trading stage geometry, boost mode, and assembly mode. These analyses together with the results of interface design definition, mission operation requirements, and independent but interrelated thermodynamics, propellant management and astrionics investigations are being integrated into total systems for baseline design(s) selection, and ultimately reference vehicle definition. 


\section{SYSTEM DEFINITION ACTIVITIES}

- CONFIGURATION PARAMETRIC ANALYSIS

- TRADE STUDIES

- SUBSYSTEMS DESIGN

- INTEGRATED DESIGN STUDIES

- REFERENCE VEHICLE DEFINITION 
The configurations under consideration consist of the dual cell elliptical concept and variations of the conical aft bulkhead designs as shown in the accompanying figure. The former is the resulting baseline from the previous contracted activities and will not be further investigated pending the outcome of current independent radiation analyses.

The single cell conical configuration is currently receiving the core of the design analyses. The parametric investigations include variations in half-cone angle from 5 to 15 degrees and cap radius from 25 to 125 inches. It is of importance to note that this configuration was investigated during the previous study contract and a baseline established at 15 degrees half-cone angle and 100 inches cap radius. The assessment of the lower range dimensional parameters is being emphasized to evaluate the reduction in radiation dose to the tank top; launch vehicle impact commensurate with alternate methods of launching the stage; and performance gains associated with reduction in external radiation shield. Resulting attractive arrangements of this basic concept will be further evaluated with the addition of an external small tank - hybrid design - as well as with a small inner tank - modified dual cell - to establish the performance and operational payoffs, if any, of the resulting systems. 


\section{PHASE III RNS CONFIGURATIONS}

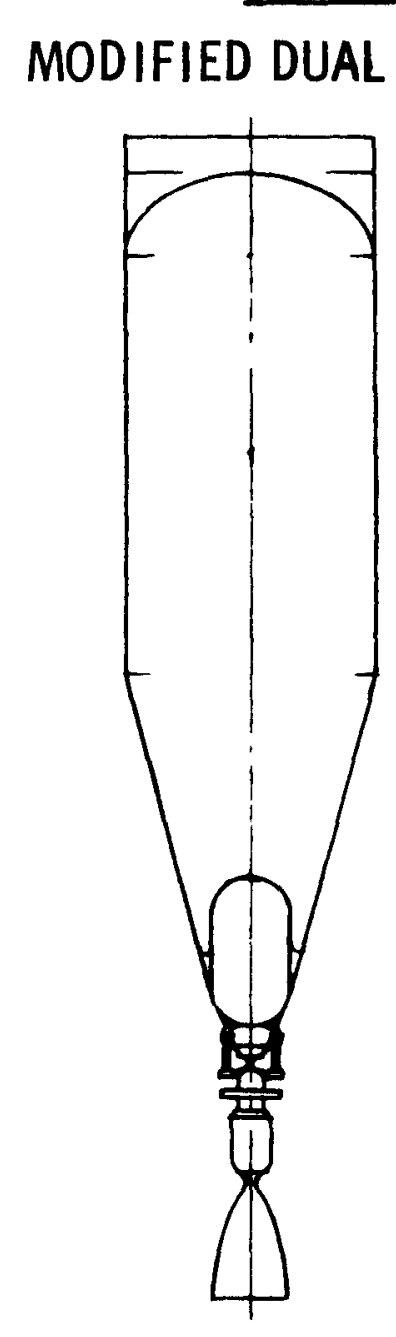

\section{CONICAL AFT BULKHEAD}

SINGLE CELL

HYBRID
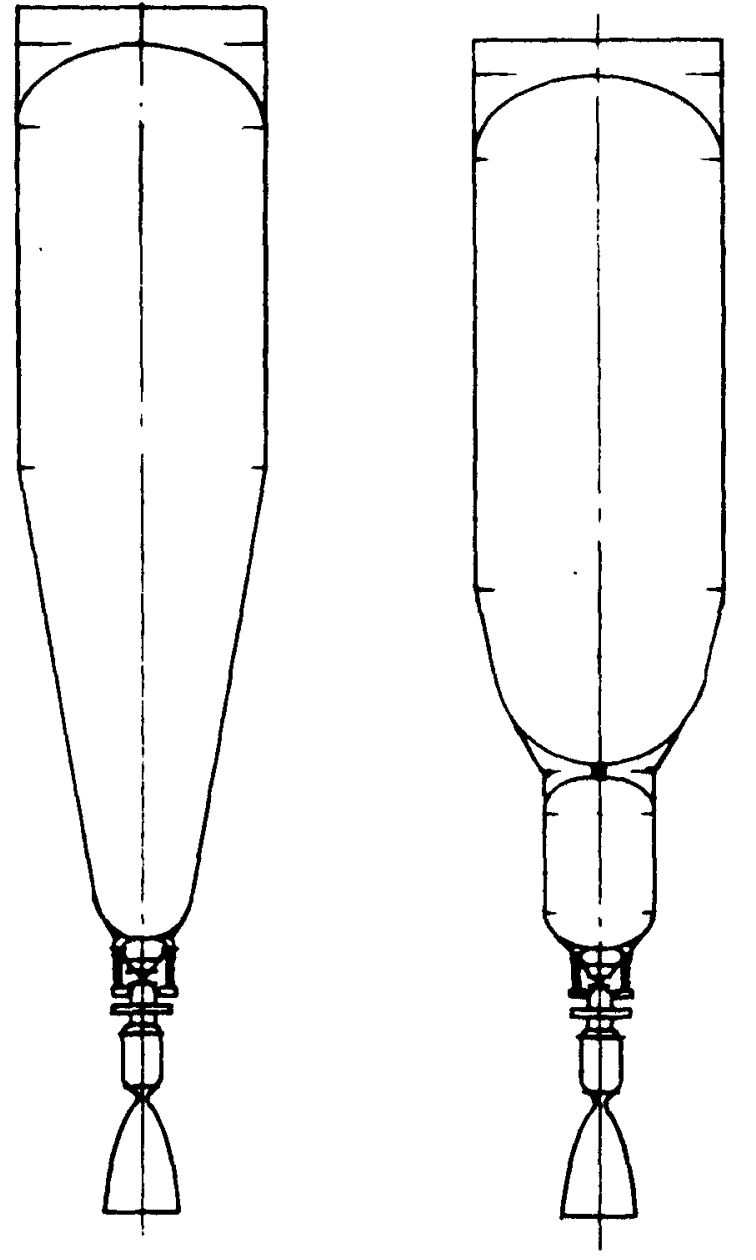

DUAL CELL- ELLIPTICAL

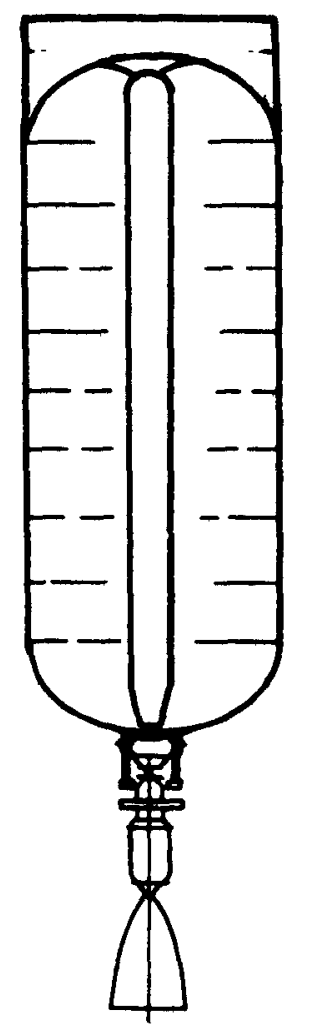


The design issues outlined in the opposite charts a re configuration and operations dependent and serve as guides in the design investigations. For example, the stage length increases inversely proportional to aft bulkhead cone angle and end cap radius. As the stage length increases so does the surface area and weight. On the other hand, the weight of the external radiation shield required for dose attenuation to the payload decreases with increase in fineness ratio of the cone. Consequently, the tradeoff yields a point of minimum total weight which denotes the stage design with the highest flight performance. Yet, to complete the tradeoff the resulting stage geometry has to be evaluated for launch vehicle and facilities impact in order to arrive at a realistic and reliable solution.

Other design issues such as propellant location, and thrust vector control must be considered in the overall system evaluation and design concept selection. It is of importance in this case to consider commonality of application for a given design concept. For example, a small inner cell as depicted in the figure can be beneficial for propellant settling and location control, and also for radiation attenuation to the payload, especially towards the end of the last engine burn and last cooldown. On the other hand, engine gimbal requirements for thrust vector control can affect the stage radiation shadow shield envelope and must be considered in the overall evaluation. This analysis must take into consideration the engine 1.5 degree thrust misalignment criteria as well as the possible stage and payload lateral center of gravity displacement resulting in as much as an additional 0.5 degrees gimbal requirement.

Other design issues that must be considered in the system evaluation include interfaces, as well as engine disposal requirements. As shown in the figure, interface design must respond to a wide range of considerations when applied to hybrid and single cell stage configurations. These include the inherent complexity associated with mating propellant lines and power receptacles. Also of consideration in this case is the fact that NERVA design criteria specifies that the engine must be removable from the tank in earth orbit.

The engine disposal also presents a wide range of design considerations when related to a hybrid stage design. In this case, the limitations imposed by the Space Shuttle makes an auxiliary propellant tank necessary if disposal in heliocentric orbit is desired. Additionally, a separate astrionics and RCS will be necessary for the operation. 


\section{DESIGN ISSUES}
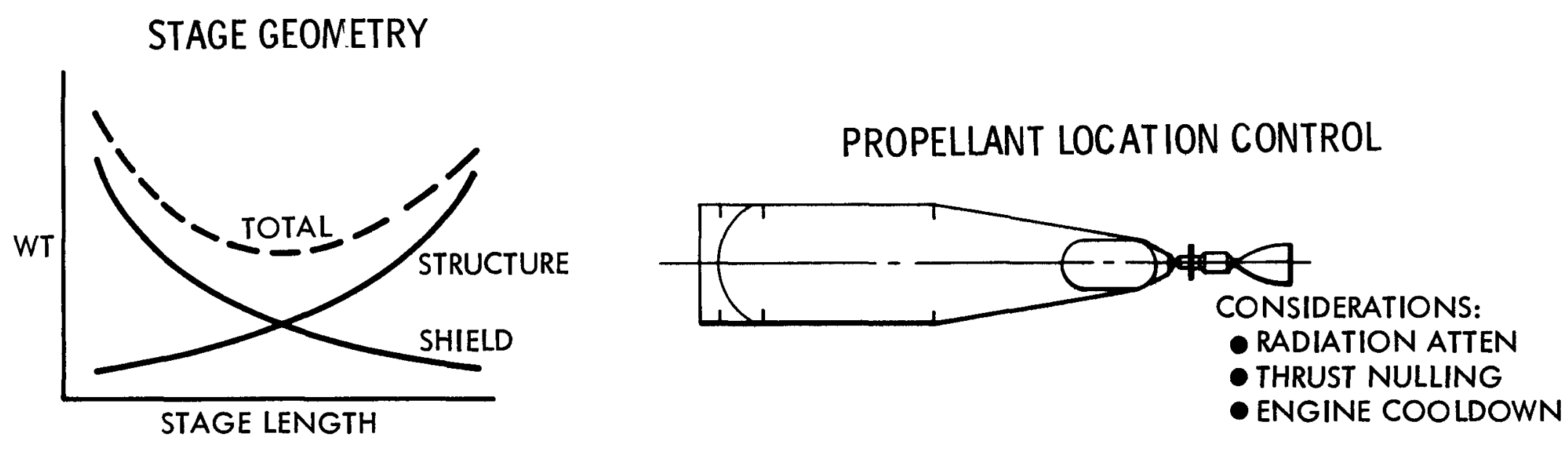

LAUNCH VEHICLE IMPACT
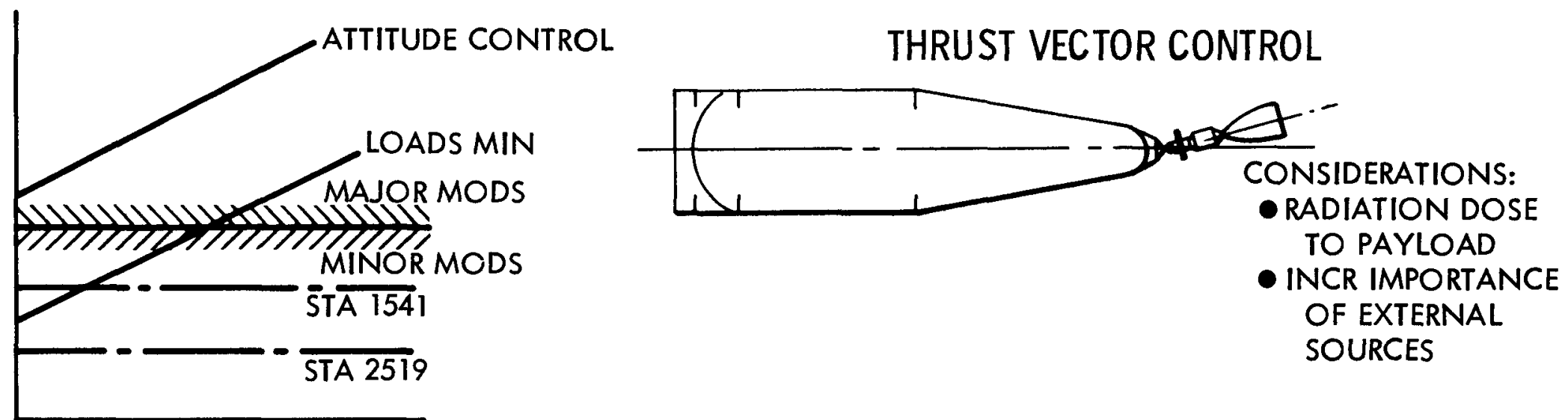

STAGE LENGTH 


\section{DESIGN ISSUES (CONT)}

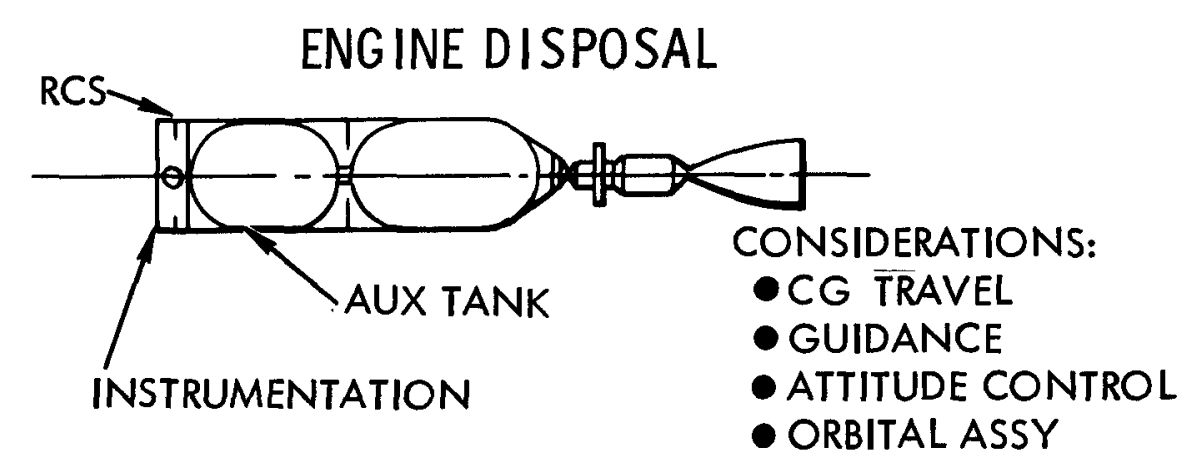

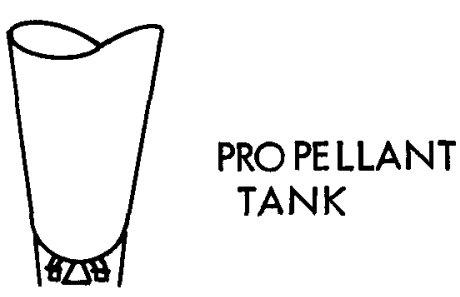

TO

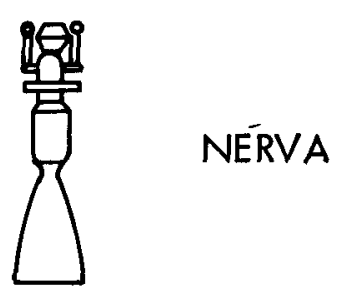

\section{INTERFACES}

CONSIDERATIONS

- ORBITAL ASSEMBLY

- CHECKOUT

- DESIGN COMPLEXITY

- MAINTENANCE

- NERVA DESIGN CRITERIA

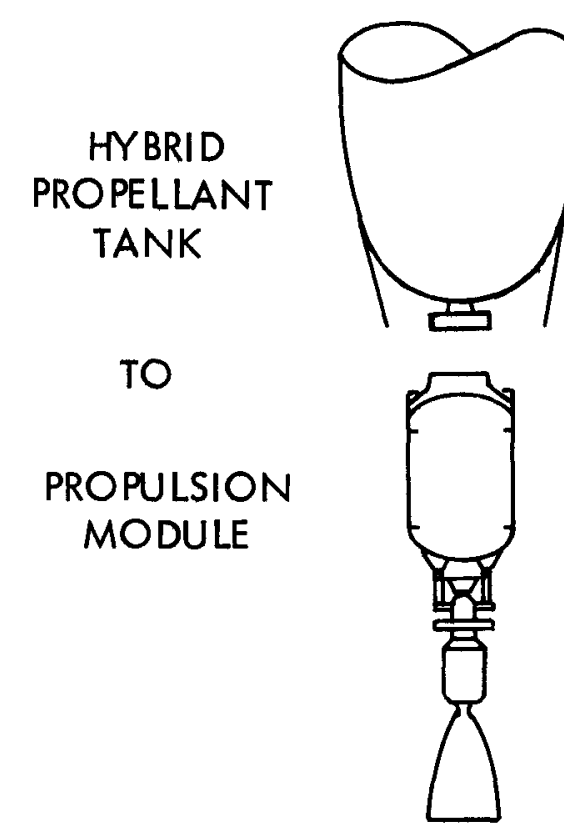


As shown in the accompanying figures, a wide range of stage launch assemblies were investigated to establish the minimum loading impact on the launch vehicle. Also, in addition to the INT-21, the S-IIB/Shuttle Booster is being considered to launch the RNS. This latter system is currently under contracted study on an S-II change order and data will be presented as it becomes available.

The totally assembled RNS is shown in the first figure for launch on the INT-21 both right side up and upside down. The gains associated with the upside-down launch are two-fold. First, the height is reduced by approximately 20 feet thereby producing a reduction in load. Secondly, the aerodynamic characteristics of the resulting nose cone also yields a reduction in loads through a reducttion in normal forces and aft movement of the center of pressure. The upside-down boost, nevertheless, will require assessment of the effect of longitudinal acceleration of the order of $5 g^{\prime} s$ on the engine reactor and astrionics equipment in the upside-down position.

The second figure shows the INT-21 with the RNS boosted unassembled with the engine in the rightside-up position. The basic advantage of this configuration over the assembled upside-down boost previously shown is that the engine is in the right-side-up position in all cases. An adjunct to this, nevertheless, is the requirement of orbital assembly of the engine wi th the tank module.

The third figure shows the tank module boosted by the INT -21 and the engine launched by the Space Shuttle. This approach applies to both a single cell configuration with orbital mating of the NERVA/ propellant tank and the hybrid design where a small propellant module is launched with the engine. There is a 34-foot reduction in length when comparing the envelope resulting from the tank alone with that of the total stage, both boosted right side up. There is a further reduction of 20 feet when the tank is launched upside down. This last configuration, therefore, produces the lowest loads by virtue of the reduced length and aerodynamic characteristics of the nose cone. 
RNS/BOOST VEHICLE OPTIONS

NO ORBITAL ASSEMBLY

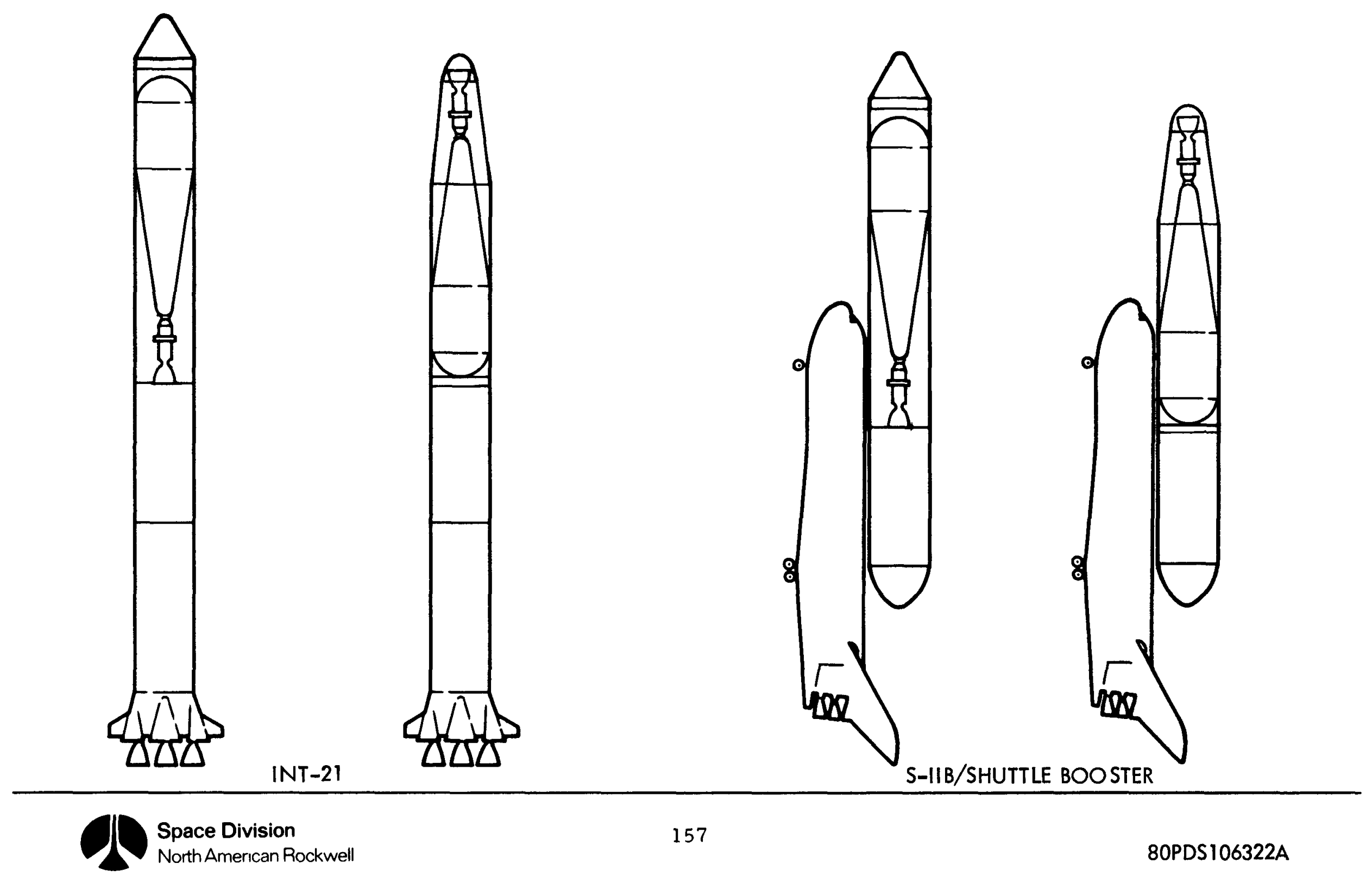



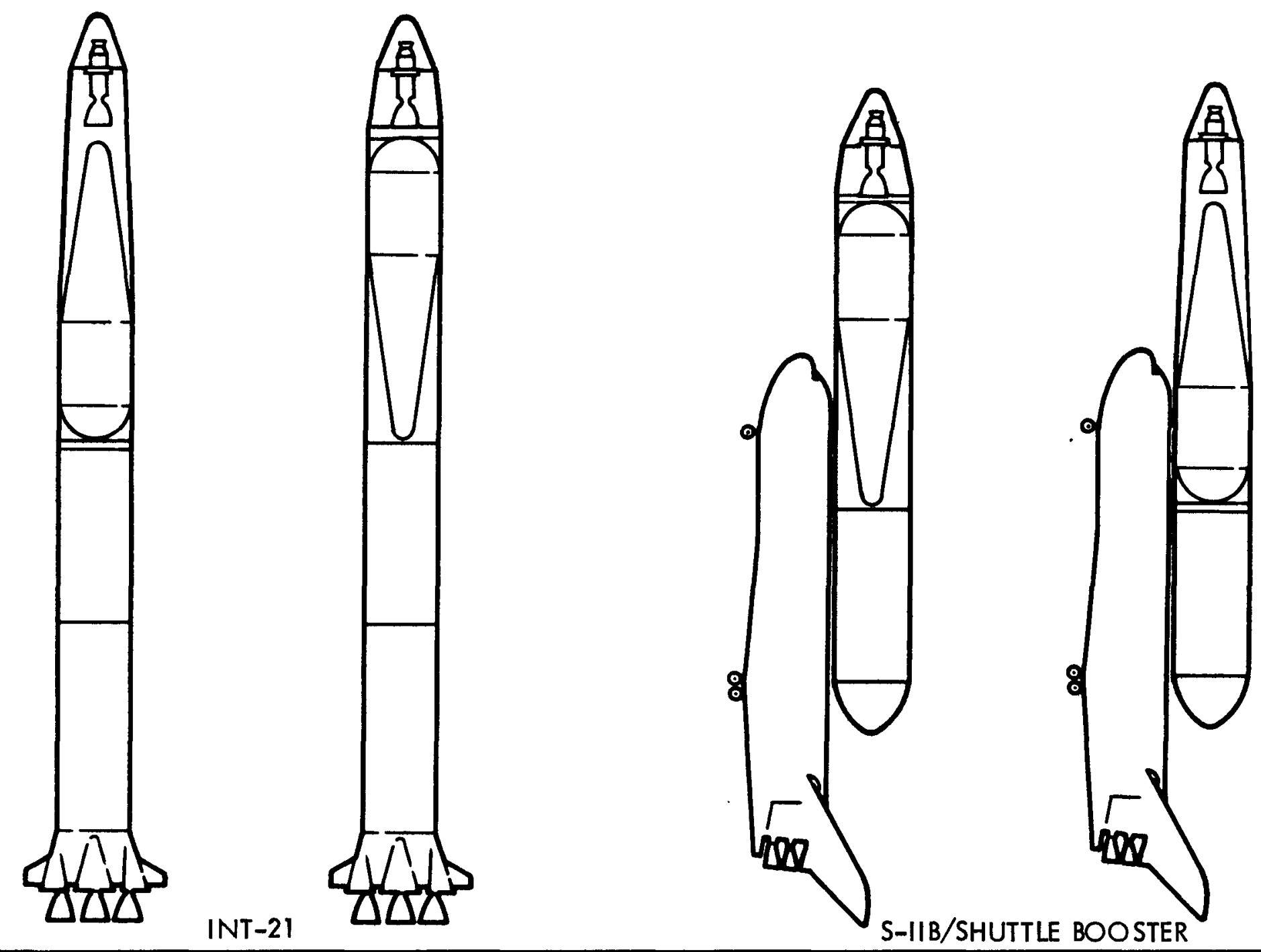


\section{RNS/BOOST VEHICLE OPTIONS}

\section{ORBITAL ASSEMBLY}
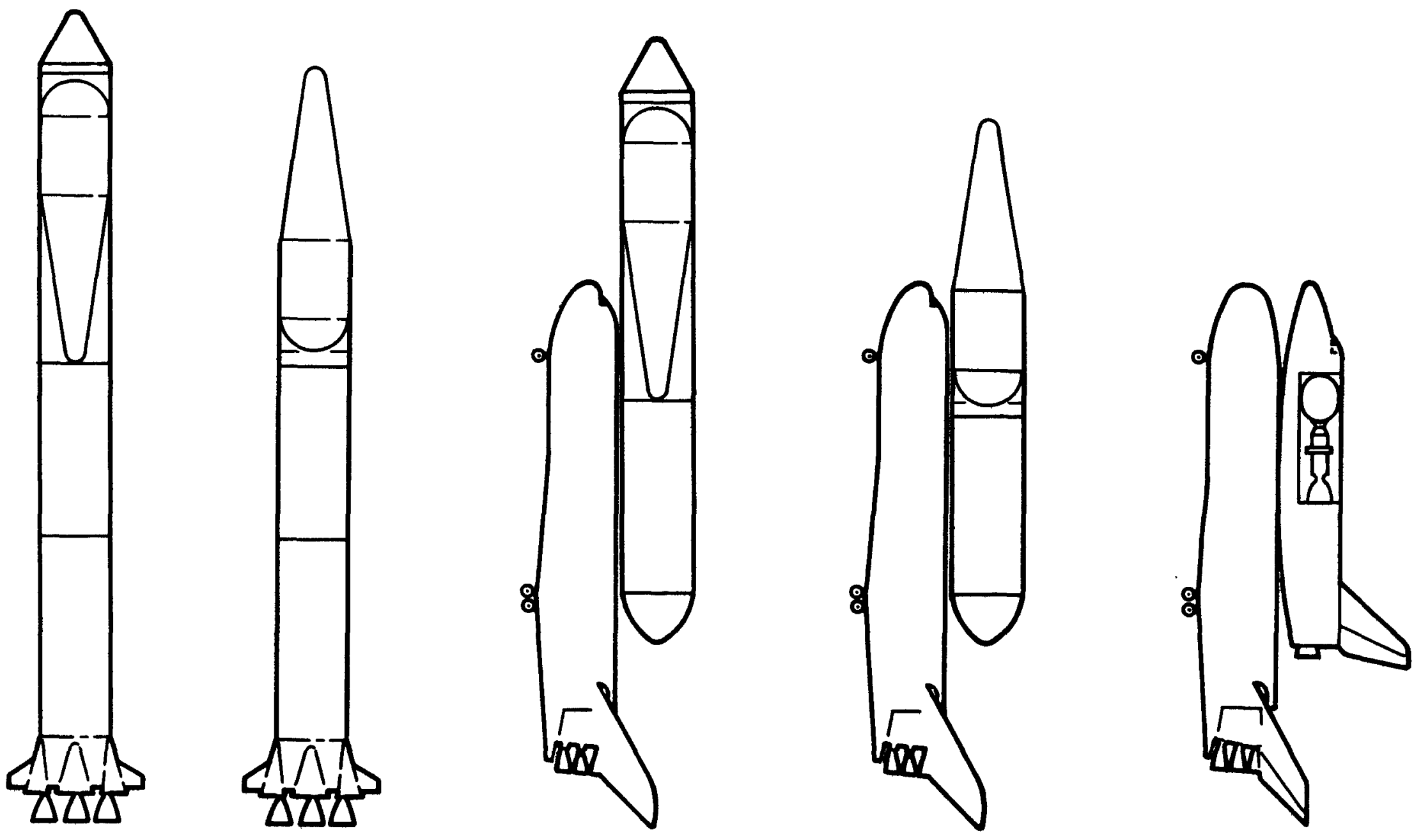

[NT-21 
A preliminary assessment of the loading impact of the conical aft bulkhead RNS configuration on the INT-21 was performed considering three RNS launch configurations. The analysis encompasses variations in the conical aft bulkhead half-cone angle below 15 degrees as well as changes in cap radii. Focus was placed on the two critical areas of the S-II, i. e., the base of the forward skirt, and the base of the LH2 tank wall, stations 199 feet and 154 feet, respectively. Using the load minimum boost flight profile established in Phase II of the present study, the bending moment variation at max (q $d$ ) versus height of RNS is presented on the right hand side of the chart. Along side this first plot, the boost vehicle height variation with changing half cone angles and end cap radius is shown to permit correlation between vehicle height and bending moment at the two referenced stations. The capabilities of the present S-II forward skirt and $\mathrm{LH}_{2}$ tank wall have been identified at their respective stations on the bending moment curves as vertical lines. To the right of the latter the structural capabilities of the two components are exceeded. This establishes an upper bound for the stage configuration of 165 feet above which structural modifications at the INT -21 will be necessary. In addition, a horizontal line has been drawn which represents the VAB facilities, constraining the RNS height to 190 feet.

Considering each chart in turn, the first one refers to a complete RNS vehicle, right side up, requiring no orbital assembly. As can be seen, all vehicles considered exceed the strength capability constraint and most of the configurations with 25 and 50 -inch radii exceed the facility constraint. Therefore, the use of this configuration entails modifications to the launch vehicle.

An alternate configuration considers the same complete RNS vehicle as in the first chart with the exception that it is inverted. In so doing, the overall stage height is reduced approximately 20 feet. The impact of this shortening is indicated on the next chart. A substantial segment of the vehicle configurations falls within the launch vehicle strength capabilities and well over half between this and the facility constraint. Since the engine structural criteria may not permit the use of an engine upside down, it is suggested that the NERVA be separated from the main tank and placed right side up in the nose cone. However, in this instance, orbital assembly of the two RNS components will be necessary.

The remaining chart depicts the effect of delivering the NERVA (or the hybrid propulsion module) to orbit via the Space Shuttle. With the RNS propellant tank module right side up, a further reduction of 14 feet will result. As can be seen, over half the configurations fall within the strength capability of the launch vehicle and nearly all of them are included within the facility constraint. By inverting the RNS propellant module, a further 20-foot reduction is achieved which has the effect of bringing most all configurations within the launch vehicle capabilities. The latter two configurations also will require orbital assembly. 


\section{LOAD IMPACT OF CONICAL AFT BULKHEAD CONFIGURATIONS}

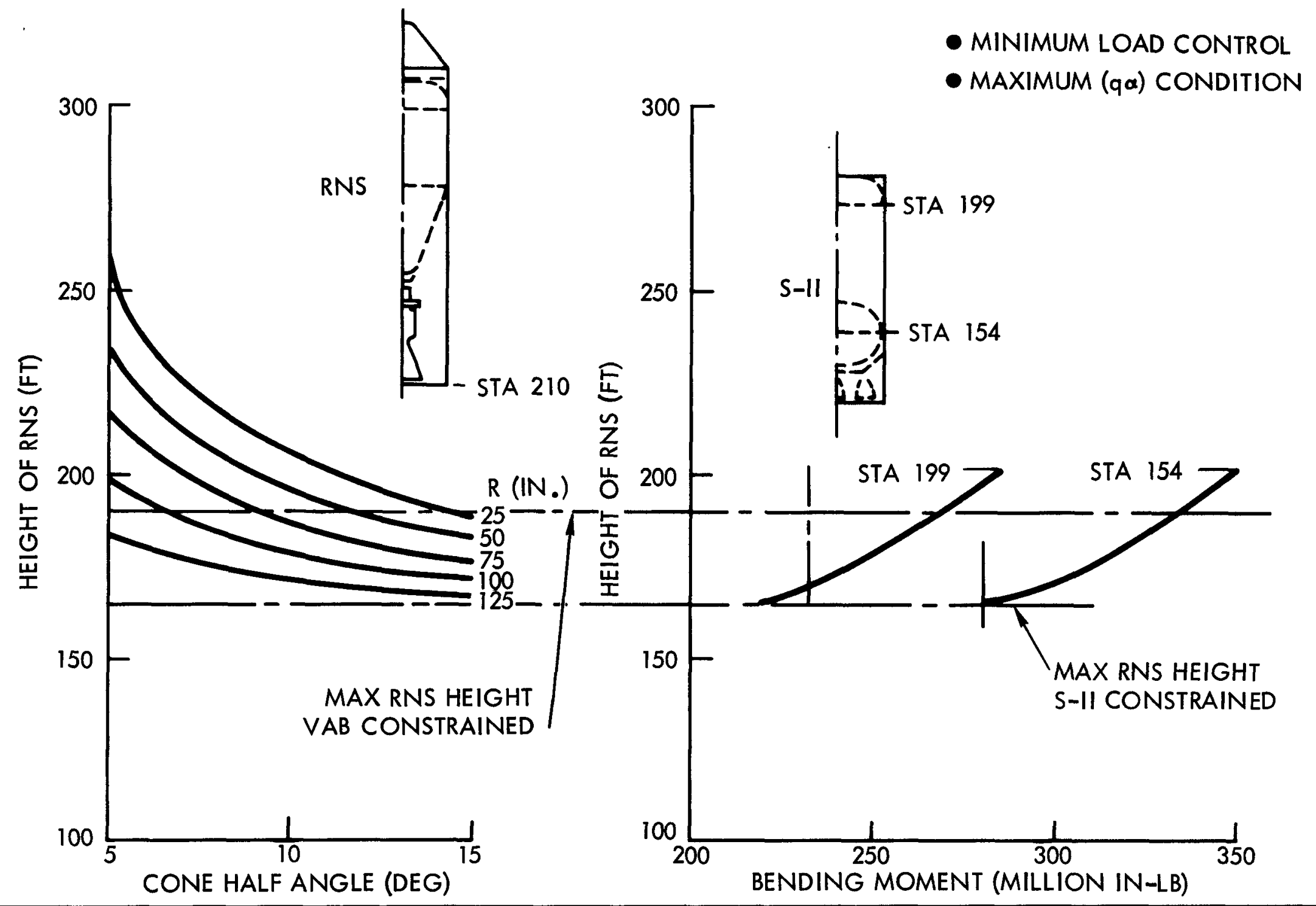




\section{LOAD IMPACT OF CONICAL AFT BULKHEAD CONFIGURATIONS}

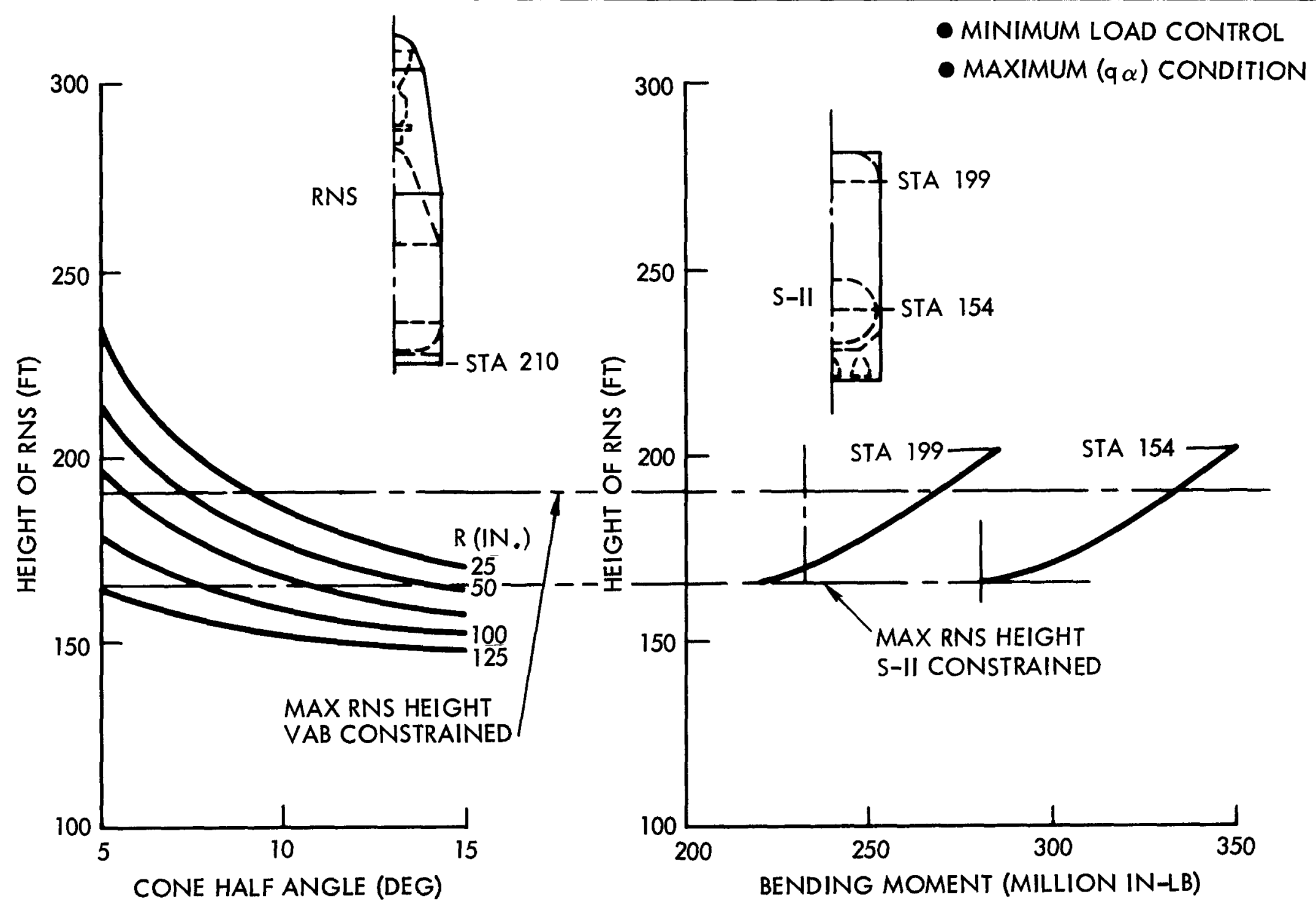




\section{LOAD IMPACT OF CONICAL AFT BULKHEAD CONFIGURATIONS}

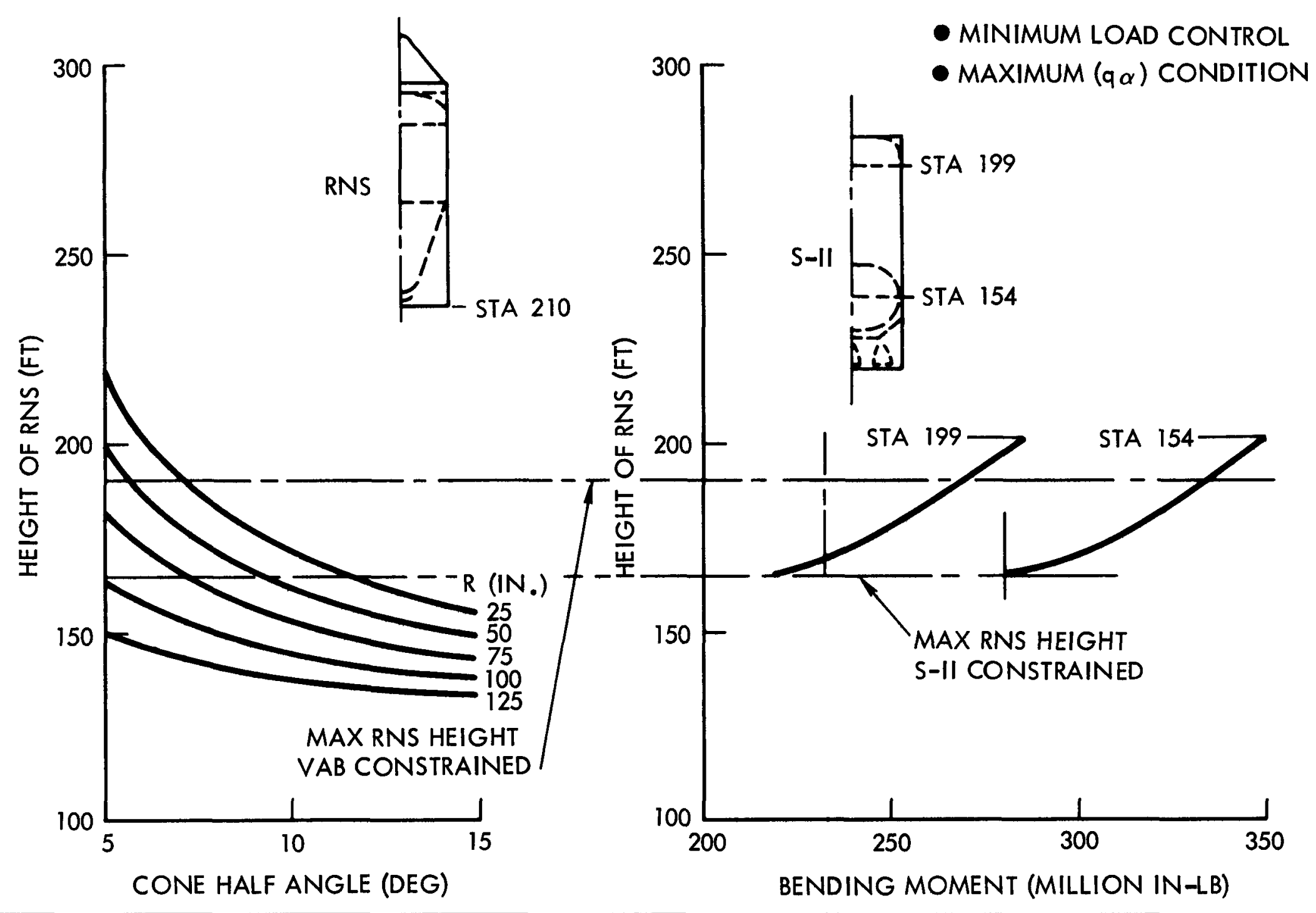


The adjacent chart summarizes the leading geometrical and mass data resulting from the parametric analysis conducted on a single tank configuration with conical aft bulkheads. The propellant tank is sized for 300,000 pounds of $\mathrm{LH}_{2}$ with 5 percent ullage volume. The tank configuration consists of three segments: forward elliptical bulkhead of 1.5 aspect ratio, cylindrical section $33-$ feet in diameter and a conical aft bulkhead. The parametric analysis concerned itself with determining the impact on the stage of aft bulkhead half cone angle variation below 15 degrees and changes in cap radius from 25 to 125 inches in 25 -inch increments. The resultant stage length variation, including engine and astrionics bay, is presented in the left hand graph. The maximum stage length variation is approximately 90 feet between the 5 degree half cone angle with 25 -inch cap radius and 15 degrees counterpart with 125 -inch cap radius, accountable to both the change in half-cone angle and cap radius.

The center graph summarizes the resultant surface areas of the tank including forward bulkhead, cylinder and aft bulkhead. The tank total surface area variation over the range of the parameters being considered is less than $25 \%$, whereas that of length is $190 \%$. Since surface area can be related to weight, this result implies that a relatively small weight variation can be expected between the tank geometries under study. This conclusion is confirmed in the right hand graph which summarizes the stage dry weight.

The latter excludes the interstage weight but includes forward and aft skirts with four feet heat blocks, foam and HPI for ground and space thermal protection, double walled meteoroid protection for one year exposure at 0.995 probability of no impact and fixed weight components consisting of the propulsion subsystem, astrionics, RCS, thrust structure, etc.

The resultant weights indicate that the maximum difference between stage dry weights is approximately 2, 800 pounds and that the majority of this weight difference is in the meteoroid/thermal protection system which responds to the surface area variation. In addition, the variation in surface area increases the heat input to the tank and, therefore, increases the weight variation over that presented by an additional 1500 pounds. 


\section{DIMENSIONAL \& MASS PROPERTIES VARIATIONS}

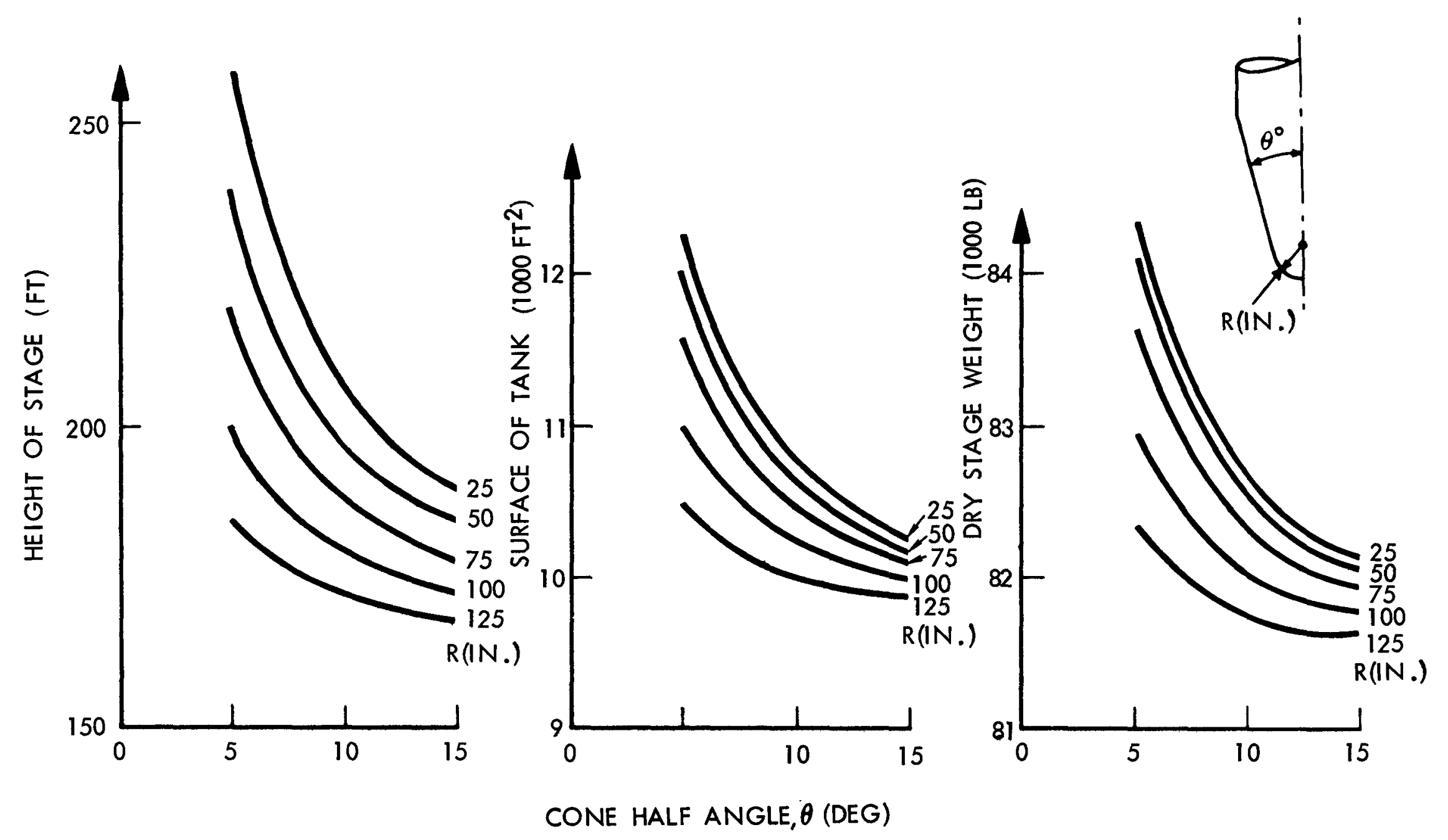




\section{SHIELD ENVELOPE}

The accompanying figure depicts the range of geometrical models surveyed to assess the variation of on-axis gamma radiation levels from the PVARA source. Also shown are the comparative residual liquid hydrogen levels for the various configurations for after shutdown cooling requirements following the last engine burn. Analysis has shown this residual $\mathrm{LH}_{2}$ to be between 5, 000 to 6, 000 pounds for representative lunar shuttle missions varying the outbound and inbound payload mix. The residual propellant includes cooldown requirements plus the amount that will be vaporized during the last cooldown. It is of importance to note that maximum propellant depth prior to the last cooldown beneficial for radiation attenuation - is accrued by a judicious combination of both cap radius and cone angle. This can be compared to the depth of propellant attained with a short inner cell as shown in the figure.

Additionally, the figure shows the geometric effect on shadow shield cone angle by gimbaling the engine 2.5 degrees. This could be of significance in the selection and design of the reference system. 


\section{PROPELLANT RESIDUAL LEVELS/SHADOW SHIELD ENVELOPE}

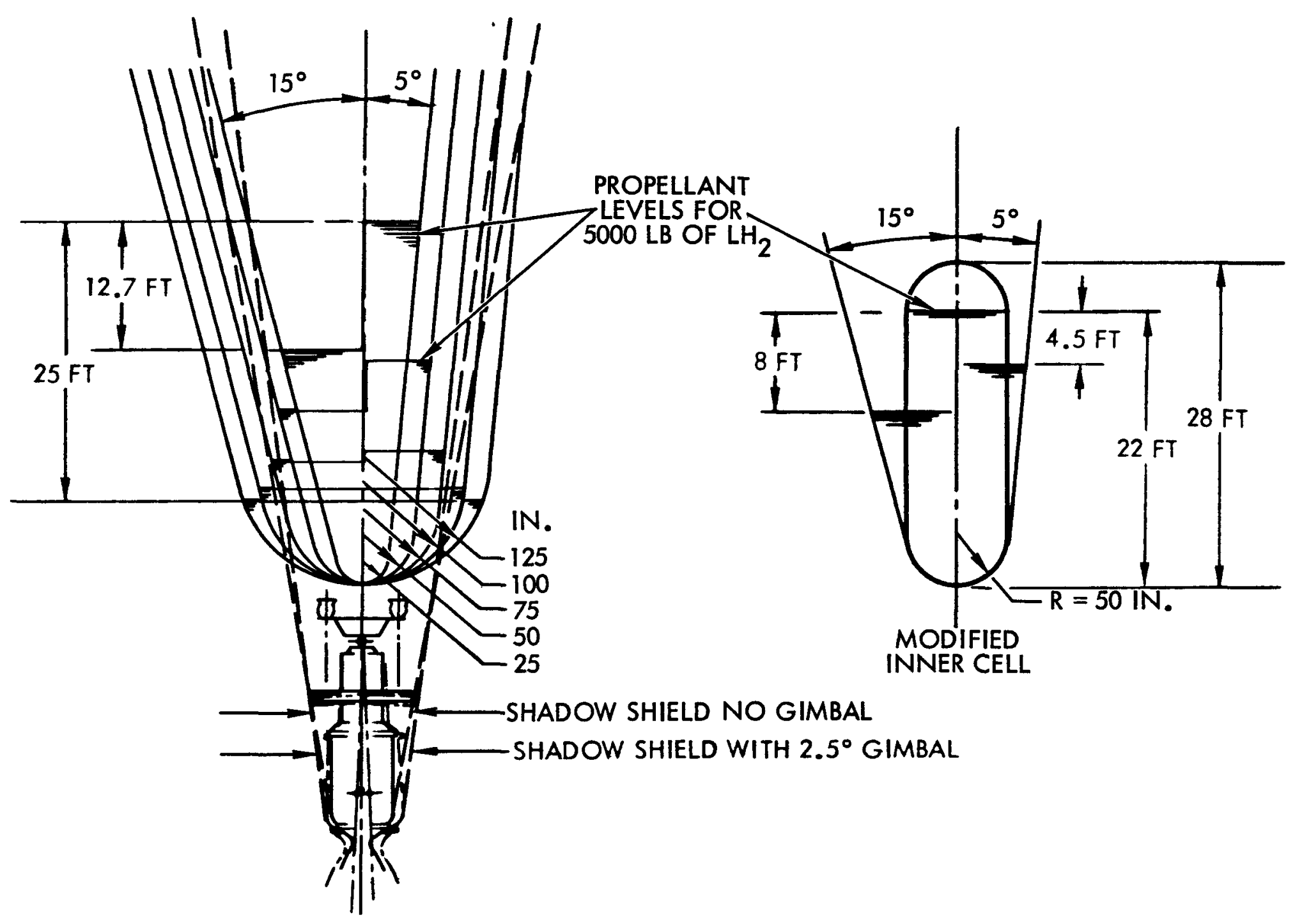


The preliminary screening analysis was made to obtain a comparative evaluation of the PVARA source contributions to the integral tank top gamma dose for conical aft bulkhead, single cell geometries as a function of varying half cone angle from 5 to 15 degrees and cap radius from 25 inches to 100 inches. Preliminary assumptions for the parametric evaluation included a 300,000 pound liquid hydrogen

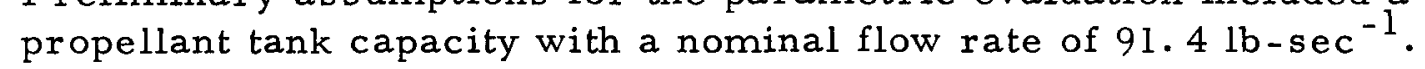

The PVARA integral tank top dose variation as a function of cap radius and half cone angle is shown relative to a value of $561 \mathrm{rads}$ for the tank configuration employing an aft bulkhead with a 15 degree half cone angle and a 100 inch end cap radius. The data indicates that significant reductions in tank top integral dose are effected by decreasing the half cone angle from 15 to 5 degrees and the end cap radius from 100 inches to 25 inches. However, decreasing the cap radius from 100 inches to 25 inches as the half cone angle is decreased from 15 degrees to 5 degrees has a progressively more significant effect on maximum utilization of the available $\mathrm{LH}_{2}$ for shielding purposes. This is analogous to the effect inherent in the inner cell for dual cell configurations. Additionally, the figure demonstrates that a reduction in cap radius for a given half cone angle is a more effective method of enhancing the $\mathrm{LH}_{2}$ shielding effectiveness than reducing half cone angles within a fixed cap radius for the selected boundary conditions with regard to size of half cone angle and cap radius. This effect is further illustrated for constant values of tank length, i. e., 109, 113, 119, and 135 feet, respectively.

Summarily, it may be concluded that preliminary results indicate more significant relative dose reductions are achievable at the smaller half cone angles of 6 to 8 degrees and smaller cap radii of 25 inches to 60 inches. 


\section{RADIATION ENVIRONMENT FOR CONICAL TANK GEOMETRIES}
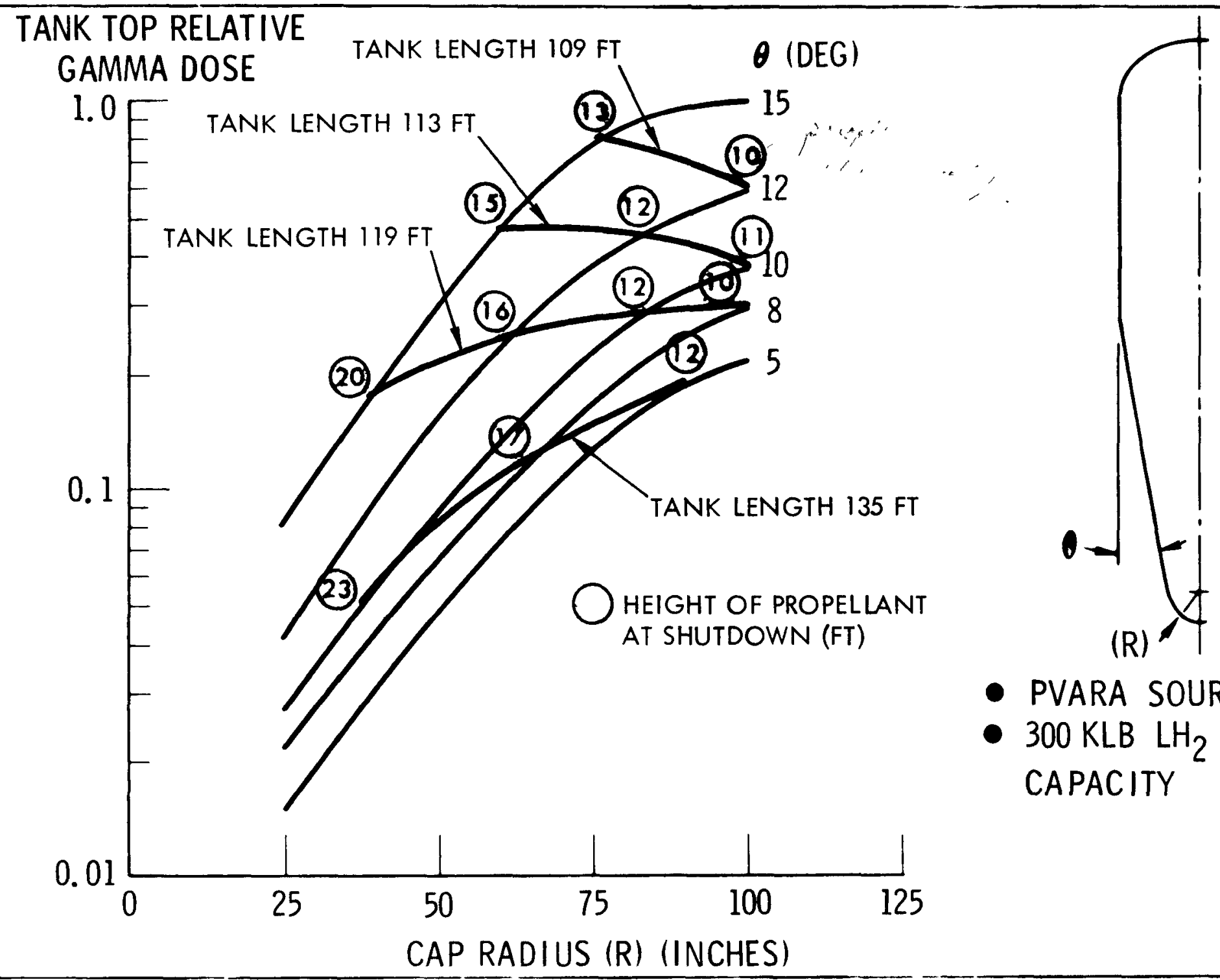

- pVARa source

- $300 \mathrm{KLB} \mathrm{LH}_{2}$ PROPELLANT CAPACITY 
The independent but interrelated parametric analyses in structures, radiation and thermal protection discussed in the preceding charts are brought together in the following three charts to determine the "optimum" vehicle size. The study considered the effects of variation of the aft bulkhead conical half angle and associated cap radius on structural/thermal/meteoroid protection weight, and the shield weight associated with three integral radiation doses at the tank top of respectively 10,25 and 50 REMS.

The first chart reflects the $10 \mathrm{REM}$ radiation dose criteria. The stage dry weight and the shield weight are given as a function of half cone angle and cap radius. As can be seen, the stage dry weight maximum variation is 2,800 pounds. The shield weight on the other hand, changes by as much as 13,500 pounds. At the 5 degrees half cone angle and 25 -inch radius shield weight requirement is zero. The shield weight differential reduces as the cap radius increases. By adding the stage dry weight to the corresponding internal shield and including the effective boiloff penalties results in the curve. Also, the minimum point shifts towards a smaller half cone angle as the cap radius increases. The "optimum" stage size has a 7 -degree half cone angle and 25 -inch radius.

The next two charts present similar data for the $25 \mathrm{REM}$ and 50 REM criteria. As will be noticed for the $25 \mathrm{REM}$ case, the optimum size has shifted towards a higher half cone angle on the 25-inch cap radius. The reason for the sharp break in the curve of the 25 -inch cap radius can be traced to the fact that no shield is required below 8 degrees. In the case of the $50 \mathrm{REM}$, no shield weight is required over the range of half cone angles considered in conjunction with the 25 -inch cap radius. In this instance the optimum vehicle size half cone angle has shifted all the way to 15 degrees.

These results do not account for the facilities or INT-21 strength capabilities constraint. By referring to the charts on "Load Impact of Conical Aft Bulkhead Configurations" it can be determined that, for the most stringent radiation dose criteria, i. e., 10 REM, lofting a 165-foot RNS propellant module inverted (within INT-21 strength capabilities) results in a vehicle with 8.5 degrees half cone angle and 25-inch cap radius. This configuration, from a performance standpoint, is very close to the optimum since the curve in that general area is very flat. 


\section{STAGE WEIGHT/RADIATION DOSE TRADEOFF}

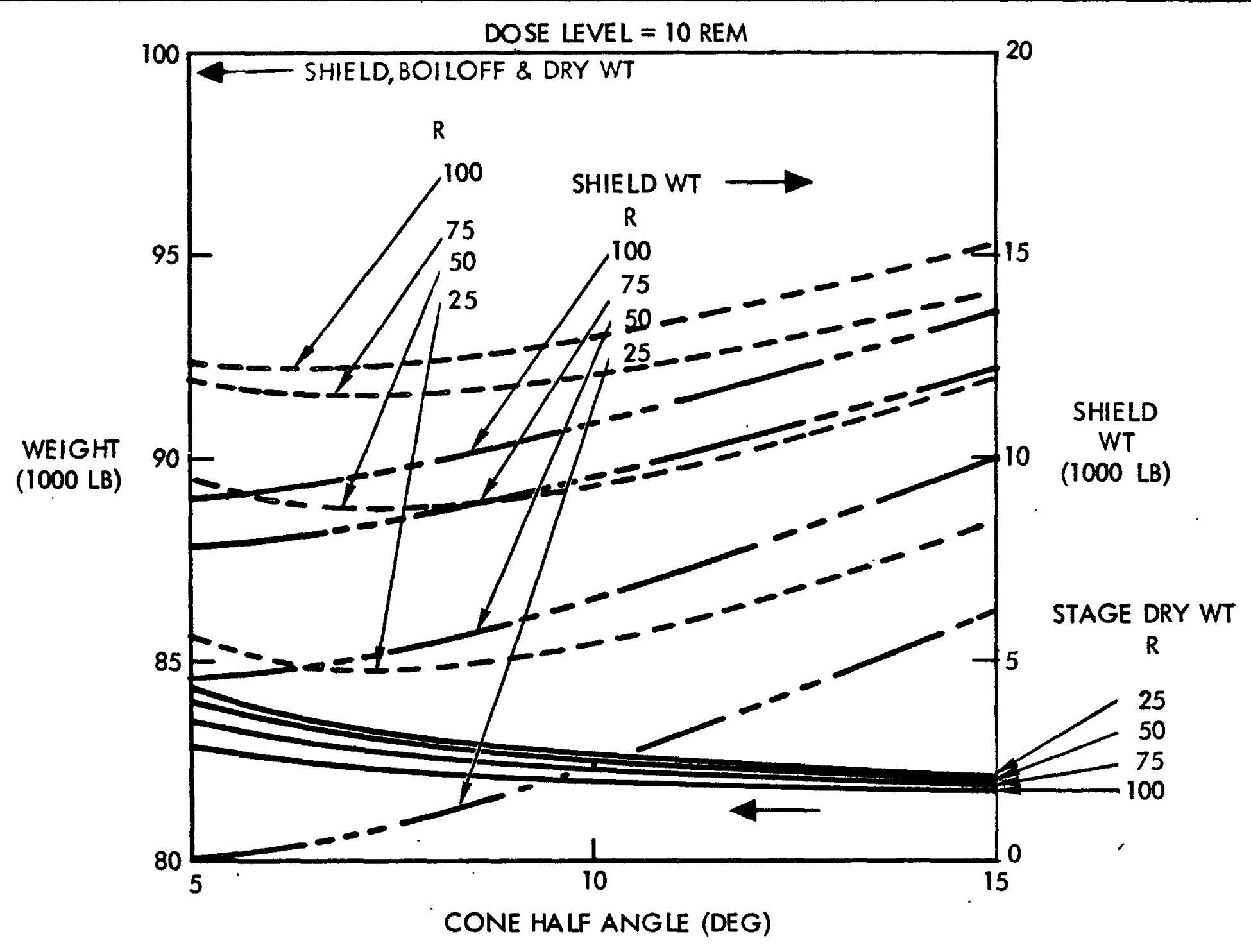




\section{STAGE WEIGHT/RADIATION DOSE TRADEOFF}

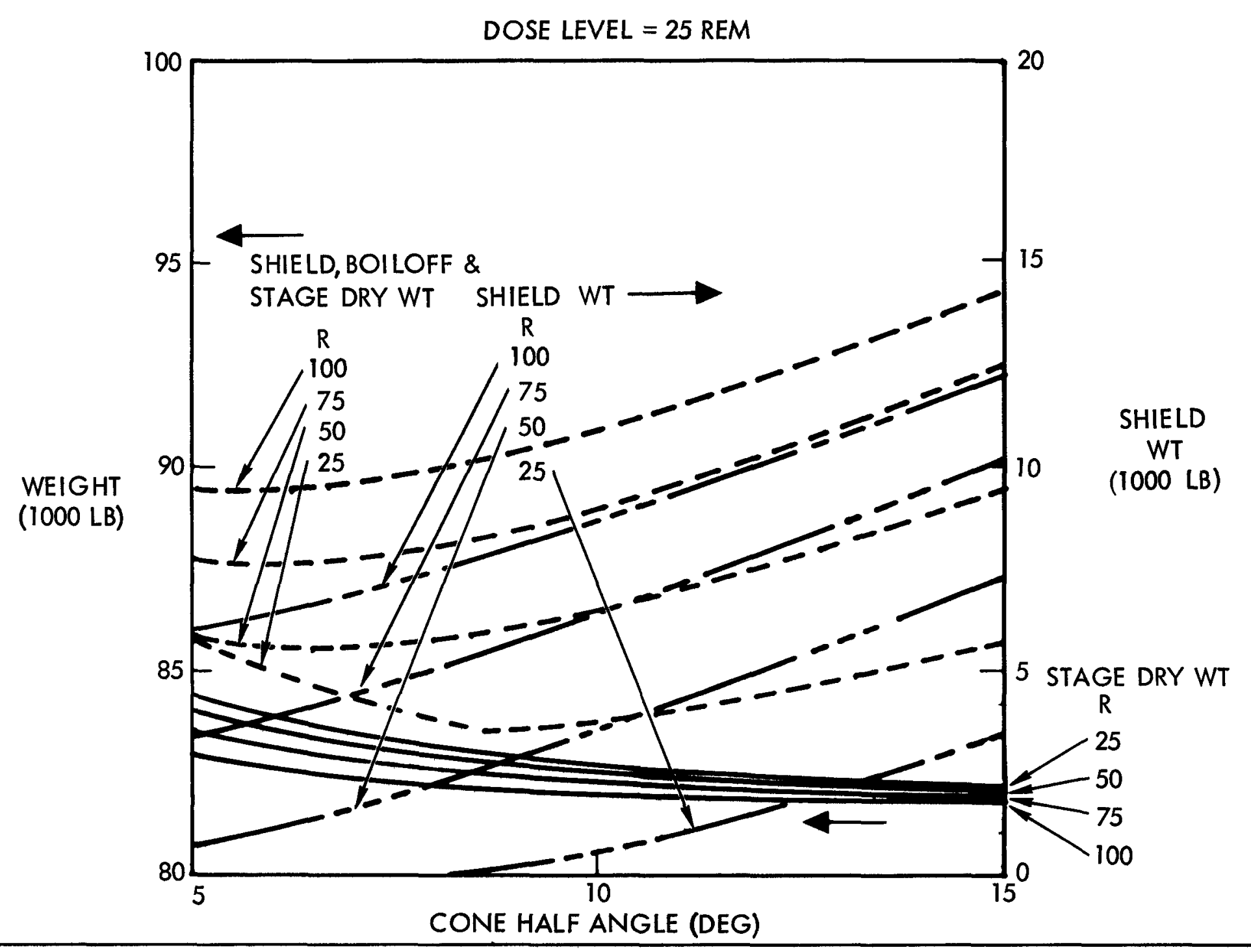




\section{STAGE WEIGHT/RADIATION DOSE TRADEOFF}

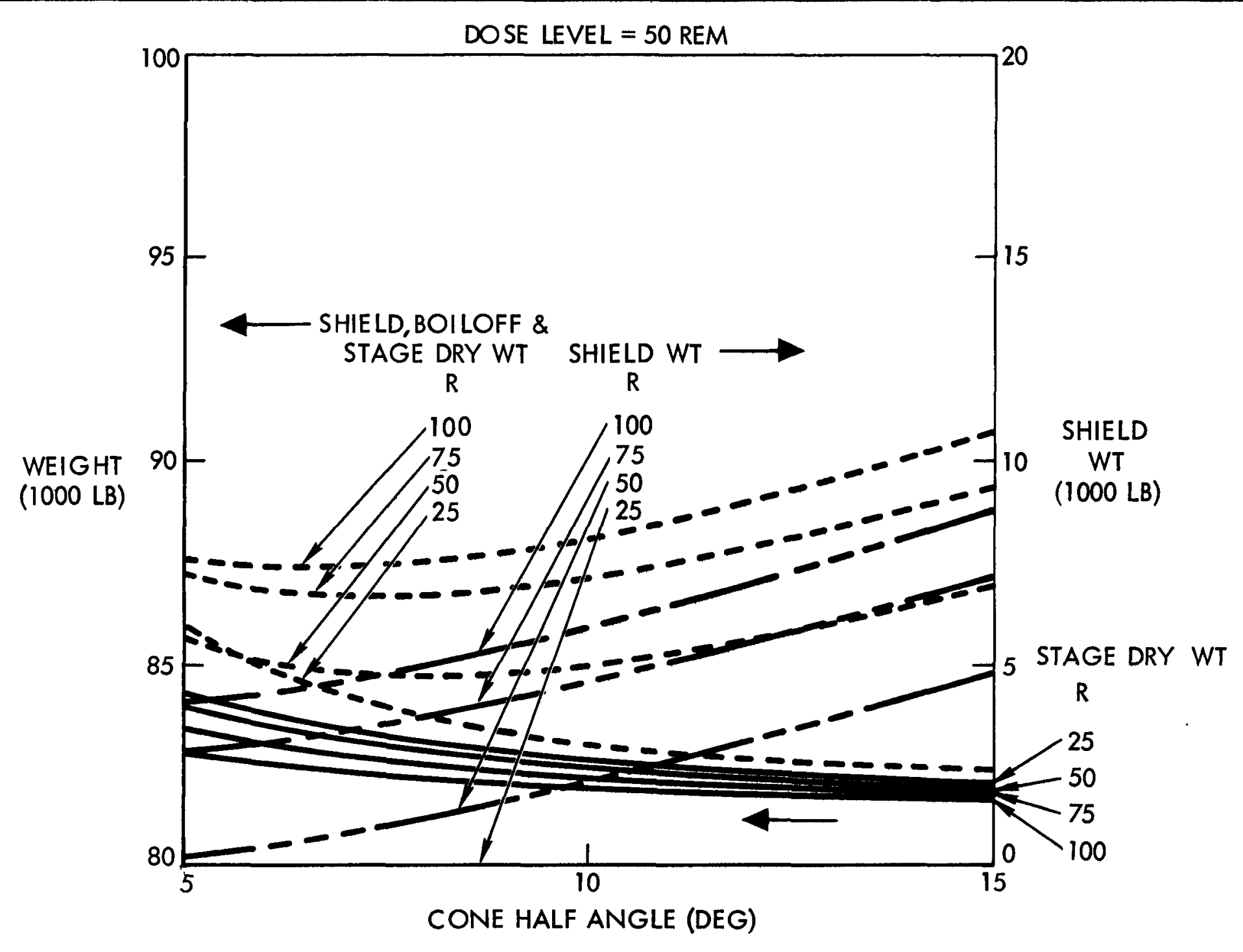




\section{HYBRID CONFIGURATION TANK/PROPULSION \\ MODULE INTER F A E E}

The interface is designed to provide direct and fully automatic docking of a propellant tank module to a propulsion module held by a tug or space shuttle vehicle without requiring auxiliary fixtures or EVA. A "standard" neuter dock of the type currently being proposed for other space elements is employed, thus affording alternate operational choices such as docking the unmated units to a propellant maintenance depot, etc. Subsequent demating requires provisions for reacquisition of the propulsion module by a tug or similar vehicle, or use of a demating fixture. On the other hand, the propulsion module might be provided with RCS and astrionics system at the outset, in which case it can provide its own power and intelligence for mating and demating procedures.

The docking rings are supported by conical skirt extensions on each tank which also serve as the carry through structure once the two components are joined. The bulkier active dock section is installed on the propellant tank module while the shorter passive one is located on the propulsion module to maximize the tank length within the space shuttle cargo bay. The dock design provides for lateral and rotational compensation of approach misalignments as well as attenuation of impact loads. It incorporates powered actuators and latches for final pull-up and structural lock.

The propellant management system interface includes a 20 -inch main transfer line, an 8-inch fill line and a 3-inch pressurization line. Spring or bellows-loaded bayonet couplings are predicated to provide the necessary sealing across the fluid lines' joints. The loading bellows are located on the engine side. Mechanical hold back of the bayonets until the structural mating is completed will be required to prevent seal damage during the docking and subsequent drawing and locking operation. Shutoff valves are incorporated in the main transfer and pressurization lines on the propellant tank module only since it will be partially filled during launch.

The electrical/instrumentation interface is represented by a multipin connector, designed to mechanically engage after structural mating. 


\section{HYBRID CONFIGURATION TANK/PROPUSION MODULE INTERFACE}

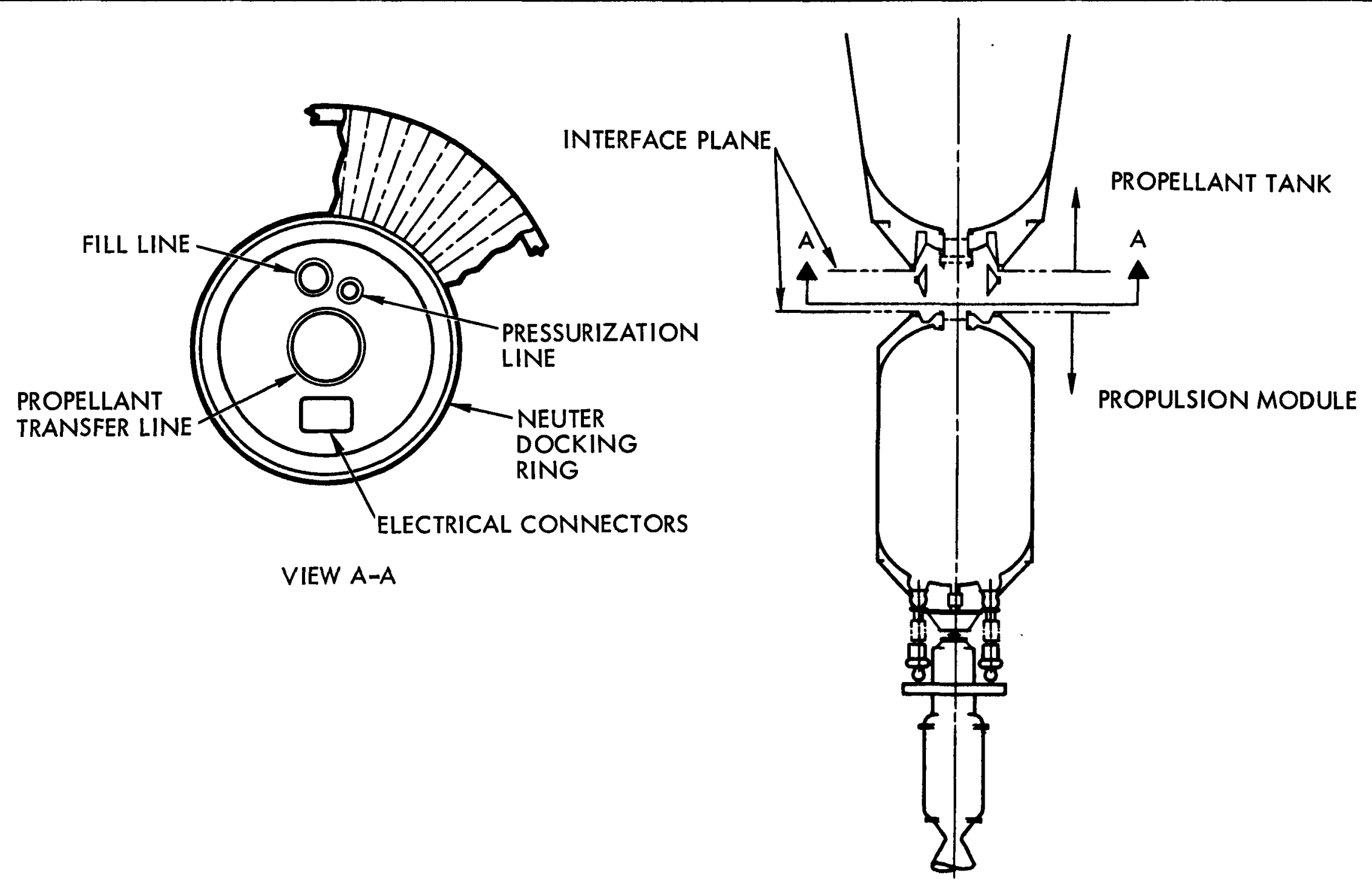




\section{CONICAL TANK/NERVA INTERFACE}

The interface is designed for direct and fully automatic docking of a conical propellant tank module to a modified NERVA held by a tug or space shuttle vehicle without requiring auxiliary fixtures or EVA. Engine removal for disposal will require, however, attachment provisions for reacquisition of the engine by a tug or alternately demand the use of a demating fixture.

The main interface structure consists of a tank skirt to which is attached a thrust cone, designed to mate with the engine forward thrust structure. As shown, a cone frustum has been added to the NERVA interface and represents the probe structure. The drogue is extended on shock attenuator and is designed to compensate for lateral and rotational approach misalignments and attenuate the docking impact loads. Latches provide initial locking and powered actuators draw the two components together which are subsequently rigidly held by additional mechanical latches.

The propellant management system interface includes the main feed lines (2), the cooldown feed line and the tank pressurization line. Spring or bellows-loaded bayonet couplings are predicated to provide the necessary sealing across the fluid line's joints. The loading bellows are located on the engine. Mechanical hold back of the bayonets until the structural mating is completed will be required to prevent seal damage during the docking and subsequent drawing and locking operation.

The electrical/instrumentation interface is represented by a multipin connector, designed to mechanically engage after structural mating. 


\section{CONICAL TANK/NERVA INTERFACE}

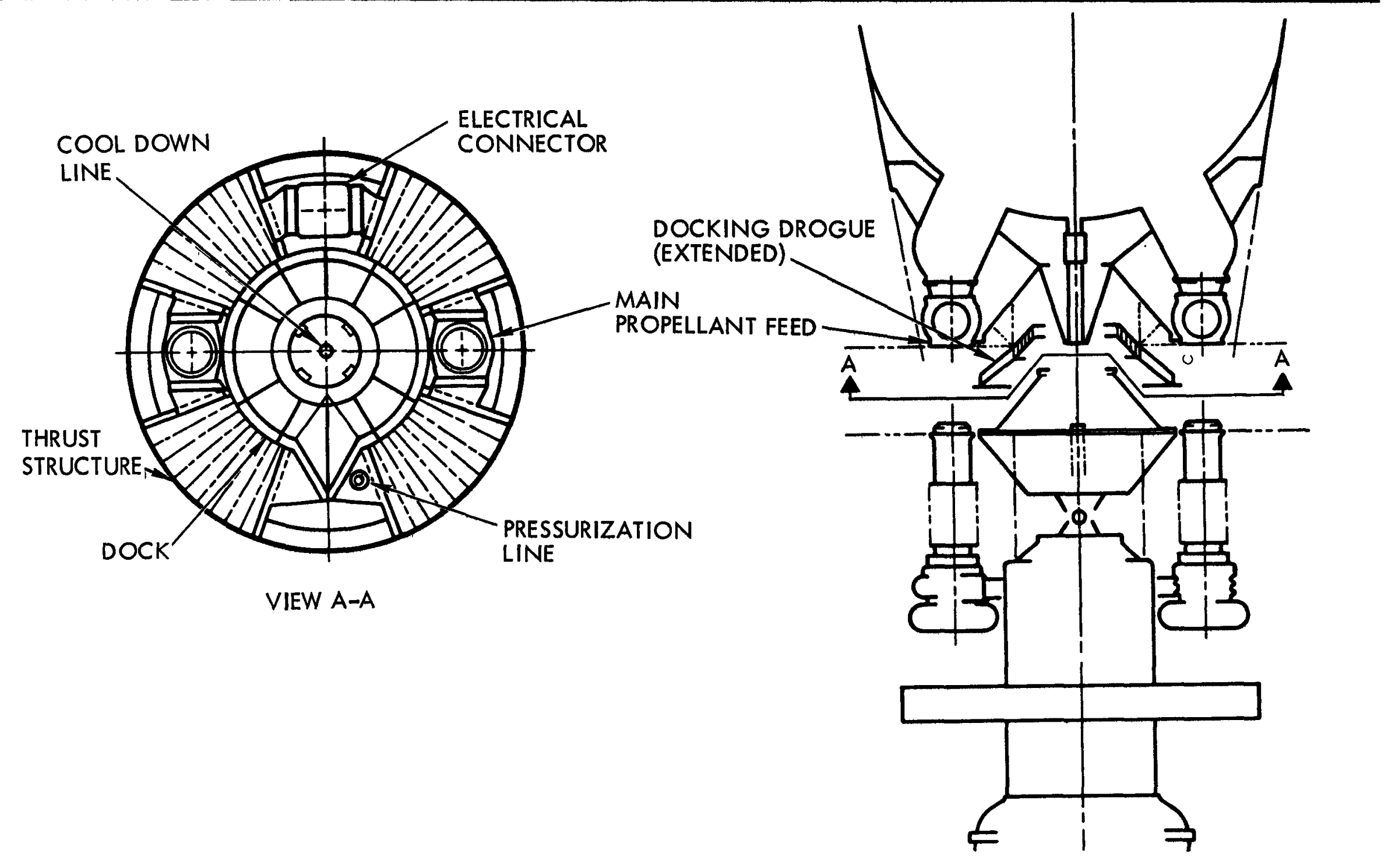




\section{A UXILIARY TANK/G\&C MODULAR UNIT}

Disposal of the NERVA engine at end of life in a heliocentric orbit requires approximately 18,600 pounds of $\mathrm{LH}_{2}$ when structural and cooldown requirements are taken into consideration. An auxiliary propellant module which would either complement a hybrid propulsion module or provide all the propellant identified above was laid out and is presented in the opposite chart. The module depicted is compatible with a hybrid propulsion module and includes G\&C, RCS, EPIC and electrical power at the forward end. The propellant tank size is geometrically the same as that of the hybrid propellant tank in the propulsion module or compatible with half the propellant required for disposal, i. e., 9, 300 pounds, permitting the use of available tooling and manufacturing techniques. The aft end of the module has the same interface discussed for the hybrid configuration tank/propulsion module interface, i. e., includes a neuter docking, the propellant transfer line, the fill and pressurization line and the electrical connection. The forward end of the module also contains a "standard" neuter dock integrated into the G\& C module structure together with propellant fill, vent, and electrical connections, to accommodate orbital service and checkout.

Because the combined center of gravity of the tank/engine combination falls close to the engine gimbal, the auxiliary module RCS is designed to satisfy the control functions during main engine operation, as well as power-off maneuvering and docking functions. Four large motors (650 lb f) have been tentatively identified to provide pitch/yaw, TVC, and forward translation impulse and eight smaller motors for vernier pitch/yaw control, roll control, and aft translation impulse. Based on an $\mathrm{O}_{2} / \mathrm{H}_{2}$ system similar to the baseline vehicle, the total RCS propellant requirements for the disposal mission are approximately $320 \mathrm{lb} \mathrm{O}_{2}$ and $80 \mathrm{H}_{2}$.

Based on an operational concept of short active life and nonreusability, batteries are the preferred electrical power source; and guidance, instrumentation and environmental protection can be minimal. 


\section{AUXILIARY TANK / G\&C MODULAR UNIT}
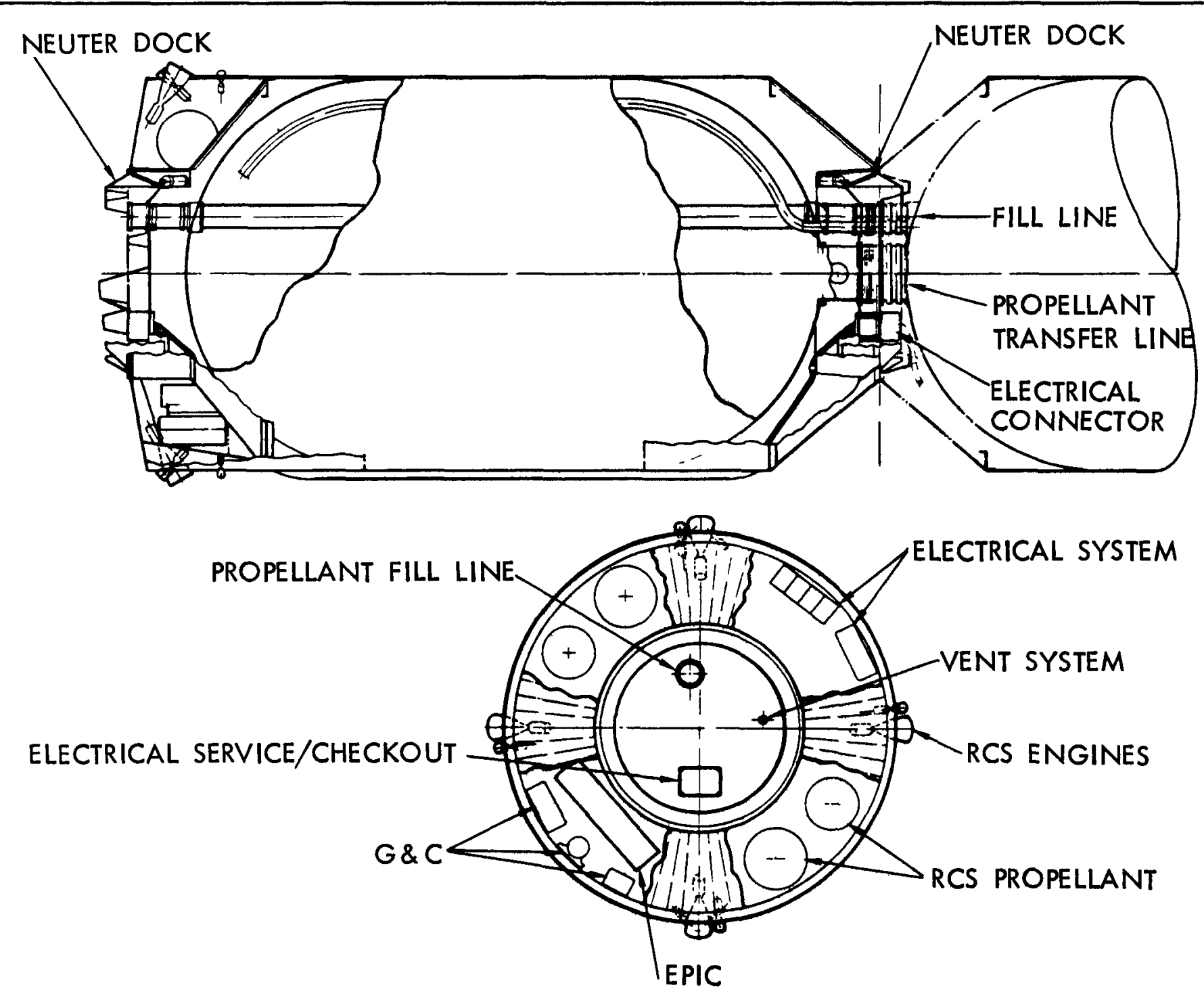
It can be concluded from the data presented that a single cell configuration with cone angles between 7 to 8 degrees with an end cap 25 inches in radius offers the maximum performance for a radiation dose of 10 REMS at tank top. As the radiation dose criterion is changed to 25 REMS, the maximum performance point shifts to half cone angles in the area of 8.5 to 9 degrees maintaining the 25 inch cap radius. A further relaxation on the radiation dose to $50 \mathrm{REM}$ shifts the maximum performance point again to approximately 15 degrees half cone angle still maintaining the 25-inch cap radius. The resulting stage length less nose cone varies from 190 feet for the 10 REM criteria to a 165 feet for the 50 REM. The respective tank lengths vary from 165 to 127 feet demanding in all cases separate launches for the tank and the NERVA to minimize launch vehicle modifications.

It is of importance to note that the loads data presented are for a minimum load trajectory where the angle of attack is limited to a maximum of three degrees during the high dynamic loads region. With the present INT-21 attitude - attitude rate control system, the strength requirements on the S-II LH 2 tank sidewalls with a 190 -foot RNS on top will increase to approximately $600 \%$ over the present capability demanding extensive modifications to that component as well as other parts of the vehicle.

The engine disposal operation also presents design considerations that could affect the overall system structural arrangement selection. For example, if a heliocentric orbit engine disposal with a small propulsion module is as sumed, the hybrid configuration will require an auxiliary propellant tank in addition to the one launched with the engine via the space shuttle. This requirement results from the present limitations of the space shuttle and the requirement of approximately 18,600 pounds of propellant including boiloff to place the engine in a heliocentric orbit with a small tank.

The considerations listed above favor the selection of a single cell configuration with a conical aft bulkhead ( $\emptyset=8.5$ degrees, $R=25$ inches) as an alternate baseline. This configuration appears to offer added flexibility over the hybrid design with a separate propulsive module.

It is further recommended that a joint Aerojet/NR engine/tank docking system design effort be initiated satisfying the engine design criteria as well as the system operational requirements associated with orbital mating and demating of engine/propellant tanks. 


\section{CONCLUSIONS AND RECOMMENDATIONS}

- LOW ANGLE \& CAP RADIUS YIELDS OPTIMUM CONFIGURATION

- OPTIMUM DESIGN POINT SHIFTS WITH RADIATION DOSE CRITERIA

- ENGINE-STAGE ORBITAL ASSEMBLY REQUIRED TO MINIMIZE IMPACT ON LAUNCH VEHICLE \& FACILITIES

- ENGINE REMOVAL CRITERIA \& DISPOSAL REQUIREMENTS FAVOR SINGLE TANK OVER HYBRID DESIGN

- CCNICAL TANK BOTTOM CONFIGURATION $\left(\theta=8.5^{\circ}, \mathrm{R}=25\right.$ IN.) RECOMMENDED AS ALTERNATE BASELINE

- CONDUCT JOINT AEROJET/NR ENGINE/ STAGE DOCKING DESIGN EFFORT 
The alternate baseline as shown on the chart consists of an integral tank design with a conical aft bulkhead selected on the basis of performance. The 33-foot diameter tank is 1,782 inches in length and accommodates 300,000 pounds of propellant with 5 percent ullage allowance. The aft bulkhead has an 8. 5 degree half cone angle with a 25-inch closeout cap radius. The pressurized and unpressurized shells are integrally stiffened aluminum alloy components. The thrust structure is also stiffened construction in titanium alloy. The double meteoroid bumper defined during the previous study contract has been retained for this configuration.

General outline of the propulsion subsystems are shown in the figure including propellant management, pressurization, and reaction control. A capillary system for propellant location control is shown and consists of three screened compartments with the lower two containing capillary pumping channels. The location of the uppermost screen, a rewetting dutch twill stainless steel mesh, is compatible with the maximum propellant required for the last cooldown. The forward compartment contains the propellant needed for the continuous flow portion of the cooldown. The next compartment contains the bulk of the cooldown propellant. Capillary channels, to assure propellant flow, are required since intermittent weightlessness will result in propellant displacement to the top of the compartment. The last (outlet region) compartment and capillary channels therein assures that propellant is available for the final phases of cooldown. Vortex and pull through baffles are provided to prevent premature vapor ingestion and minimize trapped residuals. The RCS consists of $\mathrm{O}_{2} / \mathrm{H}_{2}$ supercritically stored. The system is composed of 4 pods, with five 1,000 pound thrust nozzles mounted 90 degrees apart on the forward skirt of the stage. The LOX for the RCS is stored in three 48 inch diameter bottles, while the $\mathrm{LH}_{2} \mathrm{requires}$ 10. Also shown are a 3 -inch engine tap-off line required for the tank autogenous pressurization, routed inside the systems tunnel; ground and orbital fill and drain system located in the forward skirt; and thermodynamic venting coils.

The equipment module contains all systems for guidance, control and communications. Power is supplied by three oxygen-hydrogen fuel cells developing $7.5 \mathrm{kw}$. Waste heat from the systems is dissipated from a radiator surface located on the astrionic bay.

A neuter docking system is provided for stage docking to the propellant depot and for attachment of the payload. 


\section{SINGLE TANK DESIGN INBOARD PROFILE}

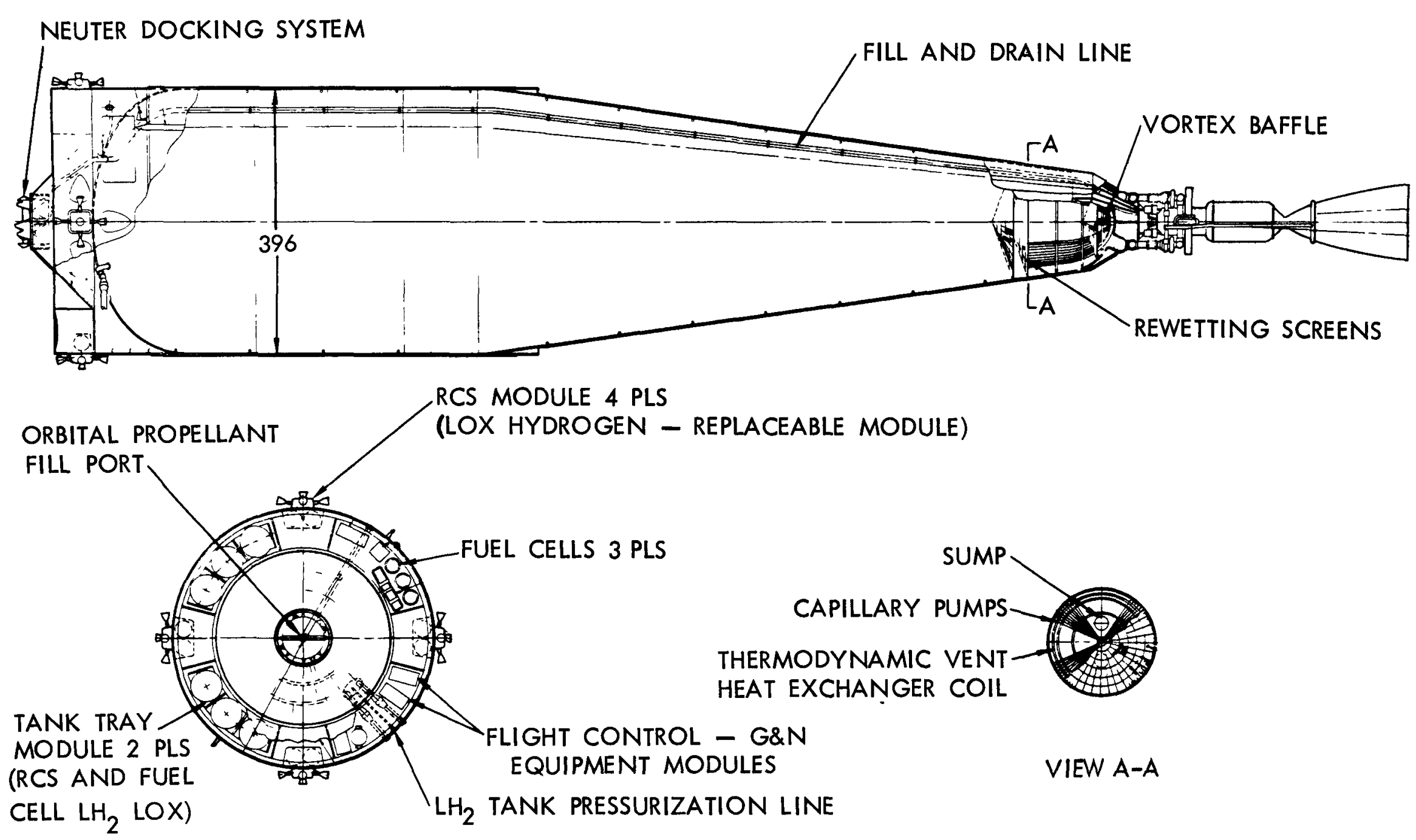




\section{REMAINING ACTIVITIES}

The remaining activities as listed in the chart include the in-depth analysis of the single cell baseline to substantiate the parametric data. This includes the assessment of the extra PVARA source radiation dose for the 25-inch cap radius.

Additionally, the hybrid design analyses will be continued by parametrically assessing the performance and operational payoffs associated with the addition of a small tank to the baseline. Also the assessment of the benefits associated with a small inner cell for propellant location control and radiation attenuation will be accomplished.

The current subsystems design effort will be continued to establish insulation requirements based on a thermal transient analysis that takes into consideration vehicle orientation and variations in surface finish. Also, a detailed thermodynamic analysis of the propellant and ullage gas will be conducted to establish tank pressure profiles and pressurant requirements. Additionally, astrionic subsystems candidates will be defined for both the lunar shuttle and a planetary mission.

The analyses will conclude with the recommendation and definition of a reference vehicle with the capability to evolve from lunar shuttle to planetary missions. Additionally, an SR\&T program will be established to evolve the stage from early shuttle to advanced planetary missions. 


\section{REMAINING ACTIVITIES}

- CONFIRM SINGLE TANK BASELINE DATA

THERMAL/ STRUCTURAL

MANUFACTURING

RADIATION

- FURTHER ASSESS HYBRID DESIGN

- ASSESS MODIFIED INNER CELL DESIGN

- COMPLETE SUBSYSTEMS DESIGN

- DEFINE REFERENCE VEHICLE 